\title{
Analysis of gas phase composition in fuel and exhaust gas in Solid Oxide Fuel Cells
}

Wei Zhang

West Virginia University

Follow this and additional works at: https://researchrepository.wvu.edu/etd

\section{Recommended Citation}

Zhang, Wei, "Analysis of gas phase composition in fuel and exhaust gas in Solid Oxide Fuel Cells" (2013). Graduate Theses, Dissertations, and Problem Reports. 116.

https://researchrepository.wvu.edu/etd/116

This Dissertation is protected by copyright and/or related rights. It has been brought to you by the The Research Repository @ WVU with permission from the rights-holder(s). You are free to use this Dissertation in any way that is permitted by the copyright and related rights legislation that applies to your use. For other uses you must obtain permission from the rights-holder(s) directly, unless additional rights are indicated by a Creative Commons license in the record and/ or on the work itself. This Dissertation has been accepted for inclusion in WVU Graduate Theses, Dissertations, and Problem Reports collection by an authorized administrator of The Research Repository @ WVU.

For more information, please contact researchrepository@mail.wvu.edu. 


\title{
Analysis of gas phase composition in fuel and exhaust gas in Solid Oxide Fuel Cells
}

\author{
Wei Zhang \\ Dissertation submitted \\ to the Eberly College of Arts and Sciences \\ at West Virginia University \\ in partial fulfillment of the requirements for the degree of \\ Doctor of Philosophy in \\ Chemistry
}

\author{
Harry O. Finklea, PhD., Chair \\ Stephen J. Valentine, PhD. \\ Alan M. Stolzenberg, PhD. \\ Justin A. Legleiter, PhD. \\ John W. Zondlo, PhD.
}

C. Eugene Bennett Department of Chemistry

\author{
Morgantown, West Virginia \\ 2014
}

Key words: Solid Oxide Fuel Cell, Mass Spectrometry, In-situ Methods, Coal Syn-gas, phosphine, degradation.

Copyright 2014 Wei Zhang 


\begin{abstract}
Analysis of gas phase composition in fuel and exhaust gas in Solid Oxide Fuel Cells
\end{abstract}

\author{
Wei Zhang
}

Direct utilization of coal syngas in Solid Oxide Fuel Cell faces a number of challenges. One of the impediments to the implementation of SOFCs is their degradation in the presence of impurities in the fuel. Phosphine $\left(\mathrm{PH}_{3}\right)$ is present in coal syngas at ppm levels, and a number of reports have shown that the nickel anode is damaged by long term exposure to ppm levels of phosphine in various fuels. Because phosphine is exposed to high temperatures $\left(\sim 800^{\circ} \mathrm{C}\right)$ and varying amounts of water and oxygen in the fuel, the exact nature of the phosphorus species reaching the anode is unknown. Thermodynamic calculations vary in the predicted species at equilibrium, some of which are HPO (mass 48), $\mathrm{HPO}_{2}$ (mass 64), $\mathrm{HPO}_{3}$ (mass 80), and $\mathrm{P}_{4} \mathrm{O}_{10}$ (mass 288). Mass spectroscopic analyses of exhaust gases from SOFC test systems are provided, with and without $\mathrm{Ni} / Y S Z$ anodes in the path of the gas flow. The mass spectrometer, a MKS Cirrus system, has a mass range of $1-100 \mathrm{amu}$ and a detection limit of $\sim 0.001$ torr. The mass spectrometry is applied to full-cell tests. The cell is operated in $\mathrm{H}_{2}$ as fuel. The cell is tested with and without 10-20 torr water added, with and without $20 \mathrm{ppm} \mathrm{PH}_{3}$ added, and with different current applied to the cell. Degradation in cell performance is observed over short times during $\mathrm{PH}_{3}$ exposure but not over the entire course of experiment. The water generated by the electrochemical oxidation of $\mathrm{H}_{2}$ is detected. Leaks are assessed in the tests and air impurities such as $\mathrm{N}_{2}, \mathrm{O}_{2}, \mathrm{Ar}$ and $\mathrm{CO}_{2}$ signals are also detected. No new mass signals appear in all conditions, suggesting that the possible phosphine reaction products have a mass outside the 100 amu range of the mass spectrometer. Post-mortem analysis of the cell using SEM, EDX and XRD was performed. After $\mathrm{PH}_{3}$ exposure, a new layer of crystalline nickel phosphide material was found on the anode surface similar to the previous studies. 
Dedicated to my mother Fengying Bian, father Mingjiu Zhang and my great wife Lu Luo 


\section{Acknowledgements}

I would like to dedicate this dissertation to my family, my parents and my wife, for their consistent support.

I would like to express my deeply thanks to Dr. Harry O. Finklea, as my advisor during the graduate study. He is a great mentor, supporter, teacher and scientist. Without his efforts, I would not be able to learn so much about chemistry. It is an honor of me to study toward my PhD degree under his guidance.

I would like to thank my graduate committee members: Dr. Stephen Valentine, Dr. Alan Stolzenberg, Dr. Justin Legleiter and Dr. John Zondlo for their helpful advice and suggestions on my graduate study and dissertation.

Special thanks go further to our co-workers: Dr. Bruce Kang, Dr. Huang Guo and Dr. Chunchuan Xu. It was my pleasure to study and work with them.

I also wish to thank the Finklea group, Dr. Oktay Demircan, Dr. Xiaoke Chen, Mahfuzur Jony and Kaushalya De Silva. I appreciate the help from members in the WVU NIFT research team.

I appreciate financial support from the West Virginia ESPCoR project and Dr. Ismail Celik. NETL, US DOE Office of Basic Energy Sciences, WV State EPSCoR Office and West Virginia University provided the support for this study under the grant number of DE-FG02-06ER46299. The Administrative Manager is Dr. Richard A. Bajura and the Technical Manager and Principal Investigator is Dr. Ismail Celik. 


\section{Table of contents}

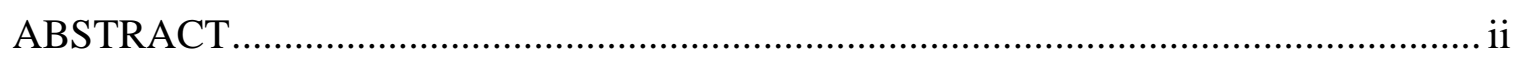

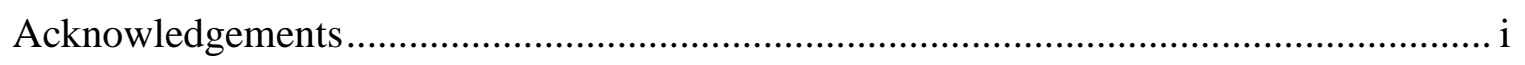

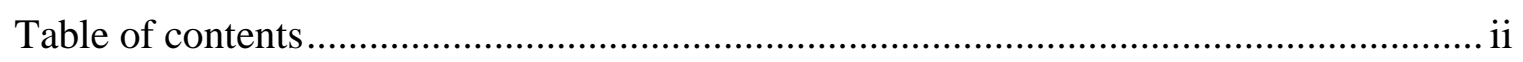

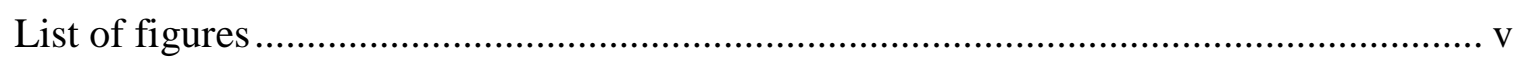

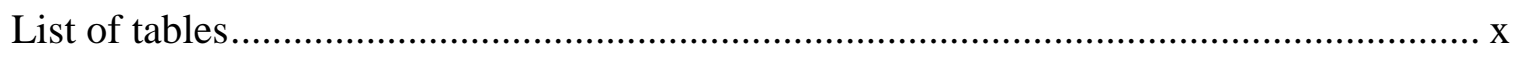

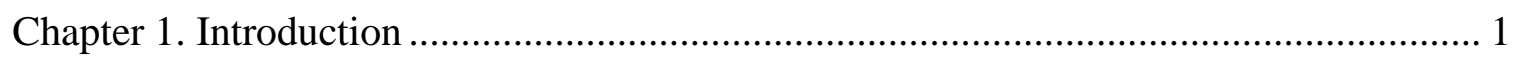

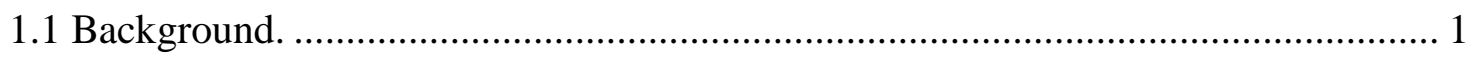

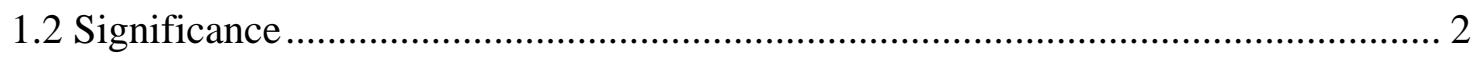

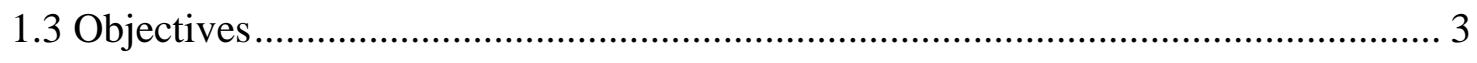

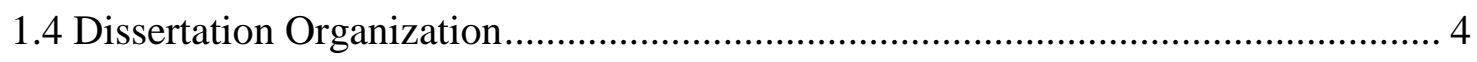

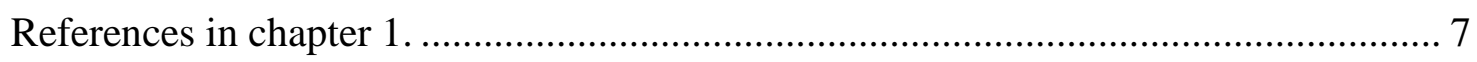

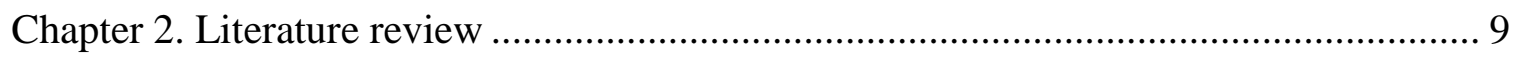

2.1 Introduction to Solid Oxide Fuel Cells (SOFC) .............................................. 9

2.2 Electrochemical characteristics of Solid Oxide Fuel Cell .................................. 14

2.3 Trace amount impurities in coal syngas......................................................... 19

2.4 Gas phase species under SOFC working conditions..................................... 22

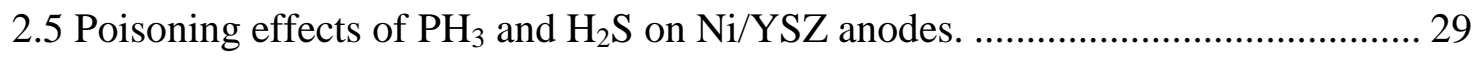

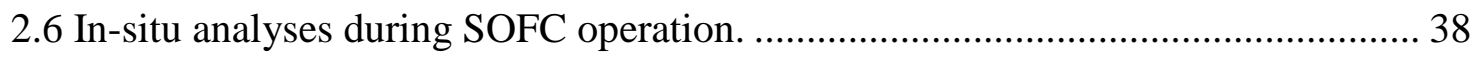

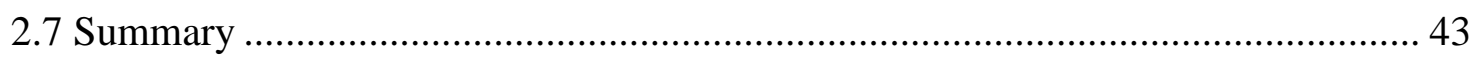

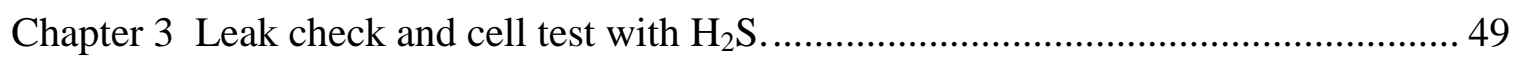

3.1 Introduction to the Cirrus Residual Gas Analyzer ............................................ 49

3.2 Experimental setup in WVU Chemical Engineering. ...................................... 54 


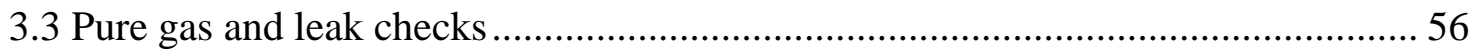

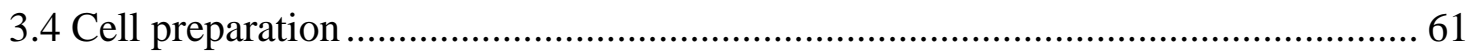

3.5 Cell tests in WVU Chemical Engineering with $\mathrm{H}_{2} \mathrm{~S}$........................................... 63

3.5.1 Ni-GDC cell test with different levels of $\mathrm{H}_{2} \mathrm{~S}$............................................... 63

3.5.2 MSRI anode supported cell test with $\mathrm{H}_{2} \mathrm{~S}$ and current change .........................66

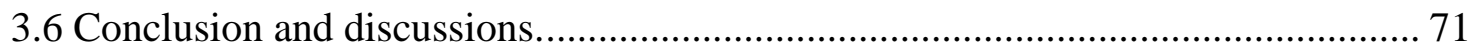

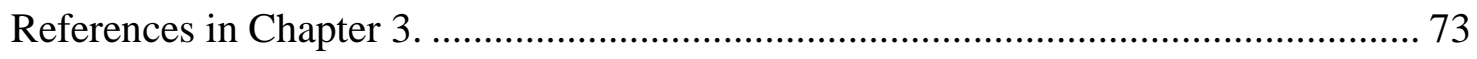

Chapter 4 Cell test in WVU Mechanical Engineering (Dr. Kang' lab) ............................. 74

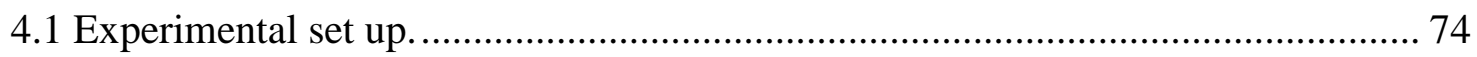

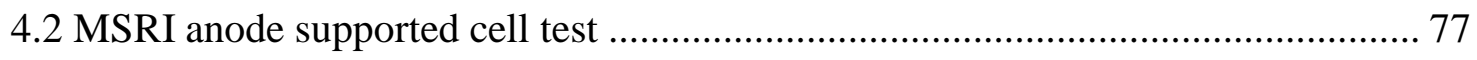

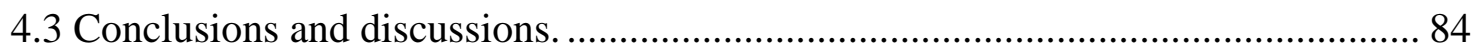

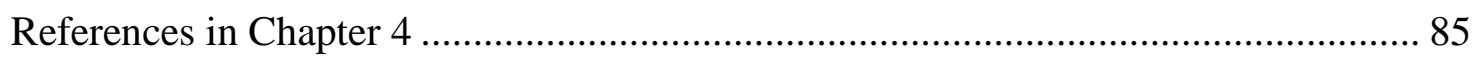

Chapter 5 Study of Reactions of $\mathrm{PH}_{3}, \mathrm{H}_{2} \mathrm{O}$ and Ni/YSZ at high temperatures. ............... 86

5.1 Gas-phase composition study with a tube furnace configuration. .......................... 86

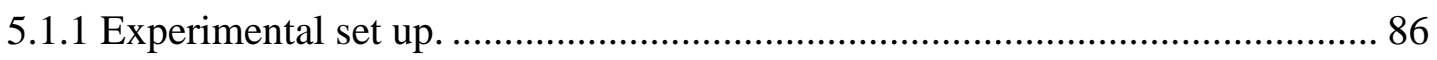

5.1.2 Gas purity check and calibration curves ......................................................... 87

5.1.3 Blank gas tests (No cell) ........................................................................... 91

5.1.4 Gas tests with $\mathrm{PH}_{3}$ and $\mathrm{NiO} / \mathrm{YSZ}$ sample piece inside the ceramic tube......... 99

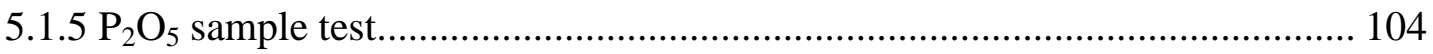

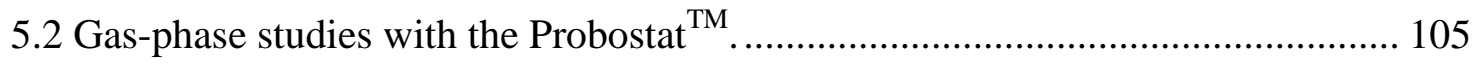

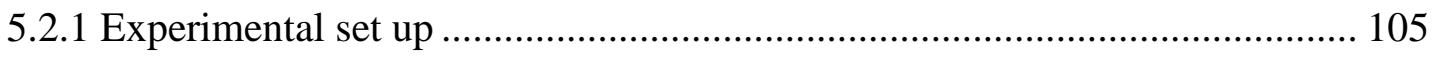

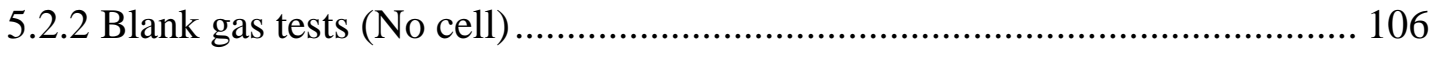

5.2.3 Gas tests with a loose NiO/YSZ sample piece inside the Probostat................ 114

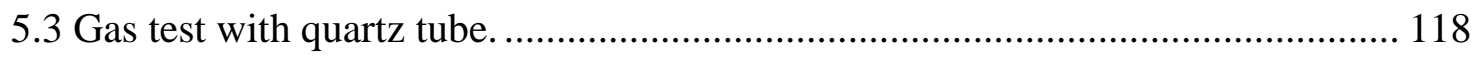

5.4 Conclusion and discussions........................................................................... 120 
References in Chapter 5

Chapter 6 In-situ cell tests with Mass Spectrometry in WVU Chemistry Research Lab 123

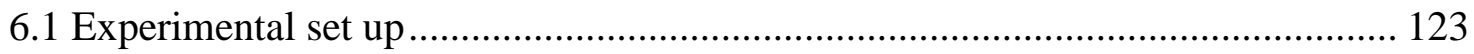

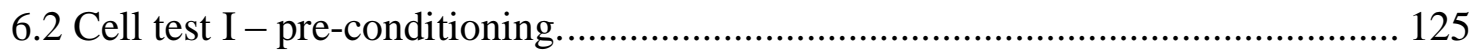

6.3 Cell test II - different gas composition and cell voltages. .............................. 130

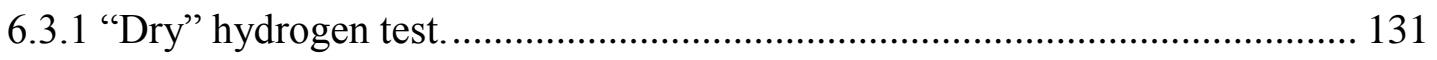

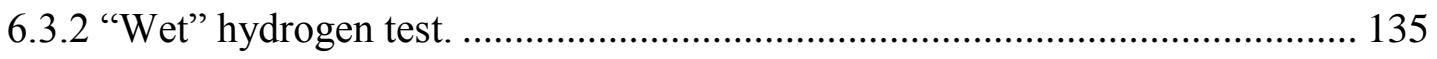

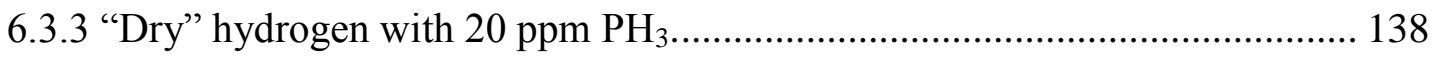

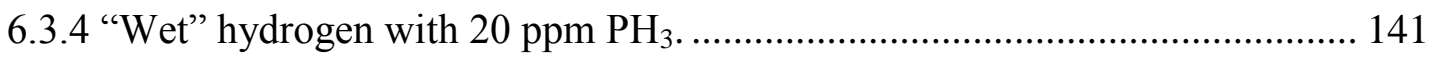

6.4 Cell test III - long term constant cell voltage tests. ..................................... 143

6.5 Post-mortem analysis of the cell ............................................................... 151

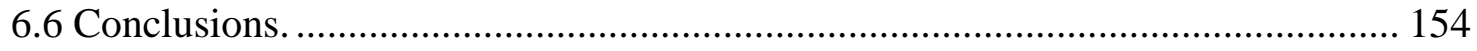

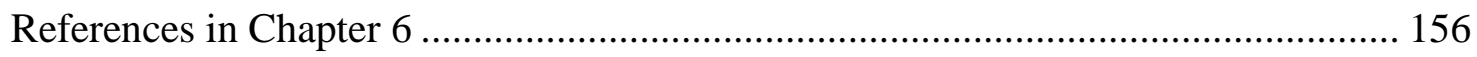

Chapter 7 Discussion, Conclusions and Future Work ........................................... 158

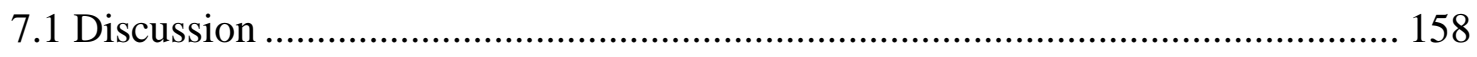

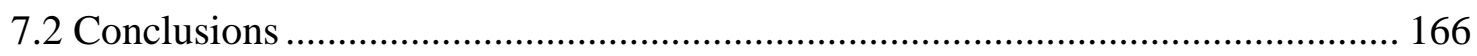

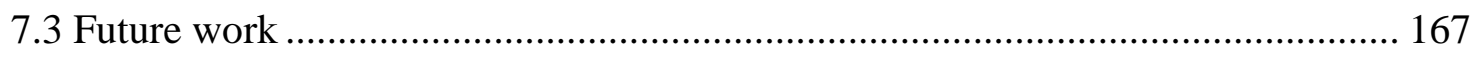

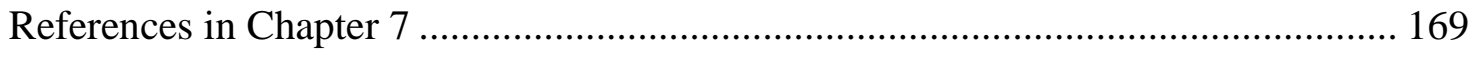




\section{List of figures}

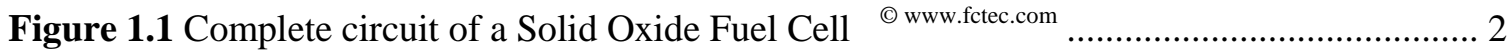

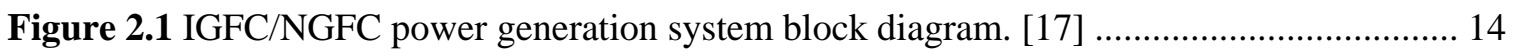

Figure 2.2 Polarization curve for a SOFC model. [25].......................................................... 17

Figure 2.3 Example of a Nyquist plot from electrochemical impedance spectroscopy............... 19

Figure 2.4 Thermodynamic phase diagram of potential Ni products with $10 \mathrm{ppm} \mathrm{of} \mathrm{PH}_{3}$ present

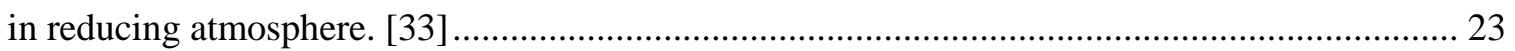

Figure 2.5 Two dimensional Ellingham diagram of a P-O-H system. [30] ................................ 26

Figure 2.6 Ellingham diagram of a Ni-P-O-H system. [30] ................................................. 27

Figure 2.7 Equilibrium concentration in $3 \%$ humidified $\mathrm{H}_{2}$ fuel and containing 5 ppm P species calculated between 400 and $1000^{\circ} \mathrm{C}$, representing $\mathrm{PH}_{3}$ as the most stable P-based compound. [49]

Figure 2.8 The cell voltage versus time under load $0.5 \mathrm{~A} / \mathrm{cm}^{2}$ operating on syngas before and after

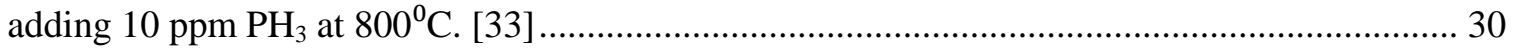

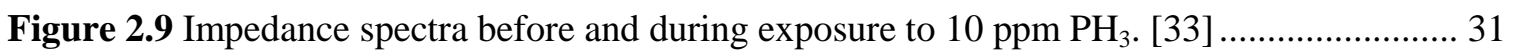

Figure 2.10 Clean reduced cell anode (left), and after $\mathrm{PH}_{3}$ exposure (right). [33] ...................... 31

Figure 2.11 SEM images of clean reduced cell anode (left), and after $\mathrm{PH}_{3}$ exposure (right). [33]

Figure 2.13 $\mathrm{R}_{\mathrm{s}}$ (left) and $\mathrm{R}_{\mathrm{p}}$ (right) for the cell before and after exposure to $\mathrm{PH}_{3} \ldots \ldots \ldots \ldots \ldots \ldots \ldots . . . . . . . .33$

Figure 2.15 SEM images of clean reduced anode top surface (left) and after exposure to $\mathrm{PH}_{3}$

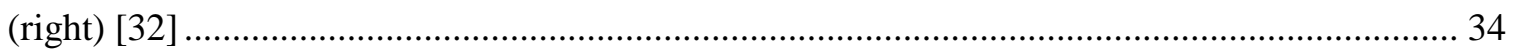

Figure 2.16 XRD analysis of $\mathrm{PH}_{3}$ exposed anode surface. $\left(\triangleleft \mathrm{YSZ} \bullet \mathrm{Ni}_{3} \mathrm{P} \bullet \mathrm{Ni}\right)$ [32] ................. 35

Figure 2.18 20 $\mu \mathrm{m}$ spot XPS analysis on the cross-section of the active layer of anode. [32]...... 36

Figure 2.19 TEM image of anode active layer in a cell exposed to $\mathrm{PH}_{3}$ for 117 hours [38] ........ 37

Figure 2.20 (a) Chemical compositions of the deposited particles. (b) Diffraction pattern taken

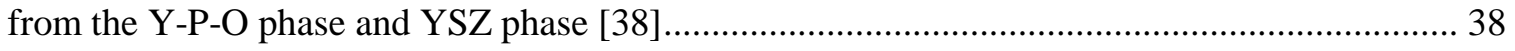

Figure 2.21 High-temperature Mass Spectrometer [29] ........................................................ 39

Figure 2.22 Production rates of anode exhaust gases in SOFC with Ni-YSZ anode and 3.85\% methane. [40]

Figure 2.23 $\mathrm{CH}_{4}, \mathrm{CO}, \mathrm{H}_{2}$ and $\mathrm{CO}_{2}$ flow rates for inlet $\mathrm{CH}_{4}=6 \mathrm{ml} / \mathrm{min}$ and chemical equilibrium composition calculated at $800^{\circ} \mathrm{C}$ with varying inlet $\mathrm{CO}_{2} / \mathrm{CH}_{4}$ ratio. [45] ................................. 42

Figure 3.1 Cirrus Residual Gas Analyzer from MKS Instruments ............................................ 49

Figure 3.2 Block diagram of RGA application on Solid Oxide Fuel Cells ................................ 51

Figure 3.3 Illustration of gas handling system in WVU CHE Fuel Cell Test Stand. .................. 55

Figure 3.4 Detailed setup around the fuel cell in the WVU CHE test stand. ..............................56

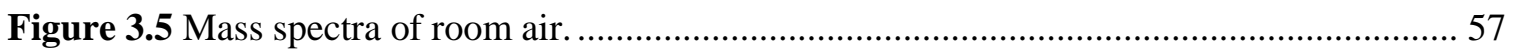

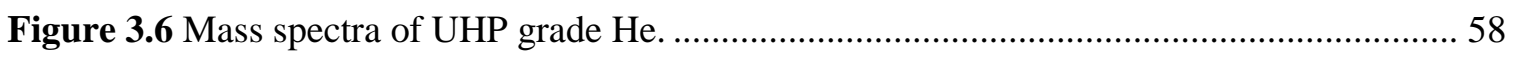

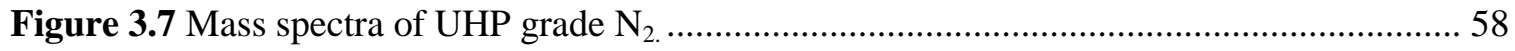

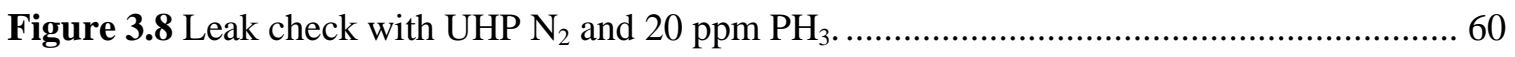

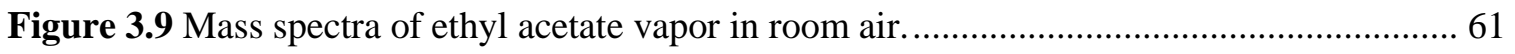

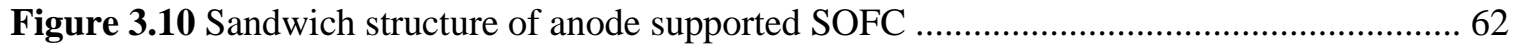


Figure 3.11 Current collectors of the anode-supported MSRI cell .......................................... 62

Figure 3.12 Mass $34\left(\mathrm{H}_{2} \mathrm{~S}\right)$ signal in the exhaust gas during cell operation at $800^{\circ} \mathrm{C}$................. 64

Figure 3.13 Mass 33 (HS) signal in the exhaust gas during cell operation at $800^{\circ} \mathrm{C}$.................... 66

Figure 3.14 Mass 34 signal in the exhaust gas with current on and off. The cell was operating at $800^{\circ} \mathrm{C}$ with $\mathrm{H}_{2} .100 \mathrm{ppm}$ of $\mathrm{H}_{2} \mathrm{~S}$ added at 0.21 hours

Figure 3.15 Mass 34 in the inlet gas with current on and off. The cell was operating at $800^{\circ} \mathrm{C}$ with $\mathrm{H}_{2} .100$ ppm of $\mathrm{H}_{2} \mathrm{~S}$ added at 0.46 hours.

Figure 3.16 Comparison of inlet and exhaust gases during cell operation at $800^{\circ} \mathrm{C}$................... 70

Figure 4.1 Picture of assembled Probostat testing platform for SOFC button cells.................... 74

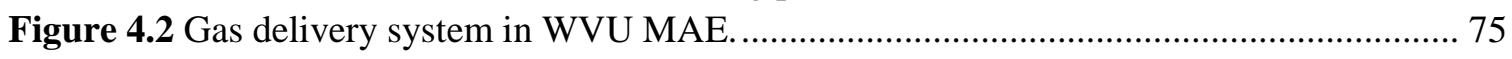

Figure 4.3 Original cell testing set up in the Probostat. The leads to the anode and cathode are the blue wires.

Figure 4.4 Cell assembly on to the Probostat using a Gold O-ring, showing the cathode current

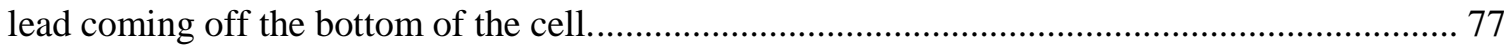

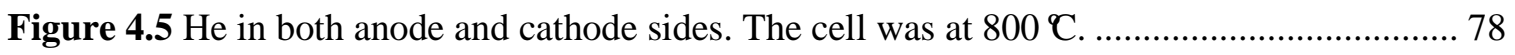

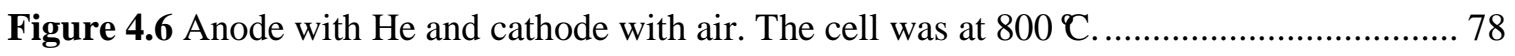

Figure 4.7 Anode with $\mathrm{H}_{2}$ and cathode with air, Cell at $\mathrm{OCV}$ and temperature at $800^{\circ} \mathrm{C} \ldots \ldots \ldots . . . .79$

Figure 4.8 Anode with $\mathrm{H}_{2}$ and cathode with air, Cell loaded with $0.7 \mathrm{~V}$ and temperature at $800^{\circ} \mathrm{C}$.

Figure 4.9 Anode with $\mathrm{H}_{2}+3 \% \mathrm{H}_{2} \mathrm{O}$ and cathode with air, cell at $\mathrm{OCV}$ and temperature at $800^{\circ} \mathrm{C}$.

Figure 4.10 Anode with $\mathrm{H}_{2}+3 \% \mathrm{H}_{2} \mathrm{O}$ and cathode with air. Cell loaded with $0.7 \mathrm{~V}$ and temperature at $800^{\circ} \mathrm{C}$.

Figure 4.11 Anode with $\mathrm{H}_{2}+10 \mathrm{ppm} \mathrm{PH}_{3}$ and cathode with air. Cell at $\mathrm{OCV}$ and temperature at $800^{\circ} \mathrm{C}$

Figure 4.12 Transient behavior of $\mathrm{PH}_{3}$ signal at the anode inlet. The cell was operating at $800^{\circ} \mathrm{C}$.

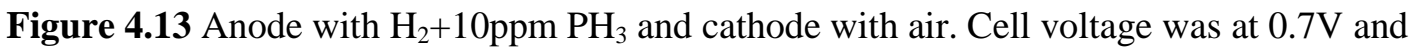
temperature at $800^{\circ} \mathrm{C}$.

Figure 5.1 Diagram of tube furnace configuration for testing possible $\mathrm{PH}_{3}$ reactions. 86

Figure 5.2 Gas manifold used in the gas phase tests. 87

Figure 5.3 Calibration curve for dry $\mathrm{H}_{2}$ in He. Symbols: measured $\mathrm{P}\left(\mathrm{H}_{2}\right)$; solid line: linear regression fit to all data points; dashed line: linear regression fit to the lowest three pressures... 90 Figure 5.4 Calibration curve for wet $\mathrm{H}_{2}$ in helium. Symbols: measured $\mathrm{P}\left(\mathrm{H}_{2}\right)$; solid line: linear regression fit to all data points; dashed line: linear regression fit to the lowest three pressures... 90 Figure 5.5 Calibration curve and linear regression fit of $\mathrm{PH}_{3}$ in hydrogen. Symbols: measured pressures; line: linear regression fit to all data points. 91

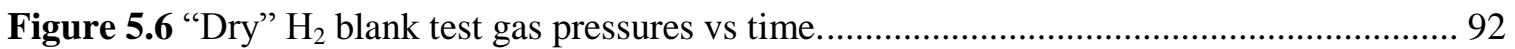

Figure 5.7 Oxygen (mass 32) vs temperature during the heating phase in "dry" $\mathrm{H}_{2} \ldots \ldots \ldots \ldots \ldots \ldots . . . . . . .92$

Figure 5.8 "Wet" $\mathrm{H}_{2}$ blank test gas pressures vs time.

Figure 5.9 Oxygen (mass 32) pressure vs temperature during heating phase in the "wet" $\mathrm{H}_{2}$ test.

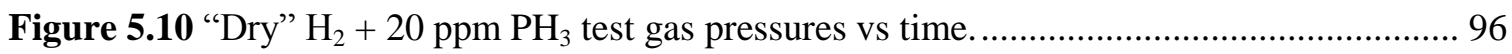

Figure 5.11 $\mathrm{H}_{2} \mathrm{O}, \mathrm{N}_{2}$ and $\mathrm{O}_{2}$ signals in "Dry" $\mathrm{H}_{2}+20$ ppm $\mathrm{PH}_{3}$ test pressures vs time.............. 96 
Figure 5.12 Details of mass 32 and 34 vs temperature during the heating process in "dry" $\mathrm{H}_{2}+20$ ppm $\mathrm{PH}_{3}$.

Figure 5.13 Details of mass 32 and 34 vs temperature during the cooling process in "dry" $\mathrm{H}_{2}+$

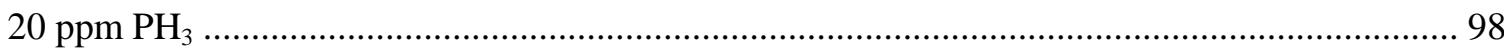

Figure 5.14 Mass spectrum comparisons of $300^{\circ} \mathrm{C}$ and $500^{\circ} \mathrm{C}$ in "dry" $\mathrm{H}_{2}+20 \mathrm{ppm} \mathrm{PH}_{3} \ldots \ldots . .99$

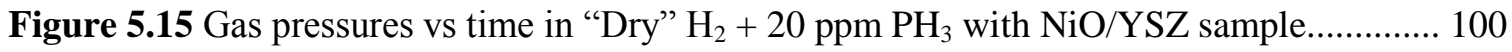
Figure 5.16 $\mathrm{H}_{2} \mathrm{O}$ and $\mathrm{N}_{2}$ pressures vs temperature during the heating phase in "dry" $\mathrm{H}_{2}+20 \mathrm{ppm}$ $\mathrm{PH}_{3}$ with $\mathrm{NiO} / \mathrm{YSZ}$ present.

Figure 5.17 $\mathrm{O}_{2}, \mathrm{~N}_{2}$, and $\mathrm{PH}_{3}$ pressures vs temperature during the heating phase in "dry" $\mathrm{H}_{2}+20$ ppm $\mathrm{PH}_{3}$ with $\mathrm{NiO} / \mathrm{YSZ}$ sample

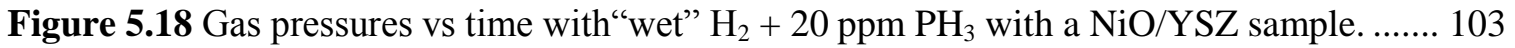
Figure 5.19 $\mathrm{H}_{2} \mathrm{O}$ and $\mathrm{N}_{2}$ pressures vs temperature during heating in "wet" $\mathrm{H}_{2}+20 \mathrm{ppm} \mathrm{PH}_{3}$ with $\mathrm{NiO} / \mathrm{YSZ}$ sample. 103

Figure 5.20 Mass spectrum of exhaust gas with $\mathrm{P}_{2} \mathrm{O}_{5}$ sample at $350^{\circ} \mathrm{C}$................................... 105

Figure 5.21 Gas pressures vs time in the "dry" $\mathrm{H}_{2}$ test with the Probostat................................. 107

Figure 5.22 Mass 34, $\mathrm{N}_{2}$ and $\mathrm{O}_{2}$ pressures vs time during the "dry" $\mathrm{H}_{2}$ test with the Probostat. 107

Figure 5.23 Gas pressure vs time in the "wet" $\mathrm{H}_{2}$ test with the Probostat................................. 108

Figure 5.24 Mass 34, $\mathrm{N}_{2}$ and $\mathrm{O}_{2}$ pressures vs time during the "wet" $\mathrm{H}_{2}$ test with the Probostat.109

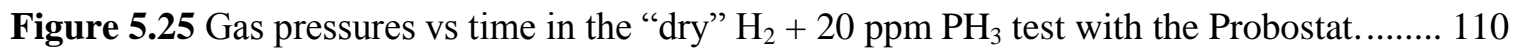

Figure 5.26 Pressures vs temperature during the heating phase of "dry" $\mathrm{H}_{2}+20 \mathrm{ppm} \mathrm{PH}_{3}$ test with the Probostat.

Figure 5.27 Gas pressures vs time during the "wet" $\mathrm{H}_{2}+20 \mathrm{ppm} \mathrm{PH}_{3}$ test with the Probostat. 112 Figure 5.28 Gas pressures vs temperature during the heating phase of "wet" $\mathrm{H}_{2}+20 \mathrm{ppm}^{\mathrm{PH}_{3}}$ test with the Probostat.

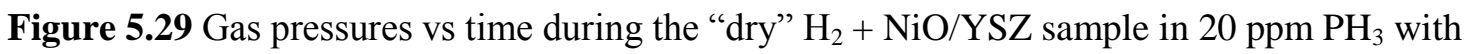
the Probostat test

Figure 5.30 Pressures of $\mathrm{O}_{2}, \mathrm{~N}_{2}$ and Mass 34 vs temperature during the heating phase of "dry" $\mathrm{H}_{2}$

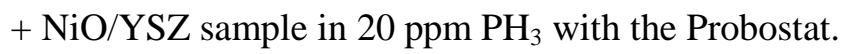

Figure 5.31 Pressures of water and $\mathrm{N}_{2}$ vs temperature during the heating phase of "dry" $\mathrm{H}_{2}+$ $\mathrm{NiO} / \mathrm{YSZ}$ sample in $20 \mathrm{ppm} \mathrm{PH}_{3}$ with the Probostat.

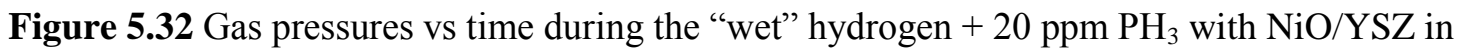
the Probostat.

Figure 5.33 Gas pressures vs temperature for water, $\mathrm{N}_{2}$ and $\mathrm{PH}_{3}$ signal during heating phase of

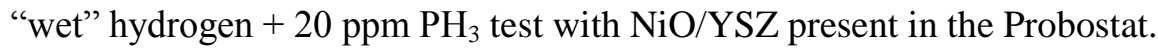

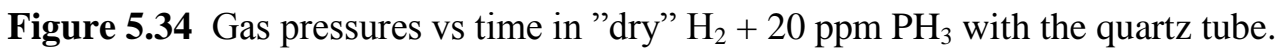

Figure 5.35 Gas pressures vs temperature for water, $\mathrm{N}_{2}$ and $\mathrm{PH}_{3}$ signal during the heating phase of the test with the quartz tube.

Figure 5.36 Comparison of mass spectra at $300^{\circ} \mathrm{C}$ and $500^{\circ} \mathrm{C}$.

Figure 6.1 gas manifold used in the cell test

Figure 6.2 Assembling a cell with glass tape seals.

Figure 6.3 Gas pressures vs time for $\mathrm{N}_{2}$ and $\mathrm{O}_{2}$ during the initial heating phase, the cell reached $800^{\circ} \mathrm{C}$ at 16.4 hours.

Figure 6.4 Gas pressures vs time for water and mass 34 during the initial heating phase, the cell reached $800^{\circ} \mathrm{C}$ at 16.4 hours. 
Figure 6.5 $\mathrm{N}_{2}$ and $\mathrm{O}_{2}$ pressures vs time during cell reduction. $\mathrm{H}_{2}$ was introduced to $10 \%$ at 32 hours, increased to $50 \%$ at 44 hours and $100 \%$ at 48 hours.

Figure 6.6 Water and mass 34 pressures vs time during cell reduction. The time of gas changes are the same as in Figure 6.5

Figure 6.7 CV and power curve after cell reduction. Cell was in pure $\mathrm{H}_{2}$ at $800^{\circ} \mathrm{C} \ldots \ldots \ldots \ldots \ldots . . . . . . .128$

Figure 6.8 Nyquist plot in dry $\mathrm{H}_{2}$ after cell reduction. The cell was at $800^{\circ} \mathrm{C}$.......................... 129

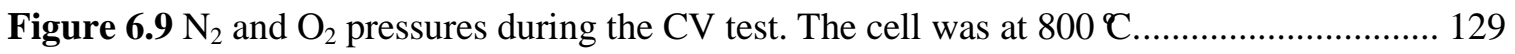

Figure 6.10 Water and mass 34 signals during the $\mathrm{CV}$ test. The cell was at $800^{\circ} \mathrm{C} \ldots \ldots \ldots \ldots \ldots \ldots . . . . . .130$

Figure 6.11 $\mathrm{N}_{2}, \mathrm{O}_{2}$, water and mass 34 pressures when a small current is applied. The cell was in

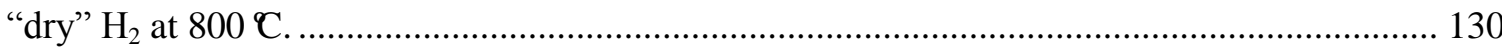

Figure 6.12 Polarization and power curves in "dry" $\mathrm{H}_{2}$ after burn-in. The cell was at $800^{\circ} \mathrm{C}$.. 132

Figure 6.13 Nyquist plot for the cell in "dry" $\mathrm{H}_{2}$. The cell was at $800^{\circ} \mathrm{C}$.................................. 133

Figure 6.14 $\mathrm{N}_{2}$ and $\mathrm{O}_{2}$ pressures in "dry" $\mathrm{H}_{2}$ during applied cell voltages. The cell was at $800^{\circ} \mathrm{C}$.

Figure 6.15 Water and mass 34 pressures in "dry" $\mathrm{H}_{2}$ during applied cell voltages. The cell was at $800^{\circ} \mathrm{C}$.

Figure 6.16 Polarization and power curves in "wet" $\mathrm{H}_{2}$. The cell was at $800^{\circ} \mathrm{C} \ldots \ldots \ldots \ldots \ldots \ldots \ldots . . . . . . . . . .136$

Figure 6.17 Nyquist plot at OCV in "wet" $\mathrm{H}_{2}$. The cell was at $800^{\circ} \mathrm{C}$................................... 136

Figure 6.18 $\mathrm{N}_{2}$ and $\mathrm{O}_{2}$ pressures during current flow in the "wet" $\mathrm{H}_{2}$ test. The cell was at $800^{\circ} \mathrm{C}$.

Figure 6.19 Water and mass 34 pressures during current flow in the "wet" $\mathrm{H}_{2}$ test. The cell was at $800^{\circ} \mathrm{C}$.

Figure 6.20 $\mathrm{N}_{2}$ and $\mathrm{O}_{2}$ signals during addition of phosphine and application of voltages in "dry" $\mathrm{H}_{2}+20 \mathrm{ppm} \mathrm{PH}_{3}$. The cell was at $800^{\circ} \mathrm{C}$.

Figure 6.21 Water and mass 34 signals during addition of phosphine and application of voltages in "dry" $\mathrm{H}_{2}+20 \mathrm{ppm} \mathrm{PH}_{3}$. The cell was at $800^{\circ} \mathrm{C}$.

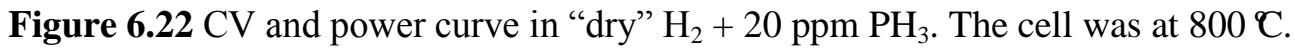

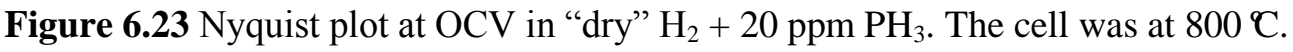

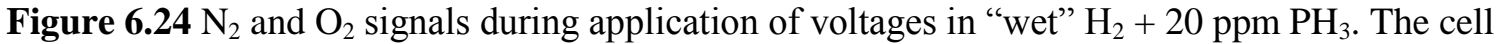
was at $800^{\circ} \mathrm{C}$.

Figure 6.25 Water and mass 34 signals during application of voltages in "dry" $\mathrm{H}_{2}+20 \mathrm{ppm} \mathrm{PH}_{3}$.

The cell was at $800^{\circ} \mathrm{C}$.

Figure 6.26 CV test in "wet" $\mathrm{H}_{2}+20 \mathrm{ppm} \mathrm{PH}_{3}$. The cell was at $800^{\circ} \mathrm{C}$

Figure 6.27 Nyquist plot of the cell at $\mathrm{OCV}$ in "wet" $\mathrm{H}_{2}+20 \mathrm{ppm} \mathrm{PH}_{3}$. The cell was at $800^{\circ} \mathrm{C}$.

Figure 6.28 Power density vs time in "dry" $\mathrm{H}_{2}$ with $0.9 \mathrm{~V}$ cell voltage. The cell was at $800^{\circ} \mathrm{C} .144$ Figure 6.29 $\mathrm{N}_{2}$ and $\mathrm{O}_{2}$ signals vs time in "dry" $\mathrm{H}_{2}$ at $0.9 \mathrm{~V}$ (first 20 hours), open circuit (20-22 hours) and in "wet" $\mathrm{H}_{2}$ (24-50 hours). The cell was at $800^{\circ} \mathrm{C}$.

Figure 6.30 Water and mass 34 signals vs time in "dry" $\mathrm{H}_{2}$ at $0.9 \mathrm{~V}$ (first 20 hours), open circuit (20-22 hours) and in "wet" $\mathrm{H}_{2}$ (24-50 hours). The cell was at $800^{\circ} \mathrm{C}$.

Figure 6.31 Power density vs time in "wet" $\mathrm{H}_{2}$ with $0.9 \mathrm{~V}$ cell voltage. The cell was at $800^{\circ} \mathrm{C} .146$

Figure 6.32 Gas pressures vs time in "wet" $\mathrm{H}_{2}$ at $0.9 \mathrm{~V}$. The cell was at $800^{\circ} \mathrm{C} \ldots \ldots \ldots \ldots \ldots \ldots \ldots . . . . . . . . . .146$

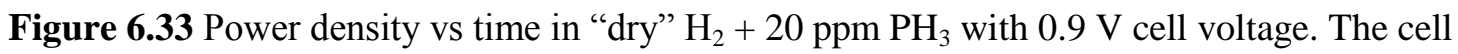
was at $800^{\circ} \mathrm{C}$ 


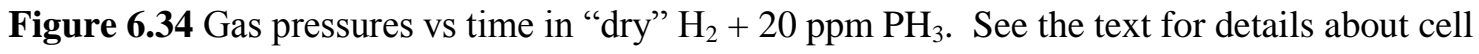
voltage and gas composition. The cell was at $800^{\circ} \mathrm{C}$

Figure 6.35 Mass spectra in dry $\mathrm{H}_{2}$ with $20 \mathrm{ppm} \mathrm{PH}_{3}$ without (40 hours) and with (60 hours) current flow.

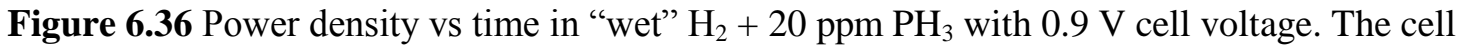
was at $800^{\circ} \mathrm{C}$.

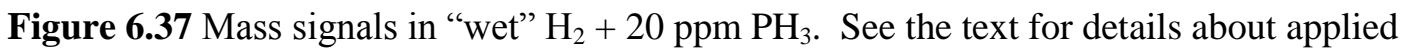
voltage and changes in fuel composition. The cell was at $800^{\circ} \mathrm{C}$. 150

Figure 6.38 SEM image of the clean reduced anode (left) and the area exposed to $20 \mathrm{ppm} \mathrm{PH}_{3}$

(right).

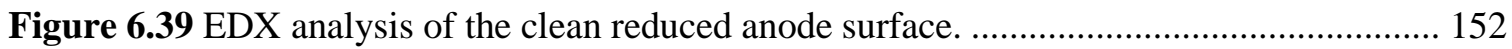

Figure 6.40 EDX analysis of the $\mathrm{PH}_{3}$ exposed anode surface.

Figure 6.41 XRD analysis of the $\mathrm{PH}_{3}$ exposed anode surface. $($ YSZ $\square$ nickel phosphide metallic $\mathrm{Ni}$ )

Figure 7.1 Deconvolution overlay comparison for dry and wet $\mathrm{H}_{2}$ conditions with no $\mathrm{PH}_{3} \ldots . . .162$

Figure 7.2 Comparison of deconvolution of impedance in dry $\mathrm{H}_{2}$, with and without $\mathrm{PH}_{3} \ldots \ldots . . .163$

Figure 7.3 Comparison of deconvolution of impedance in wet $\mathrm{H}_{2}$, with and without $\mathrm{PH}_{3} \ldots \ldots . . .164$ 


\section{List of tables}

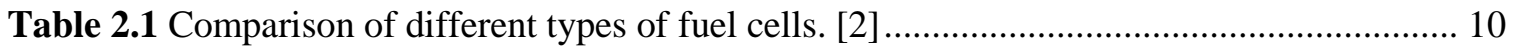

Table 2.2 Typical major gas composition in coal syngas. [20, 22]......................................... 20

Table 2.3 Trace impurities and their concentrations in coal syngas [21] .................................. 21

Table 2.4 Thermodynamically calculated partial pressures of phosphorus compounds under

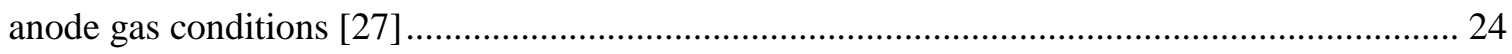

Table 2.5 Comparison of the measured and calculated partial pressures of the observed vapor

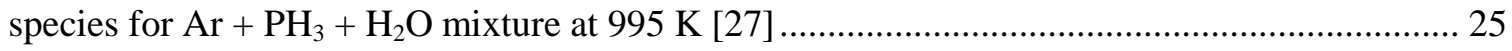

Table 3.1 Cross sections for ionization of selected molecules at $70 \mathrm{eV}[4]$............................... 53

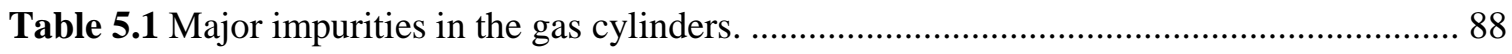

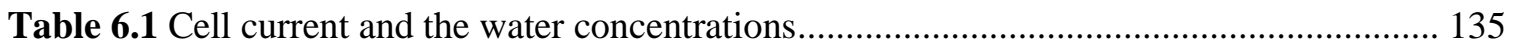




\section{Chapter 1. Introduction}

\subsection{Background.}

Solid Oxide Fuel Cells (SOFC) are devices that convert chemical energy in a gaseous fuel directly to useful electrical energy and high quality heat. SOFCs offer several advantages over heat engines. The SOFC does not need combustion, so it is highly efficient and environment friendly, and it does not contain moving parts that requires periodic maintenance. The most suited applications of SOFC will be for stationary power generation, especially power plants, where the cost of fuel and fuel delivery is high for the customers, and where it is much easier to deliver electricity to end customers. SOFC can utilize a wide variety of fuels, such as $\mathrm{H}_{2}$, natural gas (methane), coal syngas, biogas and diesel.[1-6] For most power plants, coal is the most economic and abundant fuel source.

In a solid oxide fuel cell, the fuel, such as hydrogen, is fed to the anode, and oxidized by oxygen ions, releasing electrons to the anode current lead. Then the electrons pass through the outer circuit and load, and return to the cathode of the solid oxide fuel cell. At the cathode, oxygen reacts with the electrons to form oxygen ions $\left(\mathrm{O}^{2-}\right)$. The oxygen ions pass through the electrolyte, which is ion-conductive, to the anode to complete the circuit. Figure 1.1 shows a complete circuit of a working solid oxide fuel cell, with the oxygen ion-conductive electrolyte. 


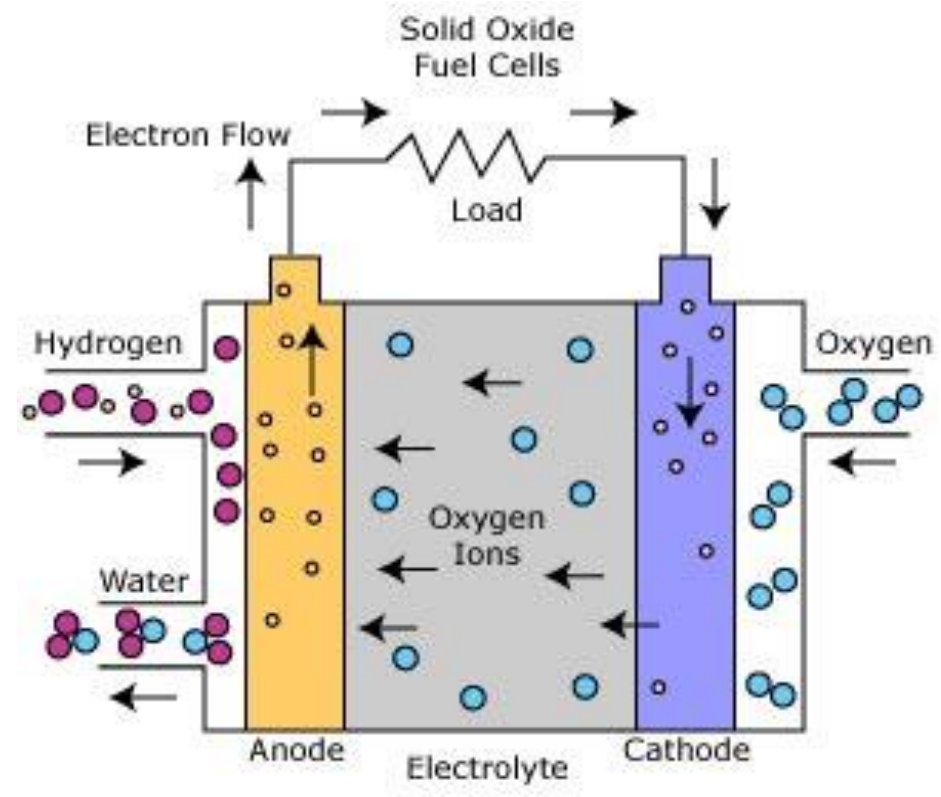

Figure 1.1 Complete circuit of a Solid Oxide Fuel Cell $\odot$ www.fctec.com

\subsection{Significance}

One of the major advantages of SOFC is the flexibility of fuel. Many types of fuel can be utilized directly by a solid oxide fuel cell. Coal is the most abundant fossil fuel in the earth. The United States of America has over one quarter of the coal reserves in the world. Currently, coal is mined in 26 of the 50 states. Primarily, coal is used to generate electricity. Over $40 \%$ of the electricity in the United States comes from burning coal.[7-9]

Solid oxide fuel cells offer great energy conversion efficiency over other power sources, while producing fewer emissions. Gasification of the coal is a relatively clean method compared to direct burning. Coal reacts with steam at high temperatures, producing syngas, a mixture of $\mathrm{H}_{2}, \mathrm{CO}, \mathrm{CO}_{2}$ and $\mathrm{H}_{2} \mathrm{O}$. Then most of the impurities in the gas, such as ash, are removed by gas cleanup. This "Clean Coal Technology" is used in 
some power plants in the states of Florida and Indiana, such as the Tampa Electric's Polk Power Station in Florida. [10]

However, after the gasification and filtering, there are still trace levels of impurities. They are not harmful to the gas turbines in the existing power plants, and they are within the health limits in the exhaust gas. However, some of them are poisons to SOFCs. Research has been performed to investigate effects of these impurities no the $\mathrm{Ni} / Y S Z$ anode of SOFCs. [11-12] Evidence of anode degradation was found because of the exposure to ppm level of impurities including $\mathrm{PH}_{3}, \mathrm{H}_{2} \mathrm{~S}, \mathrm{AsH}_{3}$, etc. A great amount of work was done at West Virginia University to determine the possible mechanism of degradation, to develop new materials that will tolerate specific levels of impurities, and to improve the long term performance of SOFCs. [11, 13-16]

In the previous studies, little is known about the actual gas-phase composition near the anode of SOFC. Impurities such as $\mathrm{PH}_{3}$ in the fuel are blended into the stream to simulate the actual syn-gas before it enters the heated operation zone. Reaction and possible products of $\mathrm{PH}_{3}, \mathrm{H}_{2}$ and $\mathrm{H}_{2} \mathrm{O}$ are not clear. There are no existing experimental data supporting the thermodynamically predicted products. What species of phosphorus is actually getting to the anode is also unknown. A detailed and accurate measurement of gas species around the anode is necessary.

\subsection{Objectives}

The major objectives of this work are the studies of reactions between impurities in coal syngas and other species at SOFC operation conditions, in-situ determination of 
gas-phase composition of fuel and exhaust gases, electrochemical characterization of the SOFC performance and degradation, and post-mortem analysis of the cells.

In this study, a new method is developed using a special type of quadruple mass spectrometer called a Residual Gas Analyzer (RGA) to determine the partial pressures of gases. The RGA continuously samples the gas phase using a one meter-long heated capillary. The RGA is connected to one of the four sampling points, inlets and exhausts of the anode and cathode, respectively. It has the capability to provide on-line data and analysis while the SOFC is operating.

Electrochemical characterizations are carried out periodically during the testing of the SOFC, including open circuit voltage (OCV), cyclic voltammetry (CV) to obtain the power curve and polarization curve, and electrochemical impedance spectrometry (EIS). The degradation of the anode caused by the poisoning effects of $\mathrm{PH}_{3}$ is evaluated by its electrochemical performance.

The micro-structural and material phase changes of the anode are determined by Scanning Electron Microscopy (SEM), X-Ray Diffraction (XRD), X-Ray Photoelectron Spectroscopy (XPS) and Energy-dispersive X-ray Spectroscopy (EDX). These post tests are done after the operation of the SOFCs on a variety of fuel compositions.

\subsection{Dissertation Organization}

This dissertation consists of 7 chapters including the introduction.

Chapter 2 is a detailed literature review of the past and current studies of impurities in the coal-derived syngas and their effects on the anode of Solid Oxide Fuel 
cells. The review emphasizes the degradation of the anode, including changes in electrochemical performance and microstructures. A brief introduction to the use of insitu analytical methods in the solid oxide fuel cell studies is also provided.

The work in this dissertation started in a fuel cell test stand in WVU Chemical Engineering with air tests and leak checks of the system. After a few cell tests, the sealing of the cell was found to be loose and difficult to improve. Then the work was moved to WVU Mechanical Engineering (WVU MAE) to use the Probostat apparatus as the testing platform. In the year 2012, due to safety reasons, the work was moved to the WVU Chemistry Research Lab (CRL).

In Chapter 3 the work done in WVU Chemical Engineering is discussed. This test stand has gas supplies of $\mathrm{H}_{2}, \mathrm{~N}_{2}, \mathrm{H}_{2} \mathrm{~S}$ and $\mathrm{PH}_{3}$. Leak checks of the gas handling system, humidifier and furnace were conducted. Whole cell tests with different levels of $\mathrm{H}_{2} \mathrm{~S}$ and current change were performed despite the leaks in the system. The leak to the air was very hard to eliminate completely. The work on this test stand was terminated.

In Chapter 4, the work carried out in the MAE with the use of the Probostat is described. The Probostat is introduced as a new cell test platform. The results of the cell test with $\mathrm{PH}_{3}$ are provided.

In Chapter 5 the gas phase reactions of impurities in coal syngas at high temperatures (no cell) are addressed. The heart of this chapter is focused on the gas composition and reaction tests done in the CRL with a tube furnace configuration and the Probostat. Several testing conditions including dry and wet $\mathrm{H}_{2}$, with and without $\mathrm{PH}_{3}$, and 
with and without a Ni/YSZ sample piece were investigated in detail with the mass spectrometer.

In Chapter 6, the discussion focuses on the whole cell tests with a glass tape seal in the CRL. The results of different gas compositions and different current densities are provided.

Chapter 7 summarizes the major observation of the work, and provides conclusions and a plan for the future research. 


\section{References in chapter 1.}

[1] S. Primdahl and M. Mogensen, J. Electrochem. Soc, 1997, 144, 3409-3419

[2] J. Liu and S. A. Barnett, Solid State Ionics, 2003, 158, 11-16

[3] Murray, E. Perry Tsai, T. Barnett, Nature, 1999, 400, 649-651

[4] Jan Van Herle, Yves Membrez, Olivier Bucheli, J. Power Sources, 2004, 127, 300312

[5] Zhongliang Zhan, Yuanbo Lin, Manoj Pillai, Ilwon Kim, Scott A. Barnett, J. Power Sources. 2006, 161, 460-465

[6] Berry, David A.; James, Robert; Gardner, Todd H.; Shekhawat, Dushyant, International Conference on Fuel Cell Science. Apr. 21-23, 2003

[7] United States Department of Energy. Fossil Energy Today Newsletter 2013, Issue No. 9, First Quarter,

[8] S. V. Vassilev, C. G. Vassileva, Fuel Processing Technology 1996, 48, 85-106

[9] International Energy Agency. 2012 Key World Energy Statistics.

[10] NETL Tampa Electric Polk Power Station Integrated Gasification Combined Cycle Project. Final Technical Report. August 2002.

[11] F.N. Cayan, M. Zhi, S.R. Pakalapati, I. Celik, N. Wu, R. Gemmen. J. Power Sources 2008, 185, 595-602 
[12] J.P. Trembly R.S. Gemmen, D.J. Bayless. J. Power Sources 2007, 163, 986-996

[13] M. Zhi, X. Chen, H. Finklea, I. Celik, NanQiang Wu, J. Power Sources 2008, 183, $485-490$

[14] O. Demircan, W. Zhang, C. Xu, J. Zondlo, H. Finklea, Journal of Power Sources

2010, 195, 3091-3096

[15] Chunchuan Xu, J. Zondlo, H. O. Finklea, O. Demircan, M. Gong, X. Liu Journal of Power Sources 2009, 193, 739-746

[16] Chunchuan Xu, J. Zondlo, M. Gong, X. Liu Journal of Power Sources 2011, 196, $116-125$ 


\section{Chapter 2. Literature review}

\subsection{Introduction to Solid Oxide Fuel Cells (SOFC).}

Fuel Cells produce electrical energy directly by oxidizing a fuel. The origin of fuel cells can be tracked back to the early $19^{\text {th }}$ century. In the year of 1838 , William R. Grove developed a new type of wet cell, using hydrogen as fuel and oxygen as oxidizer, called "gas batteries". [1] Currently there are numerous types of fuel cells being developed and intensively investigated. Fuel cells are usually classified and named by the type of electrolytes used. The current major types of fuel cells include Alkaline Fuel Cell (AFC), Direct Methanol Fuel Cell (DMFC), Phosphoric Acid Fuel Cell (PAFC), Polymer Electrolyte Membrane Fuel Cell (PEMFC), Molten Carbonate Fuel Cell (MCFC) and Solid Oxide Fuel Cell (SOFC). The technical specifications of these types of fuel cells are listed in Table 2.1. [2]

Solid Oxide Fuel Cells operate at relative high temperature ranging from $600{ }^{\circ} \mathrm{C}$ to $1000{ }^{\circ} \mathrm{C}$. While generating electricity, SOFC also produce a gas stream at high temperature. In a large-scale stack, after it has been successfully started up, the SOFC system itself can produce enough heat to remain at operational conditions, and the byproduct heat is also very useful. [3-4]

The energy conversion efficiency of fuel cells is excellent, ranging from $40 \%$ $70 \%$, much better than most heat engines. Internal combustion engines retain an average efficiency of $18 \%-20 \%$, while there is a theoretical thermodynamic limit of $37 \%$. Large 
electricity-generating steam turbines have an efficiency of up to $40 \%$. Gas turbines offer a range of efficiencies from $20 \%-60 \%$, depending on the specific working model and mode. [5] Among the different types of fuel cells, the SOFC gives the highest efficiency, up to $70 \%-80 \%$. The hot exhaust gas can be used to operate a gas turbine, making it a combined cycle, thus further increasing the overall system efficiency. [6-7]

Table 2.1 Comparison of different types of fuel cells. [2]

\begin{tabular}{|c|c|c|c|c|}
\hline Types of fuel cell & Electrolyte & $\begin{array}{c}\text { Operation } \\
\text { temperature }\end{array}$ & Fuel & Efficiency \\
\hline $\begin{array}{l}\text { Alkaline fuel cell } \\
\qquad(\mathrm{AFC})\end{array}$ & $\begin{array}{l}\text { Potassium hydroxide } \\
\qquad(\mathrm{KOH})\end{array}$ & $50-200^{\circ} \mathrm{C}$ & $\begin{array}{l}\text { Hydrogen/ } \\
\text { hydrazine }\end{array}$ & $50-55 \%$ \\
\hline $\begin{array}{l}\text { Direct methanol fuel } \\
\text { cell (DMFC) }\end{array}$ & Polymer & $60-200^{\circ} \mathrm{C}$ & Methanol & $40-55 \%$ \\
\hline $\begin{array}{c}\text { Phosphoric acid fuel } \\
\text { cell (PAFC) }\end{array}$ & Phosphoric acid & $160-210^{\circ} \mathrm{C}$ & Hydrocarbons & $\sim 40 \%$ \\
\hline $\begin{array}{l}\text { Proton-exchange } \\
\text { membrane fuel cell } \\
\text { (PEMFC) }\end{array}$ & $\begin{array}{c}\text { Proton-exchange } \\
\text { membrane (polymer) }\end{array}$ & $50-80^{\circ} \mathrm{C}$ & Hydrogen & $40-50 \%$ \\
\hline $\begin{array}{l}\text { Molten carbonate fuel } \\
\text { cell }(\mathrm{MCFC})\end{array}$ & $\begin{array}{c}\text { Molten carbonate } \\
\text { salt }\end{array}$ & $\sim 650^{\circ} \mathrm{C}$ & $\begin{array}{l}\text { Hydrogen, } \mathrm{CO}, \\
\text { natural gas }\end{array}$ & $45-55 \%$ \\
\hline $\begin{array}{l}\text { Solid oxide fuel cell } \\
\text { (SOFC) }\end{array}$ & $\begin{array}{l}\text { Yttria stabilized } \\
\text { zirconia (YSZ) }\end{array}$ & $600-1000^{\circ} \mathrm{C}$ & $\begin{array}{l}\text { Hydrogen, } \mathrm{CO} \text {, } \\
\text { natural gas, coal } \\
\text { syngas, oil, etc. }\end{array}$ & $70-80 \%$ \\
\hline
\end{tabular}

SOFCs have three major components, the anode, the cathode and the electrolyte. The three parts are sandwiched together and the anode and cathode are separated by the electrolyte. Materials used in SOFCs must be carefully selected to meet the special needs (high temperature, oxidation/reduction atmosphere) of functions and operating conditions. 
The anode has multiple functions and must meet several requirements. The anode material is usually made very porous to allow diffusion of the fuel to the active layer near the electrolyte. The material in the anode is often nickel mixed with yttria stabilized zirconia ( $\mathrm{YSZ}, \mathrm{ZrO}_{2}$ doped with $\mathrm{Y}_{2} \mathrm{O}_{3}$ ). Most of the oxidation reactions occur within 20 $\mu \mathrm{m}$ from the electrolyte, a region called the active layer. [47] In some studies and in commercially available SOFCs, the anode is made of two layers: the active layer next to the electrolyte, and the supporting Ni/YSZ structure. $\mathrm{Ni}$ is a good electron conductor. At the same time, Ni serves as a catalyst for the oxidation of hydrogen. YSZ is an oxygen ion conductor above $500^{\circ} \mathrm{C}$. It transfers the oxygen ions from the electrolyte to the oxidized fuel, and upon reaction, water and $\mathrm{CO}_{2}$ are formed. [8] With hydrogen fuel, for example, the anode reaction is:

$$
\mathrm{H}_{2}+\mathrm{O}^{2-} \rightarrow \mathrm{H}_{2} \mathrm{O}+2 e^{-}
$$

The electrolyte is a dense layer that separates gases from the anode and cathode sides. Yttria stabilized zirconia (YSZ), which is dense and hard, is widely used as a major electrolyte material in SOFCs. It is purely ion conductive in operation, and only allows oxygen ions to pass from the cathode through the electrolyte to the anode, but not the electrons. Yttrium in the YSZ creates vacancies for the oxygen ions to flow, and the yttrium stabilizes the cubic crystal structure of zirconia. Gadolinium-doped ceria (GDC) and samarium-doped ceria (SDC) are also used in some studies to promote oxygen ion conductivity and lower the working temperature. [9-12]

The cathode material is often lanthanum strontium manganate (LSM, $\left.\mathrm{La}_{0.8} \mathrm{Sr}_{0.2} \mathrm{MnO}_{3}\right)$. It is electron-conductive at high temperatures. Furthermore, in this 
perovskite structure, missing oxygen ions in the face-center position can create oxygen vacancies, thus making it ionically conductive as well. [13] As in the anode, the LSM is blended with YSZ in the cathode structure. The cathode is also made porous. A site where the cathode, electrolyte and oxygen gas meet together is called triple-phase boundary (TPB). Oxygen molecules are reduced at the TPB. [14] The cathode half reaction is:

$$
\mathrm{O}_{2}+4 e^{-} \rightarrow 2 \mathrm{O}^{2-}
$$

Kröger-Vink notation ( $V_{o}^{o o}$ is oxygen vacancy, $O_{o}{ }^{x}$ is oxygen ion in the lattice) of the cathode half reaction (consuming oxygen vacancies) is:

$$
\mathrm{O}_{2}+4 e^{-}+2 \mathrm{~V}_{o}^{o o} \rightarrow 2 \mathrm{O}_{o}{ }^{x}
$$

Kröger-Vink notation of the anode half reaction (generating oxygen vacancies) is:

$$
2 \mathrm{H}_{2}+2 \mathrm{O}_{o}{ }^{x} \rightarrow 2 \mathrm{H}_{2} \mathrm{O}+2 \mathrm{~V}_{o}^{o o}+4 e^{-}
$$

The overall cell reaction is:

$$
2 \mathrm{H}_{2}+\mathrm{O}_{2} \rightarrow 2 \mathrm{H}_{2} \mathrm{O}
$$

The application of the SOFC is often focused on power generation, from largescale power plants to small generators (less than $100 \mathrm{~kW}$ ) such as residential, transportation and auxiliary power units. Currently, research is directed at reducing the cost - both initial and operational. The U.S. Department of Energy's (DOE) Solid State Energy Conversion Alliance (SECA) program has proposed to develop SOFC systems that cost no more than $\$ 700$ per kilowatt. [15] In the year 2010, a $25 \mathrm{~kW}, 120$ cell stack was tested at FuelCell Energy Inc. with a claimed cost of $\$ 400 / \mathrm{kW}$. [16] Power plants 
using SOFC together with on-site coal gasifiers are proposed to be a good substitute for conventional coal burning plants, with their ability to remove most of the impurities and to capture the $\mathrm{CO}_{2}$. This type of power plant is often called integrated gasification fuel cell (IGFC). With the SOFC's ability to reform methane internally, natural gas fuel cell (NGFC) systems are also a promising clean power source. [17-18] Figure 2.1 is an illustration of SOFC system integrated with either coal gasification or a natural gas system.

Future work on SOFC will focus on increasing the life span, lowering cost, developing large stack systems and capturing the $\mathrm{CO}_{2}$. The DOE is planning to initiate $250 \mathrm{~kW}$ modules in 2017, and this size of modules is to be used as bricks to build multimegawatts power plants. By 2020, these systems are expected to have a life span of about 10,000 hours. This will allow, by 2025, the commercialization of 1-5 MW coal and natural gas-based power plants, with no less than $99 \% \mathrm{CO}_{2}$ captured and nearly zero $\mathrm{NO}_{\mathrm{x}}$ emission. [17] 


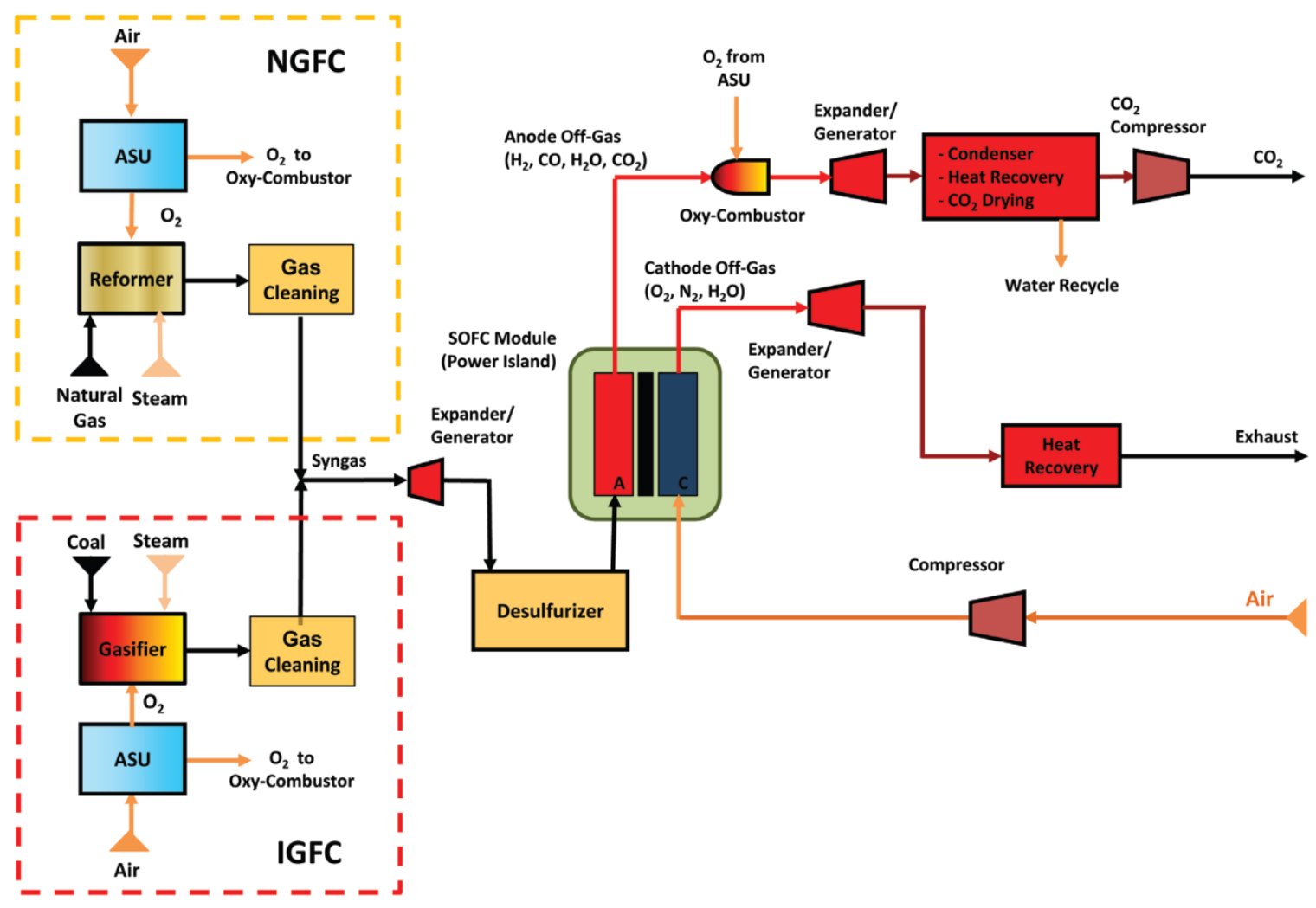

Figure 2.1 IGFC/NGFC power generation system block diagram. [17]

\subsection{Electrochemical characteristics of Solid Oxide Fuel Cell}

Electrochemical characterization of a SOFC is done as a routine tool to judge the performance of the fuel cell. The redox reactions on the electrodes are intensively investigated in experiments and theoretical calculations. [23] There are two types of electrochemical methods often used in characterization. [24] The DC methods include open circuit voltage (OCV), polarization curve (I-V curve) and galvanostatic tests. The common AC method used is electrochemical impedance spectroscopy (EIS).

Theoretically, the reversible open circuit voltage of a solid oxide fuel cell under standard conditions can be calculated by the change of Gibbs free energy. Taking 
hydrogen as fuel for example, the overall reaction is shown in Equation 2-3. The reversible $\mathrm{OCV}$ in theory is:

$$
\Delta E^{0}=\frac{-\Delta G^{0}}{4 F}
$$

Then the $\mathrm{OCV}$ at another given temperature $\mathrm{T}$ is:

$$
\Delta E_{T}=\Delta E^{0}+\frac{\Delta S}{4 F}\left(T-T^{0}\right)
$$

The OCV with a given gas composition can be calculated using the Nernst equation, $(\alpha$ is the activity for the gases.)

$$
\Delta E=\Delta E^{0}+\frac{R T}{4 F} \ln \left(\frac{\alpha_{H_{2}}^{2} \cdot \alpha_{O_{2}}}{\alpha_{H_{2} O}^{2}}\right)
$$

For a hydrogen cell working at $800^{\circ} \mathrm{C}$, with $3 \%$ water vapor present in the fuel stream and pressure at $1 \mathrm{~atm}$, the calculated OCV is $1.103 \mathrm{~V}$. However, due to possible gas leaks between the anode side and the cathode side, the theoretical OCV is difficult to reach in actual fuel cell tests. Usually the OCV is around 1.06-1.08 V depending on the fuel type in practice. The OCV is an important factor for the evaluation of SOFC performance.

The efficiency of SOFC can be calculated by the ratio of the electrical energy (Gibbs free energy) to the total change of enthalpy of the reaction.

$$
\eta=\frac{\Delta G}{\Delta H} \times 100 \%
$$


For hydrogen fuel cells, the enthalpy change $\Delta \mathrm{H}=-243.83 \mathrm{~kJ}$ per mole of gas phase water formed. This is called the Lower Heating Value (LHV), as the production water will not condense under SOFC working temperatures. The LHV acknowledges the true total heat that could theoretically be recovered from the hydrogen combustion reaction. Then the enthalpy change can be expressed by the voltage $\mathrm{E}_{\mathrm{h}}$ :

$$
E_{h}=\frac{-\Delta H}{z F}=1.26 V
$$

So the efficiency becomes:

$$
\eta=\frac{\Delta G}{\Delta H}=\frac{E}{E_{h}}=\frac{V}{1.26 V} \times 100 \%
$$

For a typical hydrogen cell at $1.103 \mathrm{~V}$, the theoretical efficiency is about $85 \%$.

The polarization of a SOFC is the sum of several voltage losses. The various polarizations reduce the performance, so efforts are made to minimize the voltage loss, although it is impossible to eliminate them completely. The three major types of polarization are reaction rate loss, ohmic resistance loss and concentration loss. An example of calculated polarizations and their effective ranges in a SOFC model are shown in the I-V curve in Figure 2.2. [25] 


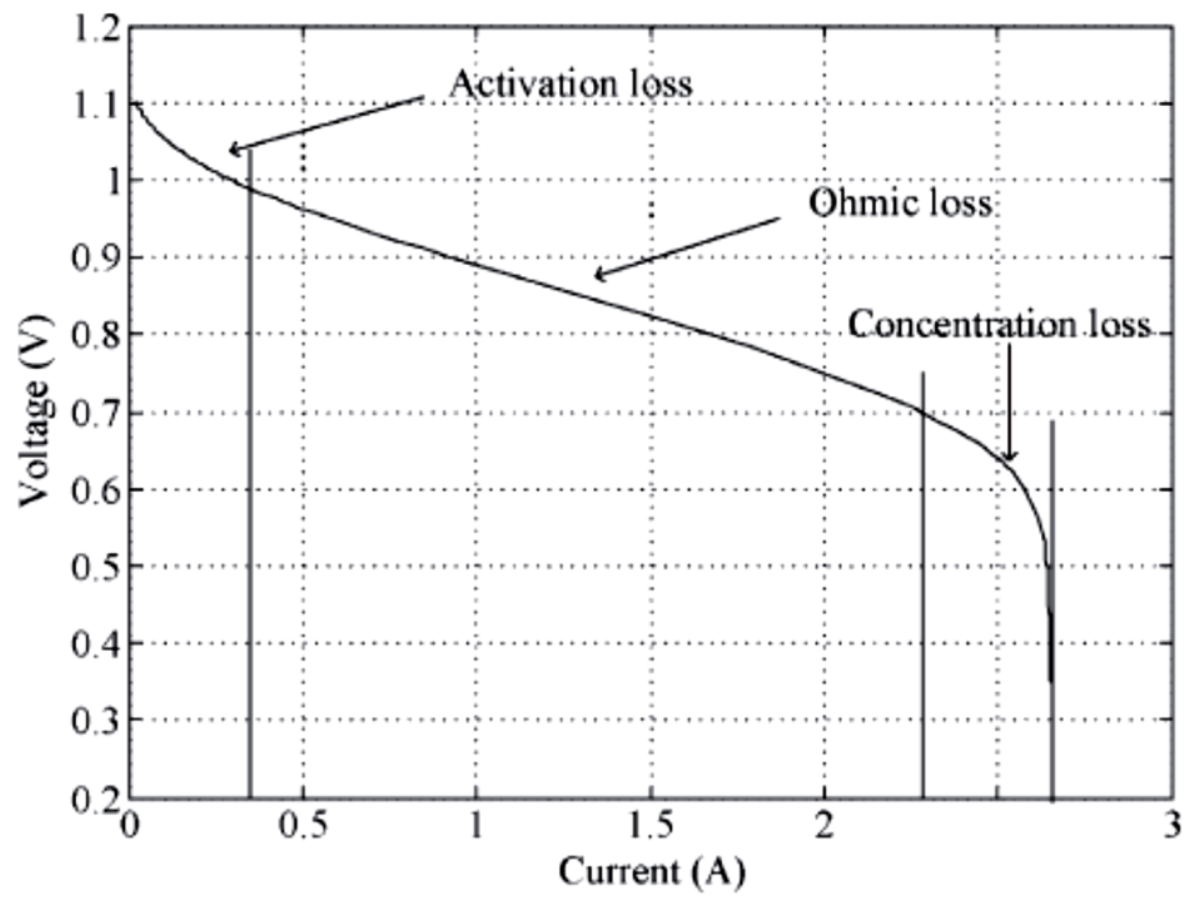

Figure 2.2 Typical polarization curve for a SOFC model. [25]

The actual output voltage is given by:

$$
V_{F C}=E-V_{a c t}-V_{o h m i c}-V_{c o n c}
$$

Here in the equation, $V_{F C}$ is the output voltage of the fuel cell at any current. $E$ is the Nernst reversible voltage. $V_{a c t}$ is the activation voltage loss. This loss is due to the activation energy that the redox reaction needs to overcome to proceed. $V_{\text {ohmic }}$ is the ohmic voltage loss, including the ion resistance in the electrolyte, which is dominant, and electron resistance within the electrodes. $V_{\text {conc }}$ is the concentration voltage loss. This occurs mainly at high current because of the mass transfer rate limitation of reactant to the active zone of each electrode. 
Electrochemical impedance spectroscopy is another useful characterization method. In EIS measurements, an AC voltage is applied to the cell, while the amplitude and phase of the AC current are monitored.

The AC voltage is:

$$
E_{a c}=\left|E_{a c}\right| \sin (\omega t)
$$

The AC current is:

$$
I_{a c}=\left|I_{a c}\right| \sin (\omega t+\varphi)
$$

$\varphi$ is the phase shift of current relative to the AC voltage.

By definition from Ohm's law, the impedance is expressed as:

$$
Z(\omega)=\frac{E_{a c}}{I_{a c}}=\frac{\left|E_{a c}\right| \sin (\omega t)}{\left|I_{a c}\right| \sin (\omega t+\varphi)}=|Z| \frac{\sin (\omega t)}{\sin (\omega t+\varphi)}
$$

The impedance is often expressed using complex numbers, to reveal its real part (Z') and imaginary part $(Z ”):(j$ is the square root of -1$)[26]$

$$
Z(\omega)=\frac{E_{a c}}{I_{a c}}=|Z|(\cos \varphi+j \sin \varphi)=Z^{\prime}+Z^{\prime \prime}
$$

The two parts are often plotted on the Nyquist plot. The real part is on the horizontal axis and the negative value of the imaginary part is on the vertical axis. Figure 2.3 is an example of Nyquist plot. The higher frequency is on the left (smaller Z') side and the lower frequency is on the right (larger Z') side. The high frequency intercept on the horizontal axis represents the ohmic (or series) resistance $\mathrm{R}_{\mathrm{s}}$. The low frequency intercept represents the sum of ohmic and all polarization resistances $R_{s}+R_{p}$. 


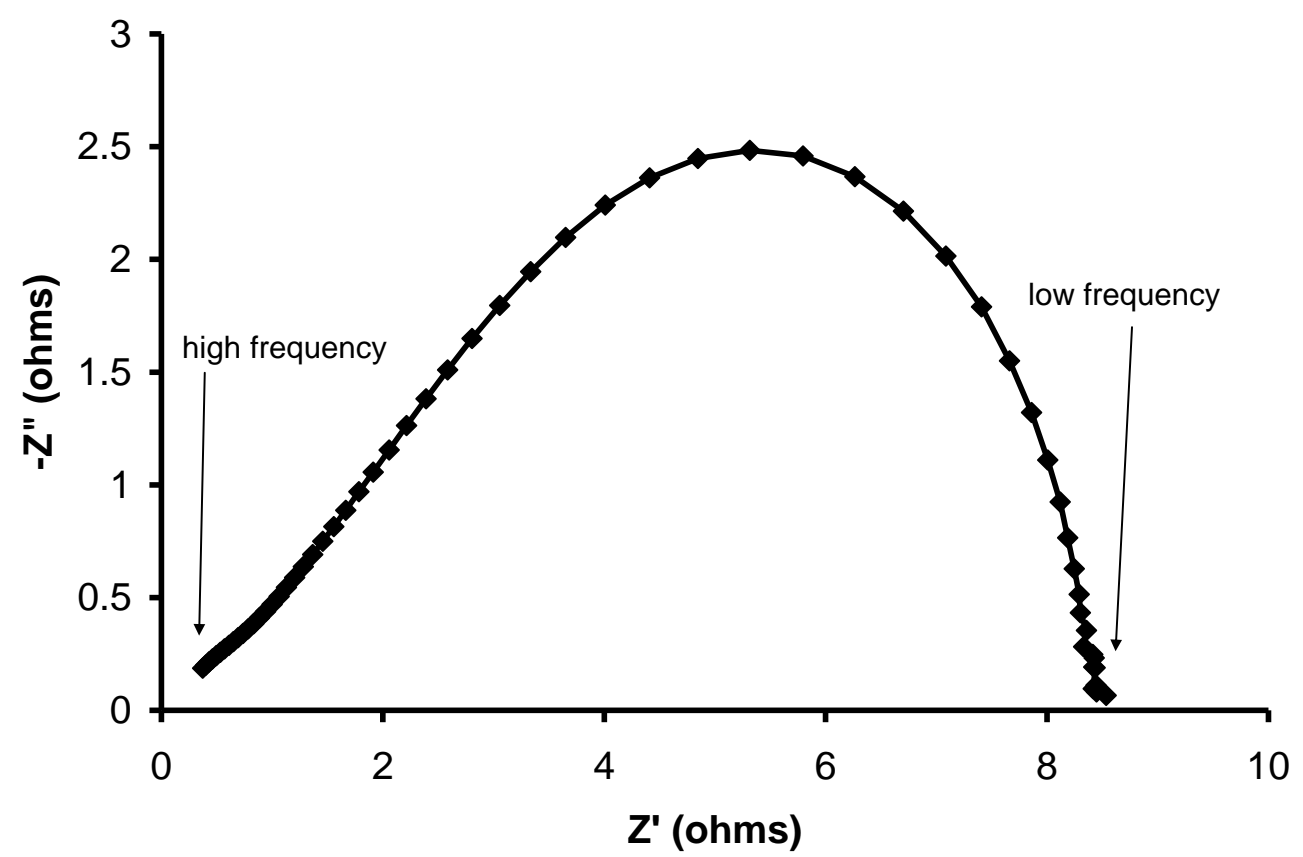

Figure 2.3 Example of a Nyquist plot from electrochemical impedance spectroscopy.

\subsection{Trace amount impurities in coal syngas.}

The cleanest way to utilize coal is through gasification. Coal gasification not only generates combustible syngas, but also produces useful materials for the chemical industry, without the necessity of burning the coal. For example, syngas can be used in the Fischer-Tropsch process to produce diesel, or converted into methane, methanol, and dimethyl ether in catalytic processes. [48] In a coal gasification reactor, the coal is heated to high temperature $\left(600-1000^{\circ} \mathrm{C}\right)$, and is reacted with steam and oxygen at high pressure (up to $70 \mathrm{~atm}$ ). [19] The reaction includes the partial oxidation of carbon, steam-carbon oxidation and the water-gas shift reaction:

$$
2 C_{(s)}+O_{2(g)} \rightarrow 2 C_{(g)} \quad \Delta \mathrm{E}=-221.0 \mathrm{~kJ}
$$




$$
\begin{array}{ll}
C_{(s)}+H_{2} O_{(g)} \rightarrow C O_{(g)}+H_{2(g)} & \Delta \mathrm{E}=131.3 \mathrm{~kJ} \\
\mathrm{CO}_{(g)}+\mathrm{H}_{2} \mathrm{O}_{(g)} \rightarrow \mathrm{CO}_{2(g)}+H_{2(g)} & \Delta \mathrm{E}=-41.2 \mathrm{~kJ}
\end{array}
$$

The major components of coal syngas are $\mathrm{H}_{2}, \mathrm{CO}, \mathrm{CO}_{2}$ and $\mathrm{H}_{2} \mathrm{O}$, with some trace amount of impurities. The composition of syngas products varies from different gasification plants. Table 2.2 shows an example of product gas from a typical gasification plant product gas. [20, 22]

Table 2.2 Typical major gas composition in coal syngas. [20, 22]

\begin{tabular}{cc}
\hline Component & Concentration (vol. \%) \\
\hline $\mathrm{H}_{2}$ & 29.3 \\
$\mathrm{CO}$ & 28.7 \\
$\mathrm{CO}_{2}$ & 11.8 \\
$\mathrm{H}_{2} \mathrm{O}$ & 27.2 \\
$\mathrm{~N}_{2}$ & 3.0 \\
\hline
\end{tabular}

The trace impurities also differ by plant and the geographical origin of the coal. SOFCs can use the $\mathrm{H}_{2}$ and $\mathrm{CO}$ in syngas as fuel. CO is a fuel and not a poison for SOFC anodes. However, some trace amount of impurities will harm the anode in many ways. There are methods of gas clean-up treatment for syngas to remove $\mathrm{H}_{2} \mathrm{~S}$, halides and ash particles at ambient temperature. But for a more energy efficient process, future power plant design is expected to include removal of $\mathrm{H}_{2} \mathrm{~S}, \mathrm{HCN}, \mathrm{HCl}$, ash and alkali at 250- 
$500^{\circ} \mathrm{C}$ in modern syngas plants, which is also being studied as a warm gas clean-up system. [21-22]

Table 2.3 Trace impurities and their concentrations in coal syngas [21]

\begin{tabular}{|c|c|}
\hline Contaminant & $\begin{array}{c}\text { Concentration at the } \\
\text { Kingsport facility (ppm) }\end{array}$ \\
\hline Arsine $\left(\mathrm{AsH}_{3}\right)$ & $0.15-0.58$ \\
\hline \multicolumn{2}{|l|}{ Thiophene } \\
\hline \multicolumn{2}{|l|}{ Chlorine (Cl) } \\
\hline Methyl Fluoride $\left(\mathrm{CH}_{3} \mathrm{~F}\right)$ & 2.6 \\
\hline Methyl Chloride $\left(\mathrm{CH}_{3} \mathrm{Cl}\right)$ & 2.01 \\
\hline Hydrogen Chloride (HCl) & $<1$ \\
\hline $\mathrm{Fe}(\mathrm{CO})_{5}$ & $0.05-5.6$ \\
\hline $\mathrm{Ni}(\mathrm{CO})_{5}$ & $0.001-0.025$ \\
\hline $\mathrm{CH}_{3} \mathrm{SCN}$ & 2.1 \\
\hline Phosphine $\left(\mathrm{PH}_{3}\right)$ & 1.9 \\
\hline Antimony (Sb) & 0.025 \\
\hline \multicolumn{2}{|l|}{ Cadmium (Cd) } \\
\hline Chromium (Cr) & $<0.025$ \\
\hline Mercury (Hg) & $<0.025$ \\
\hline Selenium (Se) & $<0.15$ \\
\hline Vanadium (V) & $<0.025$ \\
\hline \multicolumn{2}{|l|}{ Lead $(\mathrm{Pb})$} \\
\hline Zinc (Zn) & 9.0 \\
\hline
\end{tabular}

Although coal syngas is cleaned, it still carries trace impurities such as arsine, hydrogen sulfide, phosphine and hydrogen chloride. Table 2.3 lists some of the impurities found in a Kingsport, TN syngas facility. These volatile species are detected after the warm gas clean-up process where the syngas has been cooled. However, while the SOFC is under 
operating conditions with temperature up to $800^{\circ} \mathrm{C}$, it is still not clear what species actually get to the anode, and, how these species affect the anode performance. More specific information is needed in addition to the components and the elemental analyses.

\subsection{Gas phase species under SOFC working conditions.}

The form and reactions of the phosphorus compounds in coal syngas under SOFC working conditions are still not clearly known. Calculations and experimental approaches have generated various results. Phosphorus may exist as phosphine $\left(\mathrm{PH}_{3}\right)$ at ambient temperature. However, Trembly et al. have done thermodynamic modeling at equilibrium and under warm gas clean up conditions $\left(200-500^{\circ} \mathrm{C}, 1-15 \mathrm{~atm}\right)$. The initial gas composition was assumed as literature values described previously in Table 2.2 and the initial amount of $\mathrm{PH}_{3}$ was set to $1.9 \mathrm{ppm}$. The thermodynamic modeling package is the FACTSAGE software with databases from GTI-Technologies. This calculation suggests that two trace vapor-phase forms of phosphorus found in the coal syngas after warm gas clean up were $\left(\mathrm{P}_{2} \mathrm{O}_{3}\right)_{2}$ and $\mathrm{PH}_{3}$, while various trace amounts of $\mathrm{HPO}_{\mathrm{x}}$ are also found to form depending on the temperatures and pressures. [28] Of these two species, $\mathrm{PH}_{3}$ exhibits the possibility of reacting with the Ni/YSZ anode by thermodynamic calculations with a negative change of Gibbs free energy. One of the reactions is:

$$
2 \mathrm{PH}_{3(\mathrm{~g})}+5 \mathrm{Ni}_{(\mathrm{s})} \rightarrow \mathrm{Ni}_{5} \mathrm{P}_{2(\mathrm{~s})}+3 \mathrm{H}_{2(\mathrm{~g})} \quad \Delta \mathrm{G}(1073 \mathrm{~K})=-495.07 \mathrm{~kJ} \quad(2-18)
$$

The $\mathrm{PH}_{3}$ concentration is also found to depend on the partial pressure of oxygen $\left(\mathrm{P}_{\mathrm{O} 2}\right)$. A larger $\mathrm{P}_{\mathrm{O} 2}$ corresponds to more oxidized phosphorus, thus a lower $\mathrm{PH}_{3}$. [28] 
C. Xu et al. have calculated a thermodynamic phase diagram of the nickel/phosphorous system by using FACTSAGE software [33]. The phase diagram in Figure 2.4 shows that $\mathrm{PH}_{3}$ can react with $\mathrm{Ni}$ to form nickel phosphide via reaction (2-18, 2-19 and 2-20). At $800^{\circ} \mathrm{C}$, the most thermodynamically stable phases are $\mathrm{Ni}_{2} \mathrm{P}$ and $\mathrm{Ni}_{6} \mathrm{P}_{5} . \mathrm{Ni}_{5} \mathrm{P}_{2}$ may exist as a secondary phase while the local cell temperature increases due to current flow.

$$
\begin{array}{ll}
10 \mathrm{PH}_{3(\mathrm{~g})}+12 \mathrm{Ni}_{(\mathrm{s})} \rightarrow 2 \mathrm{Ni}_{6} \mathrm{P}_{5(\mathrm{~s})}+15 \mathrm{H}_{2(\mathrm{~g})} & \Delta \mathrm{G}(1073 \mathrm{~K})=-1845.84 \mathrm{~kJ} \\
2 \mathrm{PH}_{3(\mathrm{~g})}+5 \mathrm{Ni}_{(\mathrm{s})}=\mathrm{Ni}_{5} \mathrm{P}_{2(\mathrm{~s})}+15 \mathrm{H}_{2(\mathrm{~g})} & \Delta \mathrm{G}(1073 \mathrm{~K})=-495.07 \mathrm{~kJ}
\end{array}
$$

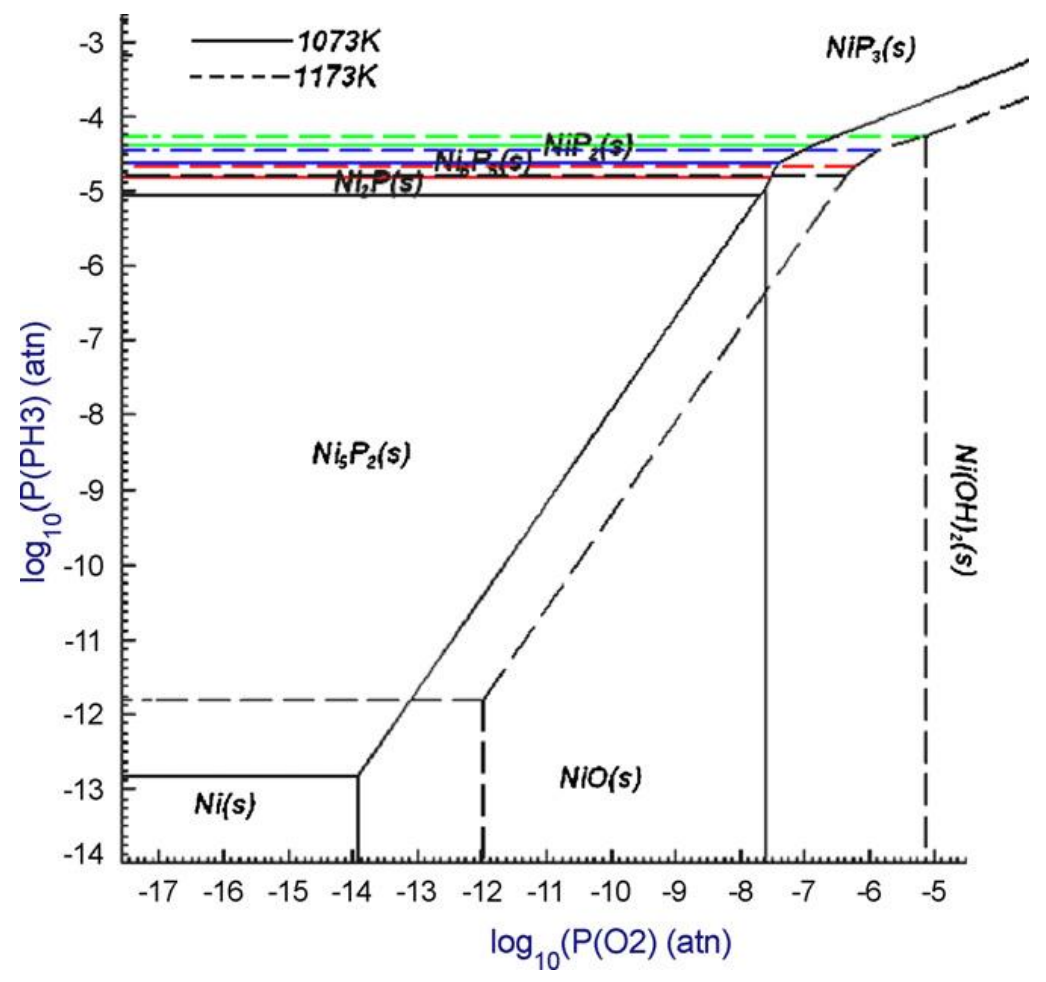

Figure 2.4 Thermodynamic phase diagram of potential Ni products with $10 \mathrm{ppm}$ of $\mathrm{PH}_{3}$ present in reducing atmosphere. [33]

Bao et al. performed thermodynamic equilibrium calculations to predict the chemical nature and abundance of relevant trace impurity species as a function of the temperature range expected in a coal gasification system. [27-29, 46] For these 
calculations, the system pressure was assumed to be $10 \mathrm{~atm}$ and the impurities level was at 10 ppm initially. Phosphorus may exist as gas phase $\mathrm{PH}_{3}$ when the gas is cooled to low temperature at high pressures after it exists the coal gasifier. However, under SOFC operation temperatures ranging from $700^{\circ} \mathrm{C}$ to $900^{\circ} \mathrm{C}$ and at $1 \mathrm{~atm}, \mathrm{PH}_{3}$ may be hydrolyzed to form mainly $\mathrm{HPO}_{2}$ and $\mathrm{HPO}_{3}$ as shown in Table 2.4.

Table 2.4 Thermodynamically calculated partial pressures of phosphorus compounds under anode gas conditions.(1 atm) [27]

\begin{tabular}{cccccc}
\hline \multirow{2}{*}{$\begin{array}{c}\text { Gaseous } \\
\text { Species }\end{array}$} & $\mathbf{7 2 7}^{\circ} \mathbf{C}$ & $\mathbf{7 7 7}^{\circ} \mathbf{C}$ & $\mathbf{8 2 7}^{\circ} \mathbf{C}$ & $\mathbf{8 7 7}^{\circ} \mathbf{C}$ & $\mathbf{8 7 7}^{\circ} \mathbf{C}$ \\
\cline { 2 - 6 } & 0.23 & 0.24 & 0.25 & 0.26 & 0.27 \\
$\mathrm{CO}$ & 0.19 & 0.17 & 0.16 & 0.15 & 0.15 \\
$\mathrm{CO}_{2}$ & 0.37 & 0.36 & 0.35 & 0.34 & 0.33 \\
$\mathrm{H}_{2}$ & 0.21 & 0.22 & 0.23 & 0.24 & 0.25 \\
$\mathrm{H}_{2} \mathrm{O}$ & $6.75 \times 10^{-8}$ & $9.33 \times 10^{-8}$ & $1.24 \times 10^{-7}$ & $1.61 \times 10^{-7}$ & $2.04 \times 10^{-7}$ \\
$\mathrm{HPO}$ & $2.85 \times 10^{-5}$ & $2.83 \times 10^{-5}$ & $2.83 \times 10^{-5}$ & $2.82 \times 10^{-5}$ & $2.81 \times 10^{-5}$ \\
$\mathrm{HPO}_{2}$ & $1.64 \times 10^{-7}$ & $1.82 \times 10^{-7}$ & $2.02 \times 10^{-7}$ & $2.23 \times 10^{-7}$ & $2.44 \times 10^{-7}$ \\
$\mathrm{HPO}_{3}$ & $1.00 \times 10^{-9}$ & $7.72 \times 10^{-10}$ & $5.96 \times 10^{-10}$ & $4.68 \times 10^{-10}$ & $3.75 \times 10^{-10}$ \\
$\mathrm{PH}_{3}$ & & & & &
\end{tabular}

In another experimental study, Bao et al. from SRI International suggest that at $995 \mathrm{~K}\left(772^{\circ} \mathrm{C}\right)$, in the presence of water vapor, $\mathrm{PH}_{3}$ will undergo a hydrolysis reaction to form $\mathrm{HPO}_{2}$ and $\mathrm{HPO}_{3}$. [29]

$$
\begin{gathered}
\mathrm{PH}_{3(\mathrm{~g})}+2 \mathrm{H}_{2} \mathrm{O}_{(\mathrm{g})} \rightarrow \mathrm{HPO}_{2(\mathrm{~g})}+3 \mathrm{H}_{2(\mathrm{~g})} \\
\mathrm{PH}_{3(\mathrm{~g})}+3 \mathrm{H}_{2} \mathrm{O}_{(\mathrm{g})} \rightarrow \mathrm{HPO}_{3(\mathrm{~g})}+4 \mathrm{H}_{2(\mathrm{~g})}
\end{gathered}
$$


Also, in a technical report prepared by SRI Intl., a high-temperature Knudsen cell mass spectrometry is used to identify the chemistry of $\mathrm{PH}_{3}, \mathrm{AsH}_{3}$, etc, at a temperature range $750^{\circ}$ to $850^{\circ} \mathrm{C}$, and the data are compared with the available calculated thermodynamic data. [27] The observed and calculated data are listed in Table 2.5. The calculations assume that all species are in equilibrium.

Table 2.5 Comparison of the measured and calculated partial pressures of the observed vapor species for $\mathrm{Ar}+\mathrm{PH}_{3}+\mathrm{H}_{2} \mathrm{O}$ mixture at $995 \mathrm{~K}$. [27]

\begin{tabular}{|c|c|c|c|}
\hline \multirow{2}{*}{ Species } & \multicolumn{3}{|c|}{ Partial Pressure (atm) } \\
\hline & $\begin{array}{l}\text { Measured } \\
\text { (without } \mathrm{H}_{2} \mathrm{O} \text { ) }\end{array}$ & $\begin{array}{l}\text { Measured } \\
\left(\text { With } \mathbf{H}_{2} \mathrm{O}\right)\end{array}$ & Calculated \\
\hline $\mathrm{Ar}$ & $3.96 \times 10^{-4}$ & $3.96 \times 10^{-4}$ & $4.17 \times 10^{-4}$ \\
\hline $\mathrm{PH}_{3}$ & $2.36 \times 10^{-8}$ & $1.26 \times 10^{-8}$ & $1.51 \times 10^{-28}$ \\
\hline $\mathrm{H}_{2} \mathrm{O}$ & & $7.60 \times 10^{-5}$ & $8.33 \times 10^{-5}$ \\
\hline HPO & & & $1.22 \times 10^{-15}$ \\
\hline $\mathrm{HPO}_{2}$ & & $1.70 \times 10^{-9}$ & $1.20 \times 10^{-9}$ \\
\hline $\mathrm{HPO}_{3}$ & & $7.20 \times 10^{-9}$ & $1.54 \times 10^{-8}$ \\
\hline $\mathrm{H}_{2}$ & & & $6.55 \times 10^{-8}$ \\
\hline $\mathrm{O}$ & & & $1.27 \times 10^{-16}$ \\
\hline $\mathrm{OH}$ & & & $4.30 \times 10^{-12}$ \\
\hline $\mathrm{O}_{2}$ & & & $8.97 \times 10^{-14}$ \\
\hline $\mathrm{PO}$ & & & $1.12 \times 10^{-14}$ \\
\hline $\mathrm{PO}_{2}$ & & & $3.20 \times 10^{-12}$ \\
\hline $\mathrm{P}_{2}$ & $5.57 \times 10^{-11}$ & & $2.95 \times 10^{-27}$ \\
\hline $\mathrm{P}_{4}$ & $2.13 \times 10^{-9}$ & & $9.29 \times 10^{-51}$ \\
\hline
\end{tabular}

The data in Table 2.5 also showed that the hydrolyzed $\mathrm{HPO}_{3}$ is significantly less than the calculated value, suggesting the reaction is kinetically slow although the product is thermodynamically stable. The decomposition of $\mathrm{PH}_{3}$ is also slow. So, the unconsumed 
$\mathrm{PH}_{3}$ remains in the fuel stream with the coal syngas, and may finally reach the anode of SOFC.

H. Kisimoto et al. generated Ellingham diagrams of P-O-H and Ni-P-O-H multigas systems. [30] This study was based upon computer calculations using a thermodynamic database. Ellingham diagrams are phase diagrams drawn to show the temperature dependence of the stability for compounds. In the diagrams, the partial pressure of $\mathrm{H}_{2}$ is fixed at $1 \mathrm{~atm}$. The horizontal axis is temperature. The vertical axis is the Gibbs free energy of oxygen, given by the equation from partial pressure:

$$
\Delta \mathrm{G}\left(\mathrm{O}_{2(\mathrm{~g})}\right)=\mathrm{RT} \ln \left(\mathrm{P}_{\mathrm{O} 2}\right)
$$

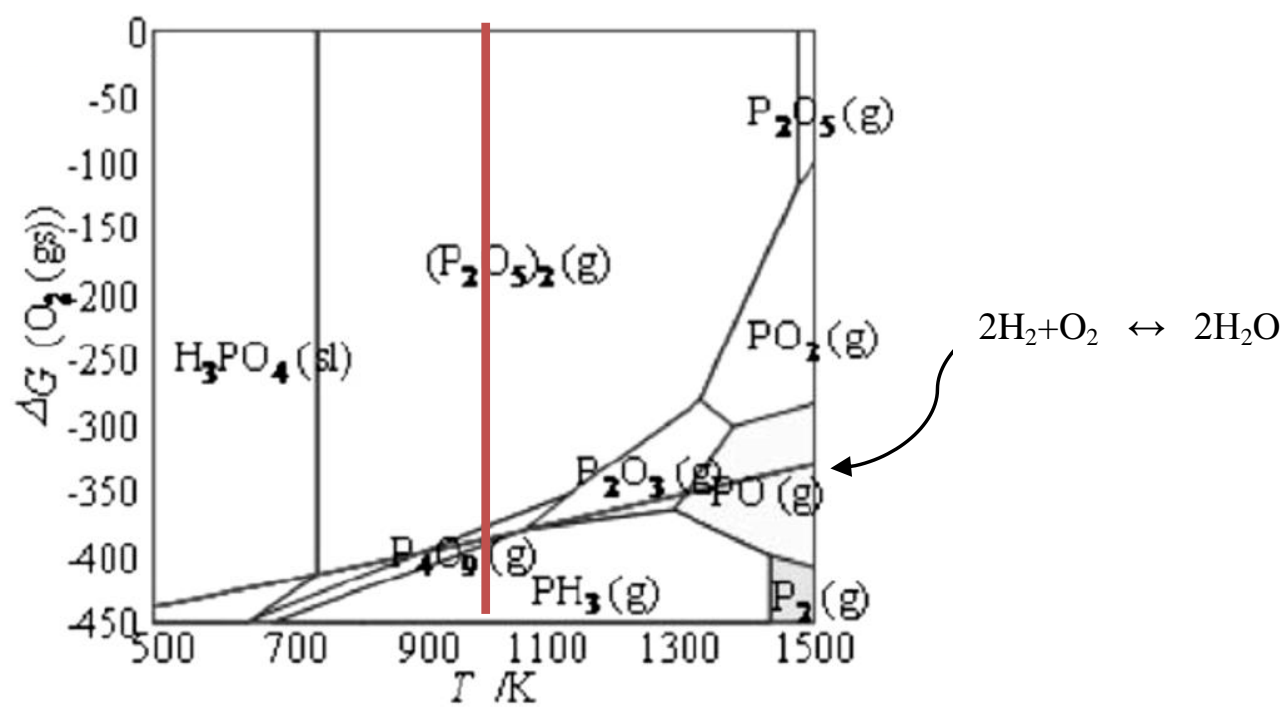

Figure 2.5 Two dimensional Ellingham diagram of a P-O-H system. [30]

The straight lines are borders of different phases. A sloping line indicates the equilibrium of $2 \mathrm{H}_{2}+\mathrm{O}_{2} \leftrightarrow 2 \mathrm{H}_{2} \mathrm{O}$. In the P-O-H diagram of Figure 2.5, the possible phosphorus species at $1000 \mathrm{~K}$ include $\left(\mathrm{P}_{2} \mathrm{O}_{5}\right)_{2}, \mathrm{P}_{4} \mathrm{O}_{9}$ and $\mathrm{PH}_{3}$. For some of the species with molecular weight greater than 200, a mass detection range of 1-300 is needed. A vertical line 
indicates the $1000 \mathrm{~K}$ position. The total partial pressure of all phosphorus species $\left(\mathrm{P}\left(P_{X}\right)\right)$ is $10^{-6}$ atm. The $\mathrm{P}_{4} \mathrm{O}_{9}$ area is narrow as a boundary between $\left(\mathrm{P}_{2} \mathrm{O}_{5}\right)_{2}$ and $\mathrm{PH}_{3}$ at calculated $\mathrm{P}_{\mathrm{O} 2}=2.6 \times 10^{-20}$ atm $(\Delta \mathrm{G}=-400 \mathrm{~kJ} / \mathrm{mol})$. The SOFC working condition at the anode is near this border line. This is consistent with Bao's finding: with $\mathrm{O}_{2}$ present, $\mathrm{PH}_{3}$ may be oxidized. But there is no kinetic data available showing how fast the process occurs.

In the extended Ellingham diagram of Ni-P-O-H system (Figure 2.6), Ni and P show strong chemical interactions at $1000 \mathrm{~K}$. The researchers also suggested that the following reactions may occur:

$$
\begin{aligned}
& 2 \mathrm{PH}_{3(\mathrm{~g})}+5 \mathrm{O}_{2(\mathrm{~g})}+2 \mathrm{Ni}_{(\mathrm{s})} \rightarrow \mathrm{Ni}_{2} \mathrm{P}_{2} \mathrm{O}_{7(\mathrm{~s})}+3 \mathrm{H}_{2} \mathrm{O}_{(\mathrm{g})} \\
& 4 \mathrm{PH}_{3(\mathrm{~g})}+8 \mathrm{O}_{2(\mathrm{~g})} \rightarrow\left(\mathrm{P}_{2} \mathrm{O}_{5}\right)_{2(\mathrm{~g})}+6 \mathrm{H}_{2} \mathrm{O}_{(\mathrm{g})} \\
& \mathrm{P}_{2} \mathrm{O}_{5(\mathrm{~g})}+4 \mathrm{Ni}_{(\mathrm{s})}+2 \mathrm{O}_{2(\mathrm{~g})} \rightarrow 2 \mathrm{Ni}_{2} \mathrm{P}_{2} \mathrm{O}_{7(\mathrm{~s})}
\end{aligned}
$$

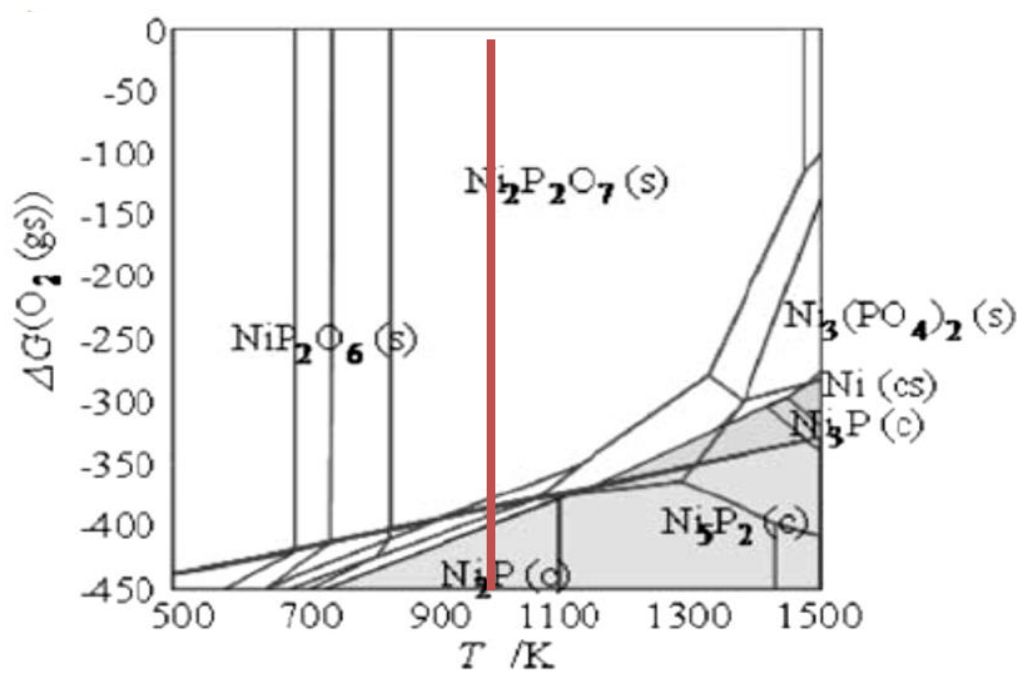

Figure 2.6 Ellingham diagram of a Ni-P-O-H system. [30] 
Both Bao and Kishimoto predicted the formation of Ni-P compounds on the anode by calculation. Nickel phosphide and nickel phosphate may cause loss of performance on the SOFC anode.

Thermodynamic calculations by K. Sasaki et al. predicted that the $\mathrm{PH}_{3}$ is a stable form of phosphorus in wet hydrogen under the SOFC anode conditions from $400-1000^{\circ} \mathrm{C}$. [49] The software HSC Chemistry (Version 4.1, Outokumpu Research Oy, Finland) was used in the calculations. Equilibrium compositions of $20 \%$ humidified $\mathrm{H}_{2}$ fuel containing 5 ppm phosphorus is shown in Figure 2.7. At $800^{\circ} \mathrm{C}, \mathrm{PH} 3$ is dominant over other phosphorus species.

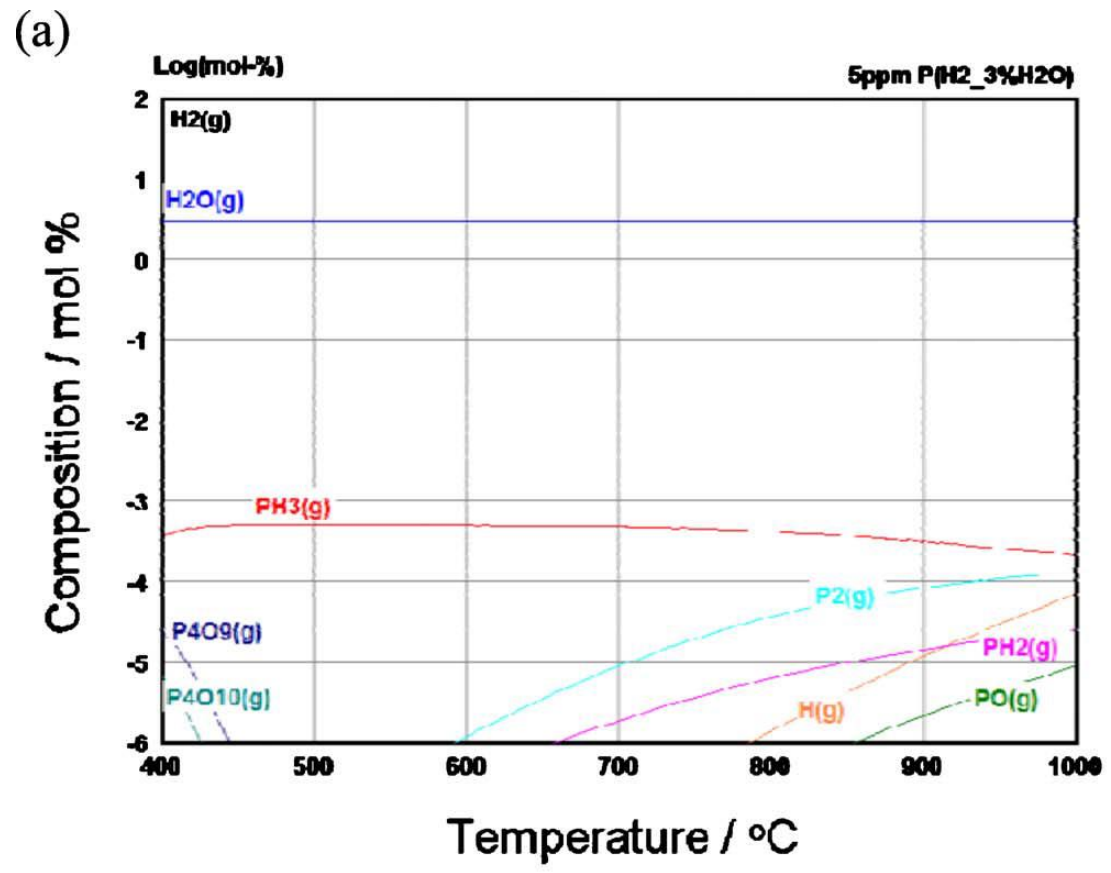

Figure 2.7 Equilibrium concentration in $3 \%$ humidified $\mathrm{H}_{2}$ fuel and containing $5 \mathrm{ppm} \mathrm{P}$ species calculated between 400 and $1000^{\circ} \mathrm{C}$, representing $\mathrm{PH}_{3}$ as the most stable P-based compound. [49]

Based upon the calculations, Sasaki et al. also used $\mathrm{P}_{2} \mathrm{O}_{5}$ heated to $300^{\circ} \mathrm{C}$ in humidified $\mathrm{H}_{2}$ to generate $\mathrm{PH}_{3}$. The concentration of $\mathrm{PH}_{3}$ in the fuel is estimated to $2.04 \mathrm{ppm}$ when 
the $\mathrm{P}_{2} \mathrm{O}_{5}$ was maintained at $300^{\circ} \mathrm{C}$. The chemical reactions explaining the generation of $\mathrm{PH}_{3}$ from the source $\mathrm{P}_{2} \mathrm{O}_{5}$ can be represented by

$$
\mathrm{P}_{2} \mathrm{O}_{5(\mathrm{~s})}+8 \mathrm{H}_{2(\mathrm{~g})} \rightarrow 2 \mathrm{PH}_{3(\mathrm{~g})}+5 \mathrm{H}_{2} \mathrm{O}_{(\mathrm{g})}
$$

The fuel containing $\mathrm{PH}_{3}$ was then fed into the SOFC. The SOFC showed loss of power and increased resistances over 100 hours of operation. Post-mortem analyses showed that a layer of nickel phosphide had formed on the anode surface. The loss of performance and the appearance of the new material are similar to the previous $\mathrm{PH}_{3}$ poisoning studies by $\mathrm{Xu}$, Zhi and Demircan et al., which implies that the $\mathrm{PH}_{3}$ generated by the heating of $\mathrm{P}_{2} \mathrm{O}_{5}$ has the same poisoning effects on the anode of the SOFC. [30-33]

\subsection{Poisoning effects of $\mathrm{PH}_{3}$ and $\mathrm{H}_{2} \mathrm{~S}$ on $\mathrm{Ni} / \mathrm{YSZ}$ anodes.}

Current studies have shown that many trace impurities including $\mathrm{H}_{2} \mathrm{~S}, \mathrm{PH}_{3}, \mathrm{AsH}_{3}$, $\mathrm{NH}_{3}, \mathrm{HCl}, \mathrm{Hg}$, etc. in the coal syngas will cause the loss of performance in SOFC anodes. [21] At West Virginia University, a large amount of work on $\mathrm{PH}_{3}$ and $\mathrm{H}_{2} \mathrm{~S}$ has been performed. In this dissertation, discussions will focus mainly on $\mathrm{PH}_{3}$ effects. Several researchers have discussed the effect of phosphine in coal syngas on Ni/YSZ anodes. J.P. Trembly reported formation of $\mathrm{Ni}_{5} \mathrm{P}_{2}$ on the anode surface in $\mathrm{PH}_{3}$ exposure tests. [30] $\mathrm{M}$. Zhi et al. examined the anode after exposure to $20 \mathrm{ppm}$ of $\mathrm{PH}_{3}$, and found nickel phosphate and zirconium phosphate phases formed on the surfaces. [31] X. Song et al. also reported findings of $\mathrm{YPO}_{4}$ phase with TEM analysis after $\mathrm{PH}_{3}$ exposure. [38]

The loss of performance caused by exposure to $\mathrm{PH}_{3}$ is immediate and irreversible. [22, 30-31, 34] The following research was conducted by Xu et al. [33] In Figure 2.8, the 
cell was kept at $0.5 \mathrm{~A} / \mathrm{cm}^{2}$ current density at $800^{\circ} \mathrm{C}$ with syngas as fuel. The cell voltage began dropping immediately upon the introduction of $10 \mathrm{ppm} \mathrm{PH}_{3}$ into the fuel stream. The voltage degraded at a constant rate of approximately $0.46 \mathrm{mV} / \mathrm{h}$. The cell OCV remained at about $0.962 \mathrm{~V}$ during the entire experiment.

In the EIS tests, both the series resistance $\left(R_{s}\right)$ and polarization $\left(R_{p}\right)$ resistance increased with time exposed to $\mathrm{PH}_{3}$. Figure 2.9 are the overlaid and normalized impedance spectra of the cell collected at different times of $\mathrm{PH}_{3}$ exposure. The $\mathrm{R}_{\mathrm{s}}$ increased at a constant rate of $0.42 \mathrm{~m} \Omega \mathrm{cm}^{2} / \mathrm{h}$, and the increasing rate of $R_{p}$ was about $0.87 \mathrm{~m} \Omega \mathrm{cm}^{2} / \mathrm{h}$.

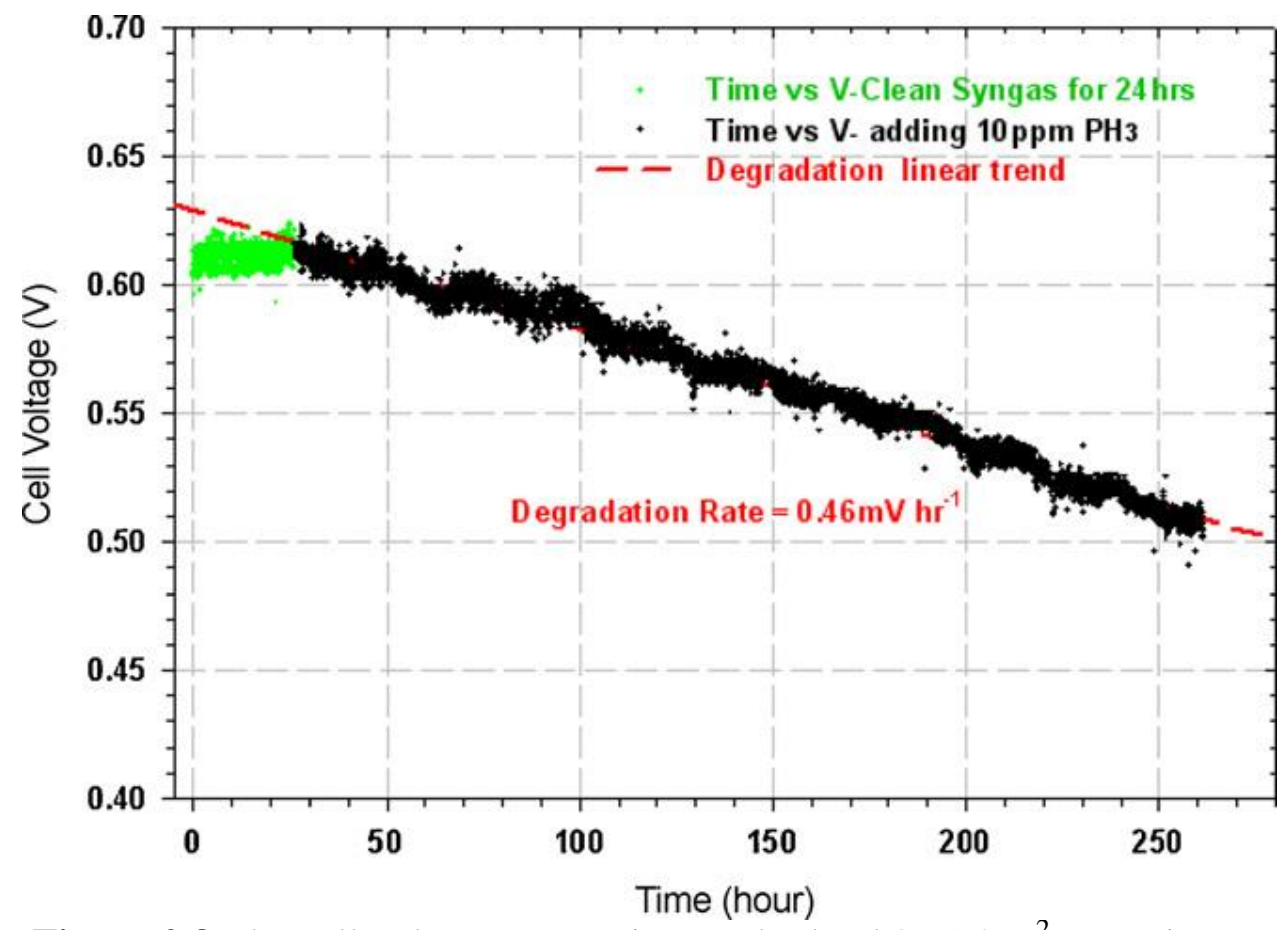

Figure 2.8 The cell voltage versus time under load $0.5 \mathrm{~A} / \mathrm{cm}^{2}$ operating on syngas

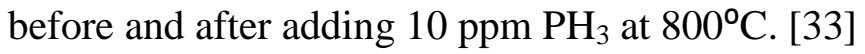




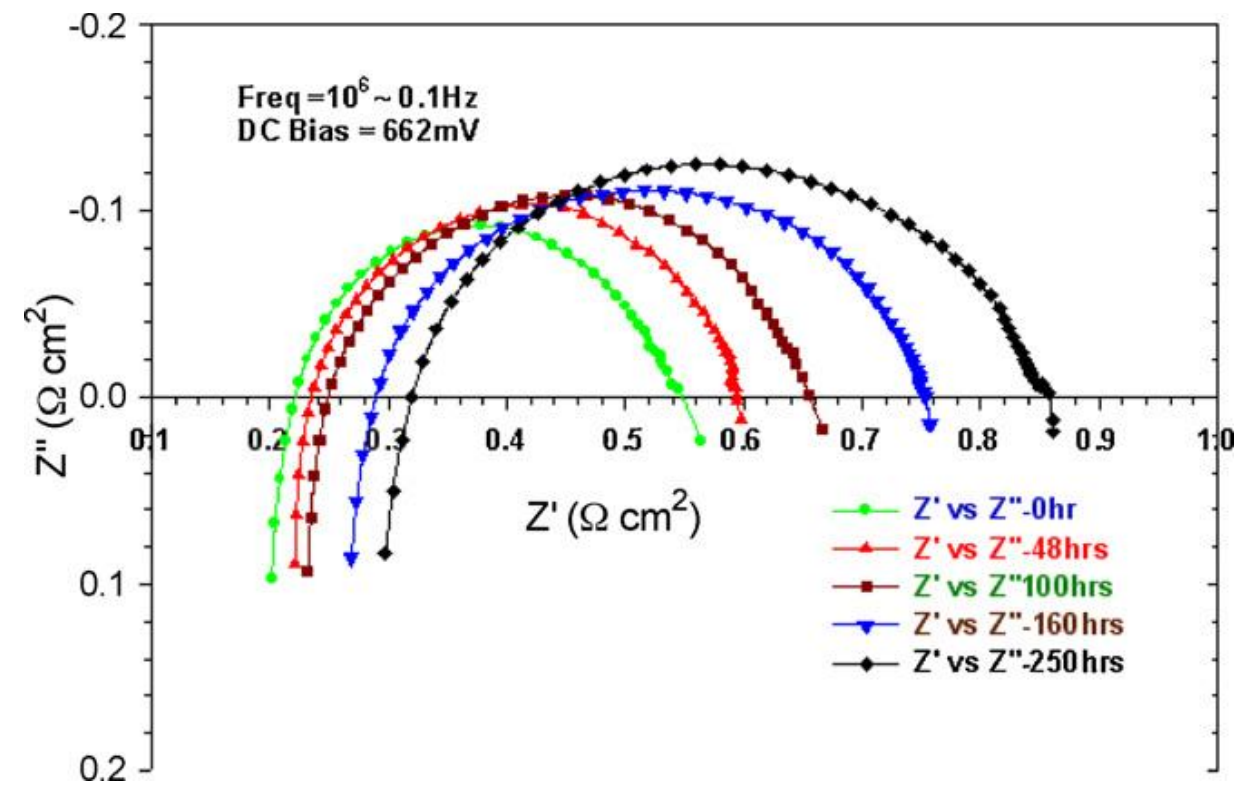

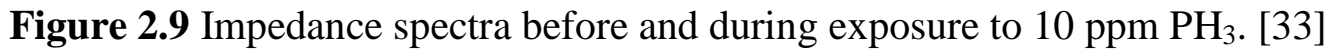

Post-mortem examination of the cell showed a significant difference from the clean reduced cell. The anode area exposed to $\mathrm{PH}_{3}$ appeared to have a shiny metallic look, (Figure 2.10) which implies that a new phase may have formed on the surface.

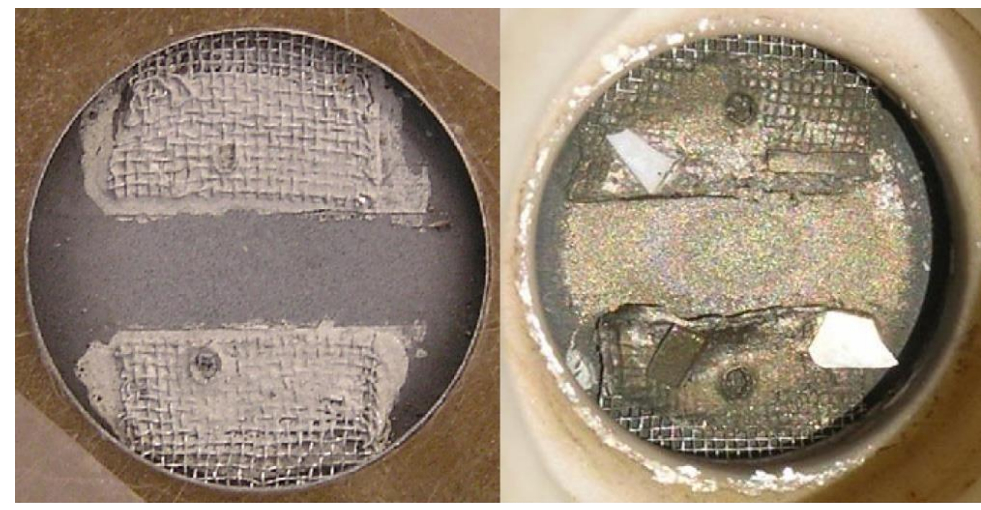

Figure 2.10 Clean reduced cell anode (left), and after $\mathrm{PH}_{3}$ exposure (right). [33]

A SEM image of the top surface in Figure 2.11 showed that the surface is less porous after $\mathrm{PH}_{3}$ exposure. XPS analysis detected peaks of phosphorus $2 \mathrm{~s} / 2 \mathrm{p}$ and nickel $3 p$, which implies the possible existence of $\mathrm{Ni}_{3} \mathrm{P}$ and $\mathrm{Ni}_{5} \mathrm{P}_{2}$. XRD data confirmed the $\mathrm{Ni}_{5} \mathrm{P}_{2}$ 
composition. This new phase is dense and not as conductive as metallic nickel, so the resistance of the cell increases, and the performance is degraded.

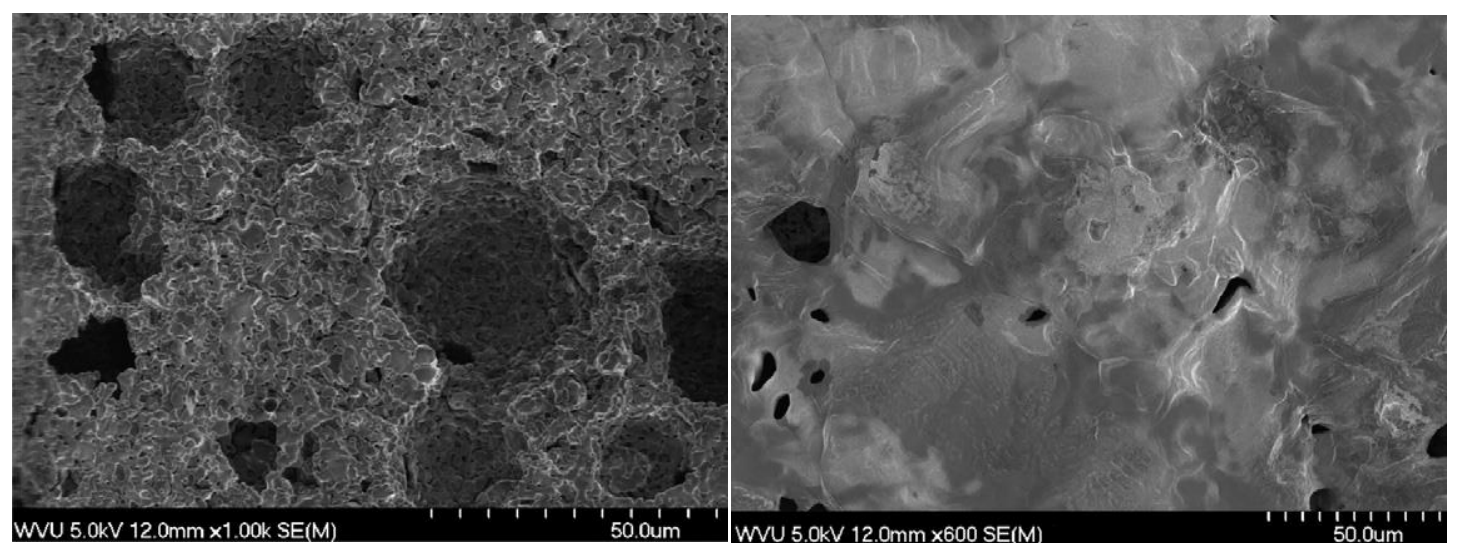

Figure 2.11 SEM images of clean reduced cell anode (left), and after $\mathrm{PH}_{3}$ exposure (right). [33]

Another study done by O. Demircan et al. examined the effect of different overpotentials of Ni/YSZ anodes. [32] Overpotential is defined as the difference between the open circuit voltage and the applied voltage. In Figure 2.12, the power density was monitored over time under constant $0.5 \mathrm{~A} / \mathrm{cm}^{2}$ load for various fuels and overpotentials. $\mathrm{PH}_{3}$ was added into the fuel at point (e). There was an immediate and continuous power loss after the addition of $\mathrm{PH}_{3}$. Three overpotentials $(0.1 \mathrm{~V}, 0.2 \mathrm{~V}$ and $0.3 \mathrm{~V})$ were investigated. At point $(\mathrm{k}), \mathrm{PH}_{3}$ was shut off but the degradation caused to the anode was irreversible. The data showed no direct relation between degradation rate and the overpotential. Figure 2.13 showed the Rs and Rp (obtained from impedance measurements) of the cell. After the $\mathrm{PH}_{3}$ was added, both $\mathrm{R}_{\mathrm{s}}$ and $\mathrm{R}_{\mathrm{p}}$ had significantly increased because a new layer formed on the top surface and Ni metal was drawn from the active layer. 


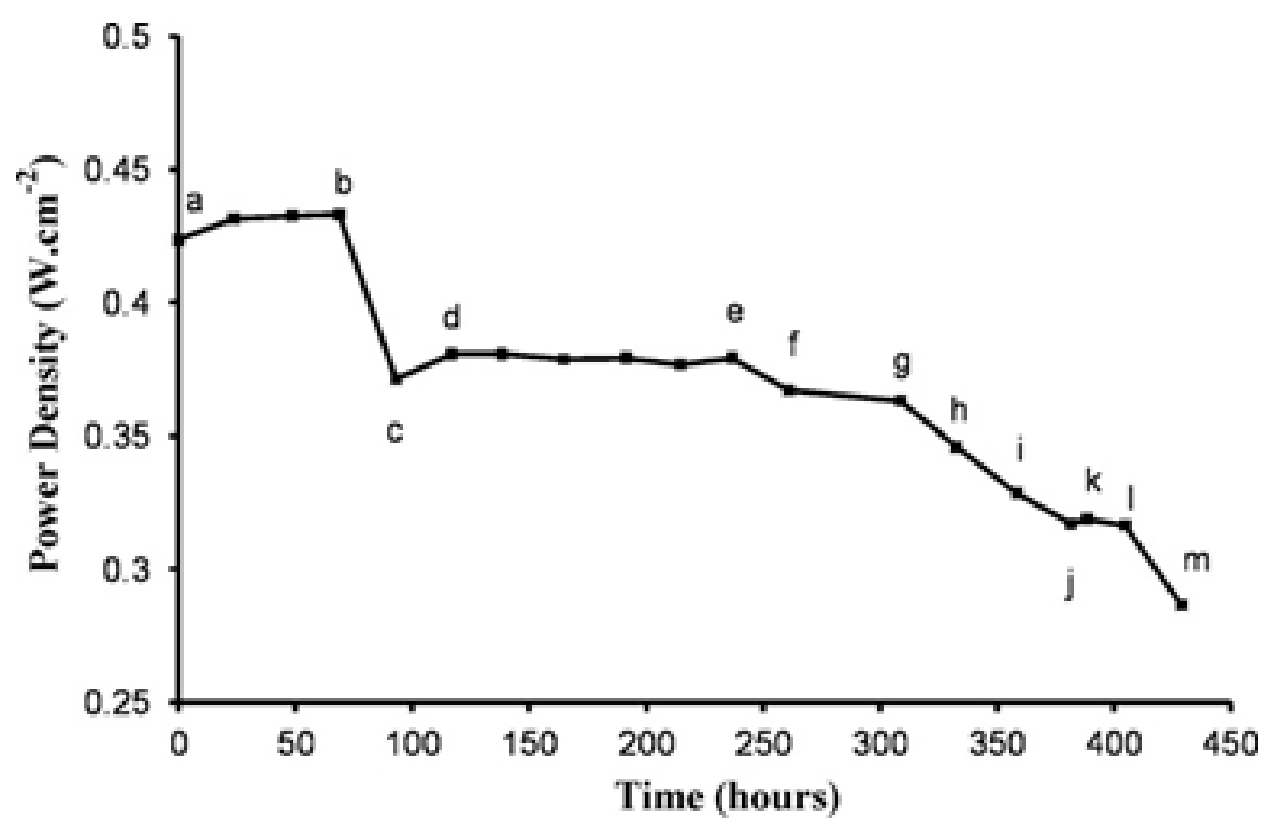

Figure 2.12 Long term power density vs time under $0.5 \mathrm{~A} / \mathrm{cm}^{2}$ load [32]

Letters in the figure: (a) start with $97 \% \mathrm{H}_{2} \mathrm{O}, 3 \% \mathrm{H}_{2}$. (b) $30 \% \mathrm{H}_{2}, 26 \% \mathrm{H}_{2} \mathrm{O}$. (c) Clean

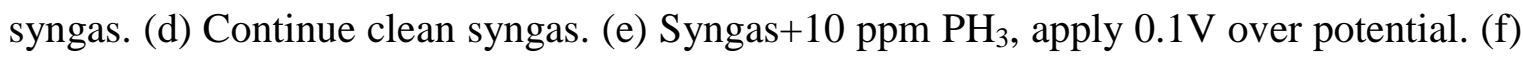
Apply 0.2V. (g) Apply 0.3V. (h) Apply 0.1V. (i) Apply 0.2V. (j) Apply 0.3V. (k) Syngas without $\mathrm{PH}_{3}$. (1) $30 \% \mathrm{H}_{2}, 26 \% \mathrm{H}_{2} \mathrm{O}$ (m) End. [32]
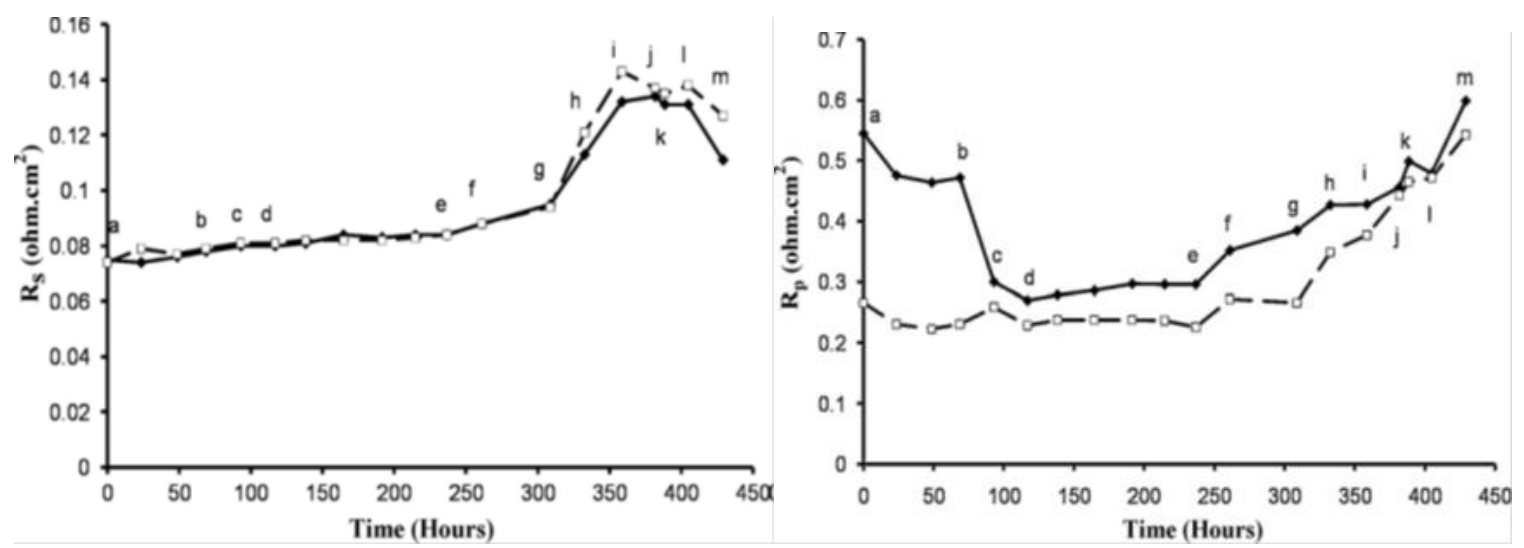

Figure 2.13 $\mathrm{R}_{\mathrm{s}}$ (left) and $\mathrm{R}_{\mathrm{p}}$ (right) for the cell before and after exposure to $\mathrm{PH}_{3}$ Letter captions are the same as Figure 2.10. Diamonds measured at OCV and squares measured at $0.2 \mathrm{~V}$ applied potential. [32]

Figure 2.14 is the cross-section SEM image of the post-mortem cell. Image "a" is a clean reduced whole anode cross section. The two thin layers at the top are the cathode and the 
electrolyte. The large area in the bottom is the anode and the anode surface is at the very bottom of the image. Image "b" is magnified to show the part of anode after exposure to $\mathrm{PH}_{3}$. The solid bottom half is the surface of anode, with a thick and dense layer attached. Analysis in Figure 2.15 indicated the presence of a new phase layer on top of the anode surface similar to that observed in previous papers. [33]
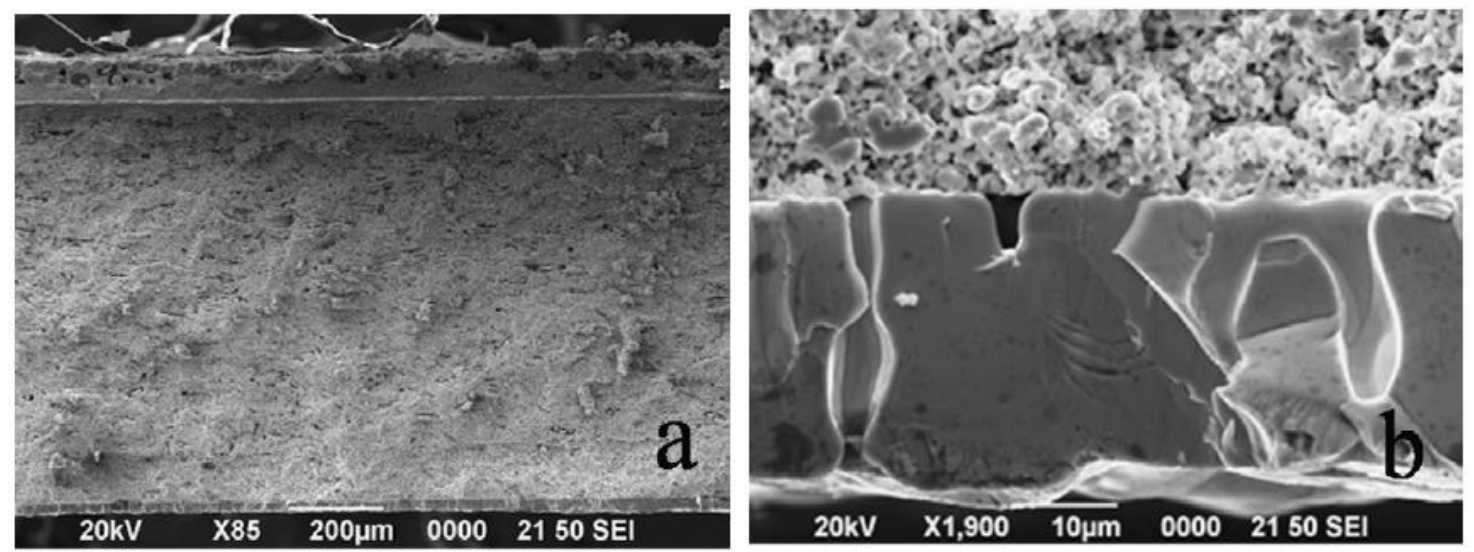

Figure 2.14 Cross section SEM images of the cell, before and after $\mathrm{PH}_{3}$ exposure. [32]
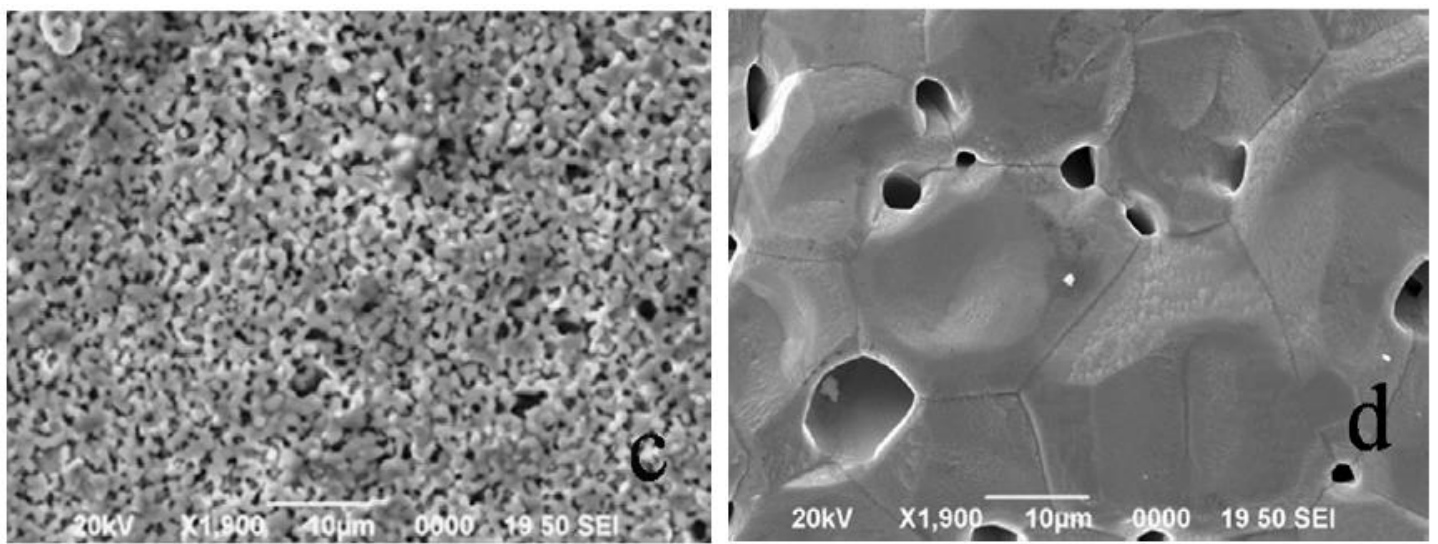

Figure 2.15 SEM images of clean reduced anode top surface (left) and after exposure to $\mathrm{PH}_{3}$ (right) [32]

The XRD spectrum in Figure 2.16 shows the existence of $\mathrm{YSZ}, \mathrm{Ni}_{3} \mathrm{P}$ and metallic Ni phases on the top surface after comparing the peak positions with the literature values. $\mathrm{Ni}_{5} \mathrm{P}_{2}, \mathrm{Ni}_{3} \mathrm{P}, \mathrm{Ni}_{8} \mathrm{P}_{3}$ and $\mathrm{Ni}_{12} \mathrm{P}_{5}$ peaks could not be assigned because their diffraction angles are very close together. 


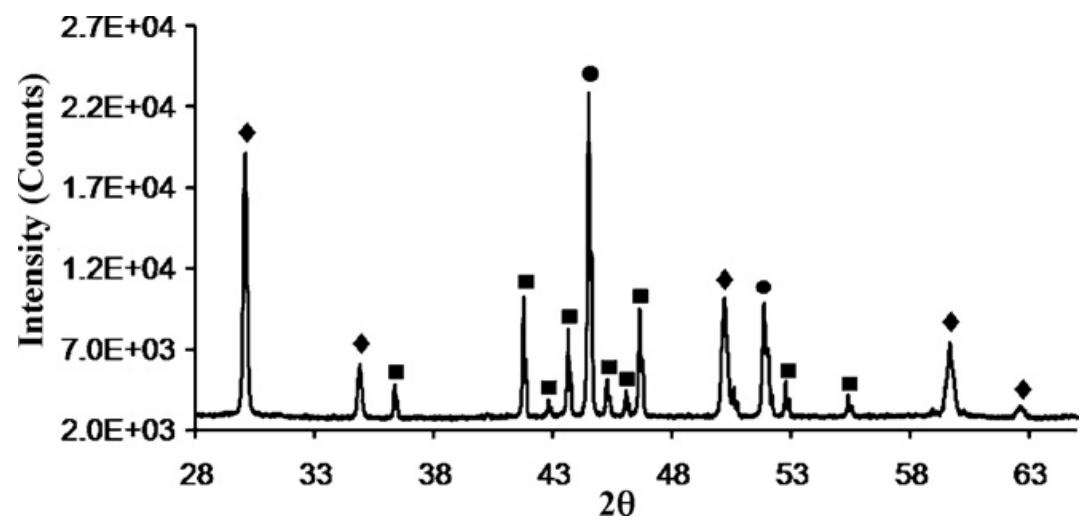

Figure 2.16 XRD analysis of $\mathrm{PH}_{3}$ exposed anode surface. ( $\bullet \mathrm{YSZ} \bullet \mathrm{Ni}_{3} \mathrm{P} \bullet \mathrm{Ni}$ ) [32]

Figure 2.17 is an XPS survey scan of the anode surface region exposed to $\mathrm{PH}_{3}$. There are no $\mathrm{Y}$ or $\mathrm{Zr}$ peaks seen, which means that the dense layer completely covers the top surface, and thus is an extra layer on top of the anode. A detailed Ni-2p3 regional scan is in the left insert. The peak at $852.8 \mathrm{eV}$ can be either elemental Ni or Ni-P compounds. The detailed $\mathrm{P} 2 \mathrm{p}$ region scan is in the insert. There are two $\mathrm{P}(2 \mathrm{p})$ peaks at 130.1 and $134.1 \mathrm{eV}$, and they can be assigned to elemental or reduced phosphorus and +5 oxidation state, respectively. This observation indicates the existence of the $\mathrm{Ni}_{3} \mathrm{P}$ phase again. The top layer may be aggregations of $\mathrm{Ni}$ and/or $\mathrm{Ni}_{3} \mathrm{P}$ chunks. 


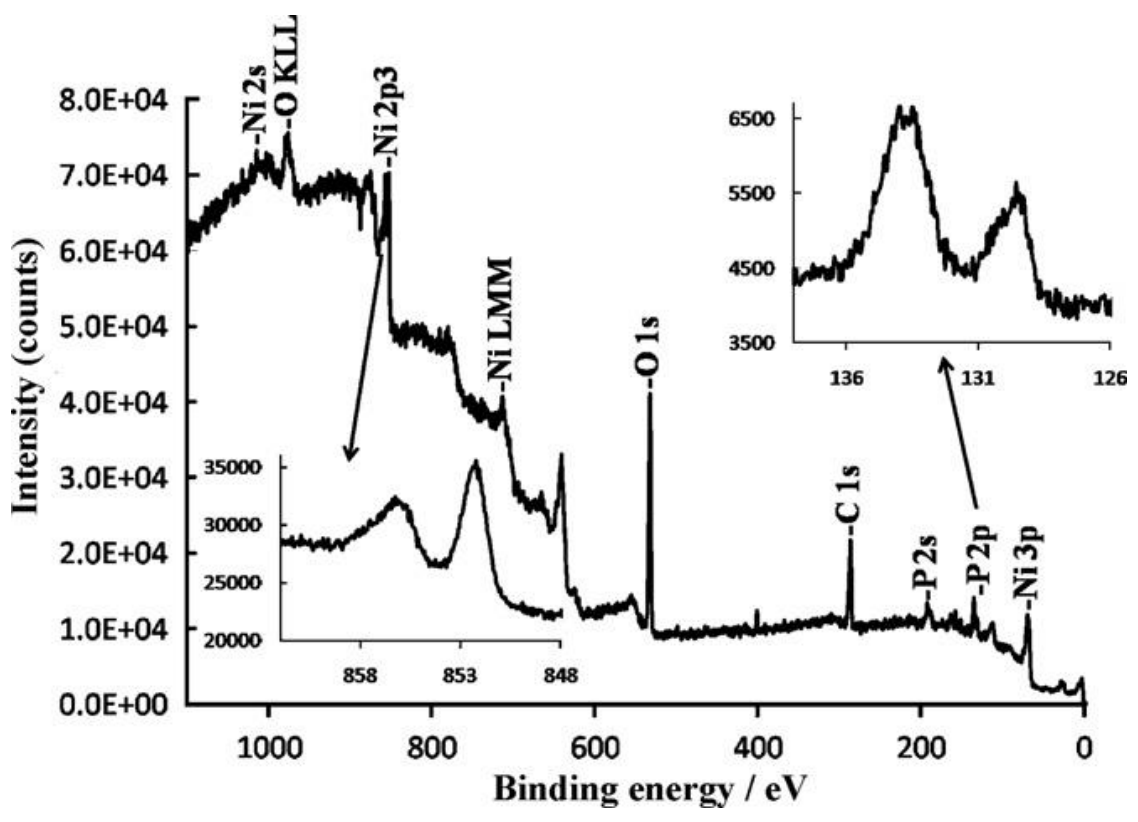

Figure 2.17 XPS survey of the $\mathrm{PH}_{3}$ exposed area on the surface of the anode. [32]

Figure 2.18 is a $20 \mu \mathrm{m}$ spot analysis on the active area of the cell anode. The presence of $\mathrm{C}, \mathrm{O}, \mathrm{Ni}, \mathrm{Y}, \mathrm{Zr}, \mathrm{Si}$ and $\mathrm{P}$ are shown by their peaks. The peak in the detailed $\mathrm{P}(2 \mathrm{p})$ area indicates that only oxidized phosphorus was detected.

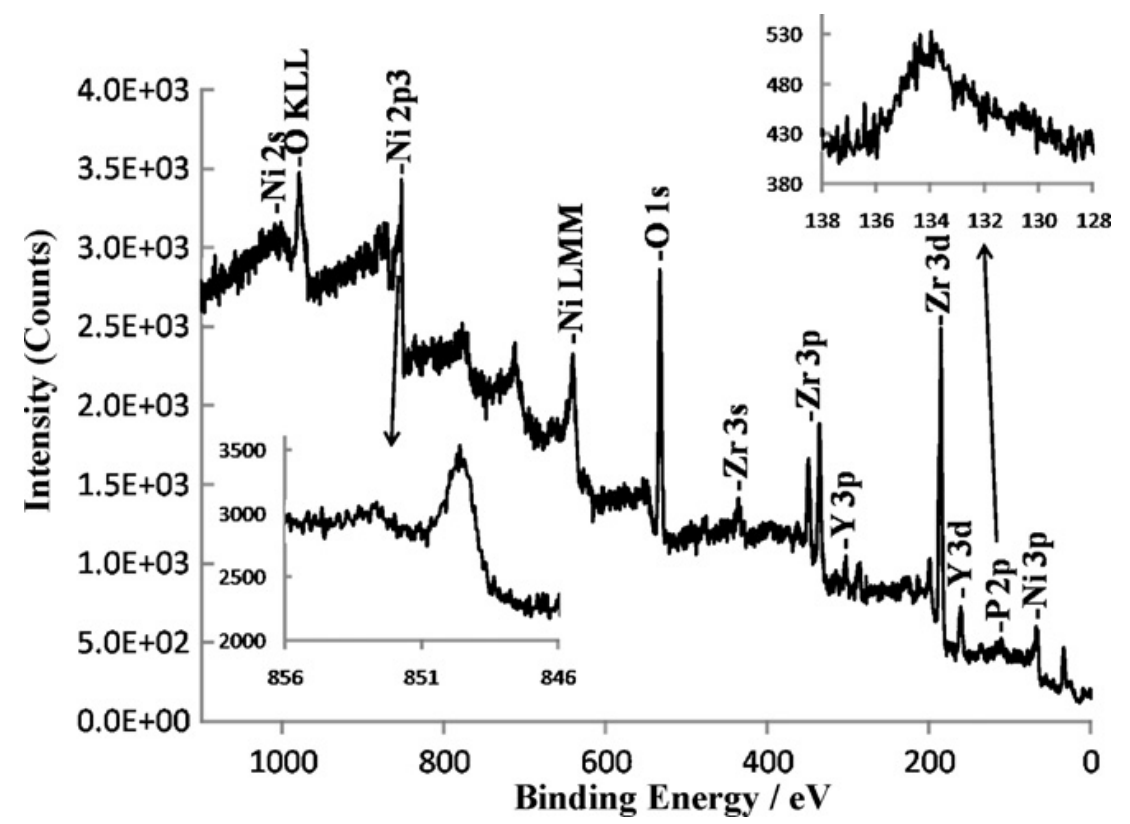

Figure 2.18 $20 \mu \mathrm{m}$ spot XPS analysis on the cross-section of the active layer of anode. 
Micro-structural studies done by X. Song et al. point out the presence of $\mathrm{YPO}_{4}$ phase on the Ni/YSZ anode after 117 hours of exposure to $\mathrm{PH}_{3}$. [38] Ni-P products, primarily $\mathrm{Ni}_{5} \mathrm{P}_{2}$, are observed on the anode top surface. This observation is similar to results in the previous studies. TEM examination was performed on the anode of a cell operated in syngas with $20 \mathrm{ppm}$ of $\mathrm{PH}_{3}$ for 117 hours. Crystals with about $100 \mathrm{~nm}$ dimension are deposited at the YSZ-YSZ/Ni boundaries. Figure 2.18 is the TEM image of the anode active layer. The EDX study implies that the particles are composed of Y, P and $\mathrm{O}$. The electron diffraction pattern in Figure 2.20 confirms that the identification as $\mathrm{YPO}_{4}$, with a tetragonal structure. The $\mathrm{YPO}_{4}$ particles are pointed out by arrows in Figure 2.19 .

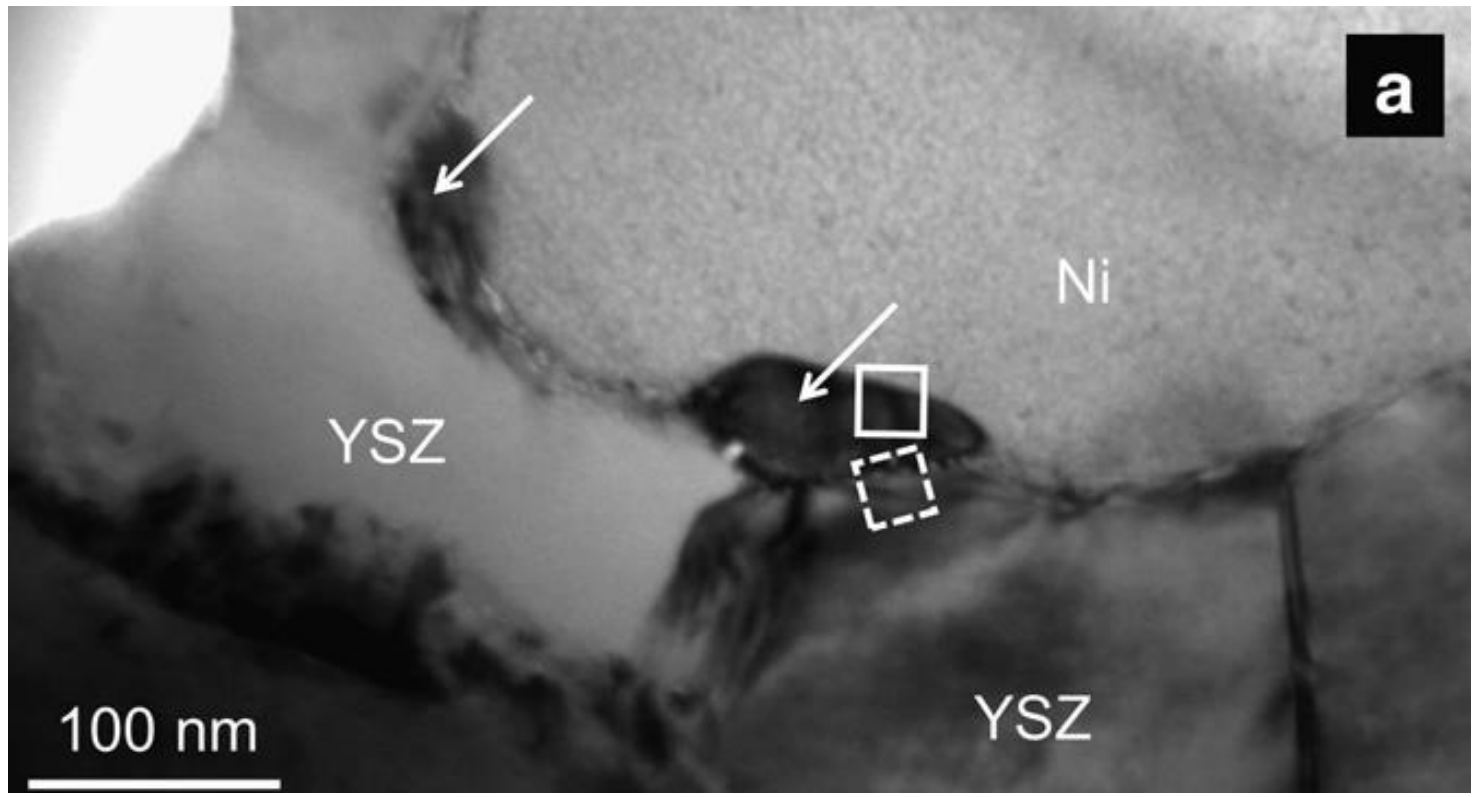

Figure 2.19 TEM image of anode active layer in a cell exposed to $\mathrm{PH}_{3}$ for 117 hours [38] 

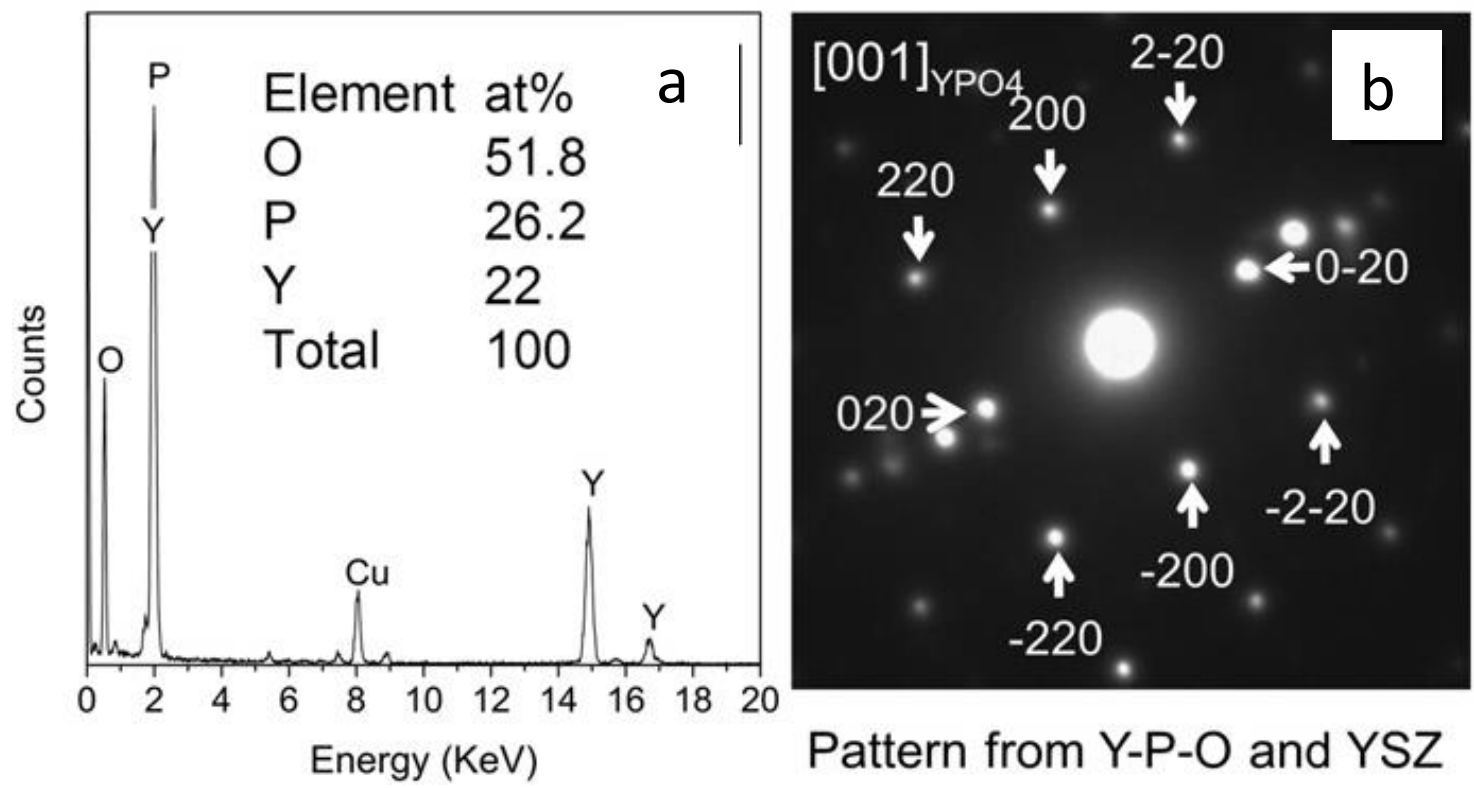

Figure 2.20 (a) Chemical compositions of the deposited particles. (b) Diffraction pattern taken from the Y-P-O phase and YSZ phase [38]

The new $\mathrm{YPO}_{4}$ phase is considered to be a corrosion product of the YSZ material. When it develops in the YSZ/YSZ/Ni tri-boundary, the reaction site is blocked, leading to loss of cell performance. The $\mathrm{YPO}_{4}$ is stable at $\mathrm{SOFC}$ operation temperature around $800^{\circ} \mathrm{C}$, but decomposes at $900^{\circ} \mathrm{C}$. [39]

\subsection{In-situ analyses during SOFC operation.}

There are several types of in-situ methods currently being used in the SOFC research. Some of the methods are material analysis such as in-situ Raman Spectroscopy, surface deformation and temperature measurements [35-36]. The standard electrochemical tests are carried out during operation, so they can be classified as in-situ methods, as well. In this section, the discussion will mainly focus on in-situ analyses during SOFC operation. Methods will include Mass Spectroscopy, Gas Chromatography, tunable diode laser spectroscopy and high-temperature Raman Spectroscopy. 
J. Bao et al. from SRI International [29] used a high-temperature (997 K) mass spectrometer to measure the partial pressures and to determine the thermochemical properties of gases. This instrument has a $30.5 \mathrm{~cm}$ radius, is single focusing, and utilizes magnetic deflection. The instrument has been employed more than 30 years to determine the thermodynamic properties of many inorganic chemicals. [37] Figure 2.21 is a schematic illustration of the system. It consists of a molecular effusion-beam vapor source, an electron impact ion source, and a magnetic mass analyzer. The analyte gases are admitted from the base through the inlet tube. The chemistry of the species in the cell is frozen in the collision free molecular path from the quartz Knudsen cell orifice (1.0 $\mathrm{mm}$ in diameter) to the ion source without encountering any instrument surfaces. The ionized particles are then accelerated and analyzed by the magnetic mass analyzer.

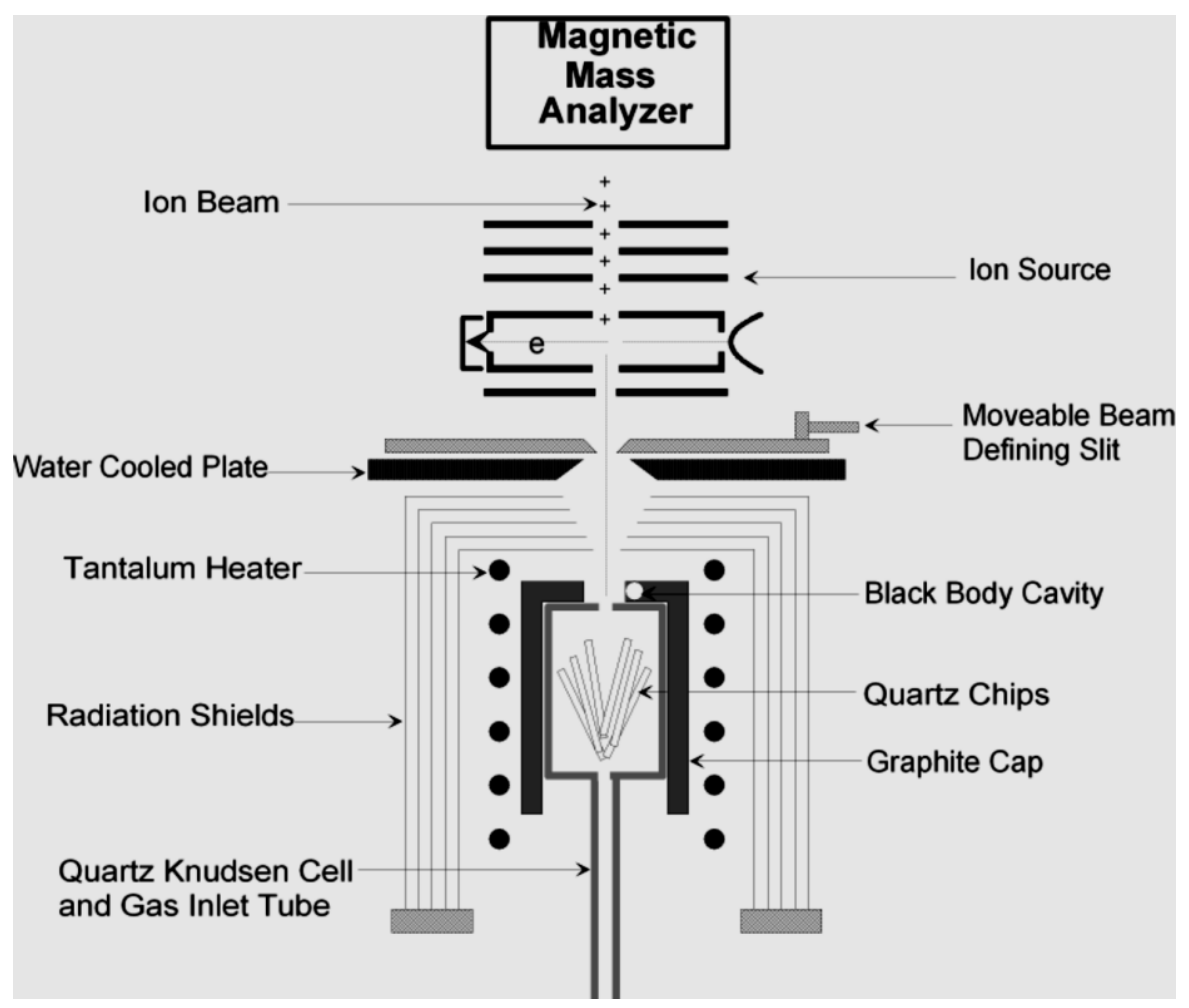

Figure 2.21 High-temperature Mass Spectrometer [29] 
This high-temperature Mass Spectrometer is believed to give accurate measurements of partial pressure within a factor of two. The detection limit for most observed species is on the order of $5 \times 10^{-11}$ atm $\left(3.8 \times 10^{-8}\right.$ torr $)$. The thermal decomposition behavior of $\mathrm{PH}_{3}$ and $\mathrm{CH}_{3} \mathrm{Cl}$ was studied using the mass spectrometer. Effects of sub-ppm level of impurities in syngas including $\mathrm{Hg}, \mathrm{AsH}_{3}, \mathrm{PH}_{3}, \mathrm{CH}_{3} \mathrm{Cl}$ and $\mathrm{H}_{2} \mathrm{~S}$ were also investigated. Part of the data related to $\mathrm{PH}_{3}$ studies was described in previous text in this dissertation (Section 2.4).

The conditions in these tests are selected to be similar to SOFC operating conditions. However, this mass spectrometer was not used on-line with a working SOFC. The degradation effects and the high temperature chemistry were tested in separate experiments. [29]

Another article by $\mathrm{H}$. You et al. probed the conversion among reactions at the SOFC anode with dry methane. [40] In-situ gas chromatography (GC) was used in this study to measure the anode exhaust gases. The reactions of methane were investigated at various current densities. The GC system measured the production rates of anode exhaust gases. Figure 2.22 is a typical data plot vs current density. The GC measurements were carried out 15 mins after changing the current density. 


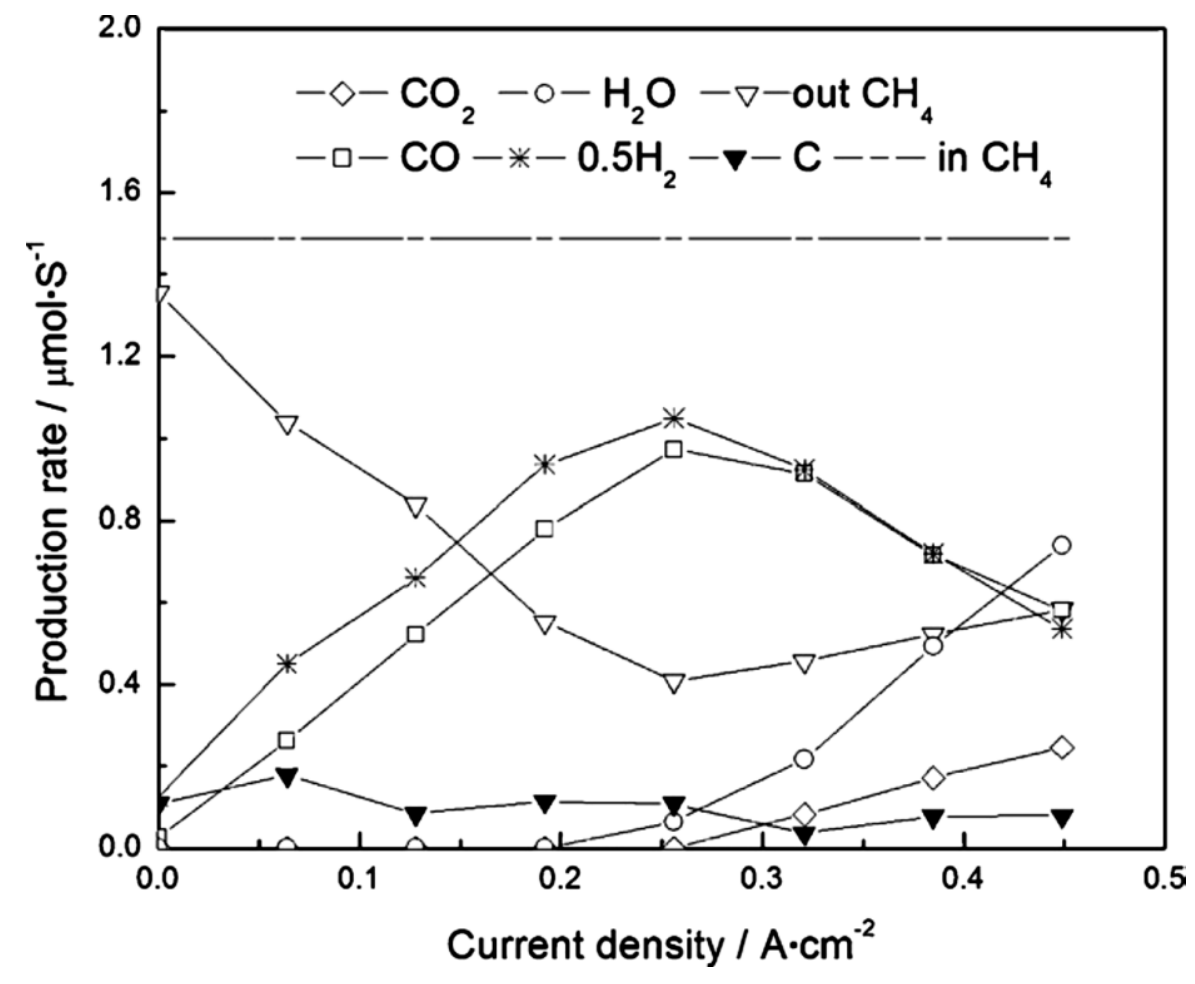

Figure 2.22 Production rates of anode exhaust gases in SOFC with Ni-YSZ anode and $3.85 \%$ methane. [40]

The detection limit and sensitivity of the GC system is suitable for major fuel gas and water vapor measurements, but not for sub-ppm level studies of impurities.

C. Guerra et al. also reported a study of dry methane direct reforming at the SOFC anode with the help of Mass Spectrometry. [45] The gas composition at the reactor outlet was monitored using a mass spectrometer. The kinetics of the reactions occurring over the anode were investigated by means of Isotherm reactions and Temperatureprogrammed reactions. 


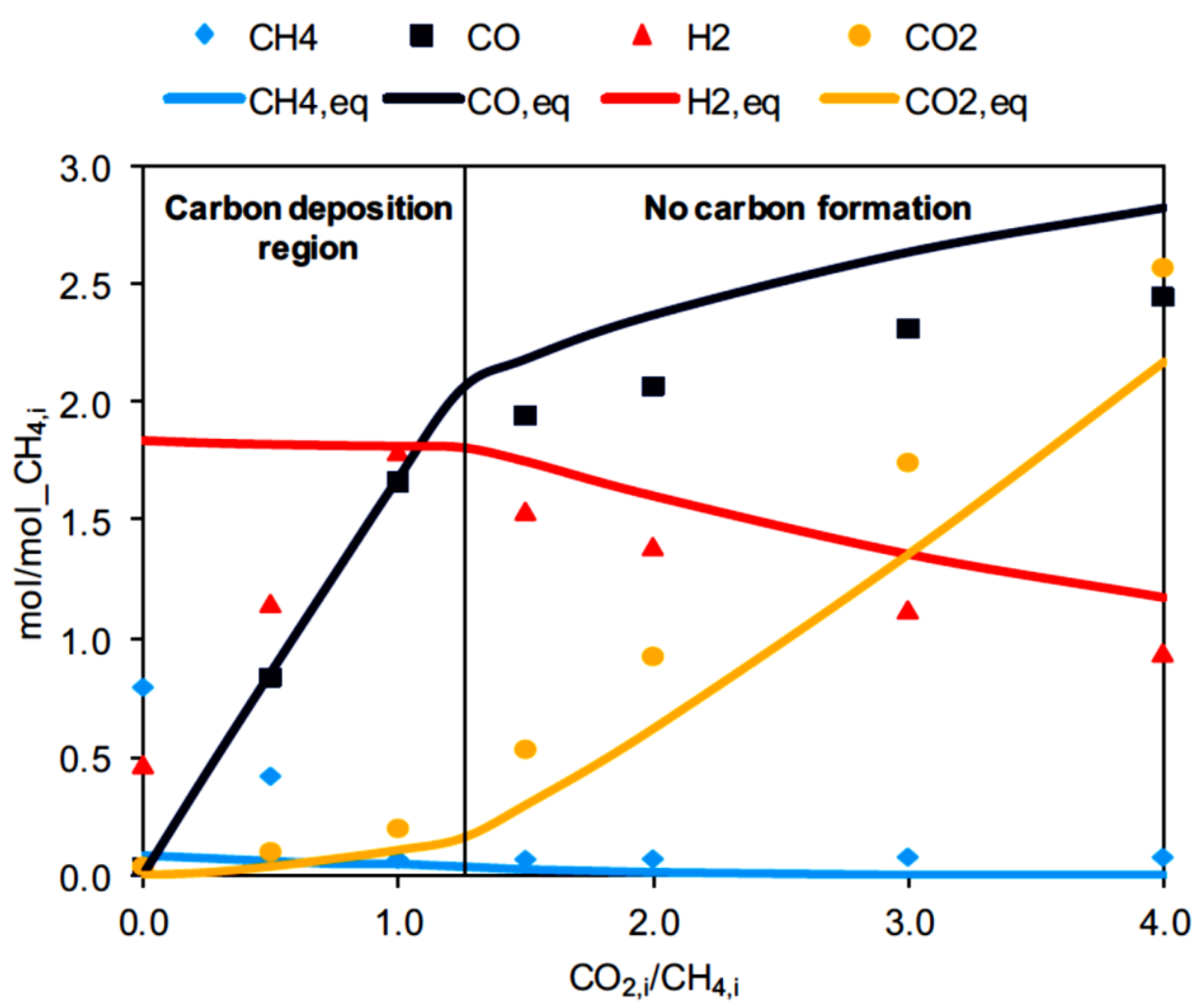

Figure 2.23 $\mathrm{CH}_{4}, \mathrm{CO}, \mathrm{H}_{2}$ and $\mathrm{CO}_{2}$ flow rates for inlet $\mathrm{CH}_{4}=6 \mathrm{ml} / \mathrm{min}$ and chemical equilibrium composition calculated at $800^{\circ} \mathrm{C}$ with varying inlet $\mathrm{CO}_{2} / \mathrm{CH}_{4}$ ratio. [45]

In Figure 2.23, the solid lines are the calculated equilibrium composition from theory. The subscript "i” means the inlet. The symbols are observed data points collected at different $\mathrm{CO}_{2}$ to $\mathrm{CH}_{4}$ ratios at the inlet. There are clearly two regions. One is the carbon deposition ("coking") region, the other is the no carbon formation ("non-coking") region. This result is consistent with the previous predictions. [41]

The catalytic properties of the Ni/YSZ anode in methane reforming are also investigated under different temperatures. Temperature programmed reforming reactions showed that the catalytic activity is poor at temperatures lower than $450^{\circ} \mathrm{C}$. The reforming reaction is very close to equilibrium when the temperature is higher than 
$620^{\circ} \mathrm{C}$. The conditions chosen to avoid coking are further confirmed by other studies. [43-44]

The Mass Spectrometer used by C. Guerra et al. was employed to detect gases with molar ratios, which means large amount of gases. [45] The details of the instrument such as model, ion source, type of detector, detection limit and sensitivity are not mentioned in the paper. Whether it is suitable for trace amount of impurities is unknown.

\subsection{Summary}

While SOFCs are a promising source of power in the future, there are many challenges to overcome. The most significant problem with direct utilization of coal syngas is the poisoning effect of many impurities. The degradation behavior and mechanism have been investigated but are still not fully clear. New methods are continuously introduced into the Solid Oxide Fuel Cell research. Further investigation of impurities tolerance, fuel flexibility and efficiencies are on-going. 


\section{References in Chapter 2.}

[1] William R. Grove Philos Magazine 1839, 14

[2] A.B. Stambouli, E. Traversa Renewable and Sustainable Energy Reviews 2002, 6, 433-455

[3] Chan. S. H., Ho H. K., Tian Y. Journal of Power Sources 2002, 109, 111-120

[4] Park SK, Oh KS, Kim TS. Journal of Power Sources 2007, 170, 130-139

[5] Granovskii M, Dincer I, Rosen MA. Journal of Power Sources 2007, 165, 307-314

[6] Haseli Y, Dincer I, Naterer GF. Thermo-chimica Acta 2008, 480, 1-9

[7] Harvey SP, Richter HJ. Proceedings of 29th intersociety energy conversion engineering conference, vol. 2. 1994, Monterey, CA

[8] W.Z. Zhu, S.C. Deevi Materials Science and Engineering A 2003, 362, 228-239

[9] Y.J Leng, S.H Chan, S.P Jiang, K.A Khor Solid State Ionics 2004, 170, 9-16

[10] Shaowu Zha, Ashley Moore, Harry Abernathy and Meilin Liu Journal of The Electrochemical Society. 2004, 151, A1128-A1133

[11] Mingfei Liu, Dong Ding, Yaohui Bai, Ting He and Meilin Liu Journal of The Electrochemical Society. 2012, 159, B661-665

[12] Xiaohong Fang, Guangyan Zhu, Changrong Xia, Xingqin Liu, Guangyao Meng Solid State Ionics 2004, 168, 31-36 
[13] Hibino, T.; Hashimoto, A.; Inoue, T.; Tokuno, J.; Yoshida, S.; Sano M. Science. 2000, 288, 2031-2037

[14] Stuart B. Adler Chem. Rev. 2004, 104, 4791-4844

[15] Traversa Enrico. The Electrochemical Society Interface, 2009, Fall, 49-52

[16] U.S. Department Of Energy NETL-SECA News Archive 2010

[17] U.S. Department Of Energy. NETL Solid Oxide Fuel Cell Project Portfolio 2013.

[18] Arnab Choudhury n, H.Chandra, A. Arora Renewable and Sustainable Energy Reviews 2013, 20, 430-442

[19] Timothy C. Williamsa, Christopher R. Shaddix, Robert W. Schefera Combustion Science and Technology 2007, 180, 64-88

[20] C. Higman and M. van der Burgt, Gasification Elsevier, 2003

[21] F.N. Cayan, M. Zhi, S.R. Pakalapati, I. Celik, N. Wu, R. Gemmen. J. Power Sources 2008, 185, 595-602

[22] J.P. Trembly R.S. Gemmen, D.J. Bayless. J. Power Sources 2007, 163, 986-996

[23] D. Sarantaridis and A. Atkinson Fuel Cells 2007, 07, 246-258

[24] Shuangqiao Yang, Tao Chen, Ying Wang, Zhenbo Peng, Wei Guo Wang, Int. J. Electrochem. Sci., 2013, 8, 2330-2344

[25] Abraham Gebregergis, Pragasen Pillay, Debangsu Bhattacharyya, and Raghunathan Rengaswemy IEEE Transactions on Industrial Electronics, 2009, 56, 139 
[26] M.E. Orazem and Bernard Tribollet, Electrochemical Impedance Spectroscopy, John Wiley \& Sons, 2008

[27] Gopala Krishnan, P. Jayaweera, J. Bao, J. Perez, K. H. Lau, M. Hornbostel, A. Sanjurjo, J. R. Albritton and R. P. Gupta Final Technical Report Dec 2008 SRI International

[28] J.P. Trembly, R.S. Gemmena, D.J. Bayless Journal of Power Sources 2007, 163, 986-996

[29] J. Bao, G.N. Krishnan, P. Jayaweera, J. Perez-Mariano, A. Sanjurjo. Journal of Power Sources 2009, 193, 617-624

[30] J.P. Trembly, Ph.D. Dissertation, College of Engineering and Technology of Ohio University 2007

[31] M. Zhi, X. Chen, H. Finklea, I. Celik, NanQiang Wu, J. Power Sources 2008, 183, $485-490$

[32] O. Demircan, W. Zhang, C. Xu, J. Zondlo, H. Finklea, Journal of Power Sources 2010, 195, 3091-3096

[33] Chunchuan Xu, J. Zondlo, H. O. Finklea, O. Demircan, M. Gong, X. Liu Journal of Power Sources 2009, 193, 739-746

[34] Chunchuan Xu, J. Zondlo, M. Gong, X. Liu Journal of Power Sources 2011, 196, 116-125 
[35] Huang Guo, Gulfam Iqbal, and Bruce S. Kang, International Journal of Applied Ceramic Technology, 2010, 7, 55-62

[36] Huang Guo, Gulfam Iqbal, and Bruce S. Kang, International Journal of Applied Ceramic Technology, 2011, 8, 68-73

[37] D. L. Hildenbrand, J. Chem. Phys. 1968, 48, 3657-3664

[38] Yun Chen, Song Chen, Gregory Hackett, Harry Finklea, John Zondlo, Ismail Celik, Xueyan Song and Kirk Gerdes Solid State Ionics 2013, 234, 25-32

[39] Y. Wang, X. Chen, W. Liu, L. Cheng, L. Zhang, Ceram. Int. 2010, 36, 755-759

[40] Hongxin You, Hongjie Gao, Gang Chen, Abuliti Abudul, Xinwei Ding. Journal of Power Sources 2011, 196, 2779-2784

[41] S. Assabumrungrat, N. Laosiripojana, P. Piroonlerkgul, Journal of Power Sources 2006, 159, 1274-1282.

[42] J.H. Edwards, A.M. Maitra, Fuel Process. Techn. 1995, 42, 269-289

[43] Y. Shiratori, T. Ijichi, T. Oshima, K. Sasaki, International Journal of Hydrogen Energy 2010, 35, 7905-7912

[44] Y. Takahashi, Y. Shiratori, S. Furuta, K. Sasaki, Solid State Ionics 2012, 225,

113-117.

[45] Cosimo Guerra, Andrea Lanzini, Pierluigi Leone, Massimo Santarelli,

Nigel P. Brandon Journal of Power Sources 2014, 245, p154-163 
[46] J. Bao, G.N. Krishnan, P. Jayaweera, J. Perez-Mariano, A. Sanjurjo. Journal of Power Sources 2009, 193, 607-616

[47] Moon, Hwan; Kim, Sun Dong; Park, Eon Woo; Hyun, Sang Hoon; Kim, Ho Sung International Journal of Hydrogen Energy, 2008, 33, 2826-2833

[48] Dieter Leckel Energy Fuels, 2009, 23, 2342-2358

[49] K. Haga, Y. Shiratori, Y. Nojiri, K. Ito, and K. Sasaki Journal of The electrochemical Society 2010, 157, B1693-B1700 


\section{Chapter 3 Leak check and cell test with $\mathrm{H}_{2} \mathrm{~S}$.}

\subsection{Introduction to the Cirrus Residual Gas Analyzer}

The main instrument for detection of gas-phase species in this study is a special type of quadrupole mass spectrometer called Residual Gas Analyzer (RGA). The RGA in this study is the Cirrus ${ }^{\mathrm{TM}}$ from MKS International (Figure 3.1). The Cirrus RGA is designed to monitor and analyze gases and gas mixtures including trace amounts of contaminants. Gas compositions can be tracked over a wide dynamic range (sub-ppm to percentage levels).

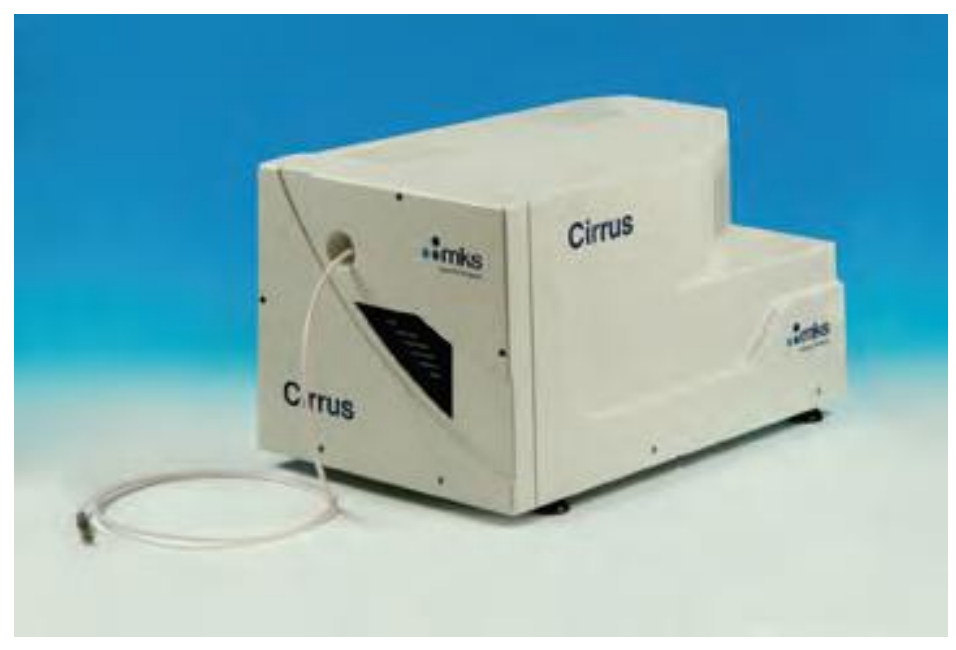

Figure 3.1 Cirrus Residual Gas Analyzer from MKS Instruments

RGAs are widely used for gas-phase analyses and monitoring, such as in leak tests, high vacuum systems, environmental controls, catalyst optimization and controlled gas sources. Researchers in Keele University, UK for example, used the Cirrus to 
determine and control the gas phase composition while testing for the optimized conditions of the reduction of a $\mathrm{NiO} / \mathrm{SiO}_{2}$ catalyst precursor. [1]

The ion source in the Cirrus RGA is a cylindrically symmetric closed ion source. It is a type of electron impact ion source. A tungsten filament is heated to emit electrons towards the accelerator. The electrons are accelerated to energies of 25 to $105 \mathrm{eV}$, depending on the operation mode. Usually in the normal RGA mode, $70 \mathrm{eV}$ is chosen for general-purpose analyses. The electrons impact the gas molecules from the sampling capillary. The ion energy is about 4 to $8 \mathrm{eV}$. This low energy will break a small fraction of the chemical bonds in small inorganic molecules. Sometimes doubly ionized species can be observed. After focusing, these ions move into the quadrupole mass analyzer.

For most analytical purposes, the quadrupole MS has the ability to resolve ions whose mass to charge ratio $(\mathrm{m} / \mathrm{z})$ differs by one atomic mass unit (amu). The Cirrus unit used in this study has a detectable $\mathrm{m} / \mathrm{z}$ range of 1-100 amu. The scan direction is always from lowest mass to highest mass. The major gases in the SOFC fuel stream are $\mathrm{H}_{2}$, and $\mathrm{H}_{2} \mathrm{O}$, with trace amounts of $\mathrm{N}_{2}, \mathrm{O}_{2}, \mathrm{Ar}, \mathrm{CO}_{2}, \mathrm{PH}_{3}$ and possibly $\mathrm{HPO}_{2}, \mathrm{HPO}_{3}$ and $\mathrm{P}_{2} \mathrm{O}_{5}$. There are three models of Cirrus systems available from MKS, with mass range 1-100, 1200 and 1-300 amu. The 1-100 amu model is chosen here because most of the analytes of interest are within $100 \mathrm{amu}$, and the 1-100 amu model offers better sensitivity and a lower detection limit than the other two models. [2]

The Cirrus RGA achieves a wide dynamic range, from atmosphere pressure (760 torr) down to $10^{-4}$ torr through the use of two detectors, a Faraday cup and an electron multiplier. Signals at $10^{-3}$ torr and above are considered to be reliable. So if an analyte 
has a partial pressure of $1 \times 10^{-3}$ torr, in other words, about $1 \mathrm{ppm}$ in concentration, it is detectable. Usually the contaminant studied in coal syngas such as $\mathrm{PH}_{3}, \mathrm{AsH}_{3}$ and $\mathrm{H}_{2} \mathrm{~S}$ varies from $1 \mathrm{ppm}$ to $10 \mathrm{ppm}$. The contaminants and their derivatives are expected to be reliably analyzed.

The RGA can sample gases from atmospheric pressure through a thin capillary with inner diameter of $1 \mu \mathrm{m}$. The silica capillary is heated to $120^{\circ} \mathrm{C}$ to prevent water condensation. The sampling connection is a standard 1/4 inch Swagelok fitting. This sampling capillary is a pressure adapter between the atmospheric pressure gas and the high vacuum inside the Mass Spectrometer chamber (usually $\sim 10^{-6}$ torr). The pumping consists of a four-stage mechanical diaphragm pump and a high-speed turbo pump.

In most cases, the RGA is used to monitor both the gas inlet and exhaust, especially the exhaust. The purpose is to study which gas species get to the anode and which species come out from it. So two sampling points, both with shut off valves, and a valve controlling the selection between the two points are included in the experimental design. The block diagram is shown in Figure 3.2:

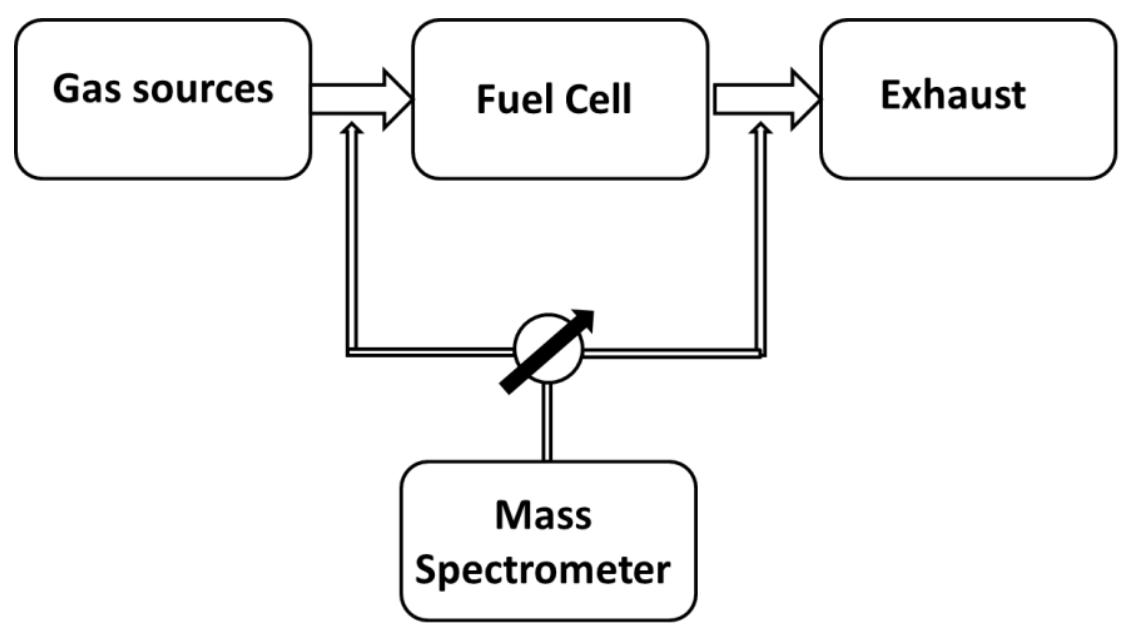

Figure 3.2 Block diagram of RGA application on Solid Oxide Fuel Cells 
The mass scan with the RGA is programmed always from lowest mass to highest mass. The speed of the scan can be set by adjusting the time spent at each mass number. The signal is integrated over the time at one mass, and then the mean of the signal is determined as the output. A full spectrum scan from mass 1 to 100 usually takes less than 1 minute. The repeat scan interval is often set to 1 minute.

The calibration of the RGA begins with the Faraday Cup detector. In this calibration, the $\mathrm{N}_{2}$ composition in the room air is assumed to be stable at 585 torr $(78 \%$ of 750 torr). The Faraday Cup is calibrated against the partial pressure of $\mathrm{N}_{2}$. A test run of the Faraday detector is usually done after the calibration process to verify the $\mathrm{N}_{2}$ reading at mass 28 is still 585 torr. Generally, the mass spectrometer exhibits a measurable loss of sensitivity over a period of 1 day.

The electron multiplier detector is more sensitive than the Faraday Cup, has lower detection limits and lower maximum detectable pressures. It can handle gas pressures only up to about 100 torr. So it is calibrated against a reading of the Faraday Cup, usually Argon at mass 40 in this study.

The RGA detector measures a current due to the ions reaching the detector. This current is assumed to be proportional to the partial pressure of the residual gas in the ionization chamber. The ions must pass through the quadrupole chamber without collision with other molecule or ions, so the mean free path must be longer than the length of the chamber. To ensure the large mean free path, a high vacuum is necessary. Usually the RGA operates under $10^{-6}$ torr pressure. In the MKS Cirrus unit, a turbo pump backed by a four stage diaphragm pump is installed to achieve the high vacuum needed. 
The amount of current at particular masses can be affected by a number of factors some of which are described below [3]:

1. The probability that a molecule will be ionized due to the electron impact. This can be determined by the cross section for ionization for each species.

2. The probability that an ion is produced by a particular molecule fragment.

3. The probability that an ion will make it into the quadrupole chamber and finally pass through the chamber to be detected.

The first factor, which is defined by the cross section for ionization, is believed to be dominant. A list of cross sections for ionization of some selected species taken at incident energy of $70 \mathrm{eV}$ is provided in Table 3.1 [4]. Based on the cross sections for ionization data, $\mathrm{O}_{2}, \mathrm{~N}_{2}$ and $\mathrm{H}_{2} \mathrm{O}$ are predicted to have the same calibration. $\mathrm{H}_{2} \mathrm{~S}$ is listed because the cross section of $\mathrm{PH}_{3}$ is predicted to be roughly the same or marginally bigger than $\mathrm{H}_{2} \mathrm{~S}$.

Table 3.1 Cross sections for ionization of selected molecules at $70 \mathrm{eV}$ [4]

\begin{tabular}{cc}
\hline Gas Species & Cross section for ionization $\left(\AA^{\mathbf{2}}\right)$ \\
\hline $\mathbf{H}_{\mathbf{2}}$ & 1.021 \\
$\mathbf{O}_{\mathbf{2}}$ & 2.441 \\
$\mathbf{N}_{\mathbf{2}}$ & 2.508 \\
$\mathbf{C O}_{\mathbf{2}}$ & 3.521 \\
$\mathbf{H}_{\mathbf{2}} \mathbf{O}$ & 2.275 \\
$\mathbf{H}_{\mathbf{2}} \mathbf{S}\left(\right.$ in place of $\left.\mathbf{P H}_{3}\right)$ & 4.145 \\
\hline
\end{tabular}


The probability of fragmentation of a particular mass is also brought into consideration. For example, $\mathrm{H}_{2} \mathrm{~S}$ produces peaks at masses 32, 33 and 34 . The peak height at mass 32 and 33 each is about $40 \%$ of the peak height at mass 34 . The sum of signals of all possible fragments is the total amount of current generated by a particular molecule. This summed value gives a first approximation to relative peak heights.

However, the RGA is only calibrated to a certain mass, often mass $28\left(\mathrm{~N}_{2}\right)$. This calibration is based on the cross section of nitrogen and used across all masses within the

detection range. The calibration method is often good within a few percent but may be off by a large amount occasionally.

In an actual observation, immediately after calibrating the RGA detectors in air, mass spectra of "dry" and "wet" $\mathrm{H}_{2}$ were obtained. In the "dry" $\mathrm{H}_{2}$, the reading for mass 2 (for $\mathrm{H}_{2}$ ) and 18 (for $\mathrm{H}_{2} \mathrm{O}$ ) were 830 torr and 1.5 torr. In the "wet" $\mathrm{H}_{2}$, the reading for mass 2 and 18 were 794 torr and 88.2 torr. The partial pressure readings for $\mathrm{H}_{2}$ are somewhat reasonable but the $\mathrm{H}_{2} \mathrm{O}$ readings are off by a factor of 4 in this case. The correct value of $\mathrm{H}_{2} \mathrm{O}$ in the wet $\mathrm{H}_{2}$ should be around 20 torr.

\subsection{Experimental setup in WVU Chemical Engineering.}

The gas handling system in WVU Chemical Engineering Department is illustrated in Figure 3.3. The gas flows are controlled by Alicat Scientific Mass Flow Controllers (MFC). The mixture of the fuel gas can either go through or around the humidifier. $\mathrm{PH}_{3}$ or $\mathrm{H}_{2} \mathrm{~S}$ can be added after the humidifier. On the cathode side, the compressed air is also regulated by a mass flow controller and then fed into the furnace. 


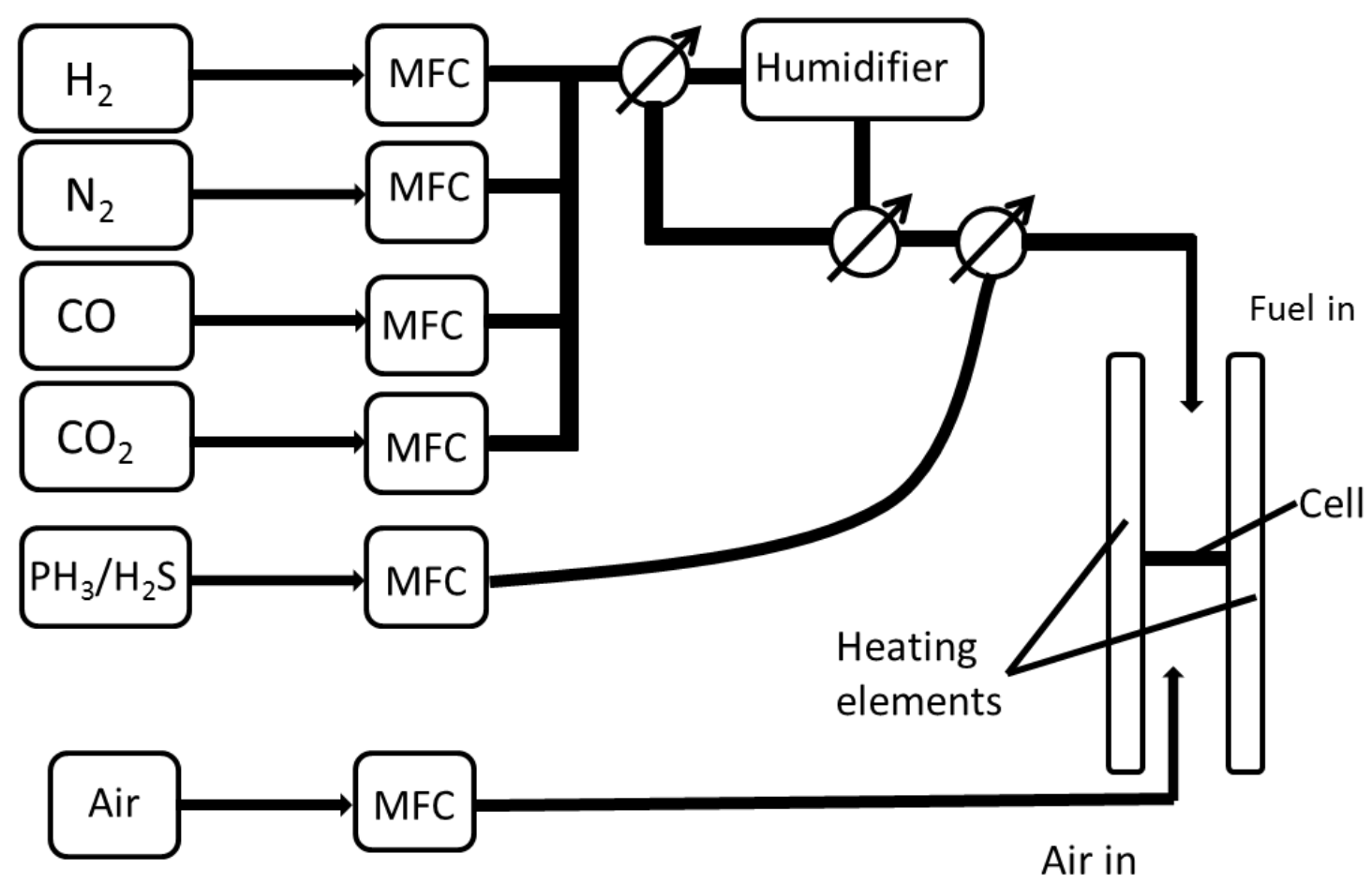

Figure 3.3 Illustration of gas handling system in WVU CHE Fuel Cell Test Stand.

The joints of the gas lines are mainly $1 / 4$ inch stainless steel Swagelok® fittings with ferrules. These joints are believed to be highly gas tight and reliable. The seals around the cell are flanges pressed together with spring loading (Figure 3.4). Mica gaskets are installed on both sides of the cell to minimize leaks. Although much effort has been put in to reduce the leaks, the seals are still not completely gas tight around the cell (see below). 


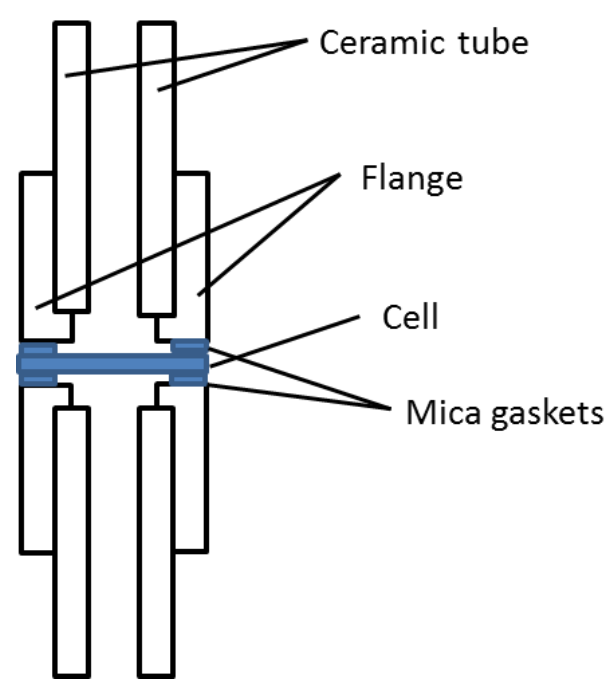

Figure 3.4 Detailed setup around the fuel cell in the WVU CHE test stand.

The gases coming out of the cylinders can either go through or bypass the humidifier, and then $\mathrm{PH}_{3}$ can be added to the fuel gas downstream. The inlet sampling point is just before the fuel stream enters the furnace, and the outlet sampling point is just after the exhaust leaves the furnace.

\subsection{Pure gas and leak checks}

Before the actual cell or gas tests, a complete leak check of the whole gas handling system was performed. This step is necessary mainly because one of the isotopes of oxygen will interfere with the mass 34 signal, the most interesting analyte in this study, the $\mathrm{PH}_{3} .{ }^{34} \mathrm{O}_{2}$ has a natural abundance of about $0.4 \%$. 


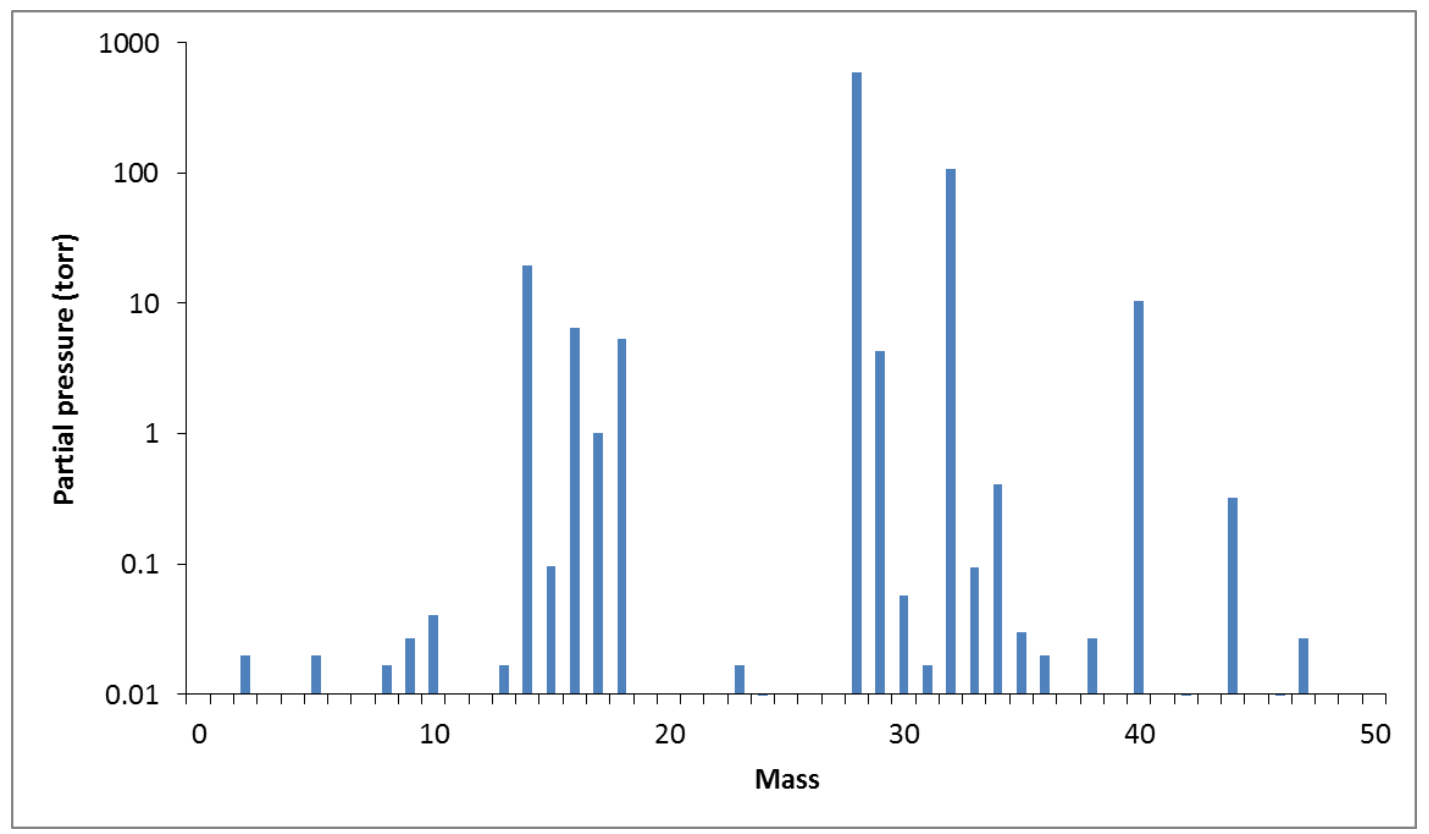

Figure 3.5 Mass spectra of room air.

A typical room air spectrum from 1 through 50 amu taken with the faraday cup detector is shown in Figure 3.5. In this figure, the mass spectrometer was calibrated in room air against Ar. The partial pressure of Ar at mass 40 is 7.2 torr, very close to its natural abundance. The detector can be calibrated for only one mass at a time, so other partial pressures including $\mathrm{N}_{2}, \mathrm{O}_{2}, \mathrm{H}_{2} \mathrm{O}$, etc. are not corrected. The partial pressure values are relative, not absolute.

Ultra High Purity (UHP) level gases are used with the mass spectrometer to avoid any possible impurity sources. The specification of UHP level claimed by Air Liquide America is at least $99.999 \%$ purity. These gases were passed through a T-junction to which the mass spectrometer capillary was connected. The mass spectrum of UHP He is shown in Figure 3.6. This spectrum is taken using the electron multiplier detector. The mass 4 was skipped when scanning due to the saturation of the electron multiplier detector. The peak at mass 8 is assigned to the bi-atomic He formed inside the ion source. 
There is small amount water content ( 0.02 torr) in the UHP He. Other than that, the UHP He is very pure. The partial pressures of $\mathrm{N}_{2}$ and $\mathrm{O}_{2}$ are down in the $10^{-3}$ torr range, very close to the noise level.

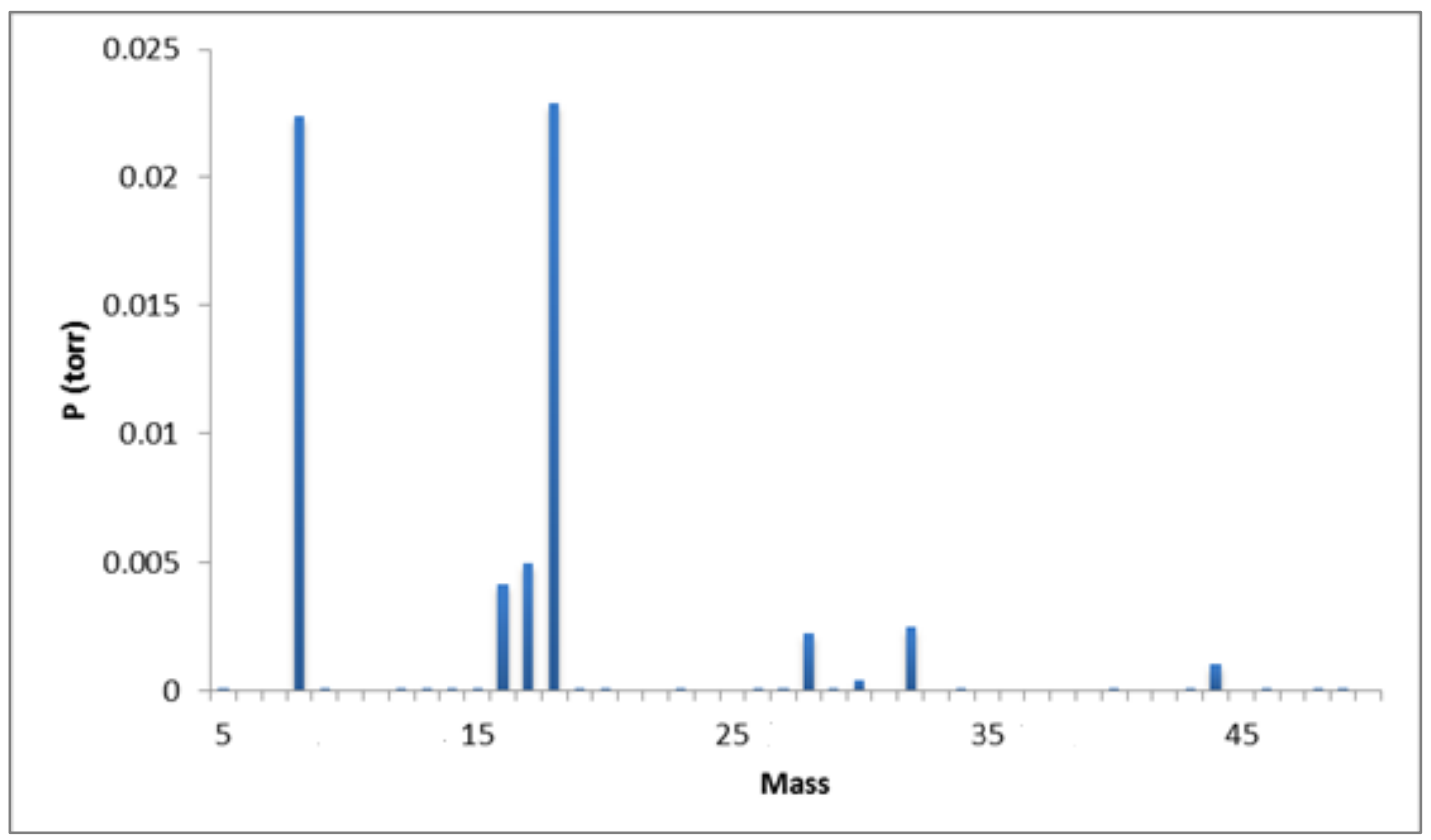

Figure 3.6 Mass spectra of UHP grade He.

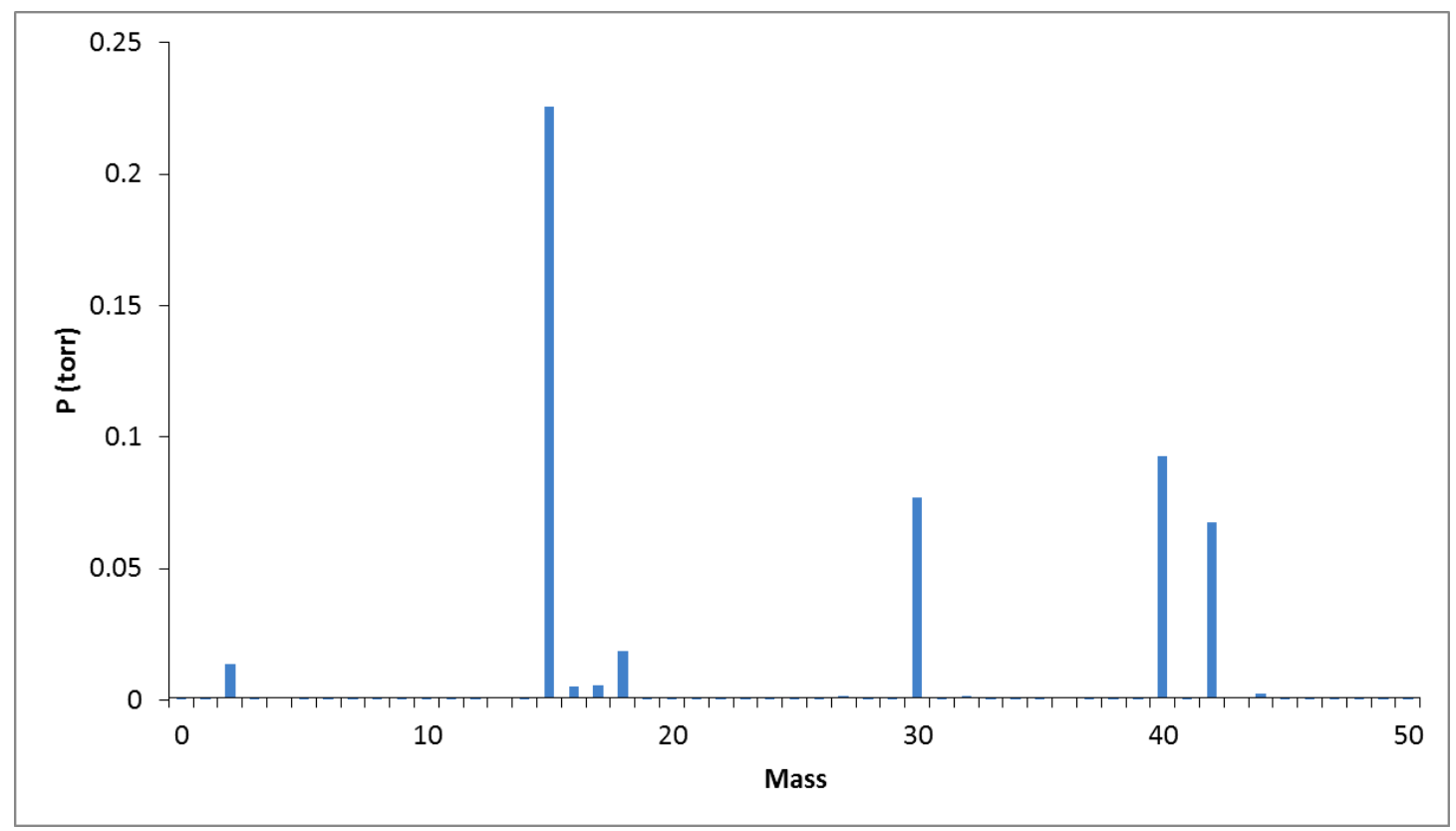

Figure 3.7 Mass spectra of UHP grade $\mathrm{N}_{2}$. 
The mass spectrum of UHP $\mathrm{N}_{2}$ is shown in Figure 3.7. The $\mathrm{N}_{2}$ contains more impurities than the He, although they are claimed to be the same purity grade. Mass 14 , 28 and 29 are skipped in the mass scans. However, the RGA detection tends to exhibit a "carry over" effect. After a very large, sometimes out of range peak is detected in the spectrum, the signal at the next higher mass number will be much larger than expected. A hypothesis of this type of observation is that the mass analyzer resolution is not sufficient to exclude the large signal from one mass from infringing the next higher mass. For example, the mass 14 was skipped due to the large amount of double ionized $\mathrm{N}_{2}$, but at mass 15 a large signal still appears on the spectrum. Mass 28 , which is the $\mathrm{N}_{2}$ molecule, is well above the detector limit range, and, the carried over mass 29, is still out of range. The "carry over" effect is still seen at mass 30. Residual Ar made its contribution to mass 40. The peak at mass 42 cannot be assigned to any gas that exists in the room air, but might be a pair of some hydrocarbons from the compressor oil.

A leak check of the system was performed with the UHP $\mathrm{N}_{2}$. There was no cell in the furnace, only a seal block (elastic film over the tube opening normally pressing against the mica seal of a SOFC). The furnace was not heated. UHP $\mathrm{N}_{2}$ was fed into the fuel lines. The mass spectrometer was hooked up to the exhaust sampling point and used to monitor the gas compositions in mass range 20-80 amu continuously for 24 hours. After 5-10 minutes from the start of mass scanning, 20 ppm of $\mathrm{PH}_{3}$ (mass 34) was fed into the stream. The plot of mass 34 and 44 versus time is in Figure 3.8. Mass $44\left(\mathrm{CO}_{2}\right)$ is chosen here because the $\mathrm{CO}_{2}$ level in the UHP $\mathrm{N}_{2}$ is very low, and $\mathrm{CO}_{2}$ serves as a leak marker. 
Results in Figure 3.8 show that there is an air leak in the system. $\mathrm{CO}_{2}$ levels of about $0.005-0.04$ torr are detected, while $\mathrm{CO}_{2}$ in room air is about 0.2 torr on average. The mass 34 signal stays low below $10^{-3}$ torr level.

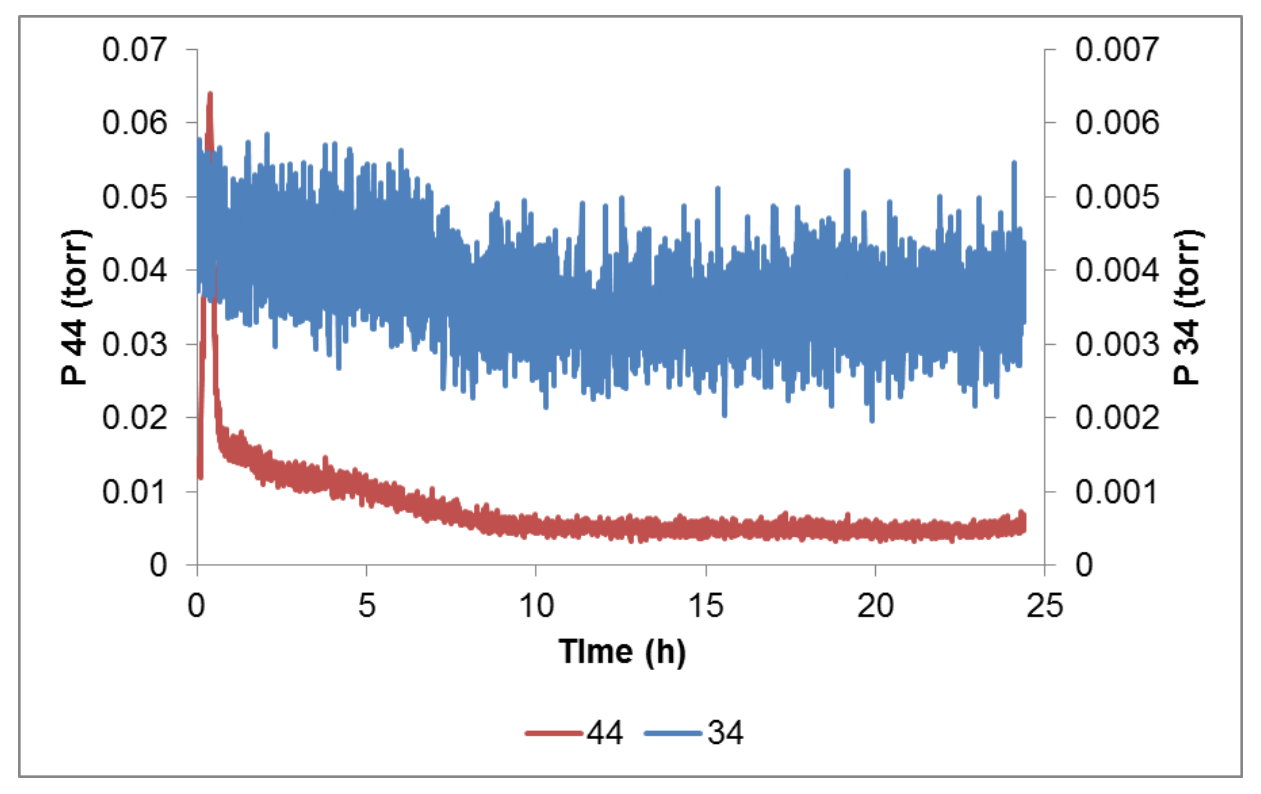

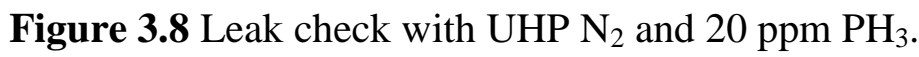

Another leak check was conducted by squirting He at every joint of the system and monitoring the exhaust gas with the RGA leak check mode (rapid scanning of mass 4). If a higher than normal level of He is detected, it means the joint being squirted is leaking.

Much effort was put into locating the leaks. Leaks in the gas transfer lines were eliminated by tightening or changing the Swagelok fittings. Leaks were also found in the humidifier, but not fixed. For many subsequent measurements, the fuel gas was routed around the humidifier.

To ensure the ability of the Cirrus unit to detect analytes within the entire range of mass to charge ratio of 1-100, some volatile organic compounds are placed near the tip of the sampling capillary for the Cirrus unit to inhale the vapor. The air is also drawn into the 
mass spectrometer with the organic compounds. The mass spectra of ethyl acetate $\left(\mathrm{CH}_{3} \mathrm{COOC}_{2} \mathrm{H}_{5}\right)$ with a molecular weight of 88 are shown in Figure 3.9.

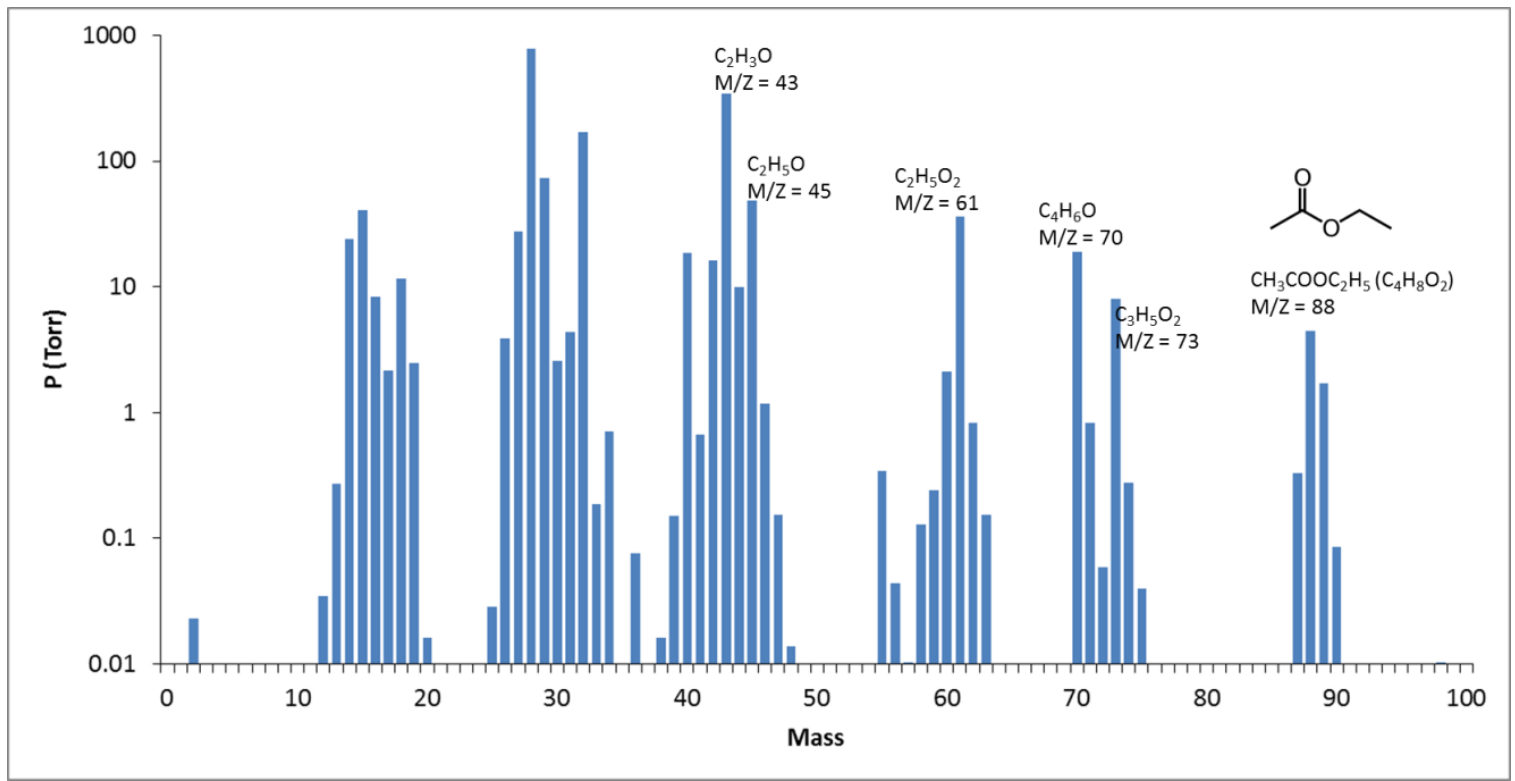

Figure 3.9 Mass spectra of ethyl acetate vapor in room air.

The molecular peak at 88 (the molecular weight of ethyl acetate) and fragments at mass $73,70,61,45$ and 43 are seen on the spectra. This result confirms the capability of the mass spectrometer to detect any mass within the range of 1-100 amu.

\subsection{Cell preparation}

The cells used in this study are commercially available MSRI (Materials and Systems Research, Inc) anode-supported button cells. Both the test bed in WVU Chemical Engineering and the Probostat can hold cells with a diameter of about $2.5 \mathrm{~cm}$. The cell usually is supported by the NiO/YSZ anode, which is $\sim 900 \mu \mathrm{m}$ in thickness. The dense YSZ electrolyte is coated on the anode as a very thin layer of about $10 \mu \mathrm{m}$. The cathode is screen-printed on the electrolyte, with a smaller diameter than the anode and 
electrolyte. These three layers are sandwiched together to make a full solid oxide fuel cell. Figure 3.10 is an illustration of the SOFC cross-section.

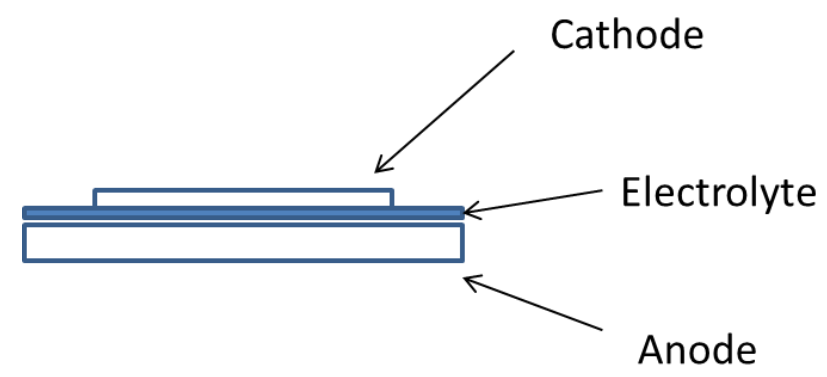

Figure 3.10 Sandwich structure of anode supported SOFC (Not to scale)

The current collectors are gold meshes attached to the cathode and anode using conducting gold paste. After applying the gold paste, the cell is heated slowly to 600$800^{\circ} \mathrm{C}$ to dry the paste and burn out any organic compounds. This step also places the gold mesh in firm contact with the cathode and anode. Figure 3.11 shows the current collector on both sides of the SOFC.
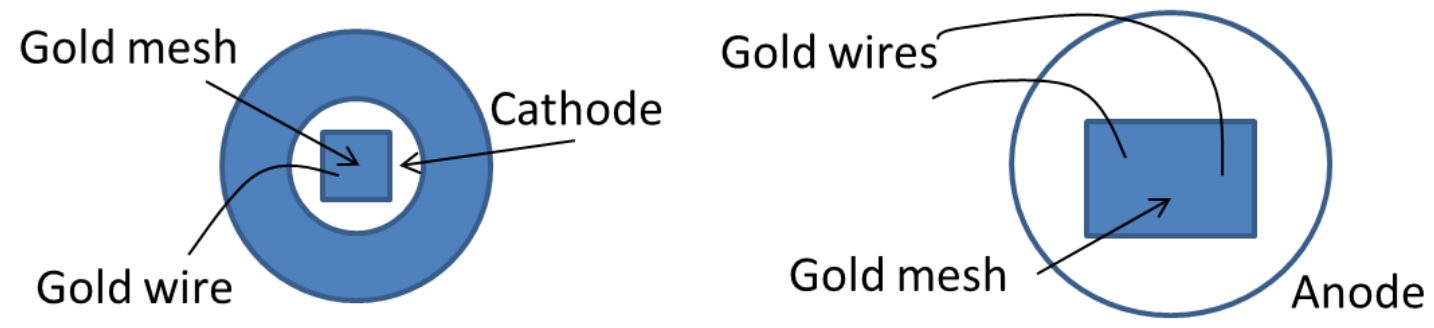

Figure 3.11 Current collectors of the anode-supported MSRI cell

On each side of the cell, there are two wires. One is for the major current flow and the other one for the voltage sense. This configuration minimizes the interference of wire resistance on the voltage measurements. 
The potentiostats in this study (Solartron or Gamry) provide four leads: working electrode (current), working sense (voltage sense), counter electrode (current) and reference electrode (voltage sense). Either the cathode or the anode were connected as the working electrode.

Before each cell test, the cell was fully conditioned. The preparation of the cell consisted of several steps. Firstly the cell was correctly wired. Then the cell was secured firmly on the test bed and sealed to minimize leaks between the fuel and air. Then the furnace was programmed to heat up slowly, usually with a rate of $1-2{ }^{0} \mathrm{C} / \mathrm{min}$. The anode side was fed with inert gas (typically $\mathrm{N}_{2}$ ) and the cathode side was fed with air while heating up. Once the temperature reached $800^{\circ} \mathrm{C}$ and was stable, the reduction of the anode began with diluted $\mathrm{H}_{2}$, usually $10 \% \mathrm{H}_{2}$ in $\mathrm{N}_{2}$ for the first 2 hours, and then the $\mathrm{H}_{2}$ was increased to $50 \%$ for another 4-6 hours. The $\mathrm{H}_{2}$ was finally increased to $100 \%$. The cell was kept at this point for $\sim 10$ hours with open circuit (no current flow). Then a small current was applied (typically $100 \mathrm{~mA}$ ) to ensure that the anode was fully reduced. A new cell has a green color from the $\mathrm{NiO}$ in the anode, but when it is reduced, the anode color becomes metallic grey because of the Ni metal.

\subsection{Cell tests in WVU Chemical Engineering with $\mathrm{H}_{2} \mathrm{~S}$}

\subsubsection{Ni-GDC cell test with different levels of $\mathrm{H}_{2} \mathrm{~S}$}

An anode-supported Ni-GDC cell was reduced in $\mathrm{H}_{2}$ and pre-conditioned with a small current to achieve a stable performance before the mass spectrometry tests. In this test, the Mass Spectrometer was connected to the exhaust of the SOFC test stand and it 
was set to scan the 30-100 amu mass range. The partial pressures of the gases were monitored over 100 hours of operation time. The total gas flow to the anode was kept at $200 \mathrm{sccm}$. The cathode was fed with $300 \mathrm{sccm}$ of air throughout the entire experiment.

In the experiment, the $\mathrm{Ni}-\mathrm{GDC}$ cell is operating on dry $\mathrm{H}_{2}$ initially, then $3 \%$ water ( 20 torr) was added ("wet" condition) at $800^{\circ} \mathrm{C}$. Then $100 \mathrm{ppm}$ of $\mathrm{H}_{2} \mathrm{~S}$ was introduced into the fuel stream after 25 hours from the beginning of the mass scans. After 50 hours, the amount of $\mathrm{H}_{2} \mathrm{~S}$ was increased to $200 \mathrm{ppm}$. After 92 hours, the $\mathrm{H}_{2} \mathrm{~S}$ flow was shut off. The major signal of $\mathrm{H}_{2} \mathrm{~S}$ is mass 34 . The plot of mass 34 versus time is shown in Figure 3.12 .

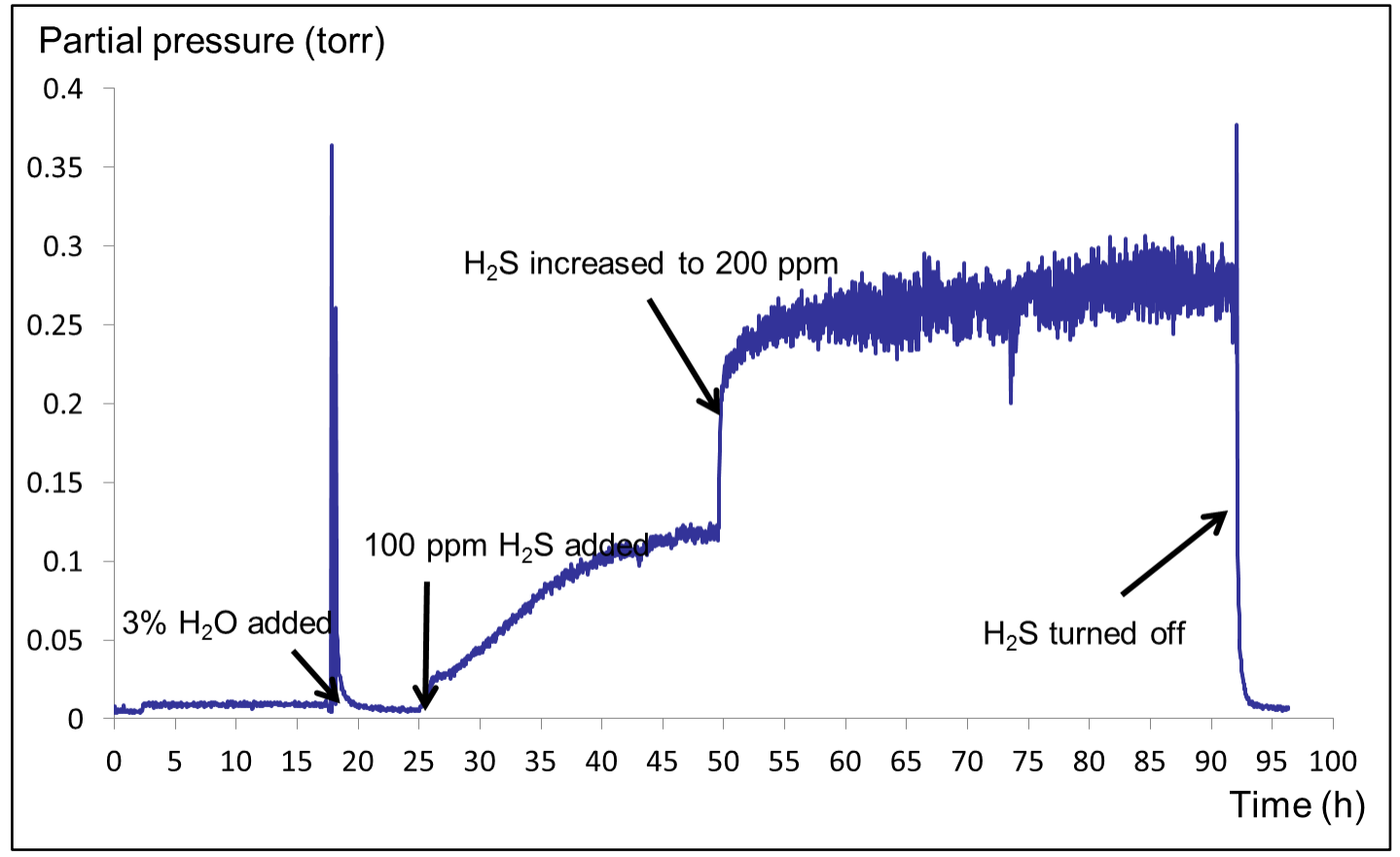

Figure 3.12 Mass $34\left(\mathrm{H}_{2} \mathrm{~S}\right)$ signal in the exhaust gas during cell operation at $800^{\circ} \mathrm{C}$.

During the first 18 hours, the cell was running on "dry" $\mathrm{H}_{2}$ without water added. At about 18 hours, the fuel stream was passed through a humidifier. The humidifier has a relatively large dead volume of air about 10 liters, so the air peaks increased sharply after 
it was turned on. The mass 34 signal also increased as a spike peak because of the contribution of ${ }^{34} \mathrm{O}_{2}$. The air was gradually purged over several hours. The addition of $\mathrm{H}_{2} \mathrm{~S}$ was delayed until a stable baseline was achieved at mass 34 .

Immediately after the addition of $100 \mathrm{ppm}_{2} \mathrm{~S}$, there was a small amount of residual air in the gas transfer line and this causes the small "bump" in the graph. Then the mass 34 signal increased very slowly to 0.14 torr (roughly double the true pressure of 0.08 torr). This transient took more than 20 hours to reach a steady value. However, the power loss of the SOFC occurred almost instantly after addition of $100 \mathrm{ppm}_{2} \mathrm{~S}$. After the $\mathrm{H}_{2} \mathrm{~S}$ was increased to $200 \mathrm{ppm}$, another transient behavior occurred, but with an initial sharp jump and much shorter time. One hypothesis of the transient phenomena is that the $\mathrm{H}_{2} \mathrm{~S}$ tends to be adsorbed on to the walls of the gas transfer system, test stand, mass spectrometer transfer line and cell itself. There might be a saturation volume of the $\mathrm{H}_{2} \mathrm{~S}$ onto the inner surfaces. The surface area is so large that it takes a long time to be fully saturated. But after the saturation, the response of signal becomes more sensitive to the change of $\mathrm{H}_{2} \mathrm{~S}$ concentration, although the increased concentration may lead to a larger saturation volume of adsorption. Another hypothesis is that the $\mathrm{H}_{2} \mathrm{~S}$ adsorbed by and reacted with the $\mathrm{Ni}$ in the cell anode. Liu et al. reported that $\mathrm{Ni}_{3} \mathrm{~S}_{4}, \mathrm{NiS}$, and $\mathrm{Ni}_{3} \mathrm{~S}_{2}$ were detected at the anode surface by in-situ Raman spectroscopy if the anode was cooled down in a fuel contaminated by $\mathrm{H}_{2} \mathrm{~S}$. [5]

When the $\mathrm{H}_{2} \mathrm{~S}$ was shut down, the signal at mass 34 dropped immediately and sharply to the baseline level. The sharp drop implies that the adsorption is not reversible or kinetically very slow. Also, the $\mathrm{H}_{2} \mathrm{~S}$ may have reacted irreversibly with the cell anode 
and bonded to the nickel to form solid products that is not volatile. Thus, no $\mathrm{H}_{2} \mathrm{~S}$ was released when the supply is shut off.

Mass 34 and 33 are the only two mass numbers that exhibit change correlating to the addition of $\mathrm{H}_{2} \mathrm{~S}$ within $30-100$ amu range. Mass 34 is believed to be $\mathrm{H}_{2} \mathrm{~S}$ and mass 33 is possibly HS. The HS may be formed from $\mathrm{H}_{2} \mathrm{~S}$ during the ionization impact with the accelerated electrons, with one hydrogen atom knocked out. The plot of mass 33 signals versus time is shown in Figure 3.13. The shape of the graph is very similar, almost identical with the mass 34 graph, just with a smaller scale.

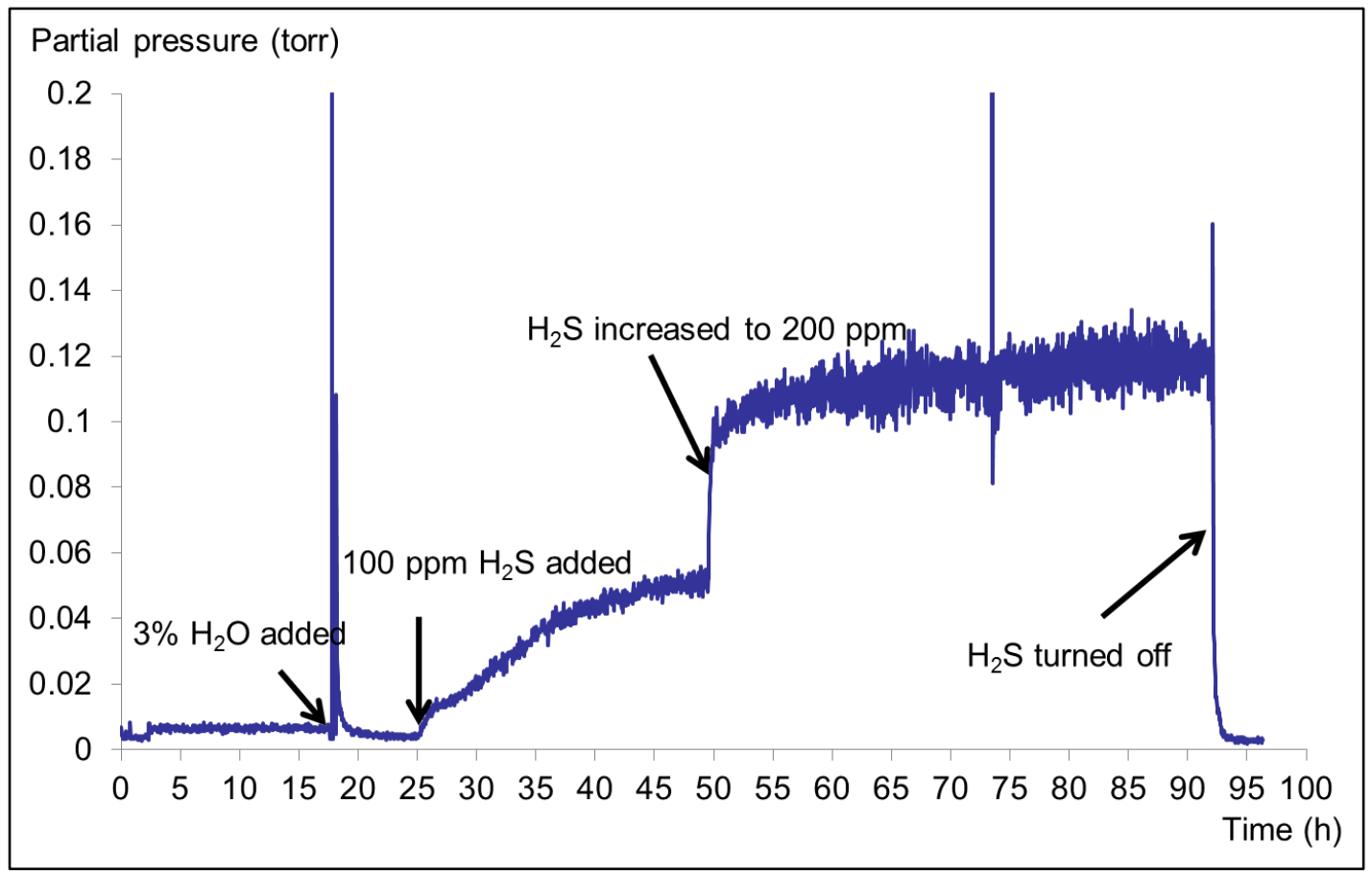

Figure 3.13 Mass 33 (HS) signal in the exhaust gas during cell operation at $800^{\circ} \mathrm{C}$.

\subsubsection{MSRI anode supported cell test with $\mathrm{H}_{2} \mathrm{~S}$ and current change}

In order to obtain a fast response of the mass spectrometry signals when the $\mathrm{H}_{2} \mathrm{~S}$ is added, the gas handling system and the furnace were pre-saturated with $\mathrm{H}_{2} \mathrm{~S}$. A YSZ 
disk is put in place of the cell to block the anode (fuel) side from air. The furnace was heated up to $800^{\circ} \mathrm{C}$ slowly. $\mathrm{H}_{2} \mathrm{~S}$ was added into the gas stream for a few hours before turning on the mass spectrometer, but a "ramp up" was still seen at mass 34 . The transient of $\mathrm{H}_{2} \mathrm{~S}$ is faster than the cell described above. Not only does the furnace system need time to be saturated, but also the mass spectrometer transfer line requires saturation. The nitrogen signal indicates a significant air leak inside the furnace or in the exhaust system. The water signal also suggests the presence of a leak. These leaks are very difficult to eliminate and they are incorporated in the tests.

A MSRI anode-supported cell was mounted onto the SOFC test stand in WVU Chemical Engineering similar to the cell described previously. The mass spectrometer was hooked up to the sampling point at the exhaust of the SOFC. The cell was prepared and pre-conditioned as before.

This cell test is conducted to investigate any change of $\mathrm{H}_{2} \mathrm{~S}$ due to the cell current during actual operation. The fuel gas was "dry" $\mathrm{H}_{2}$ and the mass spectrometer was programmed to scan the mass range 30-100 amu. The plot of mass 34 in the exhaust gas over time is in Figure 3.14 . 


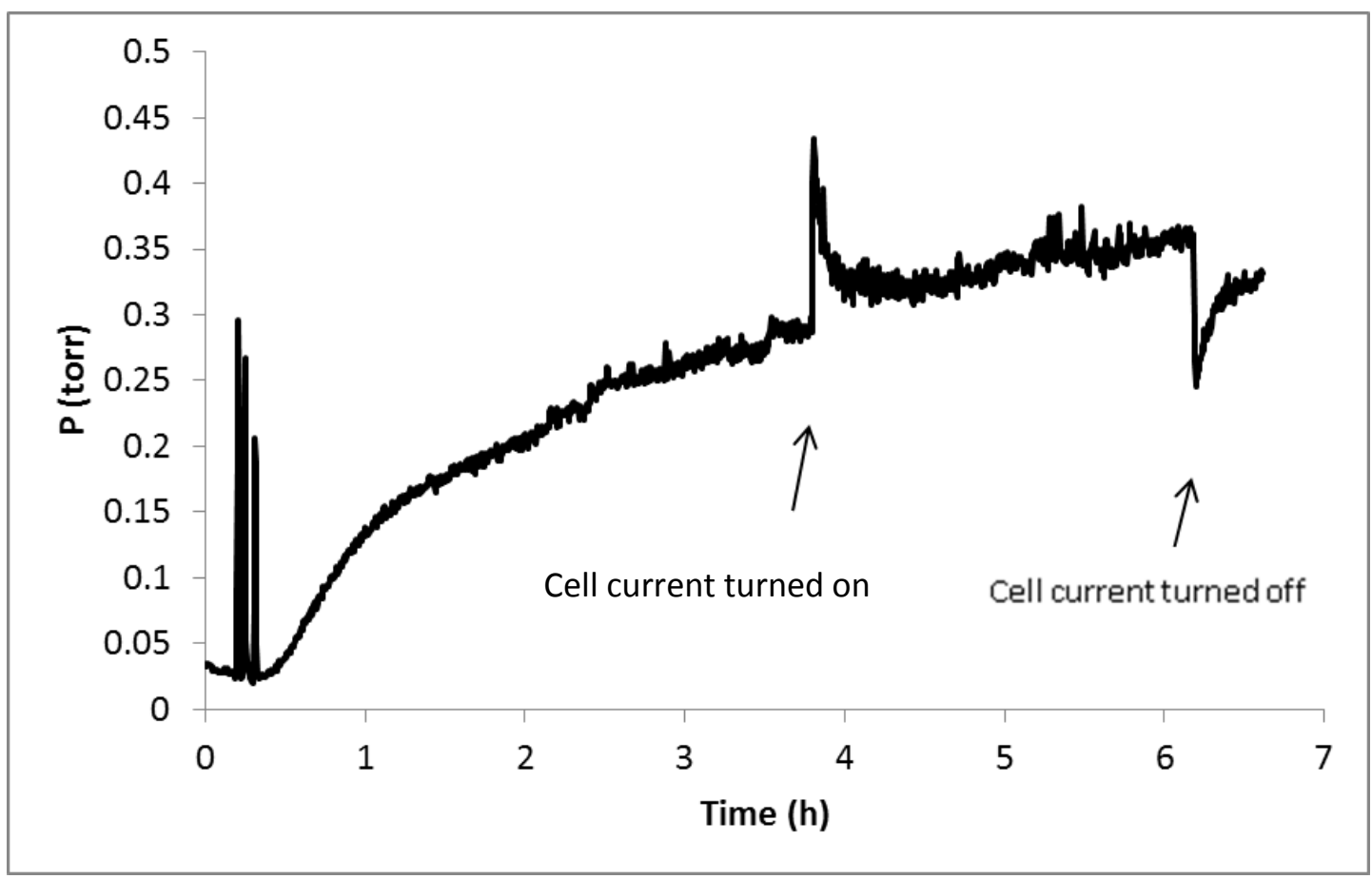

Figure 3.14 Mass 34 signal in the exhaust gas with current on and off. The cell was operating at $800^{\circ} \mathrm{C}$ with $\mathrm{H}_{2} .100 \mathrm{ppm}$ of $\mathrm{H}_{2} \mathrm{~S}$ added at 0.21 hours.

$100 \mathrm{ppm}$ of $\mathrm{H}_{2} \mathrm{~S}$ was added to the fuel stream at 0.21 hours. A transient behavior is seen in the first few hours. The mass 34 signal increased slowly during the current tests. The cell was loaded with 1 A of current at 3.8 hours. The mass 34 signal went up in 2 minutes, with no significant change of mass $64\left(\mathrm{SO}_{2}\right)$ or 60 (COS) signals. Then the mass 34 signal started to decay slowly, but was still higher than it was before applying the current. The cell current was turned off at 6.2 hours. The mass 34 signal dropped in 2 minutes, then slowly went up, but was lower than when the cell current was on.

For comparison, the inlet gas was also checked in the next experiment. The gas stream was the same as in the exhaust tests, just with the sampling point to the gas inlet before the SOFC. The mass 34 plot is in Figure 3.15. $100 \mathrm{ppm}$ of $\mathrm{H}_{2} \mathrm{~S}$ was added at 0.46 hours. In this experiment, the apparent steady state pressure of 0.35 torr is substantially 
higher than the true pressure of 0.08 torr. The cell current was turned on and off several times during the operation time but the mass 34 signal did not show a change according to the current. Without passing through the furnace area, the mass 34 signal still showed a transient, which implies that the $\mathrm{H}_{2} \mathrm{~S}$ will adsorb on to the sampling line of the RGA.

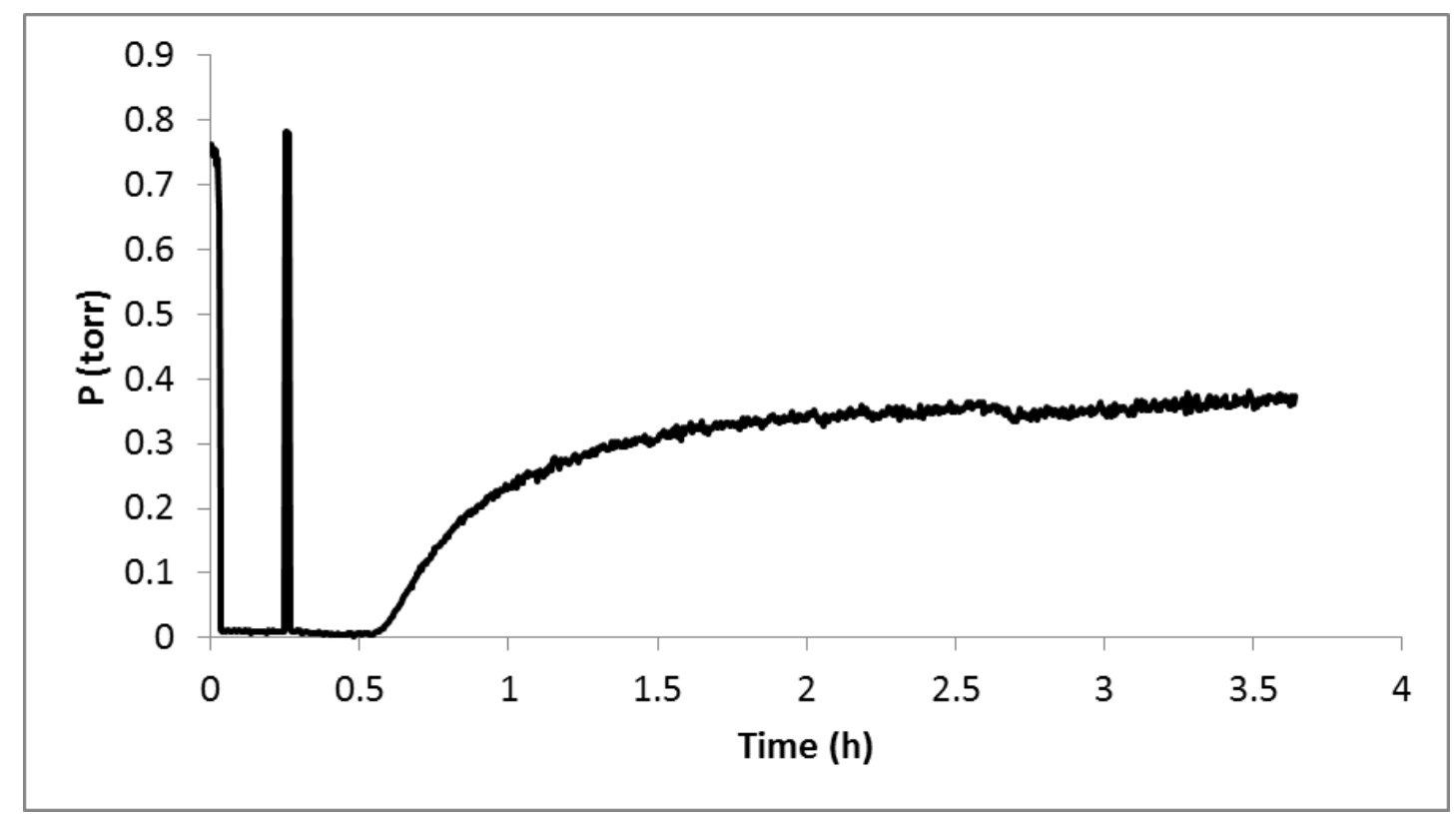

Figure 3.15 Mass 34 in the inlet gas with current on and off. The cell was operating at $800^{\circ} \mathrm{C}$ with $\mathrm{H}_{2} .100 \mathrm{ppm}$ of $\mathrm{H}_{2} \mathrm{~S}$ added at 0.46 hours.

The data from the exhaust and inlet with current flow are compared by determining the average of 5-6 hours of the exhaust data, and the average of 2-3 hours of the inlet data. In these regions, the mass signals are relatively stable. The following important masses are compared in Figure 3.16: 17(OH group, for $\mathrm{H}_{2} \mathrm{O}$, Mass 18 is out of range), 14 (atomic $\mathrm{N}$ or double ionized $\left.\mathrm{N}_{2}\right), 32\left(\mathrm{O}_{2}\right), 34\left(\mathrm{H}_{2} \mathrm{~S}\right), 40(\mathrm{Ar}), 60(\mathrm{CSO}), 64\left(\mathrm{SO}_{2}\right)$. 


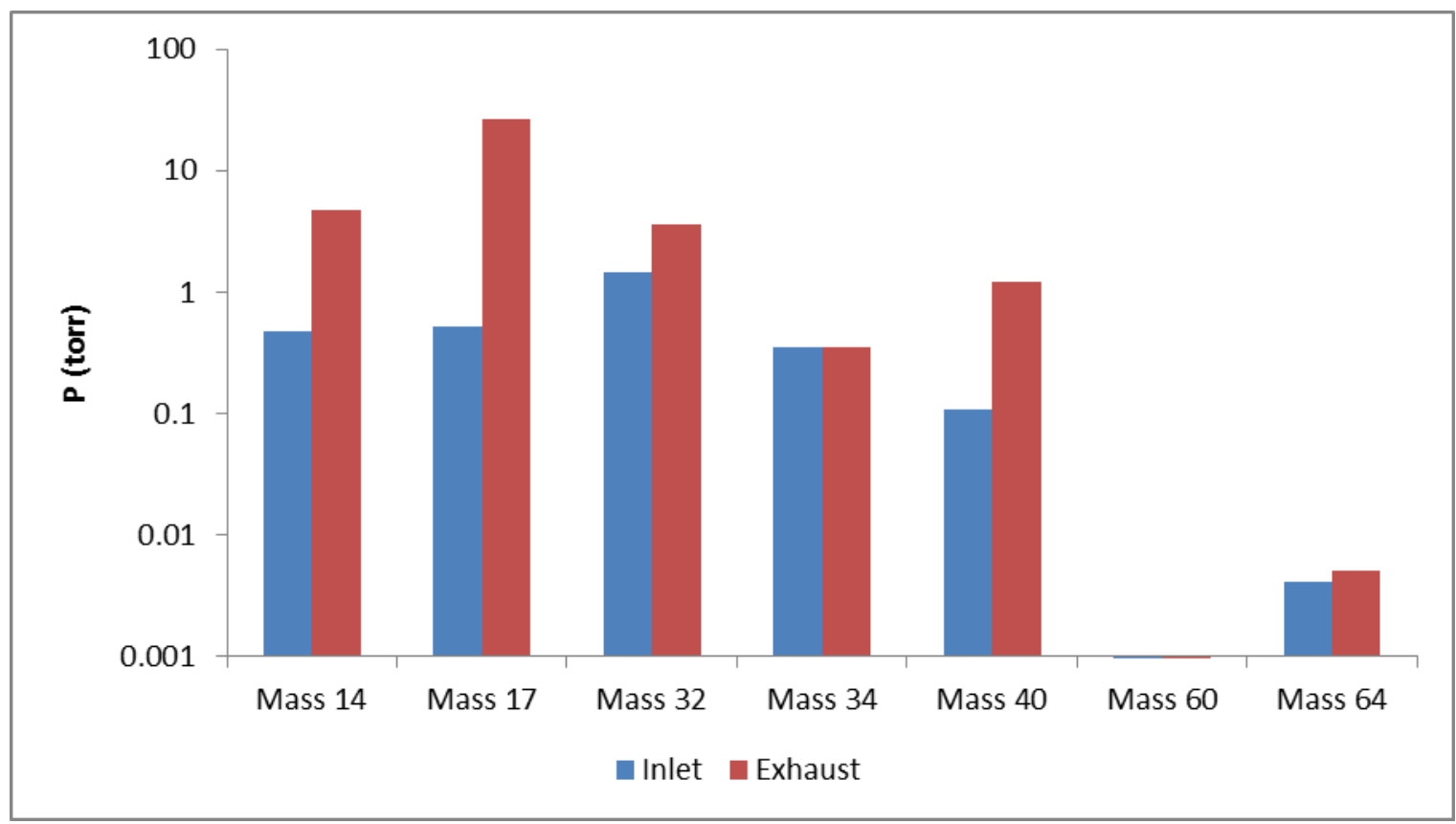

Figure 3.16 Comparison of inlet and exhaust gases during cell operation at $800^{\circ} \mathrm{C}$.

Because the $\mathrm{O}_{2}$ signal is on the order of 1 torr, the expected contribution of ${ }^{34} \mathrm{O}_{2}$ to the mass 34 signal is on the order of 0.004 torr. Such a high $\mathrm{O}_{2}$ content is not predicted by thermodynamic calculations. The equilibrium pressure of $\mathrm{O}_{2}$ in pure $\mathrm{H}_{2}$ at $800^{\circ} \mathrm{C}$ is on the order of $10^{-13}$ torr. The $\mathrm{O}_{2}$ signal at mass 32 is due to the small leaks at the place that the sampling capillary enters the mass spectrometer. Consequently, mass 34 signals are largely attributed to $\mathrm{H}_{2} \mathrm{~S}$, even with a noticeable air leak (higher mass 32 signal in the exhaust). The changes in mass 34 signal in Fig. 3.13 are attributed to desorption of $\mathrm{H}_{2} \mathrm{~S}$ from the cell during current flow (possibly due to heating of the cell during oxidation of $\mathrm{H}_{2}$ and ohmic heating), and re-adsorption of $\mathrm{H}_{2} \mathrm{~S}$ to the cell when the current is shut off.

The air peaks at mass 14, 32 and 40 are higher in the exhaust than in the inlet gas, suggesting there was an air leak between the two sampling points. The most likely place was around the cell. The water signal was also much higher in the exhaust due to the reaction of $\mathrm{H}_{2}$ in the fuel and the oxygen in the air leaking into the fuel side. Mass 34 
signals were almost the same in the two points. Considering some of the contribution to mass 34 in the exhaust is because of the oxygen isotope, some of the $\mathrm{H}_{2} \mathrm{~S}$ must have reacted. Mass 60 and 64 signals are in the noise level. There is no other mass signals above the noise level within the 30-100 mass range.

\subsection{Conclusion and discussions.}

The application of RGA on solid oxide fuel cell study offers a new way to determine the gas-phase composition. The trace gases and the major gases can be detected at the same time. However, due to the limitation of single point calibration, the absolute value of the partial pressure reading for some of the gases can be inaccurate.

A slow transient behavior is observed after the $\mathrm{H}_{2} \mathrm{~S}$ is added to the fuel stream. The $\mathrm{H}_{2} \mathrm{~S}$ might have reacted with the $\mathrm{Ni}$ in the cell anode or adsorbed on to the inner surfaces of the test stand or the sampling capillary of the RGA. However, when the $\mathrm{H}_{2} \mathrm{~S}$ was shut off, the signal dropped sharply and immediately. This implies that the reaction and adsorption of $\mathrm{H}_{2} \mathrm{~S}$ on to the gas handling system including the transfer lines to the mass spectrometer is irreversible.

The amount of $\mathrm{H}_{2} \mathrm{~S}$ detected at the exhaust of the cell is found to have a relationship with the current change. The current or the resulting local heating on the cell releases some of the adsorbed $\mathrm{H}_{2} \mathrm{~S}$. Without current, the $\mathrm{H}_{2} \mathrm{~S}$ adsorbs back on to the cell anode. 
The test stand at WVU Chemical Engineering had numerous leak points that were very difficult to eliminate. The seal around the cell was not designed to be gas tight. The small leaks at the inlet of the Cirrus unit lead to an unusually high amount of $\mathrm{O}_{2}$ from the air contaminants as well. Despite the leaks in the system, the $\mathrm{H}_{2} \mathrm{~S}$ at $100 \mathrm{ppm}$ is reliably detectable with the Cirrus RGA unit. At no point were significant amounts of $\mathrm{SO}_{2}$ or COS detected. A comparison of inlet and exhaust gas composition further confirms the large amount of leaks around the cell. Due to the difficulties caused by the leaks, the work was moved to another test platform. 


\section{References in Chapter 3.}

[1] Application Note, Overview of the Cirrus ${ }^{\mathrm{TM}}$ Gas Monitor in General Catalysis and Fuel Cell Applications, MKS International.

[2] Cirrus RGA Data Sheets, MKS Instruments.

[3] Application Note Number 8, What do Those RGA Peaks Really Represent, EXtorr Inc.

[4] NIST Chemistry WebBook, Physical Measurement Laboratory, National Institute of Standards and Technology.

[5] Z. Cheng, M. Liu, Solid State Ionics, 2007, 178, 925-935. 


\section{Chapter 4 Cell test in WVU Mechanical Engineering (Dr.}

\section{Kang' lab)}

\subsection{Experimental set up.}

The cell test in the WVU MAE laboratory was performed using a commercial testing platform named the Probostat. The Probostat is a versatile SOFC testing system designed in the Kofstad/Norby group at the University of Oslo, Norway. It consists of a two-foot long supporting tube made of alumina and a stainless steel base. When testing a fuel cell, the sample is held with a spring-loaded alumina assembly. Wires for the current leads, thermocouples and the gas in/out ports are on the metal base. Figure 4.1 is a photograph of assembled Probostat. [1-2]

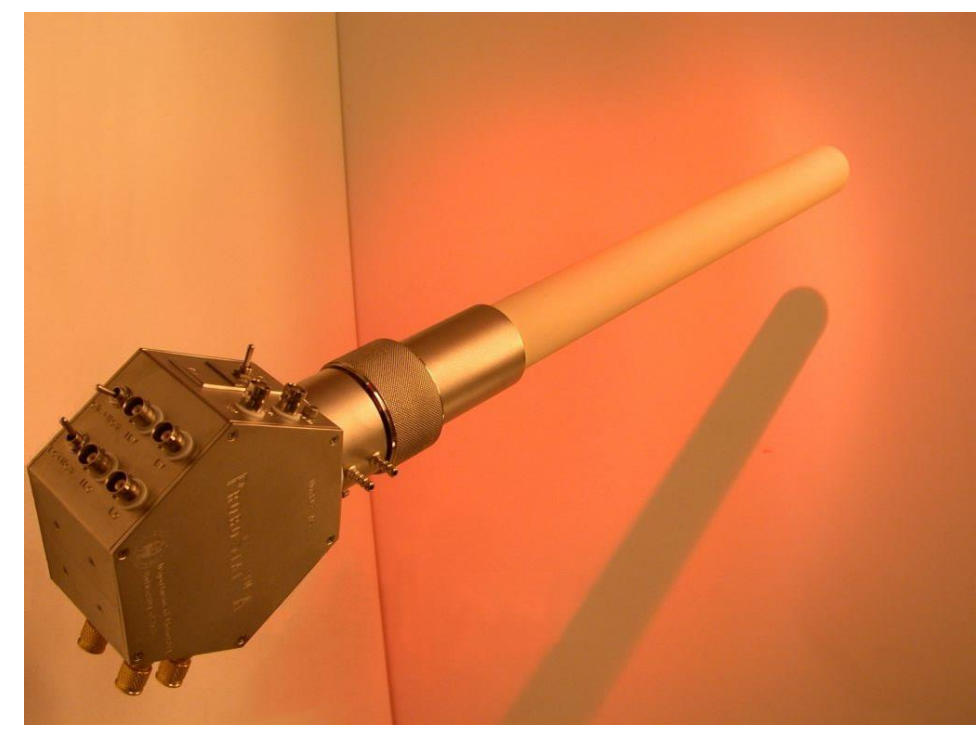

Figure 4.1 Picture of assembled Probostat testing platform for SOFC button cells.

The gas delivery system in WVU MAE is illustrated in Figure 4.2. All the gases were regulated by the Alicat Scientific Mass Flow Controllers. $\mathrm{H}_{2}, \mathrm{CO}$ and $\mathrm{CO}_{2}$ can be mixed 
to make a fuel gas mixture. The fuel mixture can either go through or around the humidifier. Helium can be fed to either or both the anode and cathode sides. $\mathrm{PH}_{3}$ can be added to the fuel stream after the humidifier from a tank containing $1000 \mathrm{ppm}^{\mathrm{P}} \mathrm{H}_{3}$ in nitrogen. The typical operating flow rate is $100 \mathrm{sccm}$ of fuel in the anode side, and 300 sccm of air in the cathode side.

There are four sampling ports for connection to the mass spectrometer: the anode inlet and exhaust, and the cathode inlet and exhaust.

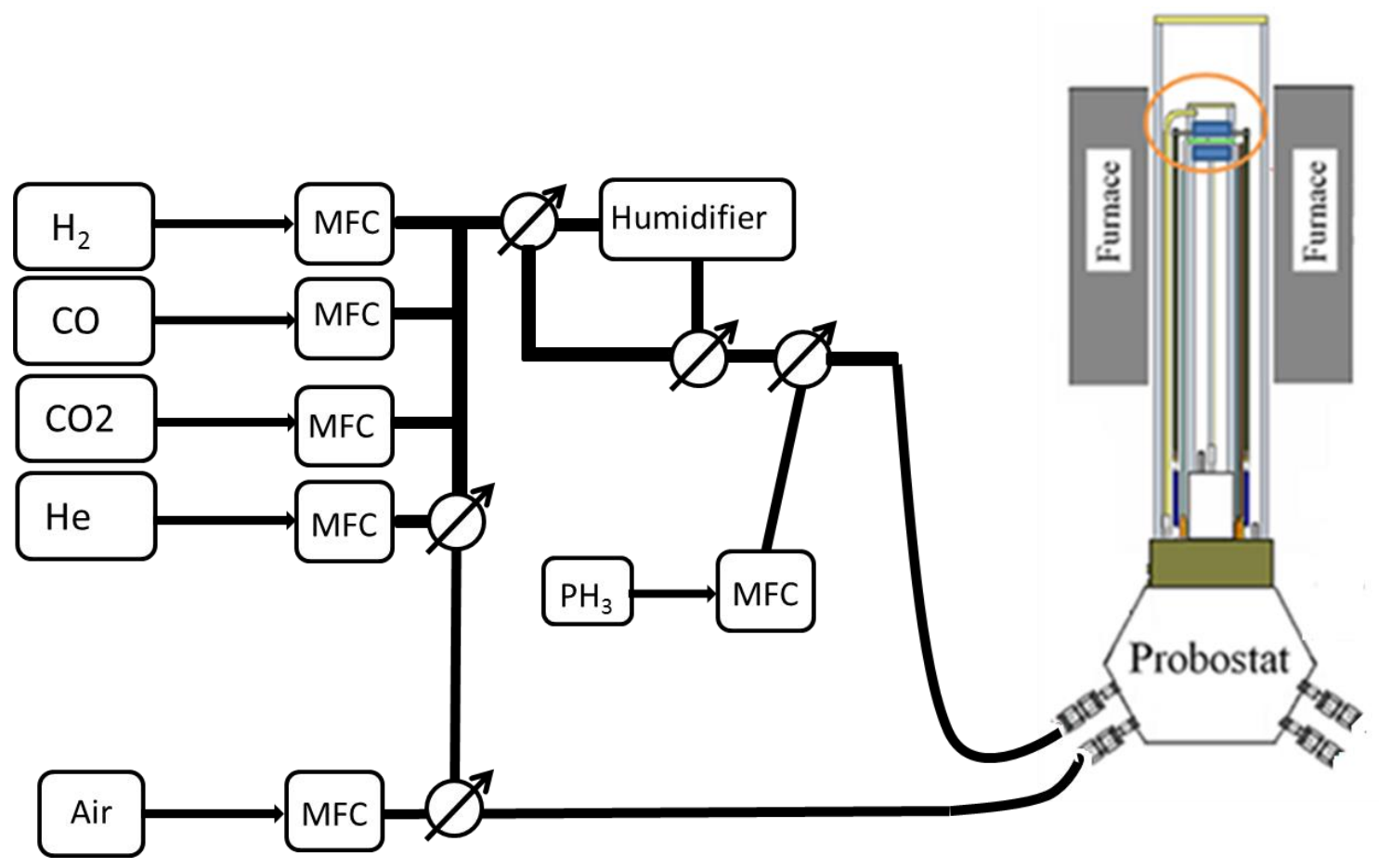

Figure 4.2 Gas delivery system in WVU MAE.

In the Probostat, the cell was usually glued with Aremco Ceramabond ${ }^{\mathrm{TM}}$ to the inner support tube with the cathode side facing down toward the base. This alumina tube has an outer diameter of $2.5 \mathrm{~cm}$. In order to minimize the air leak between the cathode side and anode side, an alternate approach for connecting the current collector and voltage leads 
was applied to the original design. In the previous tests, the current leads are usually brought out from the cell between the cell and the inner supporting tube (Figure 4.3 [1]). This leads to a gap and potential gas leaks between the cell and the tube.

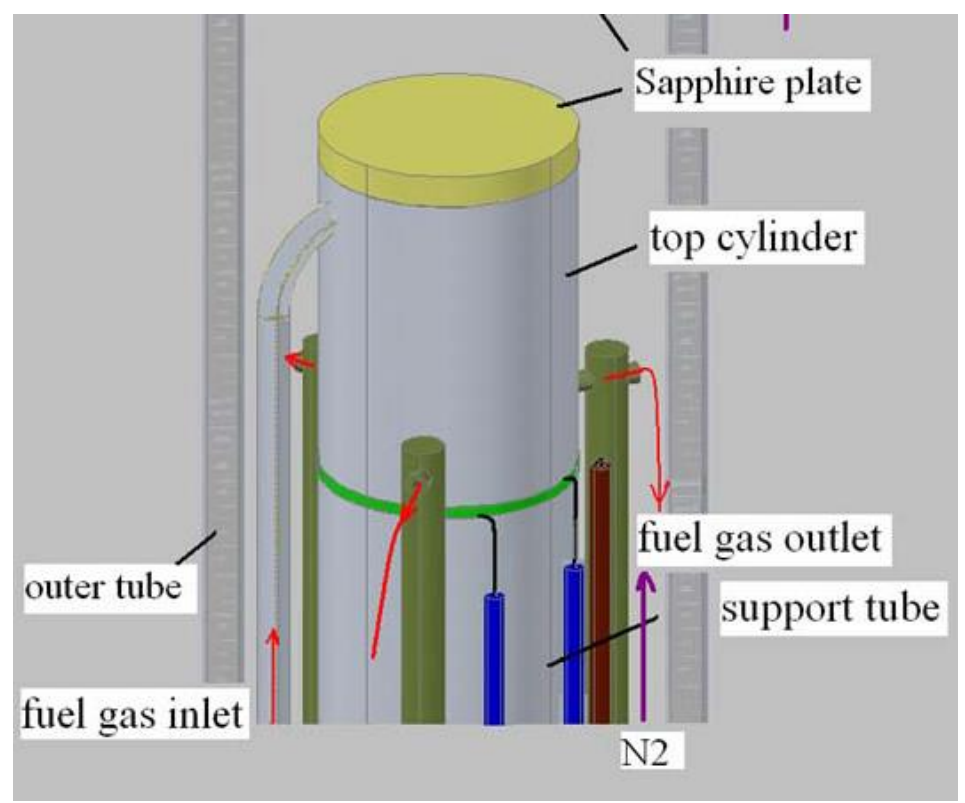

Figure 4.3 Original cell testing set up in the Probostat. The leads to the anode and cathode are the blue wires.

In the new approach, an inner current lead was attached to the cathode side. The inner lead that connected the cathode ran through the base inside the inner support tube. The cell was secured directly on the tube. A new sealing method was used in the study in contrast to the conventional ceramic glue, usually alumina or zirconia-based adhesives from Aremco. The new method used a gold O-ring with a diameter of $23 \mathrm{~mm}$, and gold paste to serve as glue. A photo of the actual cell is shown in Figure 4.4. The cathode current collector is inside the tube. The gold O-ring can be seen attached to the cell. The cell is pressed on to the tube with a spring-loaded assembly. In the test, the temperature was first ramped up to $900^{\circ} \mathrm{C}$. At this temperature, the gold O-ring becomes soft and 
deforms slightly in order to seal any possible gaps and cracks. Then the temperature was brought down to normal SOFC operation around $800^{\circ} \mathrm{C}$.

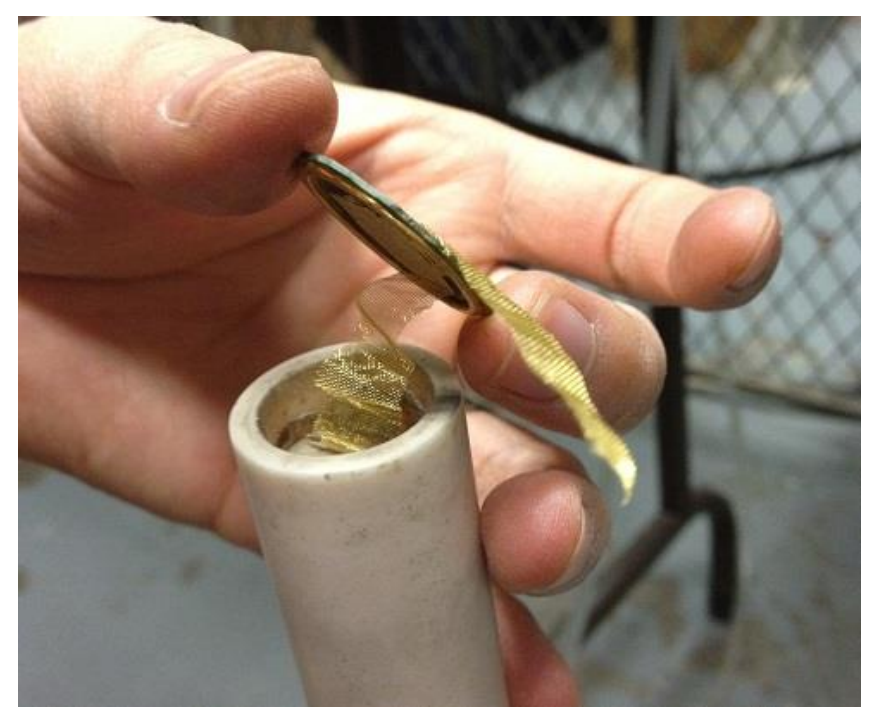

Figure 4.4 Cell assembly on to the Probostat using a Gold O-ring, showing the cathode current lead coming off the bottom of the cell.

\subsection{MSRI anode supported cell test}

An MSRI anode-supported cell was mounted using the method described above. The cell was reduced in diluted and pure $\mathrm{H}_{2}$ as discussed in Chapter 3. There were a total of 8 steps in this test. For each step, the data were taken when the mass scan was stable after changing the gas compositions and cell loads. In all the steps, the cell was at $800^{\circ} \mathrm{C}$.

1. He in both anode and cathode sides. This step was done to track any leak of air through the outer tube. The selected masses in the anode and cathode exhaust are shown in Figure 4.5. The $\mathrm{N}_{2}$ signals are in the order of 0.1 torr, which implies that the air leak at this point is very small. The $\mathrm{N}_{2}$ may also be coming from the impurities in the He cylinder as mentioned earlier in Chapter 3. 

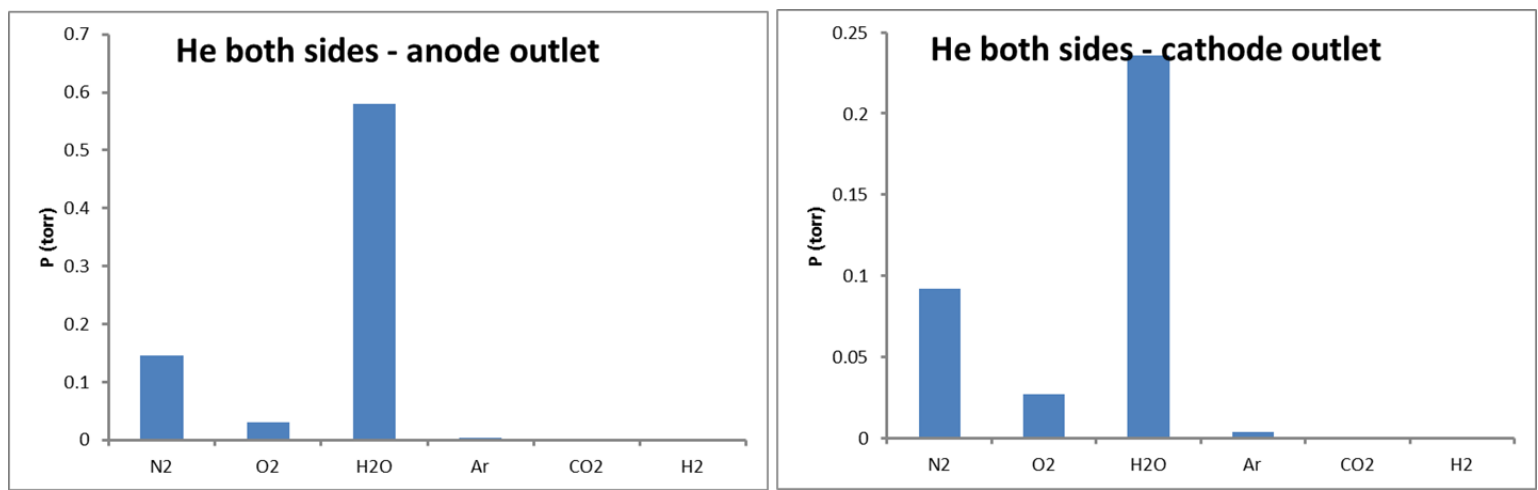

Figure 4.5 He in both anode and cathode sides. The cell was at $800^{\circ} \mathrm{C}$.

2. He in the anode side and air in the cathode side. Select masses taken from the anode and cathode exhausts are shown in Figure 4.6. This step was done to measure the leaks between the anode and cathode side. About 10 torr of $\mathrm{N}_{2}$ signal was seen in the anode side. The mass 28 signal in the cathode is skipped because it is too high and out of the detection range. Meanwhile, the He signal was also seen in the cathode side. These results confirm the presence of a leak in the gold ring seal. The experiment continued with the leaks present.
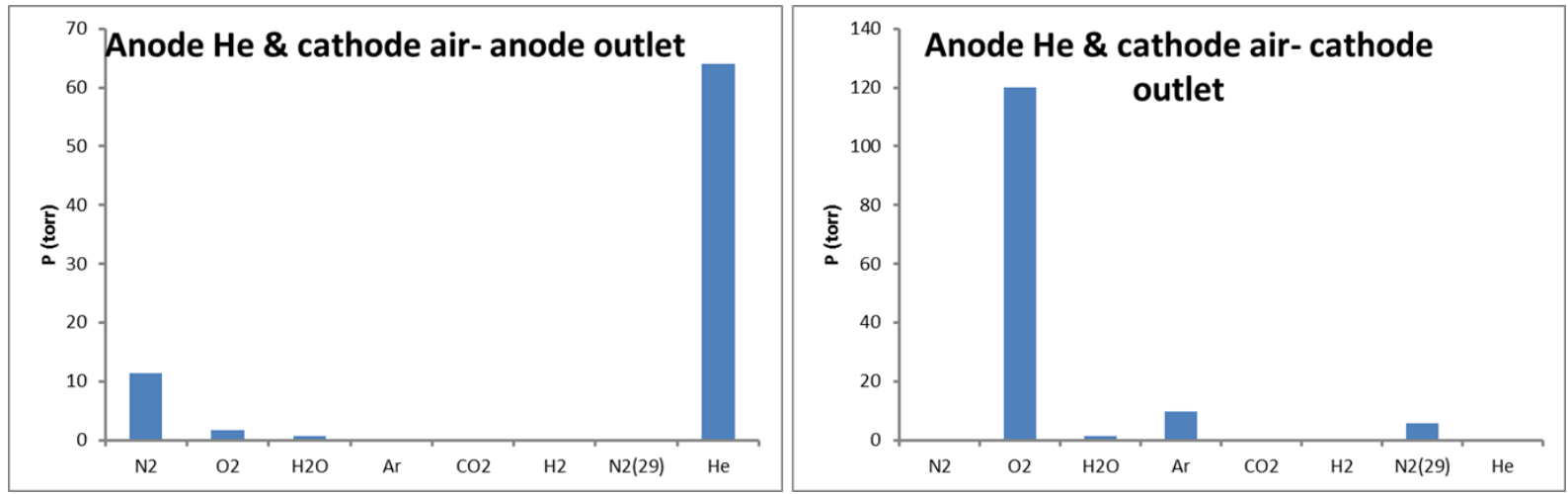

Figure 4.6 Anode with $\mathrm{He}$ and cathode with air. The cell was at $800^{\circ} \mathrm{C}$.

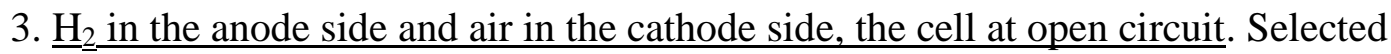
masses are shown in Figure 4.7 for both the inlets and outlets. Air peaks of $\mathrm{N}_{2}$ (shown in mass 29), $\mathrm{O}_{2}$, Ar and $\mathrm{H}_{2} \mathrm{O}$ signals are seen in the anode exhaust. The $\mathrm{H}_{2} \mathrm{O}$ at the exhaust 
comes from the reaction of the leaked $\mathrm{H}_{2}$ and air. Although the cell was left at open circuit, with no electrochemical reactions, water was still generated by the spontaneous combustion of hydrogen and oxygen at $800^{\circ} \mathrm{C}$. Excess water and some hydrogen also appeared in the cathode exhaust, suggesting that hydrogen was leaking into the air and combusting. The small amount of $\mathrm{O}_{2}$ in the anode outlet is from air leaks.

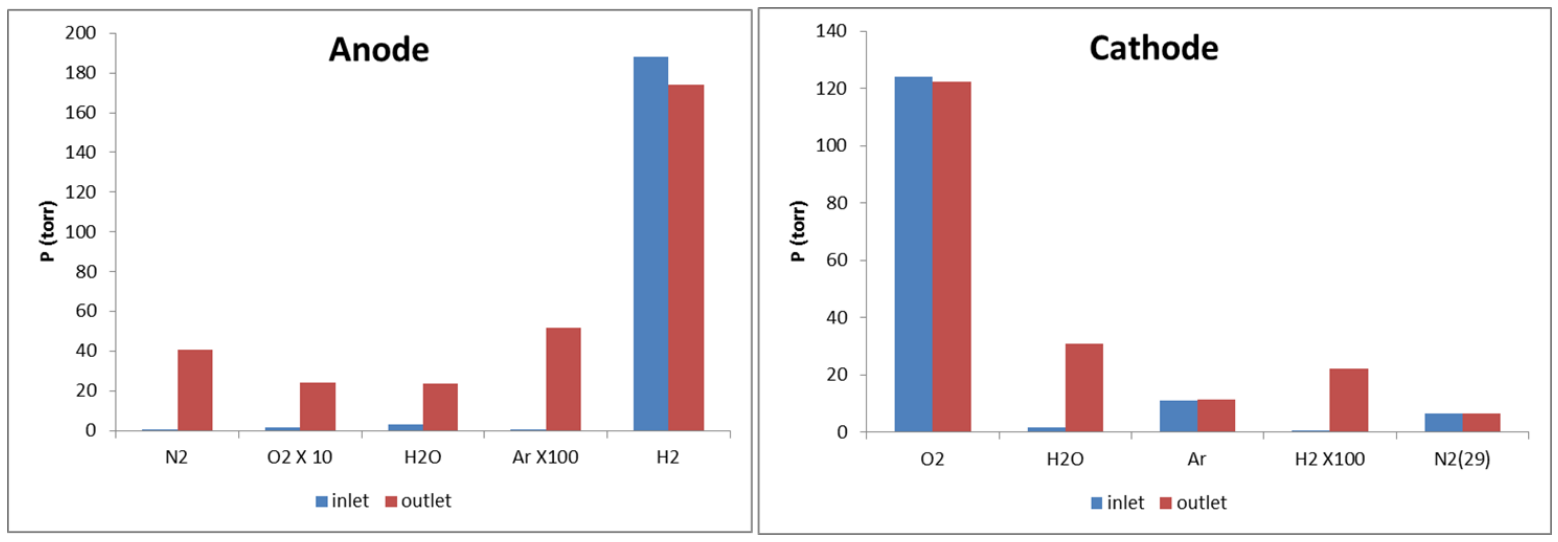

Figure 4.7 Anode with $\mathrm{H}_{2}$ and cathode with air, Cell at $\mathrm{OCV}$ and temperature at $800^{\circ} \mathrm{C}$.

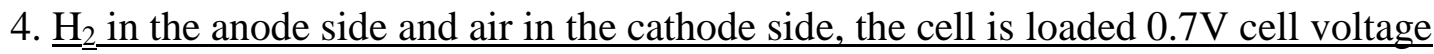
( 170 mA current). Selected masses are shown in Figure 4.8. The gas compositions were very similar to the ones in step 3 . The only significant difference is that the water signal at the anode exhaust went up from 24 torr to 60 torr. This incremental amount of water is attributed to oxidation of hydrogen at the anode of the fuel cell. The generated water leaks into the cathode side also, and leads to an increase of the $\mathrm{H}_{2} \mathrm{O}$ signals. 

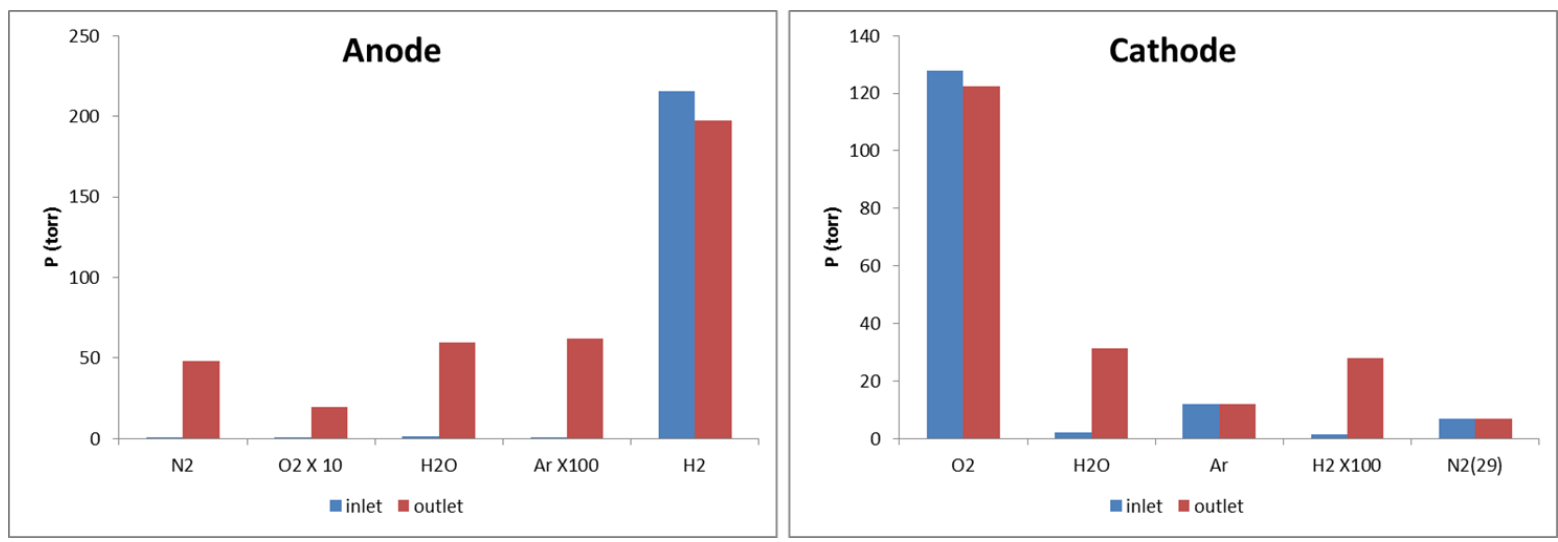

Figure 4.8 Anode with $\mathrm{H}_{2}$ and cathode with air, Cell loaded with $0.7 \mathrm{~V}$ and temperature at $800^{\circ} \mathrm{C}$.

5. $\underline{\mathrm{H}}_{2}$ with $3 \%$ water added in the anode side and air in the cathode side, the cell at open circuit. Selected masses are shown in Figure 4.9. The $\mathrm{N}_{2}$ signal at mass 28 is not shown. Mass 29 signal is chosen to represent the amount of $\mathrm{N}_{2}$ instead. A very high water signal at mass 18 was seen above 90 torr at both in the inlet and exhaust of the anode. The water at the exhaust was still a little higher than the inlet, because of the combustion of $\mathrm{H}_{2}$ with the leaked air. Air leaks are apparent in the anode exhaust $\left(\mathrm{O}_{2}, \mathrm{~N}_{2}, \mathrm{Ar}\right)$ and cathode exhaust $\left(\mathrm{H}_{2}\right)$.
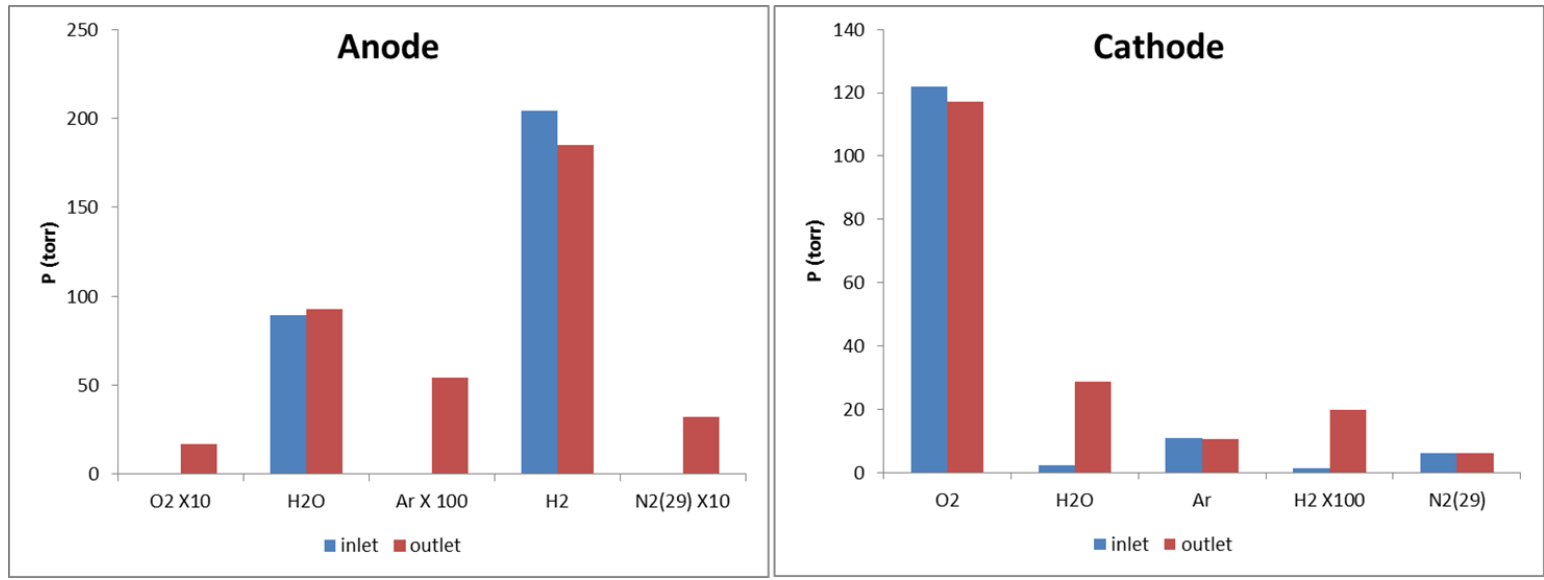

Figure 4.9 Anode with $\mathrm{H}_{2}+3 \% \mathrm{H}_{2} \mathrm{O}$ and cathode with air, cell at $\mathrm{OCV}$ and temperature at $800^{\circ} \mathrm{C}$. 
6. $\underline{\mathrm{H}}_{2}$ with $3 \%$ water added in the anode side and air in the cathode side, the cell voltage loaded at $0.7 \mathrm{~V}$. Selected masses are shown in Figure 4.10. Relative to the results in step 5, the amount of water in the anode exhaust increased slightly to 94 torr. This water increase is due to the additional electrochemical reactions of the cell.

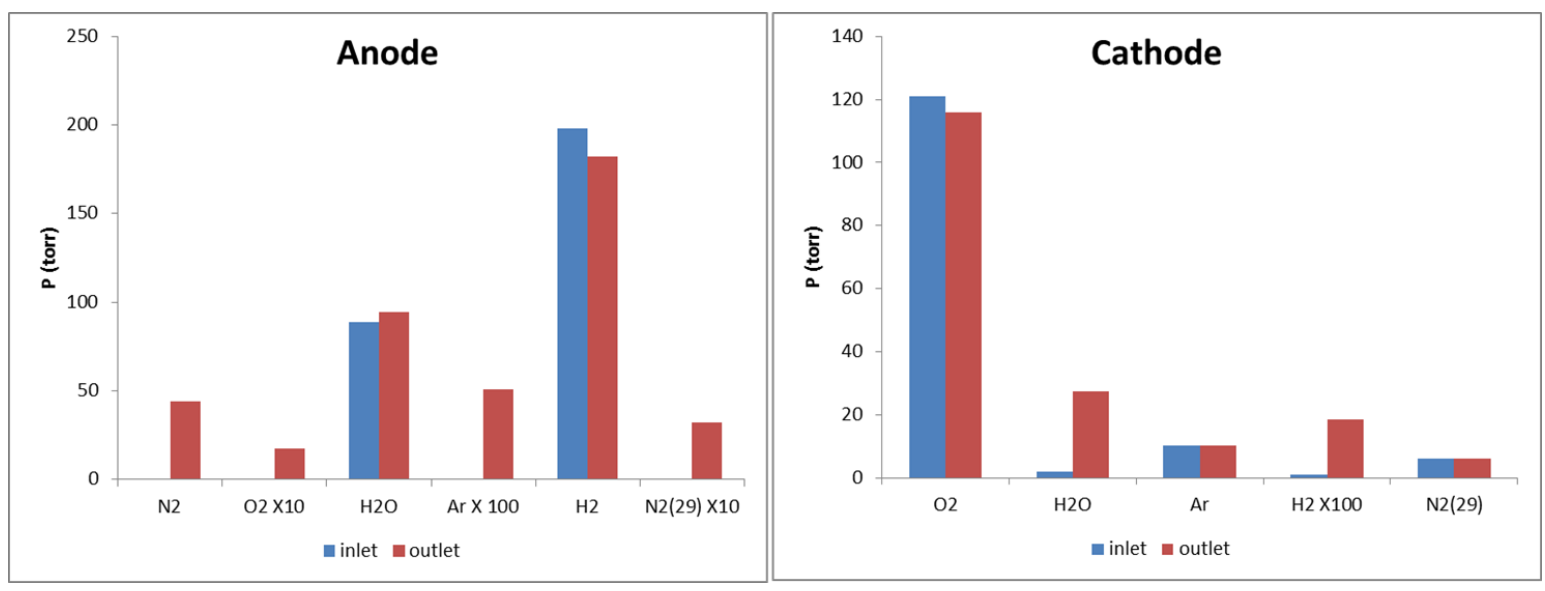

Figure 4.10 Anode with $\mathrm{H}_{2}+3 \% \mathrm{H}_{2} \mathrm{O}$ and cathode with air. Cell loaded with $0.7 \mathrm{~V}$ and temperature at $800^{\circ} \mathrm{C}$.

7. Dry $\mathrm{H}_{2}$ with $10 \mathrm{ppm} \mathrm{PH}_{3}$ added in the anode side and air in the cathode side, the cell at open circuit. Selected masses are shown in Figure 4.11. The $\mathrm{N}_{2}$ signal at mass 28 in the fuel increased because the $\mathrm{PH}_{3}$ stock cylinder is balanced with $\mathrm{N}_{2}$. The difference of mass 28 signals at the anode inlet and exhaust still shows the existence of air leaks. The $\mathrm{PH}_{3}$ signal at mass 34 is seen in the anode inlet, but is very small (down to the noise level) at the anode exhaust. The $\mathrm{PH}_{3}$ was present in the fuel gas stream, but was not detected after the fuel stream passed the fuel cell in the hot zone of the furnace. There was also a transient behavior observed in the inlet stream for the $\mathrm{PH}_{3}$ signal at mass 34 shown in Figure 4.12. The mass 34 signal was dominated by the oxygen isotopes in the first few hours. Then the $\mathrm{PH}_{3}$ started to increase slowly. After about 5 hours, the mass 34 signal reached a stable value of about 0.02 torr. This slow increase was due to the slow flow (1 


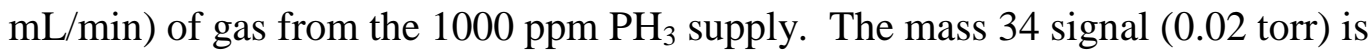
approximately three times higher than the expected signal for a gas pressure of $10 \mathrm{ppm}$ (0.008 torr).
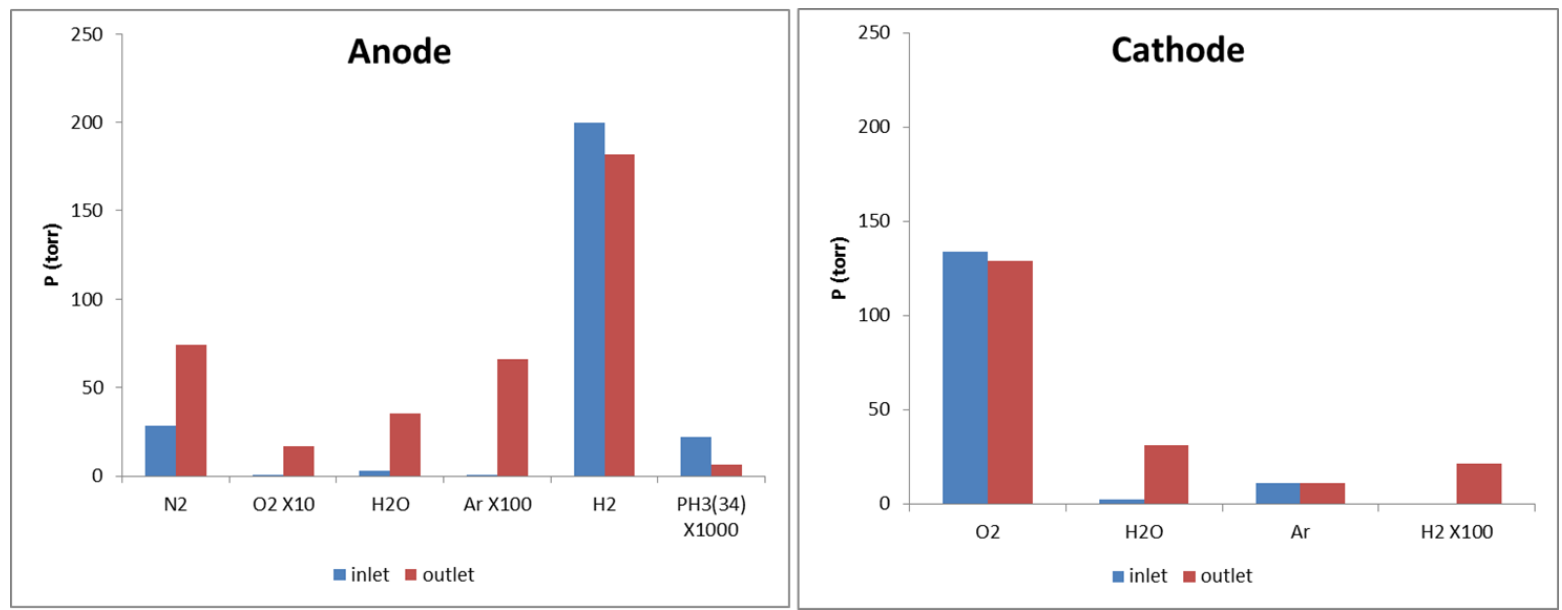

Figure 4.11 Anode with $\mathrm{H}_{2}+10 \mathrm{ppm} \mathrm{PH}_{3}$ and cathode with air. Cell at $\mathrm{OCV}$ and temperature at $800^{\circ} \mathrm{C}$.

\section{Mass 34}

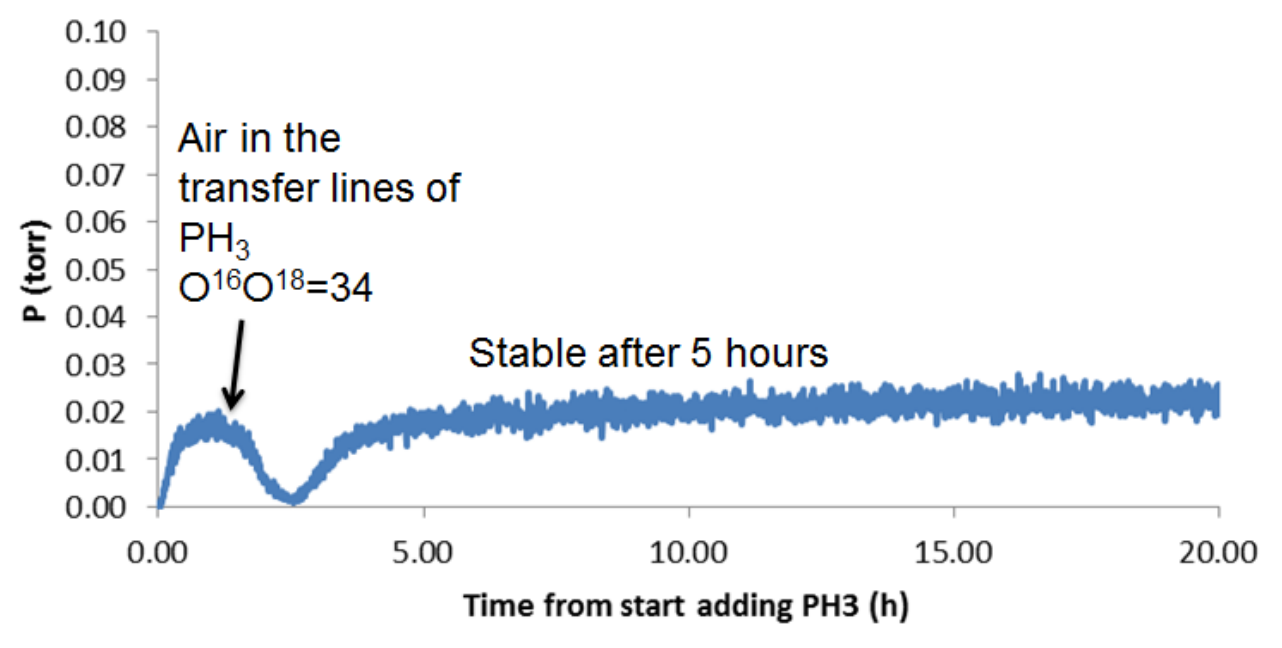

Figure 4.12 Transient behavior of $\mathrm{PH}_{3}$ signal at the anode inlet. The cell was operating at $800^{\circ} \mathrm{C}$. 
8. $\underline{\text { Dry }}_{2}$ with $10 \mathrm{ppm} \mathrm{PH}_{3}$ added in the anode side and air in the cathode side, the cell voltage at $0.7 \mathrm{~V}$. Selected masses are shown in Figure 4.13. Comparing these results to the results in step 7, the water signal at the anode exhaust was very high at about 98 torr, much higher than the test of "dry" $\mathrm{H}_{2}$ with $0.7 \mathrm{~V}$ cell voltage (60 torr in step 4$)$. The reason for the discrepancy is due to the calibration change. The amount of $\mathrm{PH}_{3}$ detected at the anode inlet and outlet was roughly the same as in step 7, meaning the current change did not have a significant effect of the amount of $\mathrm{PH}_{3}$.
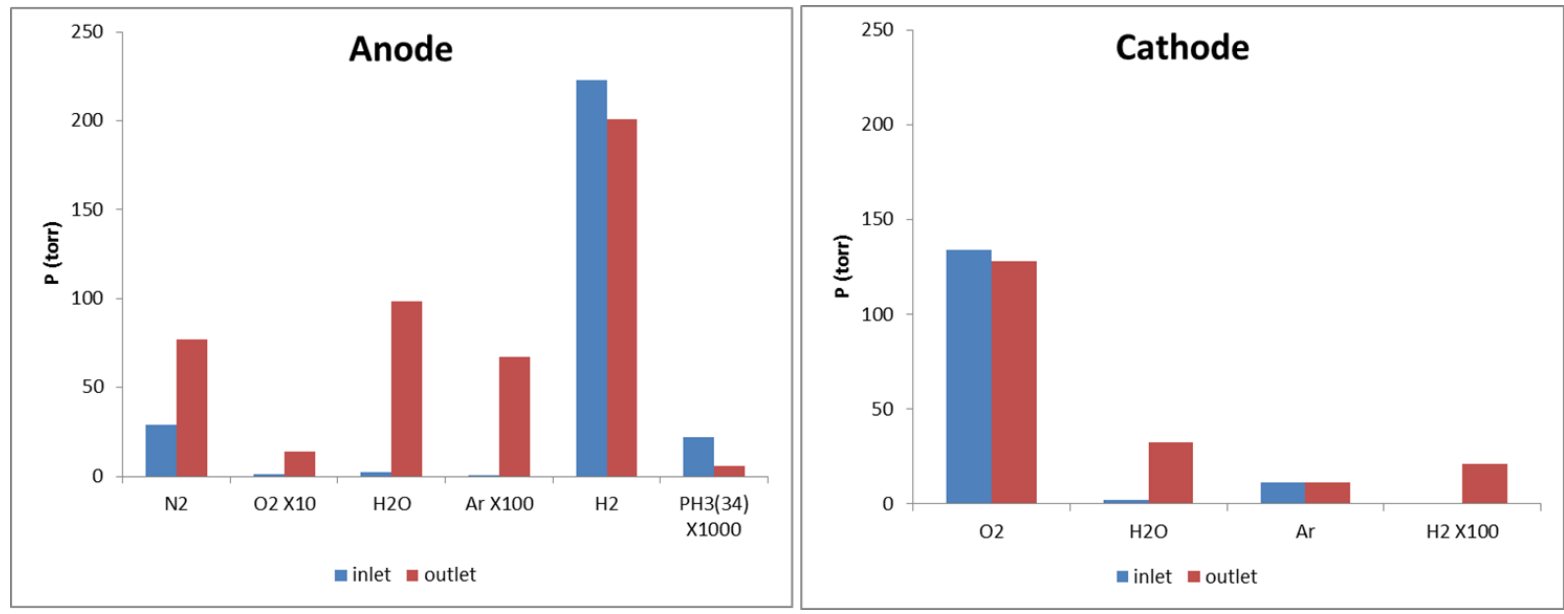

Figure 4.13 Anode with $\mathrm{H}_{2}+10 \mathrm{ppm} \mathrm{PH}_{3}$ and cathode with air. Cell voltage was at $0.7 \mathrm{~V}$ and temperature at $800^{\circ} \mathrm{C}$.

The cell test was terminated after 6 days of exposure the anode to $10 \mathrm{ppm}$ of $\mathrm{PH}_{3}$. However, there was no significant degradation of cell performance. The cell was kept at constant $0.7 \mathrm{~V}$ cell voltage. The beginning current was $192 \mathrm{~mA}$ and after 6 days, the current was $190 \mathrm{~mA}$.

There were no signals of masses greater than $44\left(\mathrm{CO}_{2}\right)$ detected in the outlet during the test. In particular, there were no increases in the signals at mass 48 (HPO), mass 64 $\left(\mathrm{HPO}_{2}\right)$ or mass $80\left(\mathrm{HPO}_{3}\right)$. The $\mathrm{PH}_{3}$ added may have quantitatively reacted to form non- 
volatile products, or products with mass larger than 100, or the $\mathrm{PH}_{3}$ was strongly

adsorbed onto the inner surfaces of the system. The cell was removed from the test platform after operation. There was a new shiny metallic new layer of material formed on top of the anode surface seen by visual examination of the cell. It is suspected that this new layer is from nickel phosphides formed during the exposure of the cell to trace level of $\mathrm{PH}_{3}$. This has been documented many times in the literature. [3-5]

\subsection{Conclusions and discussions.}

Despite the careful bonding of the gold o-ring to the electrolyte, the cell leaked between the anode and cathode sides. Gases transferred in both directions across the oring seal. $\mathrm{H}_{2}$ reacted with air to form water in both the anode and cathode exhausts. When the current was turned on, the water signal at mass 18 increased quickly in less than 5 minutes. For a current of $190 \mathrm{~mA}$, only 10 torr of water generated by the cell is expected by the calculation. However, the change of pressures of water was more than 30 torr, in some cases about 60 torr. This may due to the fact that the calibration coefficient of water in the Cirrus unit is different from the mass used for calibration. $\mathrm{PH}_{3}$ at $10 \mathrm{ppm}$ level was detectable at the gas inlet, but was not seen at the exhaust. The change of current did not affect the detected $\mathrm{PH}_{3}$ partial pressures.

Due to safety regulation changes, the cell testing in WVU MAE had to be terminated. The Probostat testing platform and the mass spectrometer were moved to the Chemistry Research Laboratory. Later tests were carried out in WVU Chemistry. 


\section{References in Chapter 4}

[1] Probostate ${ }^{\mathrm{TM}}$ User's Manual, NorECs Norwegian Electro Ceramics AS.

[2] Probostate ${ }^{\mathrm{TM}}$ Sample holder cell system for electrical and other characterization at high temperatures and under controlled atmospheres, NorECs Norwegian Electro Ceramics AS.

[3] Chunchuan Xu, J. Zondlo, H. O. Finklea, O. Demircan, M. Gong, X. Liu Journal of Power Sources 2009, 193, 739-746

[4] Mingjia Zhi, Xinqi Chen, Harry Finklea, Ismail Celik, Nianqiang Q.Wu Journal of Power Sources 2008, 183, 485-490

[5] O. Demircan, W. Zhang, C. Xu, J. Zondlo, H. Finklea, Journal of Power Sources

2010, 195, 3091-3096 


\section{Chapter 5 Study of Reactions of $\mathrm{PH}_{3}, \mathrm{H}_{2} \mathrm{O}$ and $\mathrm{Ni} / \mathrm{YSZ}$ at high \\ temperatures.}

\subsection{Gas-phase composition study with a tube furnace configuration.}

\subsubsection{Experimental set up.}

In order to understand the possible reactions of $\mathrm{PH}_{3}$ in the fuel stream in the absence of the fuel cell, a tube furnace with a ceramic tube was employed. The tube furnace configuration is illustrated in Figure 5.1. The temperature was programmed to heat at a linear rate from room temperature to $800^{\circ} \mathrm{C}$, to hold at that temperature for several hours, and then to cool to room temperature at a linear rate. The mass spectrometer could be hooked up at the inlet or exhaust to monitor any change of gas phase compositions. This test was carried out in the WVU Chemistry Department.

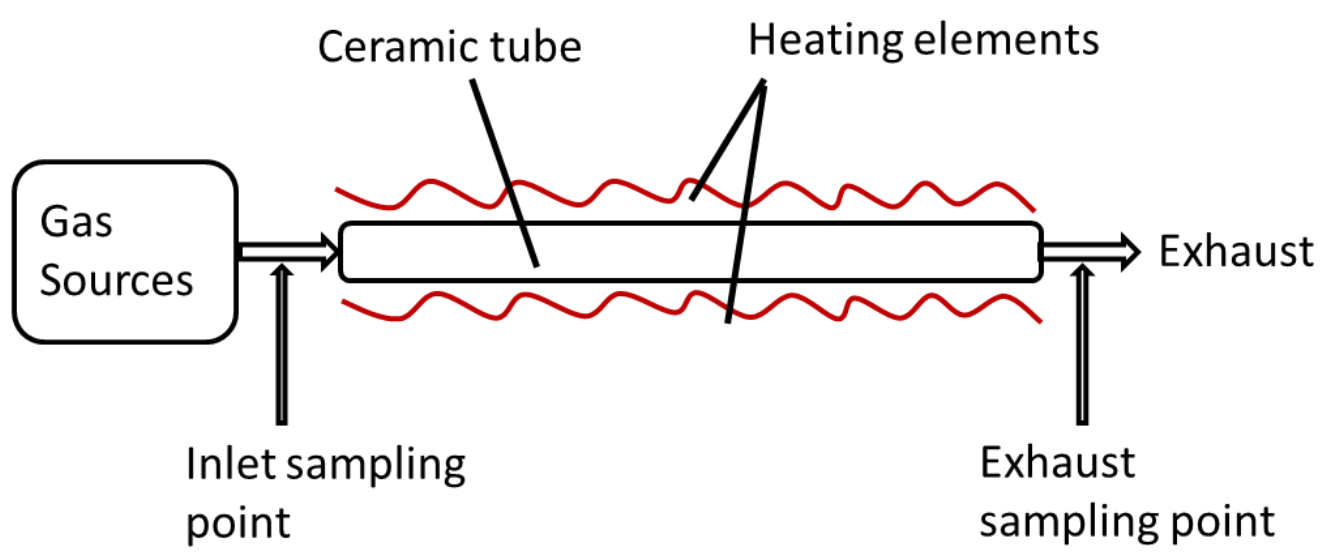

Figure 5.1 Diagram of tube furnace configuration for testing possible $\mathrm{PH}_{3}$ reactions. 
A gas manifold was built to handle the gas supplies. An illustration of the gas handling system is in Figure 5.2. A typical flow rate was $100 \mathrm{sccm}$. The $\mathrm{PH}_{3}$ stock cylinder was 40 ppm balanced with $\mathrm{H}_{2}$.

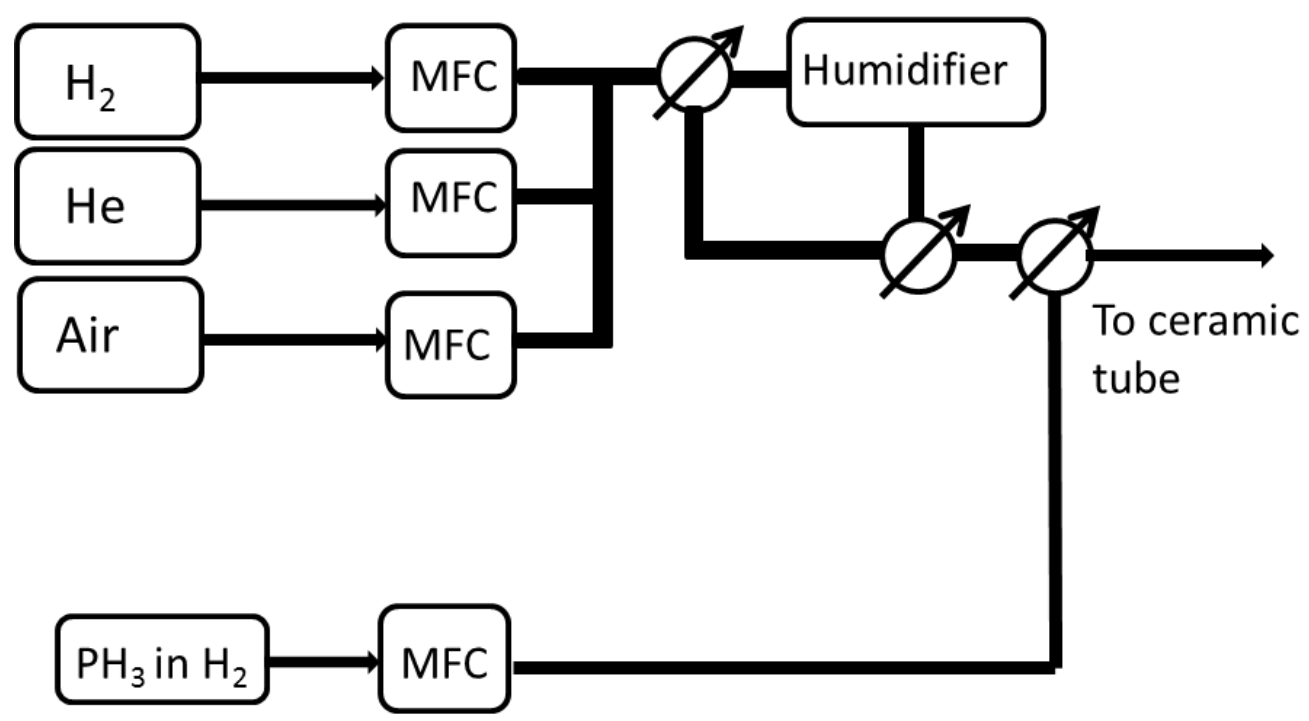

Figure 5.2 Gas manifold used in the gas phase tests.

\subsubsection{Gas purity check and calibration curves}

The $\mathrm{H}_{2}$ and $\mathrm{He}$ used in this section were ultra-high purity grade. The compressed air was breathing grade. The $40 \mathrm{ppm}( \pm 10 \%)$ of $\mathrm{PH}_{3}$ in $\mathrm{H}_{2}$ balance was custom made by Air-Liquid Company and it was claimed to be industrial grade (lower than UHP). The purity of $\mathrm{H}_{2}$, He and $\mathrm{PH}_{3}$ from the cylinders was checked using the mass spectrometer. Calibration curves of $\mathrm{H}_{2}$ in $\mathrm{He}$ up to 1 atm and ppm levels of $\mathrm{PH}_{3}$ in $\mathrm{H}_{2}$ were generated. In these tests, the mass spectrometer was connected to the sampling point right after the mass flow controllers to minimize any leaks in the transfer lines.

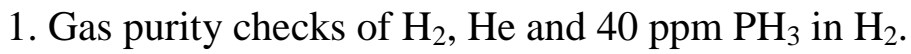


The $\mathrm{H}_{2}$ cylinder was connected to the mass flow controller and the mass spectrometer was connected to the port nearest to the mass flow controller. $\mathrm{H}_{2}$ flow was turned on at $100 \mathrm{sccm}$ for several hours to purge the air and water vapor in the transfer lines. The partial pressures reading from the RGA of the major impurities are: $\mathrm{H}_{2} \mathrm{O}$ at 1.5 torr, $\mathrm{N}_{2}$ at 0.17 torr and $\mathrm{O}_{2}$ at 0.03 torr. The purity of He was checked using the same method. The major impurities in UHP grade $\mathrm{He}$ are: $\mathrm{H}_{2} \mathrm{O}$ at 0.22 torr, $\mathrm{N}_{2}$ at 0.13 torr and $\mathrm{O}_{2}$ at 0.05 torr. The $40 \mathrm{ppm} \mathrm{PH}_{3}$ in $\mathrm{H}_{2}$ was checked at a flow rate of $200 \mathrm{sccm}$. The major impurities are: $\mathrm{H}_{2} \mathrm{O}$ at 2.75 torr, $\mathrm{N}_{2}$ at 0.47 torr and $\mathrm{O}_{2}$ at 0.19 torr. The partial pressure of $\mathrm{PH}_{3}$ in the 40 ppm cylinder is 0.123 torr at mass 34 . As noted in the preceding chapter, the measured partial pressure of $\mathrm{PH}_{3}$ is substantially higher than the actual partial pressure (40 ppm $=0.03$ torr) A summary of the impurities in different gases are listed in Table 5.1 .

Table 5.1 Major impurities in the gas cylinders.

\begin{tabular}{cccc}
\hline & \multicolumn{3}{c}{ Partial Pressure of Impurities (torr) } \\
Gras Cylinder \\
\cline { 2 - 4 } and Content & $\mathrm{H}_{2} \mathrm{O}$ & $\mathrm{N}_{2}$ & $\mathrm{O}_{2}$ \\
\hline UHP H & 1.5 & 0.17 & 0.03 \\
UHP He & 0.22 & 0.13 & 0.05 \\
$\begin{array}{c}\text { Industrial 40 ppm } \\
\mathbf{P H}_{\mathbf{3}} \text { in } \mathbf{H}_{2}\end{array}$ & 2.75 & & 0.19 \\
\hline
\end{tabular}

\section{Calibration curves.}

Calibration curves of $\mathrm{H}_{2}$ are generated both for dry and wet conditions by varying the $\mathrm{H}_{2}$ flow rate with a fixed $100 \mathrm{sccm} \mathrm{He}$ as balance. The Faraday cup detector was used for 
this study. In Figure 5.3, the partial pressure of the dry $\mathrm{H}_{2}$ reading at mass 2 is plotted versus the calculated pressure of $\mathrm{H}_{2}$ in He based on the pre-set flow rates. The curve is approximately linear over the entire range of pressures but with a noticeable positive deviation at the higher pressures. A linear regression fit of all data points yields a slope of $1.22(+/-0.05)$ and an intercept of $-35(+/-14)$ torr. The corresponding fit to the lowest three pressures yields a slope of $1.01(+/-0.03)$ and an intercept of $-7(+/-4)$ torr. The wet $\mathrm{H}_{2}$ (10 torr water) calibration curve and linear fits shown in Figure 5.4 are similar. Linear regression slopes and intercepts are $1.14(+/-0.03)$ and $-23(+/-8)$ torr for all data points and $0.99(+/-0.01)$ and $-4(+/-2)$ torr for the lowest three pressures. The positive deviations at higher pressures are attributed to changing viscosities of the gas blends. A higher hydrogen content lowers the viscosity and increases the mass flow through the capillary to the ionization chamber.

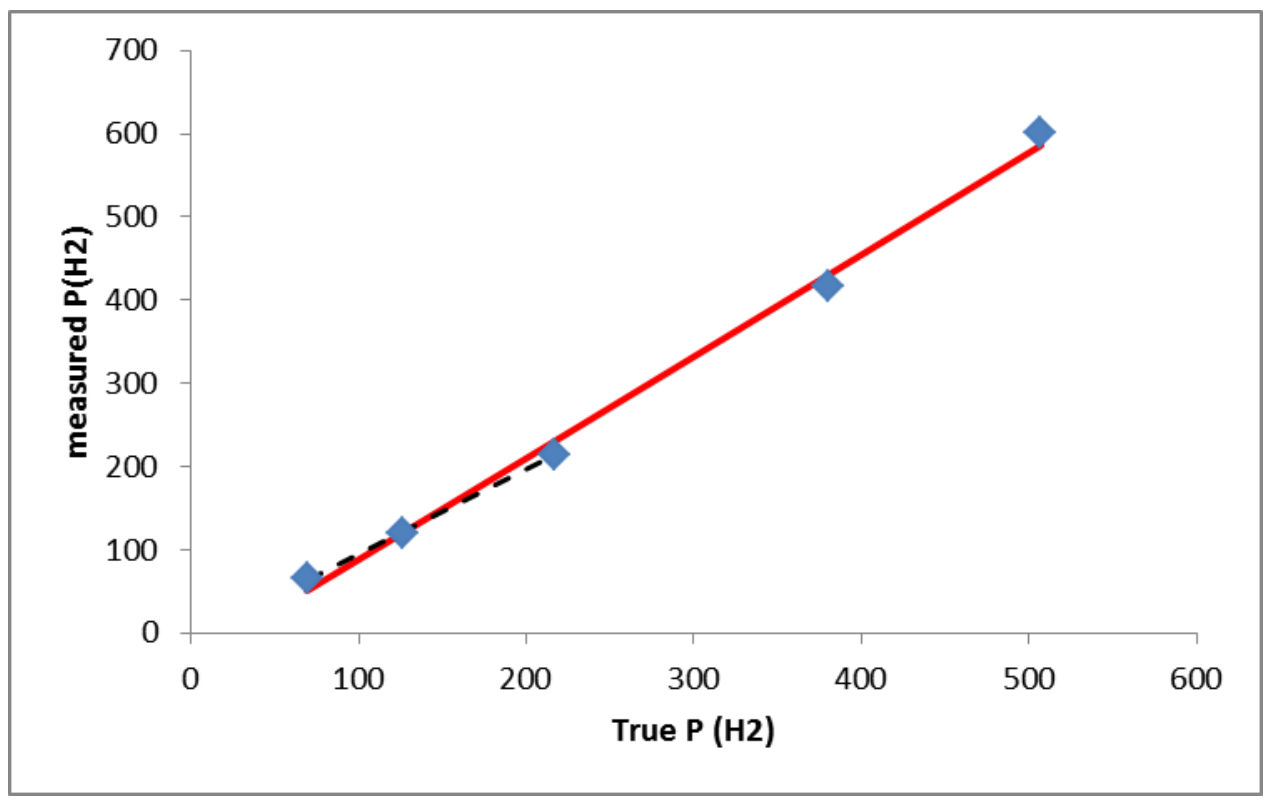


Figure 5.3 Calibration curve for dry $\mathrm{H}_{2}$ in He. Symbols: measured $\mathrm{P}\left(\mathrm{H}_{2}\right)$; solid line: linear regression fit to all data points; dashed line: linear regression fit to the lowest three pressures.

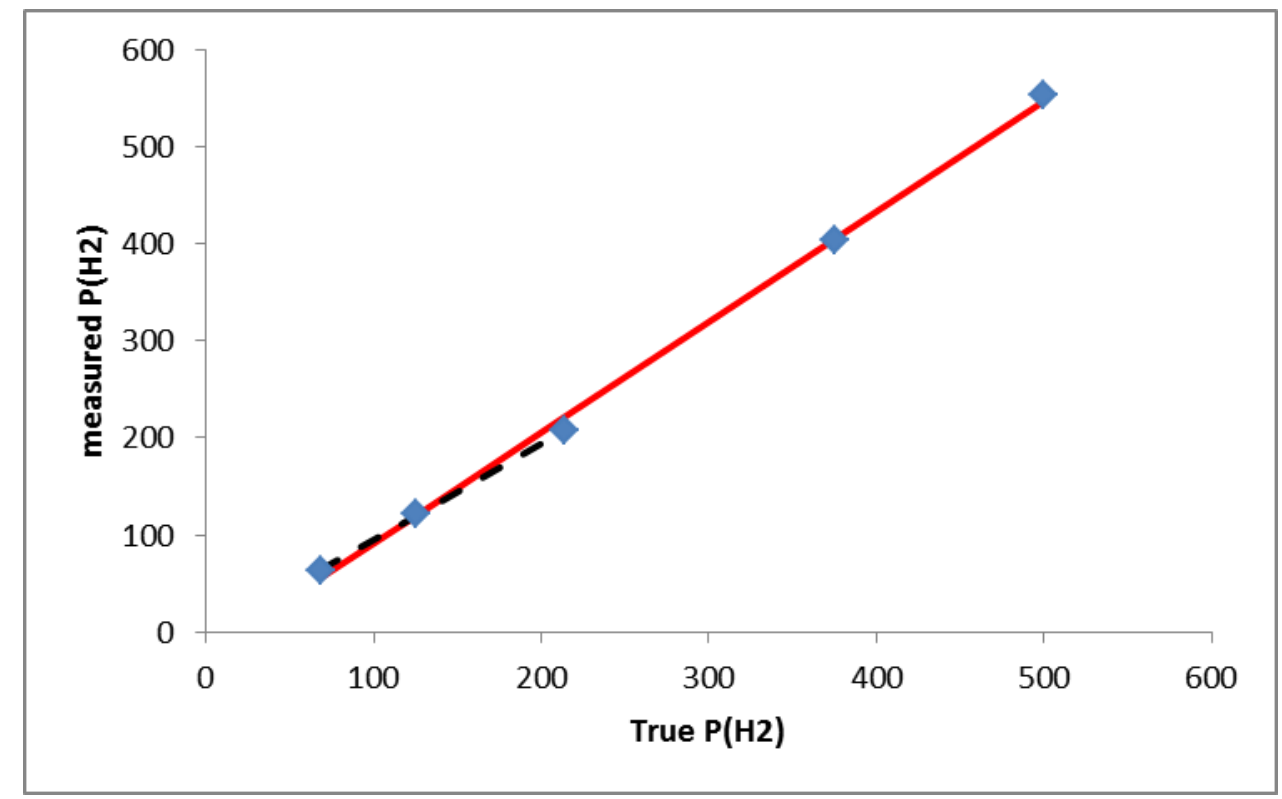

Figure 5.4 Calibration curve for wet $\mathrm{H}_{2}$ in helium. Symbols: measured $\mathrm{P}\left(\mathrm{H}_{2}\right)$; solid line: linear regression fit to all data points; dashed line: linear regression fit to the lowest three pressures.

The calibration curve of $\mathrm{PH}_{3}$ was generated using nominal concentrations of $0,10,20$ and $40 \mathrm{ppm}$. The reading at mass 34 was determined at each concentration using the electron multiplier. The curve is shown in Figure 5.5 with a linear regression fit. In mixed units, the slope is $0.00325(+/-0.00014)$ torr/ppm and the intercept is $-0.012(+/-0.004)$ torr. Conversion of ppm to torr yields a slope of 4.3(+/-0.2), Again, the measured pressure is substantially higher than the actual pressure. All the calibration curves generated confirmed the linear behavior of the mass spectrometry method from the ppm level up to $1 \mathrm{~atm}$. However, the values are relative but not absolute. 


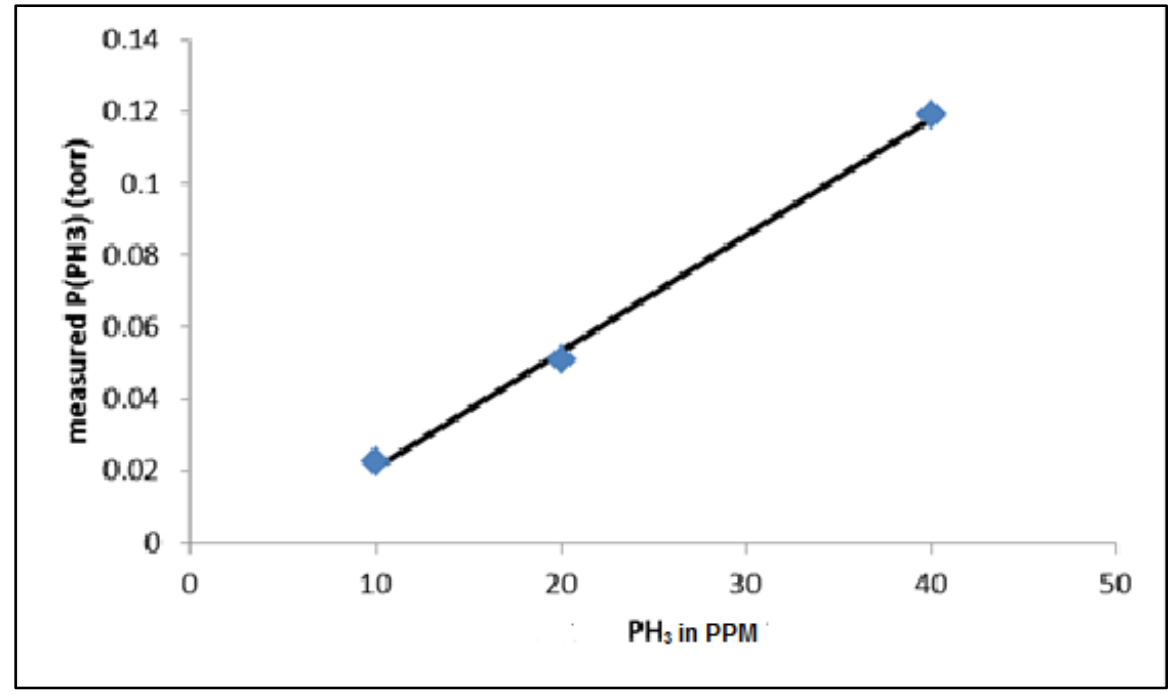

Figure 5.5 Calibration curve and linear regression fit of $\mathrm{PH}_{3}$ in hydrogen. Symbols: measured pressures; line: linear regression fit to all data points.

\subsubsection{Blank gas tests (No cell)}

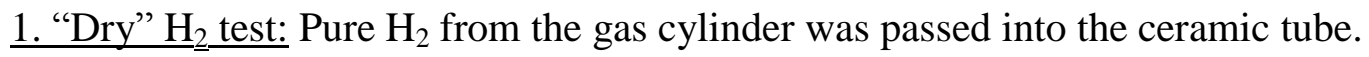
The furnace was kept at room temperature for 2 hours. Then the temperature was ramped up to $800^{\circ} \mathrm{C}$ at a linear rate over 8 hours, held at $800^{\circ} \mathrm{C}$ for 4 hours, and then cooled to room temperature at a linear rate over 8 hours. Figure 5.6 is an overview of gas profile of mass $18\left(\mathrm{H}_{2} \mathrm{O}\right), 28\left(\mathrm{~N}_{2}\right)$ and $32\left(\mathrm{O}_{2}\right)$. The $\mathrm{H}_{2} \mathrm{O}$ pressure (mass 18) increased slightly during heating and then dropped to its lowest level during cooling. Nitrogen pressures (mass 28) show a linear change with temperature. The cause for this linear change is not known since it is not observed for the Probostat tests (see below). However, it is a convenient temperature gauge in this plot. Oxygen pressures (mass 32) drop during the 
heating phase at temperatures above $400^{\circ} \mathrm{C}$ to 0.15 torr (Figure 5.7) and rise again during the cooling phase.

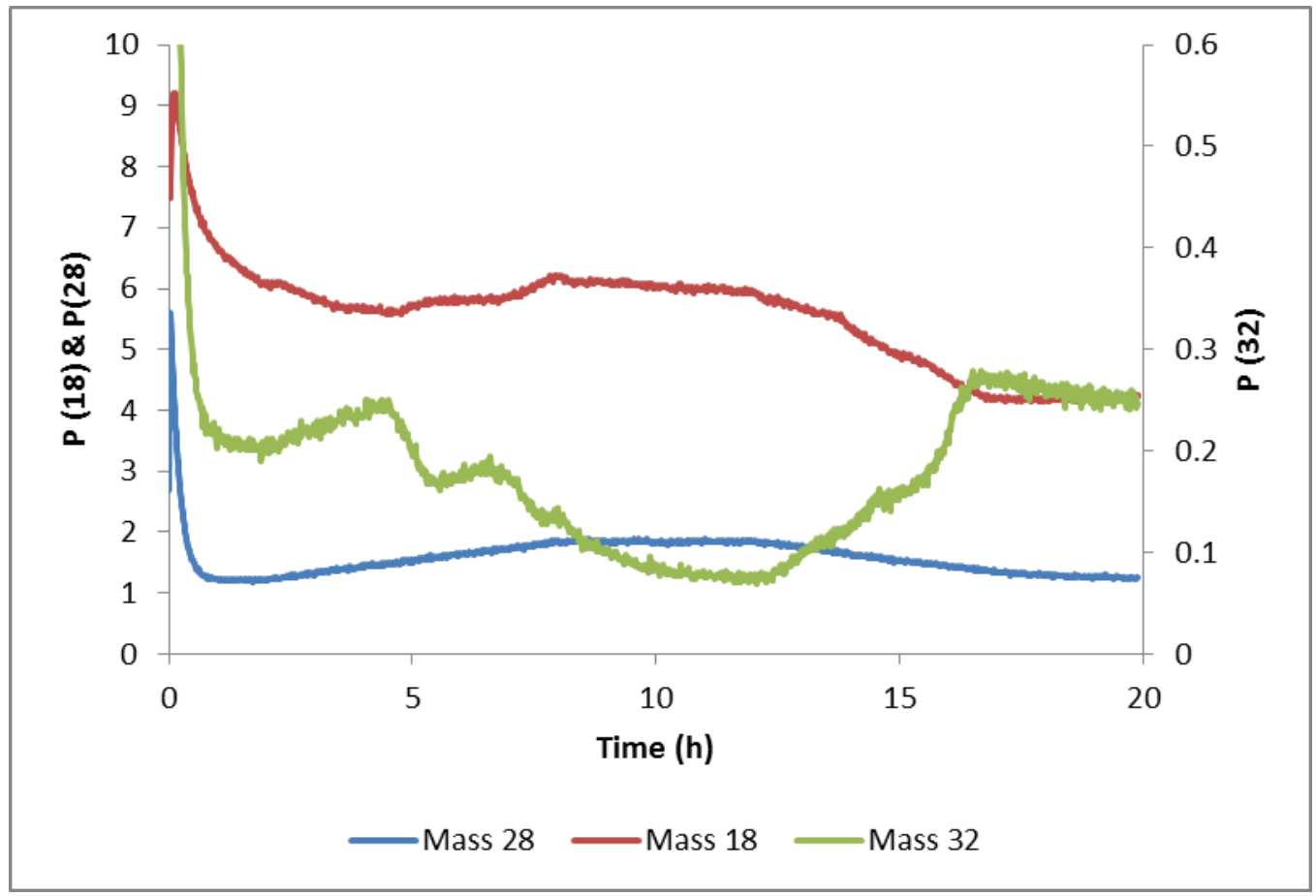

Figure 5.6 "Dry" $\mathrm{H}_{2}$ blank test gas pressures vs time.

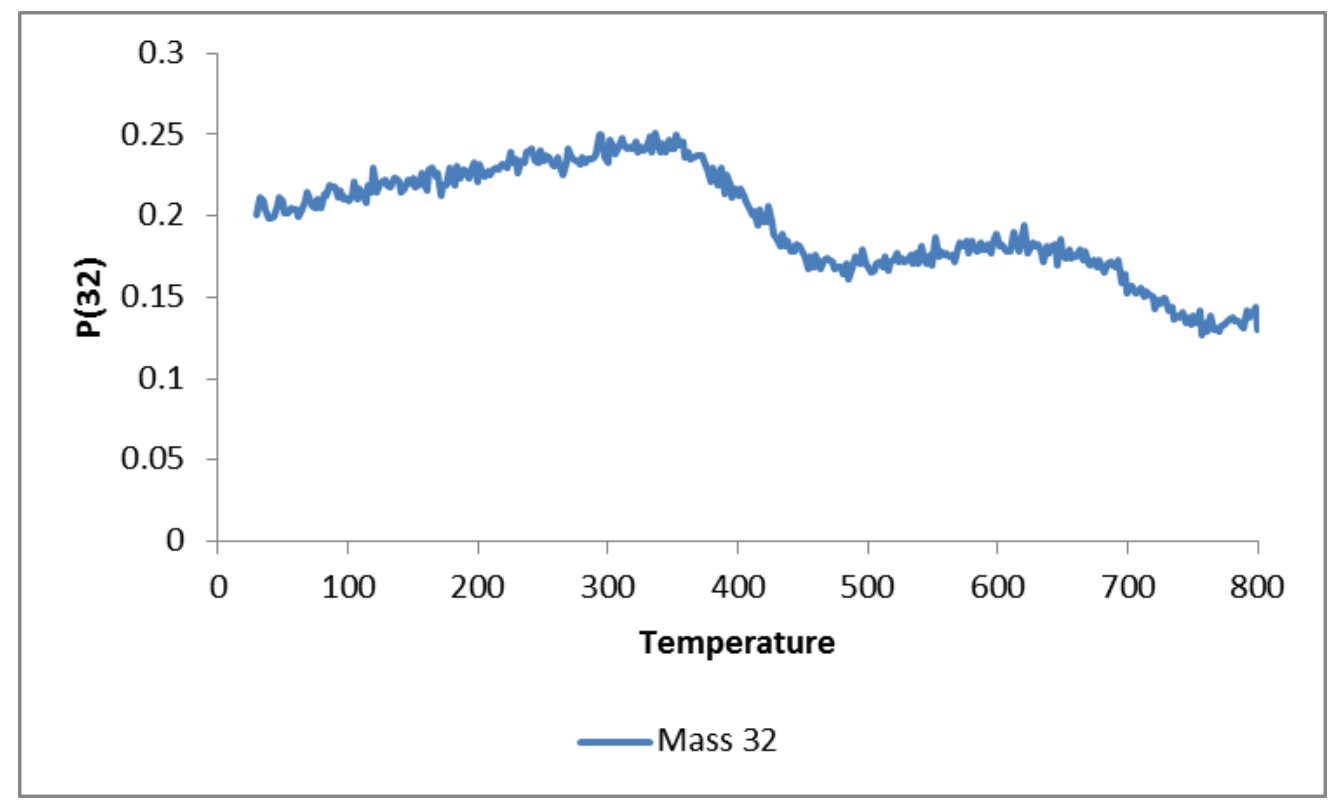

Figure 5.7 Oxygen (mass 32) vs temperature during the heating phase in "dry" $\mathrm{H}_{2}$. 
From this test, it can be said that the sealing of the tube furnace configuration is acceptable with impurities below 5 torr and the ${ }^{18} \mathrm{O}$ isotope will not interfere with the detection of $\mathrm{PH}_{3}$ at mass 34. The $\mathrm{N}_{2}$ signal is below 2 torr. There is some $\mathrm{O}_{2}$ in the system, about 0.3 torr at room temperature. The decrease of $\mathrm{O}_{2}$ at higher temperatures is due to the auto-ignition with the major component $\mathrm{H}_{2}$. However, there is still a small amount of $\mathrm{O}_{2}$ even at $800^{\circ} \mathrm{C}$. One hypothesis is that the $\mathrm{O}_{2}$ may be the fraction that did not combust. However, the combustion reaction of $\mathrm{H}_{2}$ with $\mathrm{O}_{2}$ is very fast at $800^{\circ} \mathrm{C}$. The equilibrium partial pressure of $\mathrm{O}_{2}$ in pure $\mathrm{H}_{2}$ is in the order of $10^{-11}$ torr. Another source of the $\mathrm{O}_{2}$ is small leaks in the fittings around the ceramic tube after the heated zone and the place that the sampling capillary enters the mass spectrometer. The slight increase of $\mathrm{H}_{2} \mathrm{O}$ signals also confirms the reaction of $\mathrm{H}_{2}$ and the residual $\mathrm{O}_{2}$. The "dry" $\mathrm{H}_{2}$ test sets a baseline of gas compositions for the next experiments.

2. "Wet" $\mathrm{H}_{2}$ test: Pure $\mathrm{H}_{2}$ from the gas cylinder was first passed through the humidifier, generating a gas stream with about 20 torr of $\mathrm{H}_{2} \mathrm{O}$. The furnace was kept at room temperature for 4 hours, then was ramped up to $800^{\circ} \mathrm{C}$, held at $800^{\circ} \mathrm{C}$ for 4 hours, and then cooled down in 6 hours. An overview of gas compositions versus time is in Figure 5.8.

Except for a blip at the beginning of the heating step, $\mathrm{H}_{2} \mathrm{O}$ pressures (mass 18) remain at around 130-140 torr, which is much higher than expected due to the different calibration coefficients. Again, nitrogen pressures (mass 28) show a linear change with temperature. 


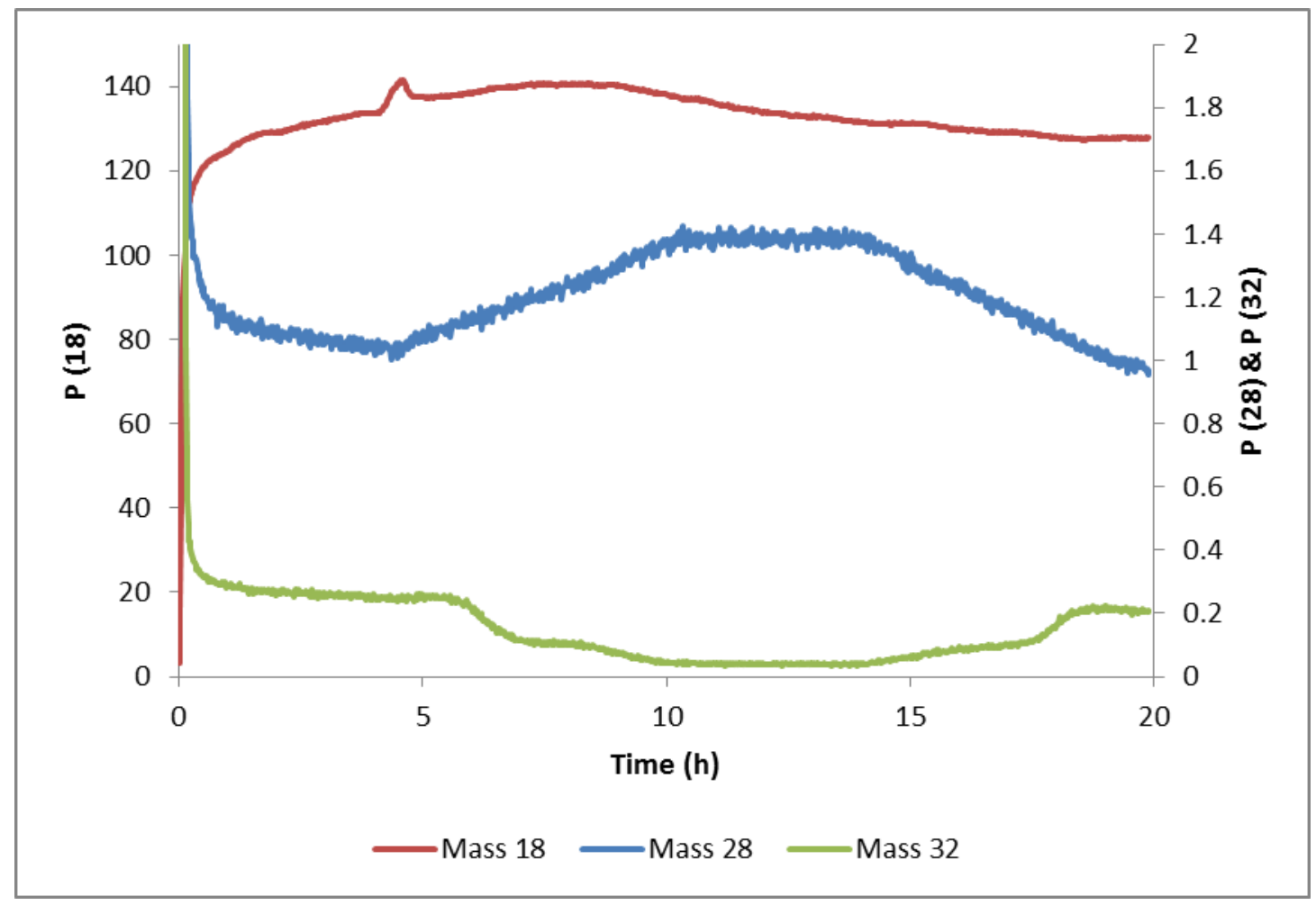

Figure 5.8 “Wet” $\mathrm{H}_{2}$ blank test gas pressures vs time.

Oxygen pressures (mass 32) drop during the heating phase and rise again during the cooling phase. The auto-ignition appears to start around $300^{\circ} \mathrm{C}$ in this case (Figure 5.9). Surprisingly, the oxygen signal remains at about 0.1 torr even at $800^{\circ} \mathrm{C}$. The oxygen in the "wet" $\mathrm{H}_{2}$ test is lower than in the "dry" test because it is partially displaced by the water vapor. 


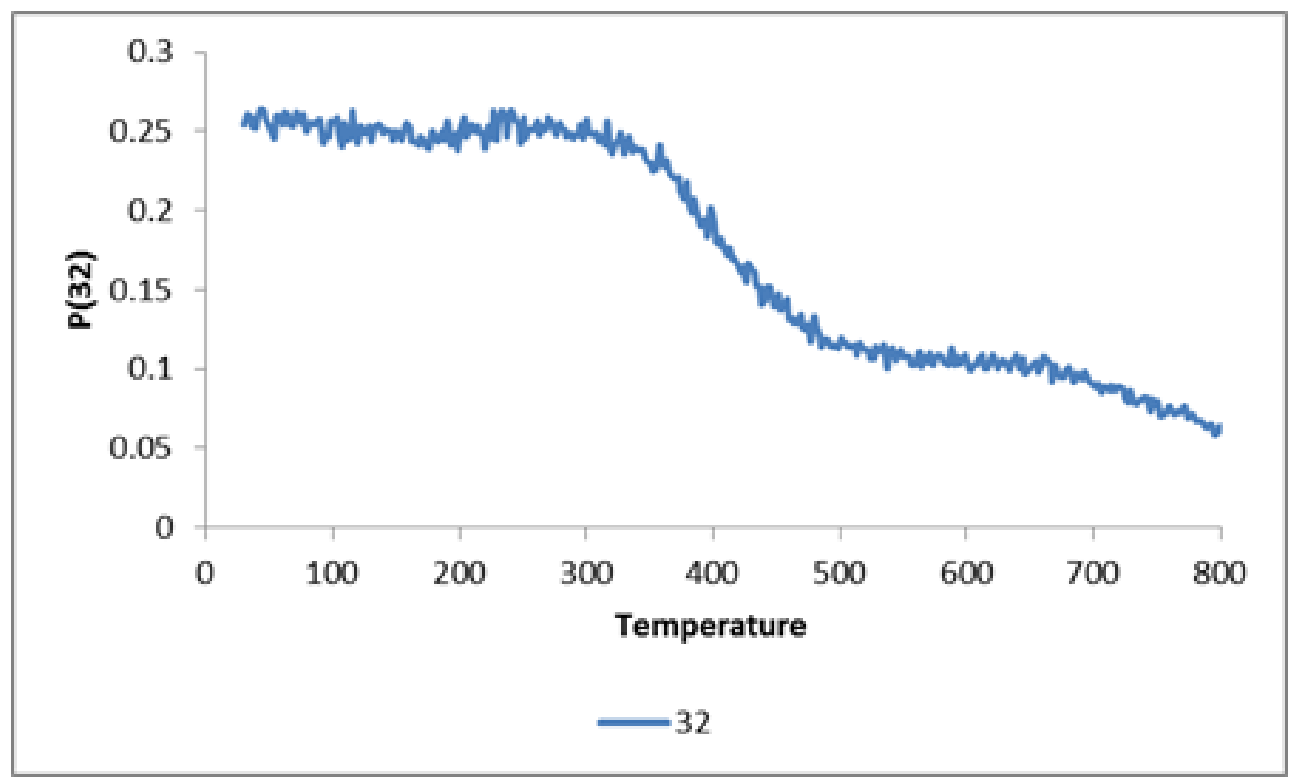

Figure 5.9 Oxygen (mass 32) pressure vs temperature during heating phase in the "wet" $\mathrm{H}_{2}$ test.

In comparison to the "dry" $\mathrm{H}_{2}$ test, the major gas compositions are similar except the $\mathrm{H}_{2} \mathrm{O}$ signal. The water content detected is much higher than the calculated value ( 120 torr vs 20 torr).

$\underline{\text { 3. "Dry" } \mathrm{H}_{2}} \underline{\text { with } 20 \mathrm{ppm} \mathrm{PH}_{3}} \underline{\text { test: }}$ The pure $\mathrm{H}_{2}$ was $1: 1$ blended with stock 40 ppm $\mathrm{PH}_{3}$ in $\mathrm{H}_{2}$, making the actual concentration of $\mathrm{PH}_{3} 20 \mathrm{ppm}$. The furnace was held at room temperature for 2 hours, then was ramped up to $800^{\circ} \mathrm{C}$ in 12 hours, held at $800^{\circ} \mathrm{C}$ for 10 hours, and then cooled to room temperature over 12 hours.

An overview of the major gases is shown in Figure 5.10. Water (mass 18 in Figure 5.11) shows a continuous decrease in signal, particularly during the cooling phase. The signal for nitrogen (mass 28 ) tracks the furnace temperature, again. The phosphine (mass 34) shows two dips during the heating and cooling of the furnace. 


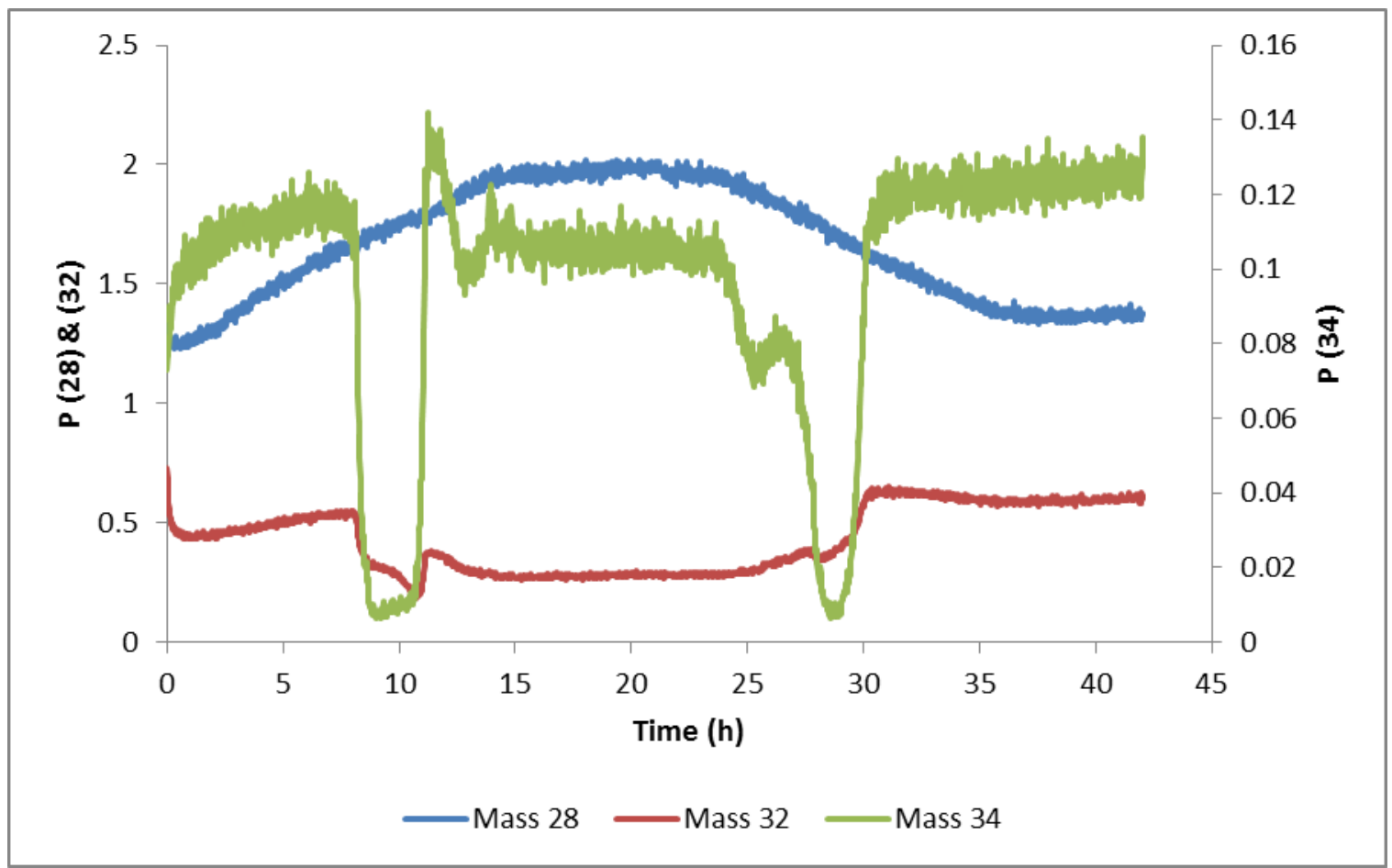

Figure 5.10 “Dry” $\mathrm{H}_{2}+20 \mathrm{ppm} \mathrm{PH}_{3}$ test gas pressures vs time.

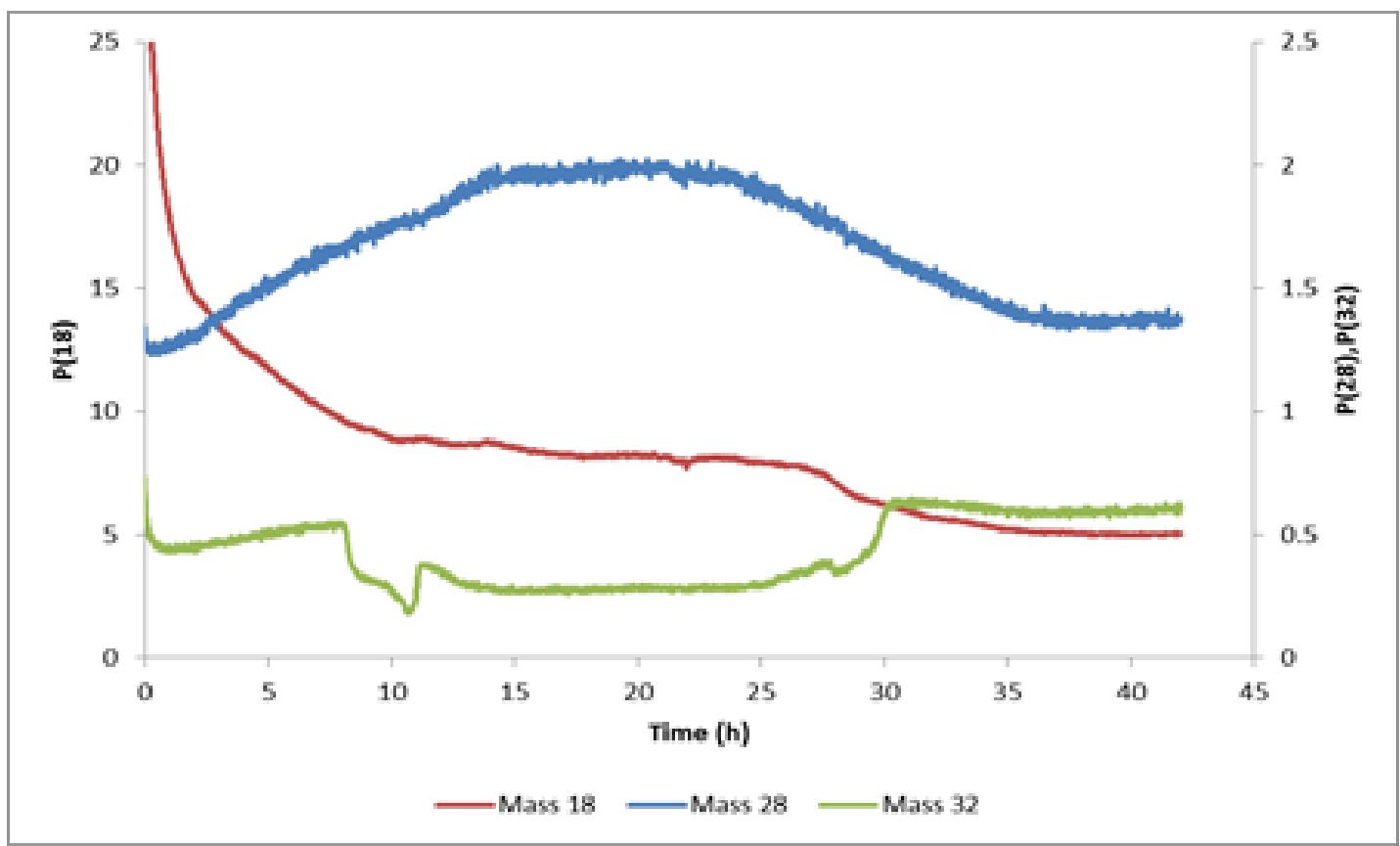

Figure 5.11 $\mathrm{H}_{2} \mathrm{O}, \mathrm{N}_{2}$ and $\mathrm{O}_{2}$ signals in "Dry" $\mathrm{H}_{2}+20$ ppm $\mathrm{PH}_{3}$ test pressures vs time. 
During heating in Figure 5.12, the $\mathrm{PH}_{3}$ signal at mass 34 remains nearly constant until about $400^{\circ} \mathrm{C}$. It drops abruptly from 0.12 torr to 0.008 torr, and then rises abruptly back to 0.12 torr just above $600^{\circ} \mathrm{C}$. The $\mathrm{O}_{2}$ signal at mass 32 also drops abruptly at $400^{\circ} \mathrm{C}$, and then rises at $600^{\circ} \mathrm{C}$. The contributions of $\mathrm{PH}_{3}$ at mass 32 are believed to be minor. The signal for PH at mass 32 is probably in the order of 0.03 torr. Consequently, the loss of $\mathrm{PH}_{3}$ at $400-600^{\circ} \mathrm{C}$ is probably due to reaction of $\mathrm{PH}_{3}$ with $\mathrm{O}_{2}$. There are no visible fluctuations in the $\mathrm{H}_{2} \mathrm{O}$ signal (mass 18 in Figure 5.11); however, $\mathrm{H}_{2} \mathrm{O}$ has a much higher concentration ( $\sim 10$ torr apparent signal, $\sim 1$ torr true pressure) because of the different calibration coefficient. The reaction of $\mathrm{PH}_{3}$ and oxygen at $400^{\circ} \mathrm{C}$ is not surprising. Possible products are $\mathrm{HPO}, \mathrm{HPO}_{2}, \mathrm{HPO}_{3}, \mathrm{H}_{3} \mathrm{PO}_{4}$ or $\mathrm{P}_{4} \mathrm{O}_{10}$. Only $\mathrm{HPO}$ (mass 48), $\mathrm{HPO}_{2}$ (mass 64) and mass $\mathrm{HPO}_{3}$ (mass 80) are in the mass range of the mass spectrometer, and there are no visible signals at these masses. The biggest surprise is the reappearance of the mass 34 signal at $600^{\circ} \mathrm{C}$. A hypothesis is that the product that is formed between 400 and $600^{\circ} \mathrm{C}$ is thermally unstable above $600^{\circ} \mathrm{C}$ and consequently $\mathrm{PH}_{3}$ is regenerated. Additional support for this hypothesis is provided by the cooling curve data plotted in Figure 5.13, which shows the same pattern in reverse. The reaction of $\mathrm{PH}_{3}$ may have a negative change of Gibbs free energy below $600^{\circ} \mathrm{C}$ and a positive change above $600^{\circ} \mathrm{C}$, and the entropy change is negative. So the reaction does not happen below $400^{\circ} \mathrm{C}$ because of an activation energy barrier. 


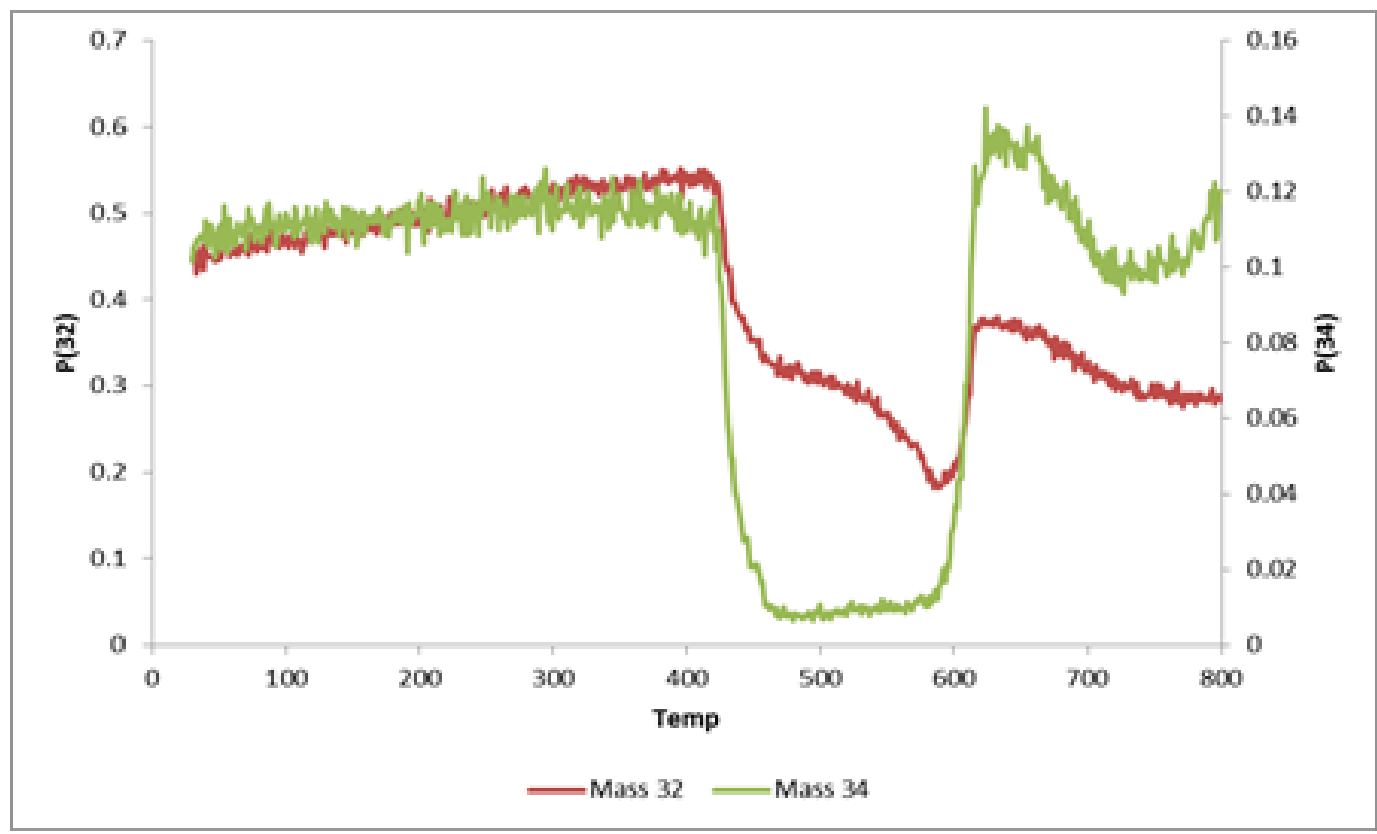

Figure 5.12 Details of mass 32 and 34 vs temperature during the heating process in "dry" $\mathrm{H}_{2}+20$ ppm $\mathrm{PH}_{3}$.

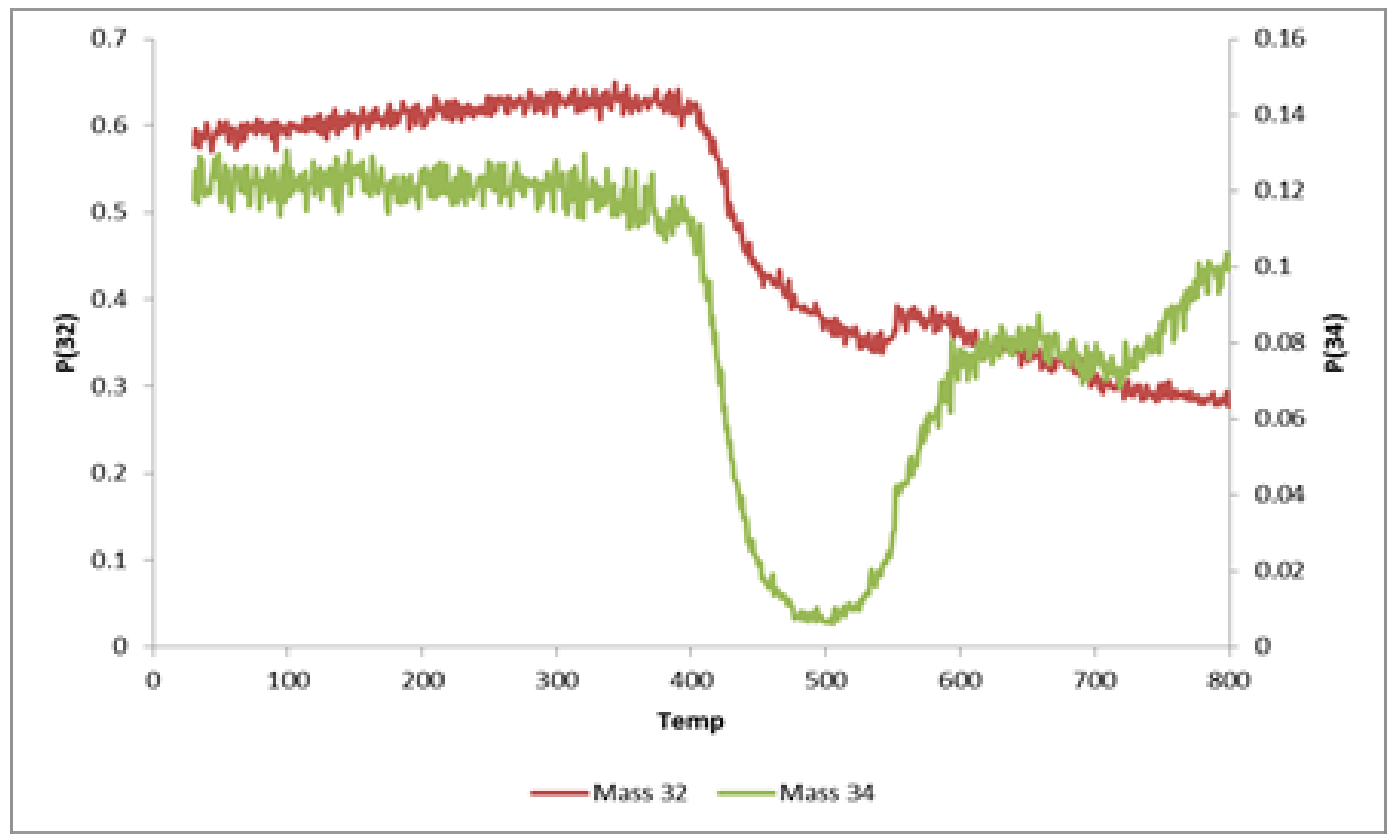

Figure 5.13 Details of mass 32 and 34 vs temperature during the cooling process in "dry"

$$
\mathrm{H}_{2}+20 \mathrm{ppm} \mathrm{PH}_{3}
$$


Mass spectra comparison of $300^{\circ} \mathrm{C}$ and $500^{\circ} \mathrm{C}$ are shown in Figure 5.14. There are no significant signals above mass $44\left(\mathrm{CO}_{2}\right)$. Masses $31(\mathrm{P}), 32\left(\mathrm{O}_{2}\right.$ and $\left.\mathrm{PH}\right), 33\left(\mathrm{PH}_{2}\right)$ and $34\left(\mathrm{PH}_{3}\right)$ show decreases going from $300^{\circ} \mathrm{C}$ to $500^{\circ} \mathrm{C}$. There is no signal increase which correlates with the loss of $\mathrm{PH}_{3}$. All other signals can be related to gases present in the mixture $\left(\mathrm{H}_{2}, \mathrm{H}_{2} \mathrm{O}, \mathrm{N}_{2}, \mathrm{Ar}, \mathrm{CO}_{2}\right)$. So there is no $\mathrm{HPO}, \mathrm{HPO}_{2}$ or $\mathrm{HPO}_{3}$ generated with 20 ppm $\mathrm{PH}_{3}$ and low water content. $\mathrm{PH}_{3}$ does react at higher temperatures. However, the products are undetectable with the current instrument.

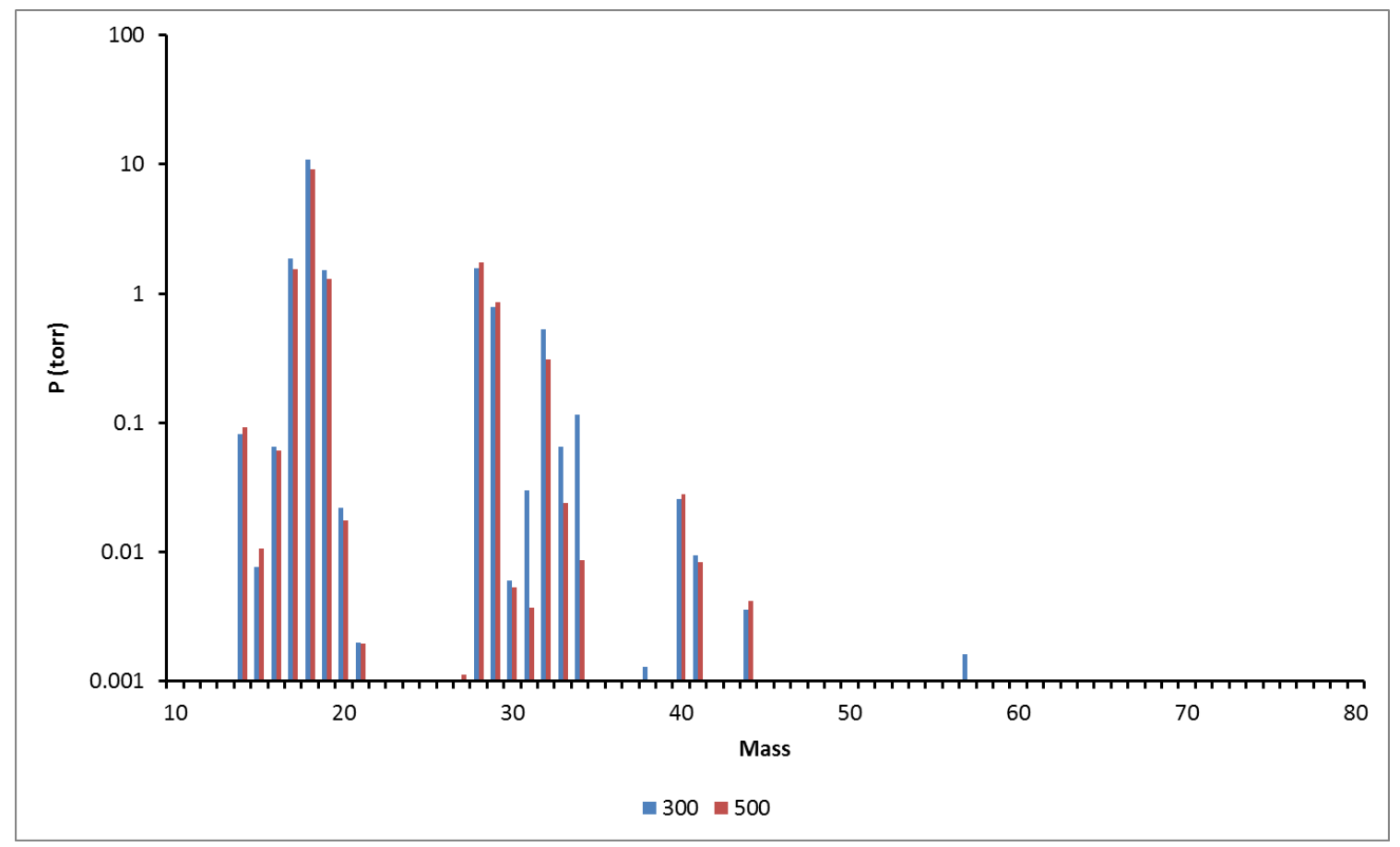

Figure 5.14 Mass spectrum comparisons of $300^{\circ} \mathrm{C}$ and $500^{\circ} \mathrm{C}$ in "dry" $\mathrm{H}_{2}+20$ ppm $\mathrm{PH}_{3}$

\subsubsection{Gas tests with $\mathrm{PH}_{3}$ and $\mathrm{NiO} / \mathrm{YSZ}$ sample piece inside the ceramic tube.}

A loose piece of fresh, unreduced $\mathrm{NiO} / \mathrm{YSZ}$ sample was put into the ceramic tube, approximately in the center of the heated zone. The sample was a piece of an anodesupported half cell with an area about $1 \mathrm{~cm}^{2}$. 
1. "Dry" hydrogen with $20 \mathrm{ppm} \mathrm{PH}_{3}$ test: Pure $\mathrm{H}_{2}$ was mixed 1:1 with $40 \mathrm{ppm}$ $\mathrm{PH}_{3}$ in $\mathrm{H}_{2}$ as described before. The furnace was kept at room temperature for 2 hours, then ramped up from room temperature to $800^{\circ} \mathrm{C}$ in 6 hours, then held for 10 hours, and then programmed to cool over 6 hours. The overview of mass 28, 32 and 34 is in Figure 5.15 .

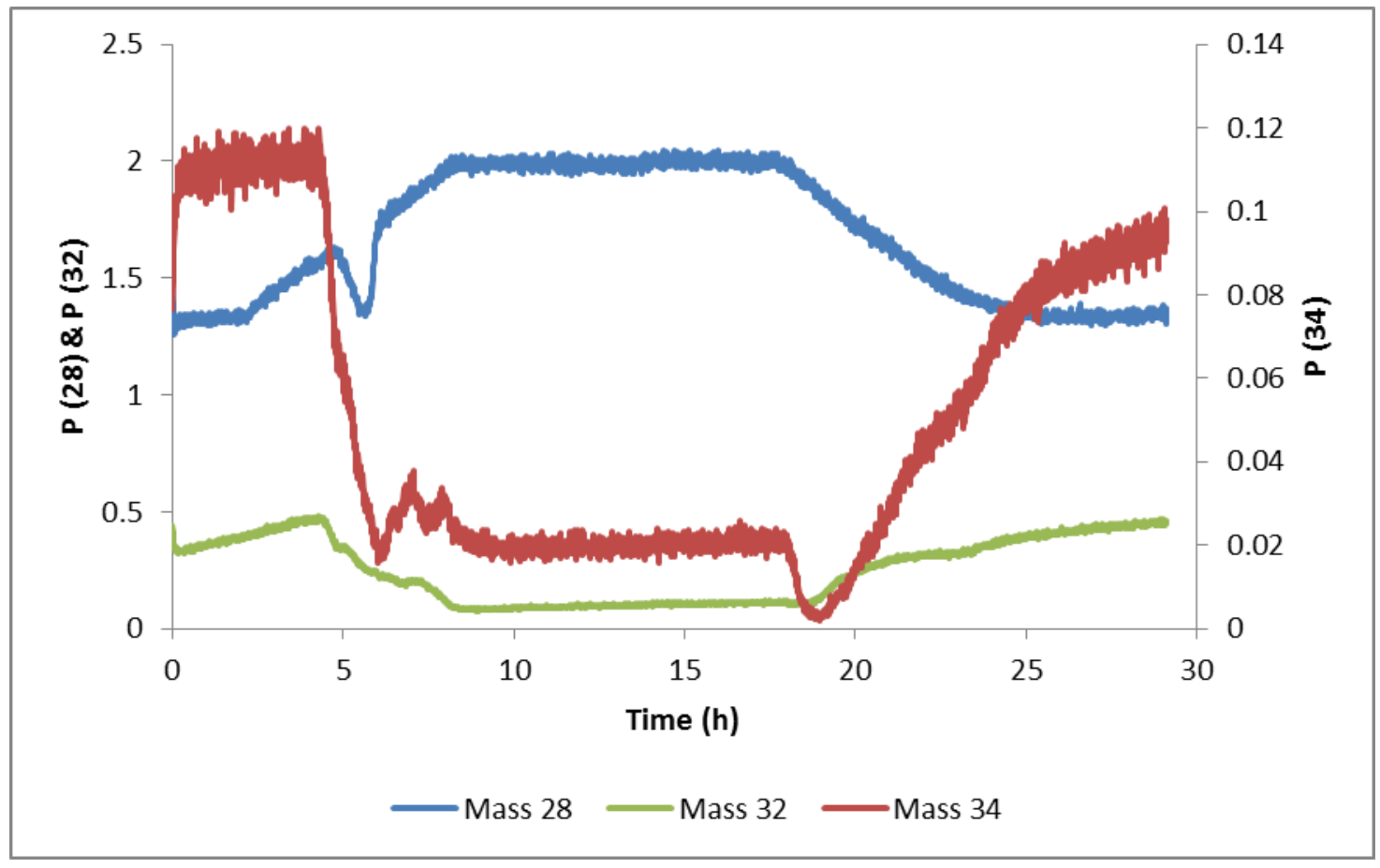

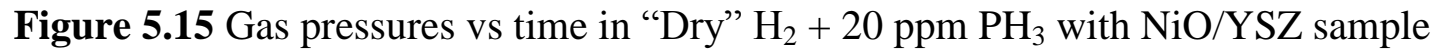

The $\mathrm{N}_{2}$ signal at mass 28 appears to correlate well with the actual furnace temperature. The heating step is linear as programmed, but the cooling step is nonlinear because the furnace did not cool as fast as the programmed temperature. As in the preceding case of $\mathrm{PH}_{3}$ in "dry" $\mathrm{H}_{2}$, the $\mathrm{PH}_{3}$ signal decreases, but it remains low at $800^{\circ} \mathrm{C}$ (compared with $\mathrm{PH}_{3}$ signal in "dry" $\mathrm{H}_{2}$ without a NiO/YSZ sample present in Figure 5.10). During cooling, the $\mathrm{PH}_{3}$ signal decreases further and then rises back to the initial 
level. After the experiment, the reduced Ni surface did not appear to have any visible new phases on the outer surface, although $\mathrm{PH}_{3}$ could have reacted with the Ni.

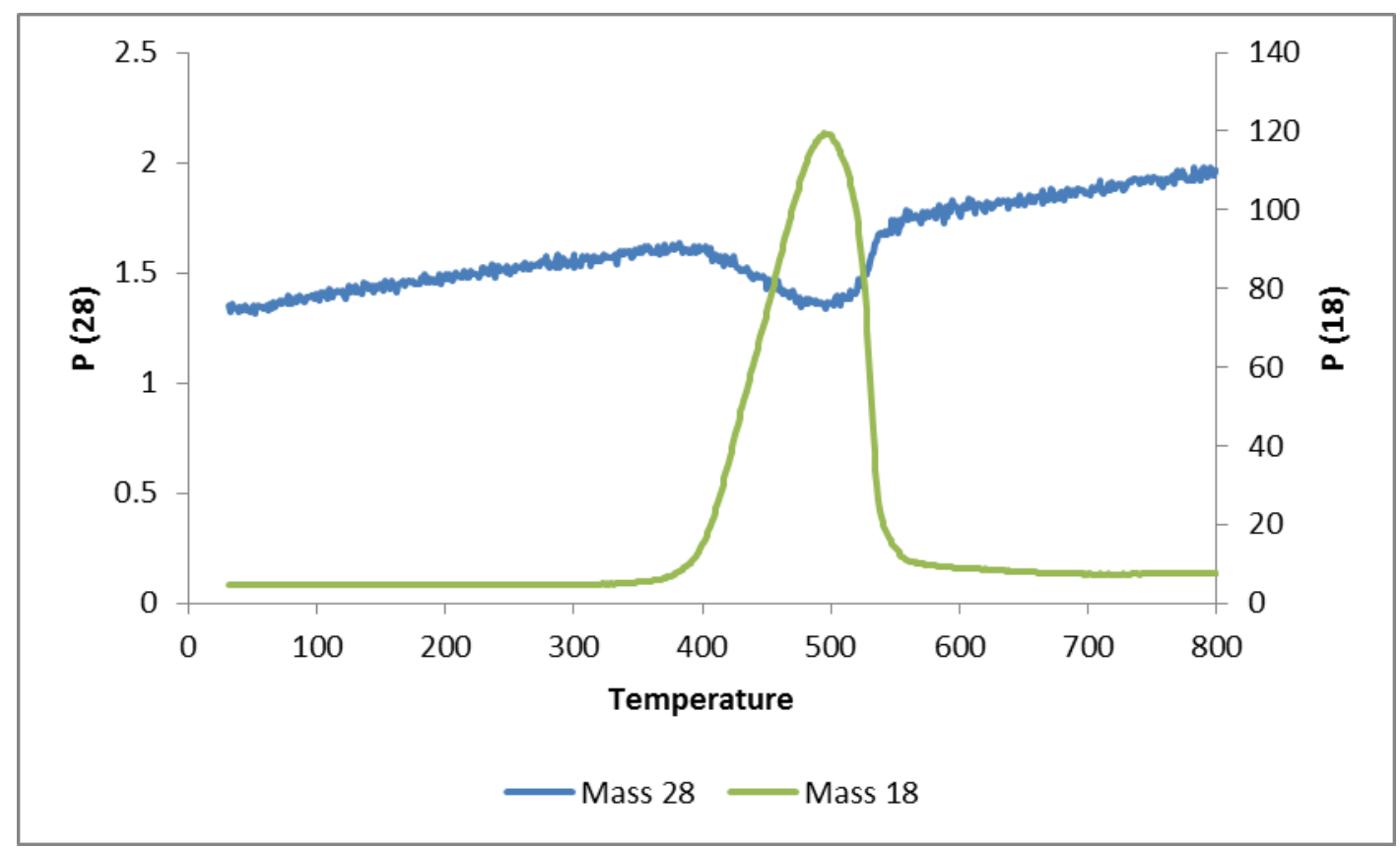

Figure 5.16 $\mathrm{H}_{2} \mathrm{O}$ and $\mathrm{N}_{2}$ pressures vs temperature during the heating phase in "dry" $\mathrm{H}_{2}+$ 20 ppm $\mathrm{PH}_{3}$ with $\mathrm{NiO} / \mathrm{YSZ}$ present.

The water signal (mass 18) in Figure 5.16 shows a spike between $400^{\circ} \mathrm{C}$ and $600^{\circ} \mathrm{C}$. This spike is not present during the cooling phase. The green $\mathrm{NiO}$ is converted to metallic $\mathrm{Ni}$ during this step. The amount of water generated is enough to replace some of the $\mathrm{N}_{2}$ and cause a dip in the $\mathrm{N}_{2}$ signal (mass 28). The $\mathrm{O}_{2}$ signal (mass 32 ) in Figure 5.17 shows a similar pattern as before, decreasing sharply at the same temperature as the drop in the $\mathrm{PH}_{3}$ signal.

In comparison to the results without a Ni/YSZ sample piece, the $\mathrm{PH}_{3}$ signal at mass 34 is much lower at $800^{\circ} \mathrm{C}$, which implies that the $\mathrm{PH}_{3}$ is reacting with the $\mathrm{Ni} / \mathrm{YSZ}$ sample. But the products are either non-volatile or out of the detectable mass range (above $100 \mathrm{amu}$ ). 


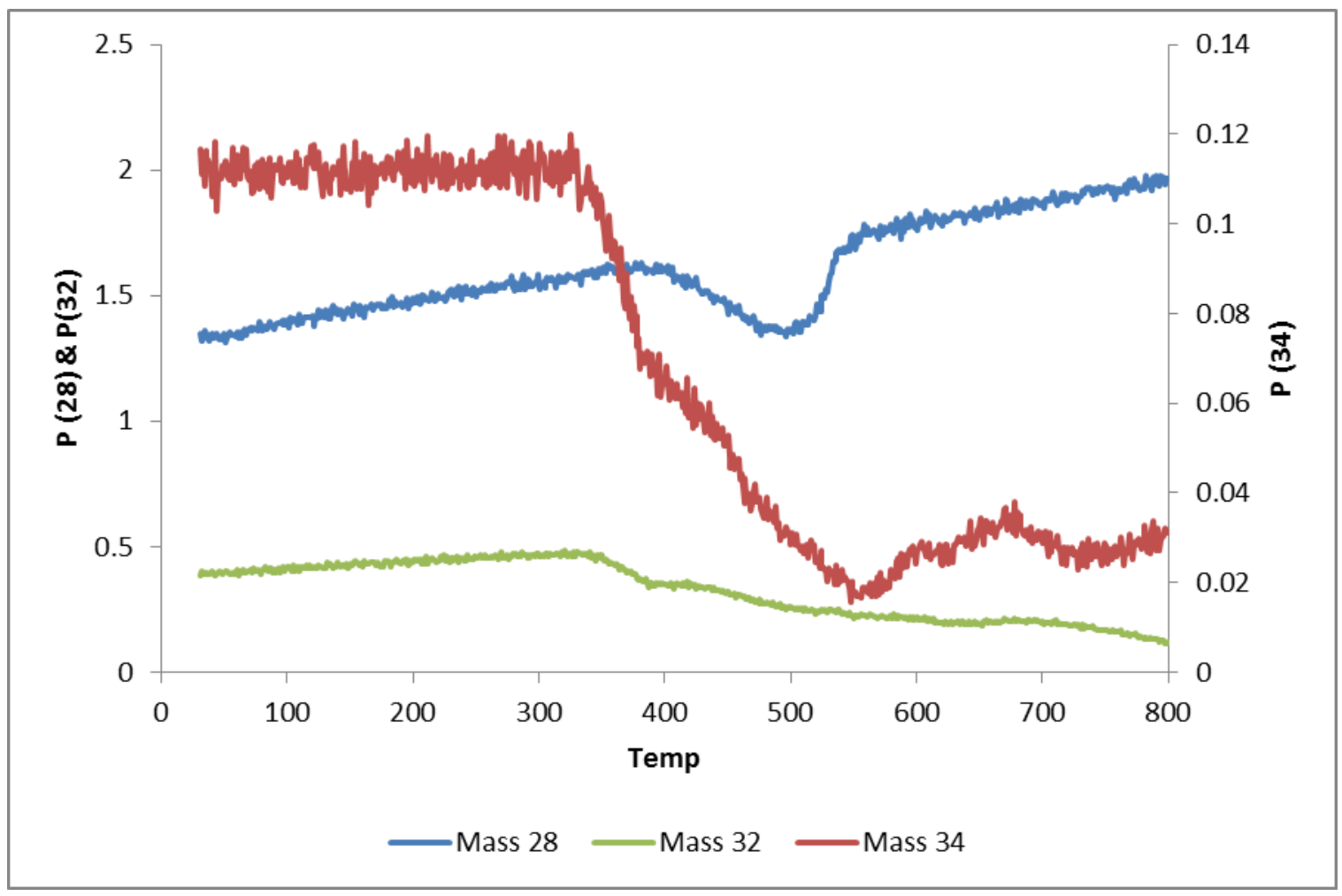

Figure 5.17 $\mathrm{O}_{2}, \mathrm{~N}_{2}$, and $\mathrm{PH}_{3}$ pressures vs temperature during the heating phase in "dry" $\mathrm{H}_{2}+20$ ppm $\mathrm{PH}_{3}$ with $\mathrm{NiO} / \mathrm{YSZ}$ sample

2. "Wet" hydrogen with $20 \mathrm{ppm} \mathrm{PH}_{3}$ test: The pure $\mathrm{H}_{2}$ was passed through the

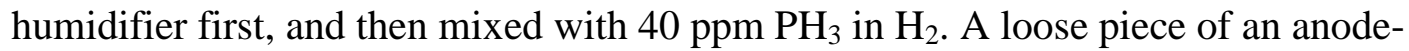
supported half cell with an area about $1 \mathrm{~cm}^{2}$ was put inside the ceramic tube near the center of the heating zone. The furnace was kept at room temperature for 2 hours, then ramped up from room temp to $800^{\circ} \mathrm{C}$ in 6 hours, then held for 10 hours, and then programmed to cool down in 6 hours. An overview of masses 28, 32 and 34 at the outlet during the whole process is shown in Figure 5.18. 


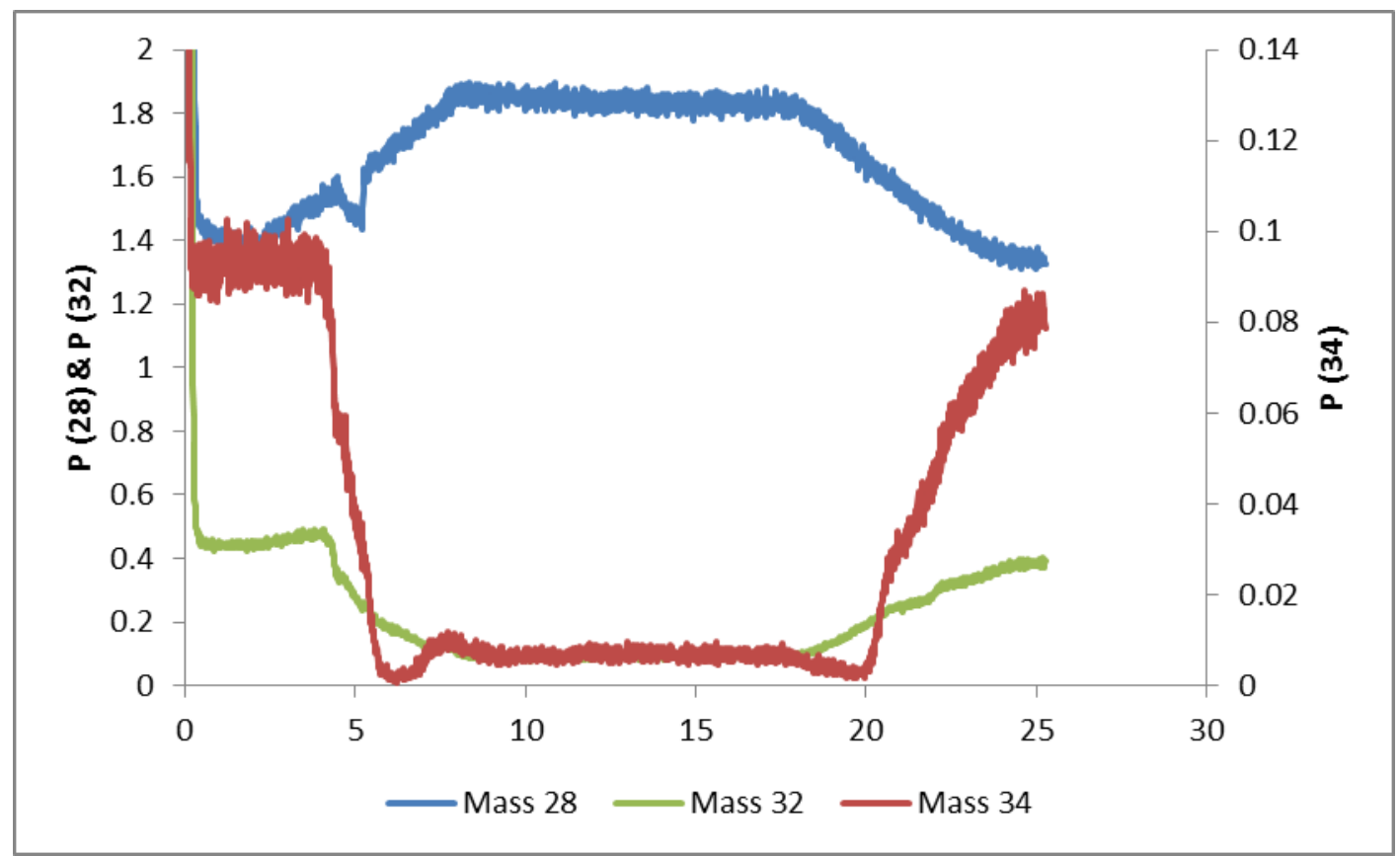

Figure 5.18 Gas pressures vs time with"wet” $\mathrm{H}_{2}+20$ ppm $\mathrm{PH}_{3}$ with a NiO/YSZ sample.

With high water content added, the $\mathrm{PH}_{3}$ signal at mass 34 drops steeply upon heating from 0.097 torr to 0.002 torr and then rises to 0.008 torr. The trend is reversed during furnace cool down.

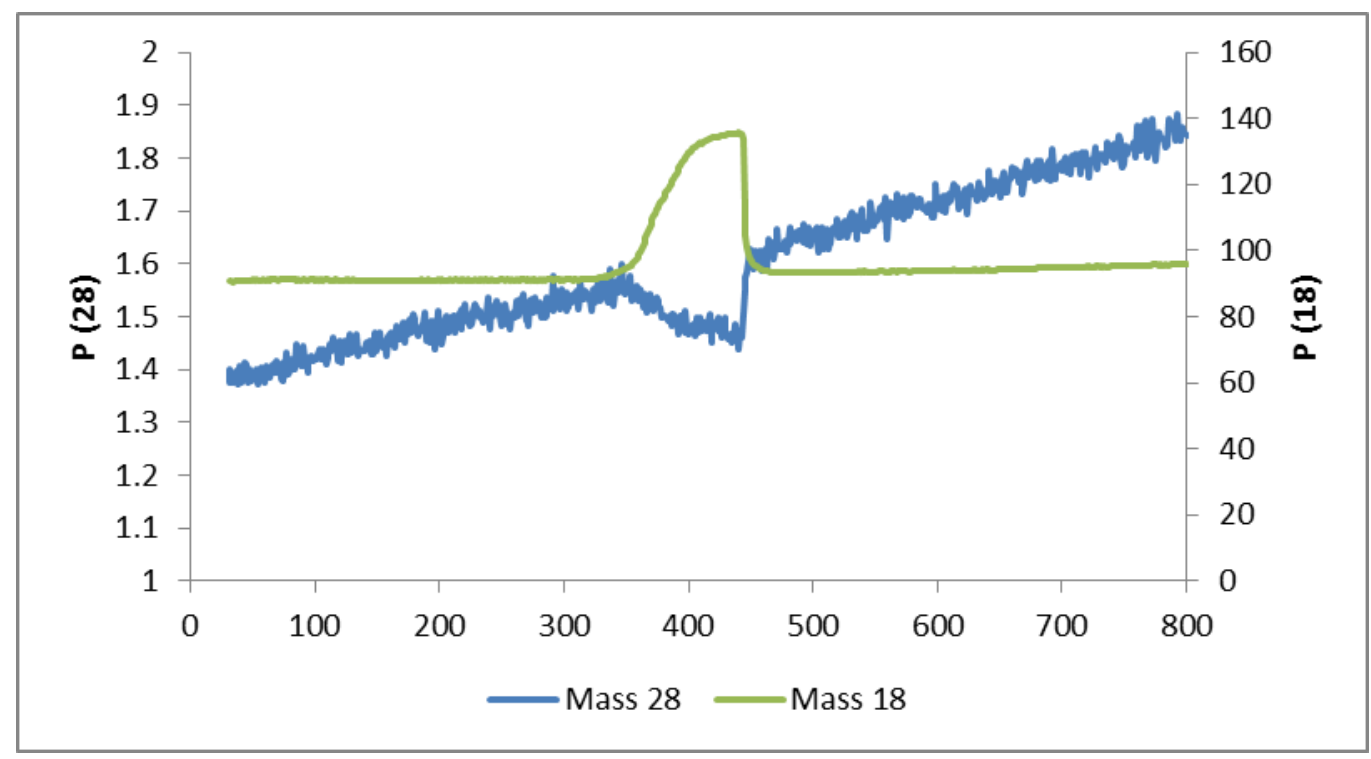

Figure 5.19 $\mathrm{H}_{2} \mathrm{O}$ and $\mathrm{N}_{2}$ pressures vs temperature during heating in "wet" $\mathrm{H}_{2}+20 \mathrm{ppm}$ $\mathrm{PH}_{3}$ with $\mathrm{NiO} / \mathrm{YSZ}$ sample. 
Despite the very high amount of added water background at about 100 torr, the spike in $\mathrm{H}_{2} \mathrm{O}$ signal when the $\mathrm{NiO}$ is reduced still very evident in Figure 5.19. The peak pressure for mass 18 appears to have reached the saturation level for the electron multiplier. Again, the generated water replaces some of the $\mathrm{N}_{2}$ so the $\mathrm{N}_{2}$ signal shows a dip in the same temperature range. $\mathrm{O}_{2}$ decreases with the dip of $\mathrm{PH}_{3}$ as well.

The $\mathrm{PH}_{3}$ level at $800^{\circ} \mathrm{C}$ is lower than the blank tests without a Ni/YSZ sample, and also lower than the "dry" $\mathrm{PH}_{3}$ with sample test. The $\mathrm{PH}_{3}$ actually gets to the sample and reacts with it. With higher water content, more $\mathrm{PH}_{3}$ is reacted. However, the products are still not detected with the Cirrus unit. The sample was removed from the furnace for a visual examination; the reduced Ni surface appeared to have a thin new shiny layer. The new material is believed to be the nickel phosphide. However, there was not an opportunity to have the sample tested with SEM or EDS to have the microstructure and elemental information.

\subsection{5 $\mathrm{P}_{2} \mathrm{O}_{5}$ sample test}

$\mathrm{P}_{2} \mathrm{O}_{5}$ and other phosphorus oxides are predicted by calculations to be possible $\mathrm{PH}_{3}$ reaction products [1,6]. $\mathrm{PH}_{3}$ can be generated by heating the $\mathrm{P}_{2} \mathrm{O}_{5}$ to $300^{\circ} \mathrm{C}$ as described in Chapter 2. [6] It is necessary to know that if the phosphorus oxide is detectable using the current instrument. A small amount of $\mathrm{P}_{2} \mathrm{O}_{5}$ sample was placed in a crucible. The crucible was then placed inside the alumina tube in the furnace. There is no other sample or cell inside the furnace. The gas flow was $\mathrm{H}_{2}$ at $200 \mathrm{sccm}$. After the air had been purged, the furnace was heated from room temperature to $350^{\circ} \mathrm{C}$ in steps of $50^{\circ} \mathrm{C}$. The melting point of $\mathrm{P}_{2} \mathrm{O}_{5}$ is $340^{\circ} \mathrm{C}$ and the boiling point is $423^{\circ} \mathrm{C}$, so sufficient vapor pressure of $\mathrm{P}_{2} \mathrm{O}_{5}$ and its possible fragments should have been generated to permit detection by the mass 
spectrometer. The mass spectrometer was connected to the exhaust. All visible signals in the mass spectra are assigned to $\mathrm{H}_{2}$ and air impurities. No new masses associated with phosphorus appear, indicating that fragment ions of $\mathrm{P}_{2} \mathrm{O}_{5}$ are not seen with the current instrument. A mass spectrum taken at $350^{\circ} \mathrm{C}$ is shown in Figure 5.20. This result contradicts the predictions by Sasaki et al.[6] One of the hypotheses is the generated $\mathrm{PH}_{3}$ has reacted before it reaches the mass spectrometer.

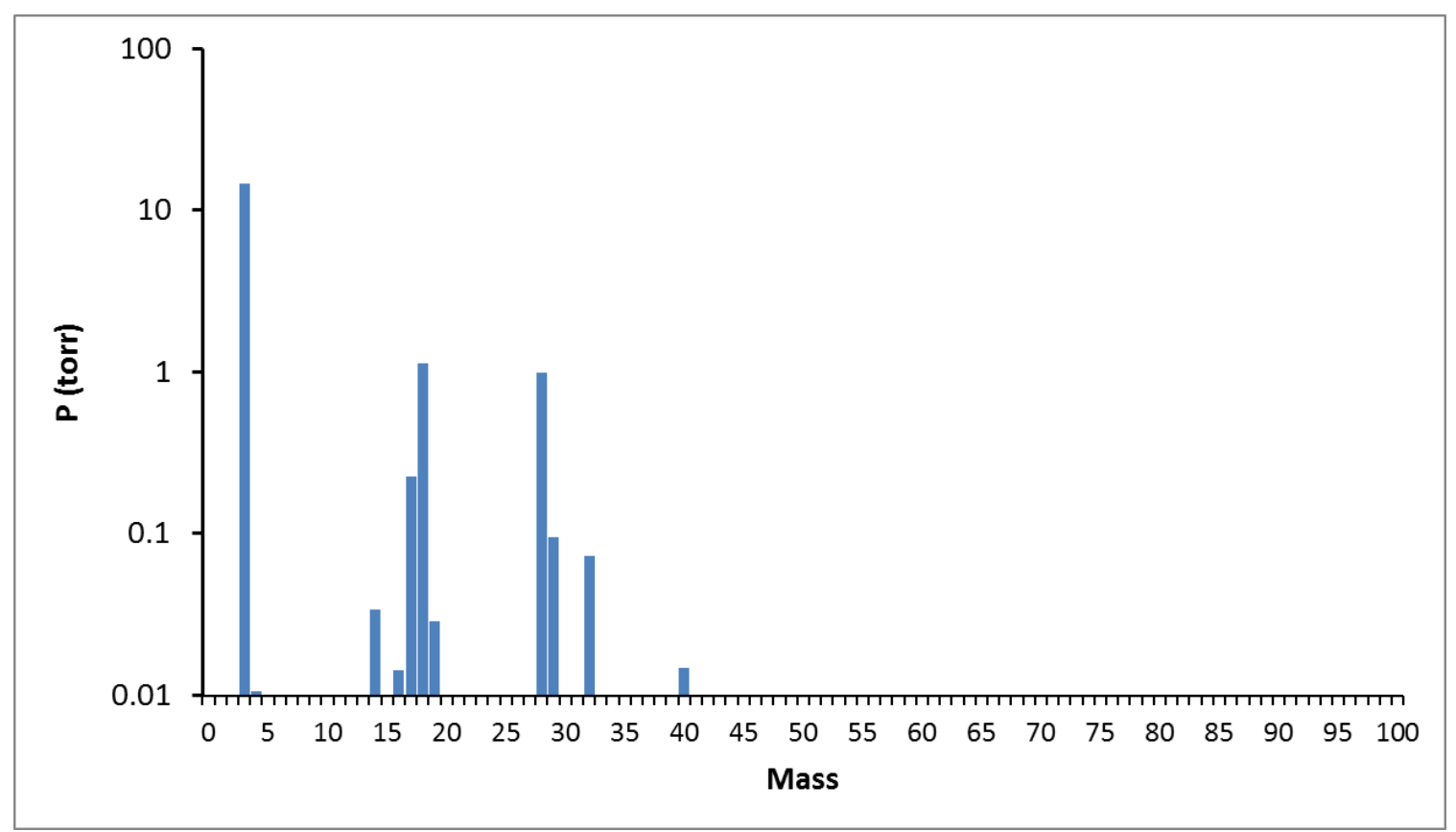

Figure 5.20 Mass spectrum of exhaust gas with $\mathrm{P}_{2} \mathrm{O}_{5}$ sample at $350^{\circ} \mathrm{C}$.

\subsection{Gas-phase studies with the Probostat ${ }^{\mathrm{TM}}$.}

\subsubsection{Experimental set up}

The preceding experiments are repeated in the Probostat to verify the patterns of reactivity and as a prelude to mounting a cell in the Probostat. In these high-temperature gas-phase studies inside the Probostat, there is only one chamber, not separated by a cell 
or sample into the anode and cathode side. The gas comes in from the base, passes through the inner tube (normally the cathode side) to the top, and then flow back down the outer tube (normally the anode side) to the base and the exhaust. The mass spectrometer is connected with a T-joint to the exhaust gas port.

\subsubsection{Blank gas tests (No cell)}

These tests replicate the ones described previously using the alumina tube in the tube furnace. Leak checks are performed before the gas tests to confirm that there is no significant air leaking into the Probostat chamber from the atmosphere air. With 200 sccm $\mathrm{H}_{2}$ fed into the inlet, $\mathrm{N}_{2}$ pressure was about 1.0 torr at the outlet sampling point by the mass spectrometer. This result confirms the presence of an acceptably gas tight seal.

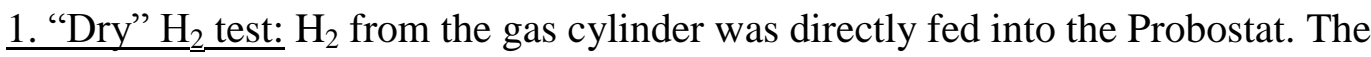
furnace was heated up in 10 hours, kept at $800{ }^{\circ} \mathrm{C}$ for 10 hours, and then cooled down on its own. The furnace surrounding the Probostat can only be programmed to ramp up the temperature during heating. Cooling is achieved by cutting the power to the furnace.

Figure 5.21 is an overview of the pressures of masses 18,28 and 32. In this test configuration, the $\mathrm{N}_{2}$ signal (mass 28) shows a different behavior from the ceramic tube set up. The $\mathrm{N}_{2}$ signal goes down linearly with temperature change. At $800^{\circ} \mathrm{C}$, the $\mathrm{N}_{2}$ is about 1.1 torr. In comparison, the $\mathrm{N}_{2}$ signal becomes higher at high temperatures in the tube furnace set up. The water signal (mass 18) decreases continuously as the water trapped is being purged and then stays at 6.7 torr. Based on the 100 torr signal obtained with 10 torr of water in the wet hydrogen, the actual pressure of water in "dry" $\mathrm{H}_{2}$ is less than 1 torr. Figure 5.22 shows the mass 34 signal together with $\mathrm{N}_{2}$ and $\mathrm{O}_{2}$ over time. Both 
the mass 34 and mass 32 signals show slight decreases upon heating to $800^{\circ} \mathrm{C}$ and increases during the cooling step.

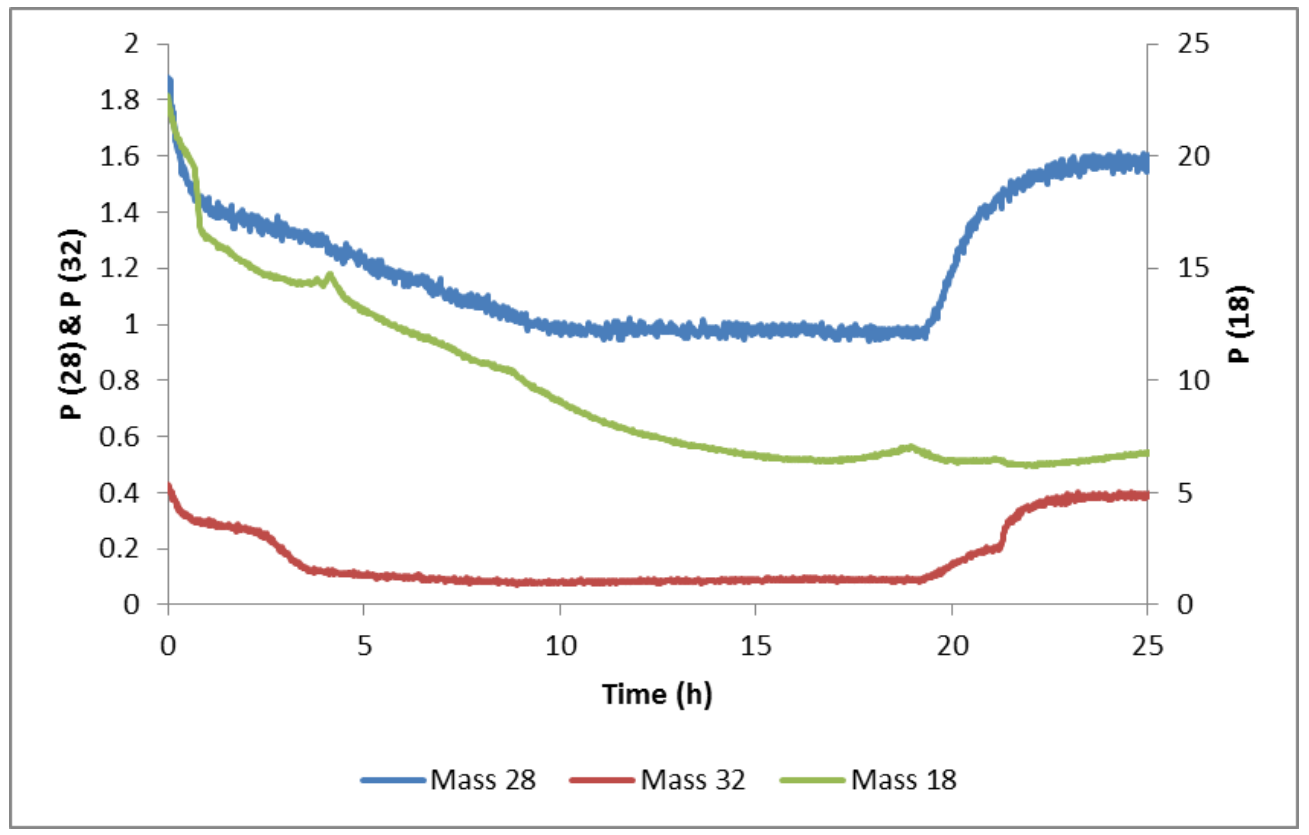

Figure 5.21 Gas pressures vs time in the "dry" $\mathrm{H}_{2}$ test with the Probostat.

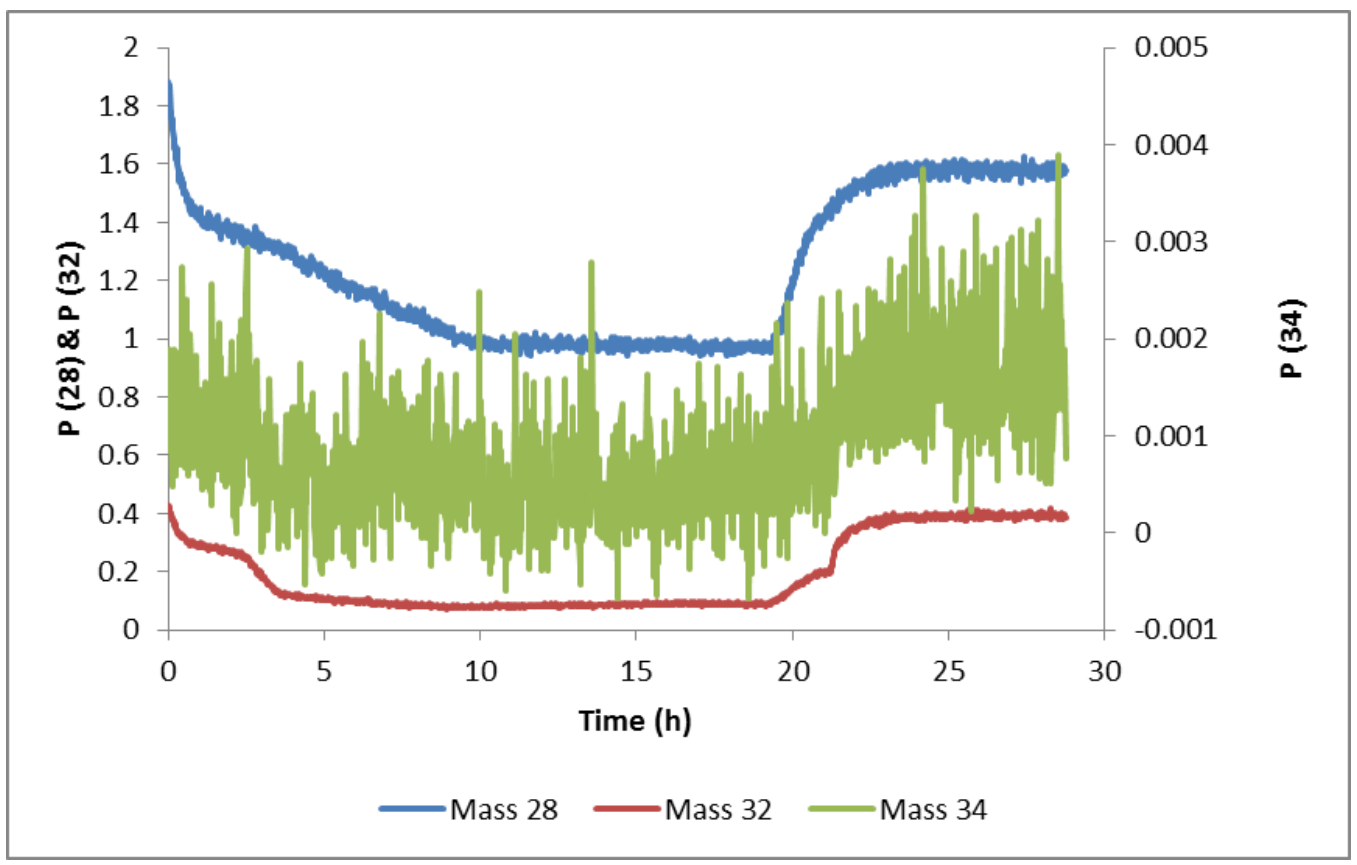

Figure 5.22 Mass 34, $\mathrm{N}_{2}$ and $\mathrm{O}_{2}$ pressures vs time during the "dry" $\mathrm{H}_{2}$ test with the Probostat. 
2. "Wet" $\mathrm{H}_{2}$ test: $\mathrm{H}_{2}$ from the gas cylinder was passed through the humidifier, and then fed into the Probostat. The true partial pressure of water was about 20 torr. The temperature was ramped up with a $1.5^{\circ} \mathrm{C} / \mathrm{min}$ rate to $800^{\circ} \mathrm{C}$, taking 8 hours. The furnace was kept at $800{ }^{\circ} \mathrm{C}$ for 9 hours and cooled down afterwards. The gas pressure overview is shown in Figure 5.23.

The water signal (mass 18) stays very high without a significant change with the temperature. The $\mathrm{O}_{2}$ signal (mass 32 ) decreases sharply when the auto ignition starts, and goes back up when the temperature drops below the ignition point during cool down. The $\mathrm{N}_{2}$ signal at mass 28 shows a linear change with temperature as described above. Figure 5.24 shows the signal at mass 34 over time with other gases. The pattern here is essentially the same as in "dry" $\mathrm{H}_{2}$. The "dry" and "wet" $\mathrm{H}_{2}$ tests are performed to define a necessary baseline of background gas compositions.

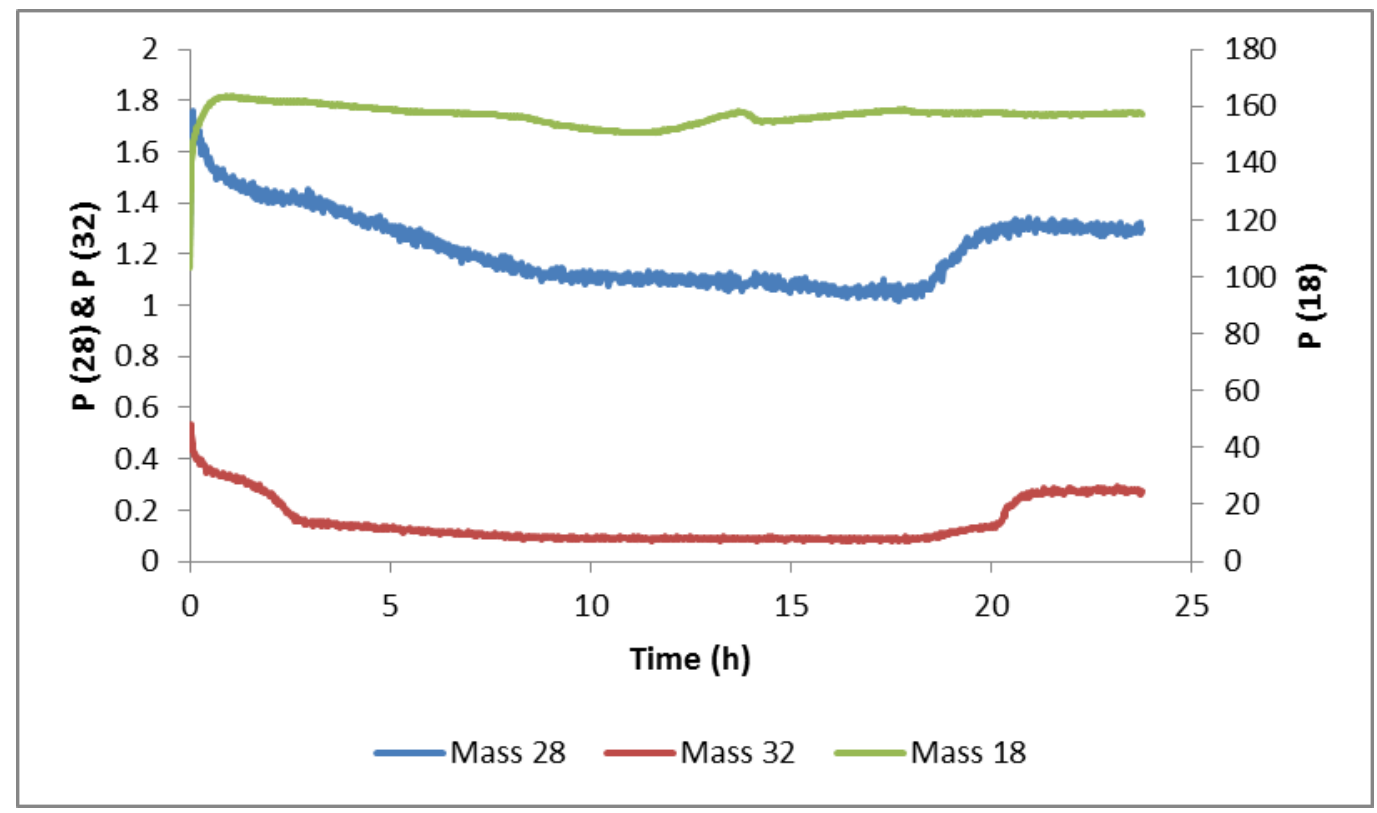

Figure 5.23 Gas pressure vs time in the "wet" $\mathrm{H}_{2}$ test with the Probostat. 


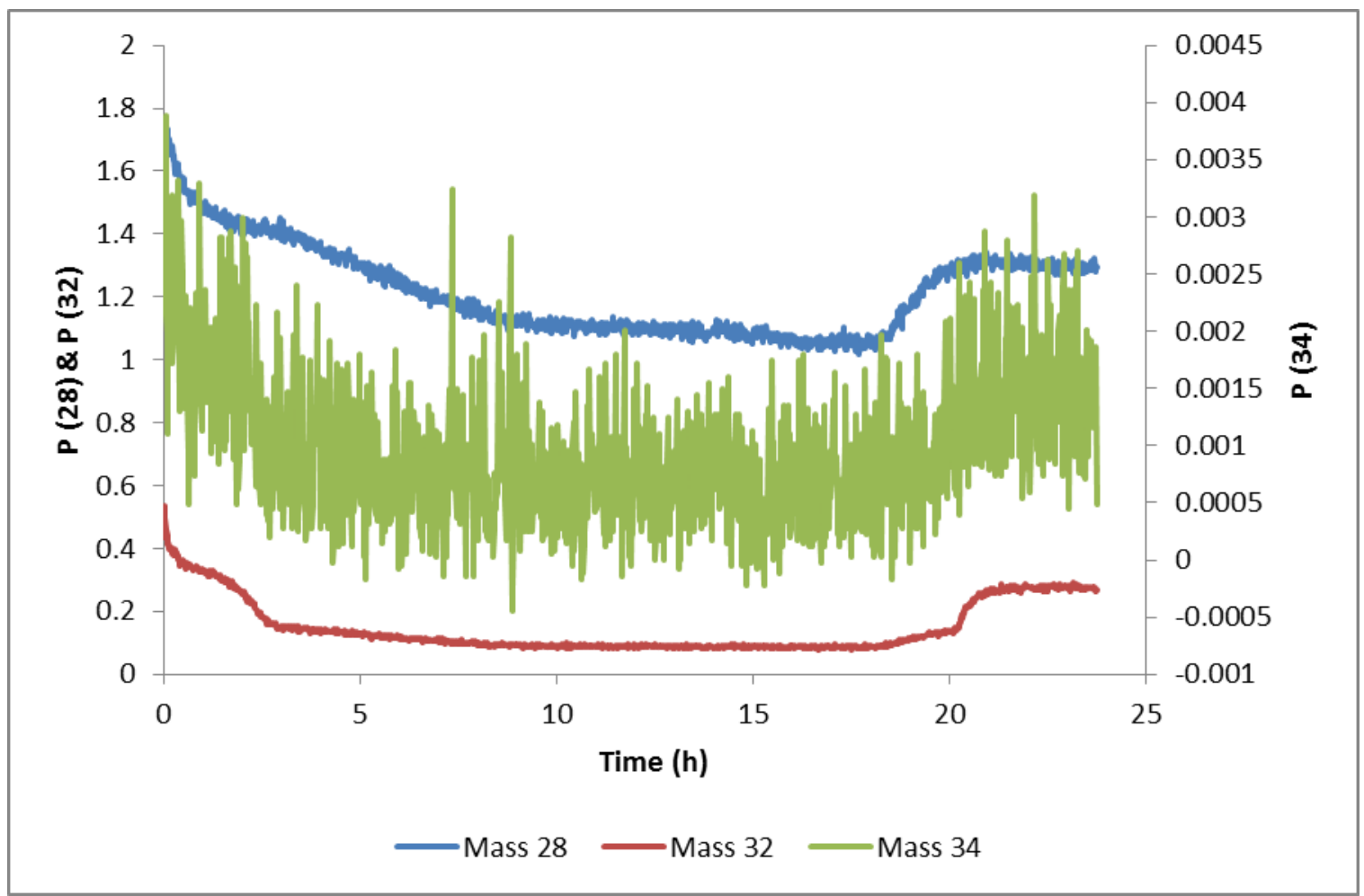

Figure 5.24 Mass 34, $\mathrm{N}_{2}$ and $\mathrm{O}_{2}$ pressures vs time during the "wet" $\mathrm{H}_{2}$ test with the Probostat.

$\underline{\text { 3. "Dry" } \mathrm{H}_{2}} \underline{\text { with } 20 \mathrm{ppm} \mathrm{PH}_{3}}$ test: $\mathrm{H}_{2}$ was mixed $1: 1$ with the $40 \mathrm{ppm} \mathrm{PH}_{3}$ stock cylinder. The temperature was controlled to ramp up with a $1.5^{\circ} \mathrm{C} / \mathrm{min}$ rate to $800{ }^{\circ} \mathrm{C}$ in about 8 hours. Then the furnace was kept at $800{ }^{\circ} \mathrm{C}$ for 12 hours, and was cooled to room temperature afterwards. The gas pressure overview is in Figure 5.25. 


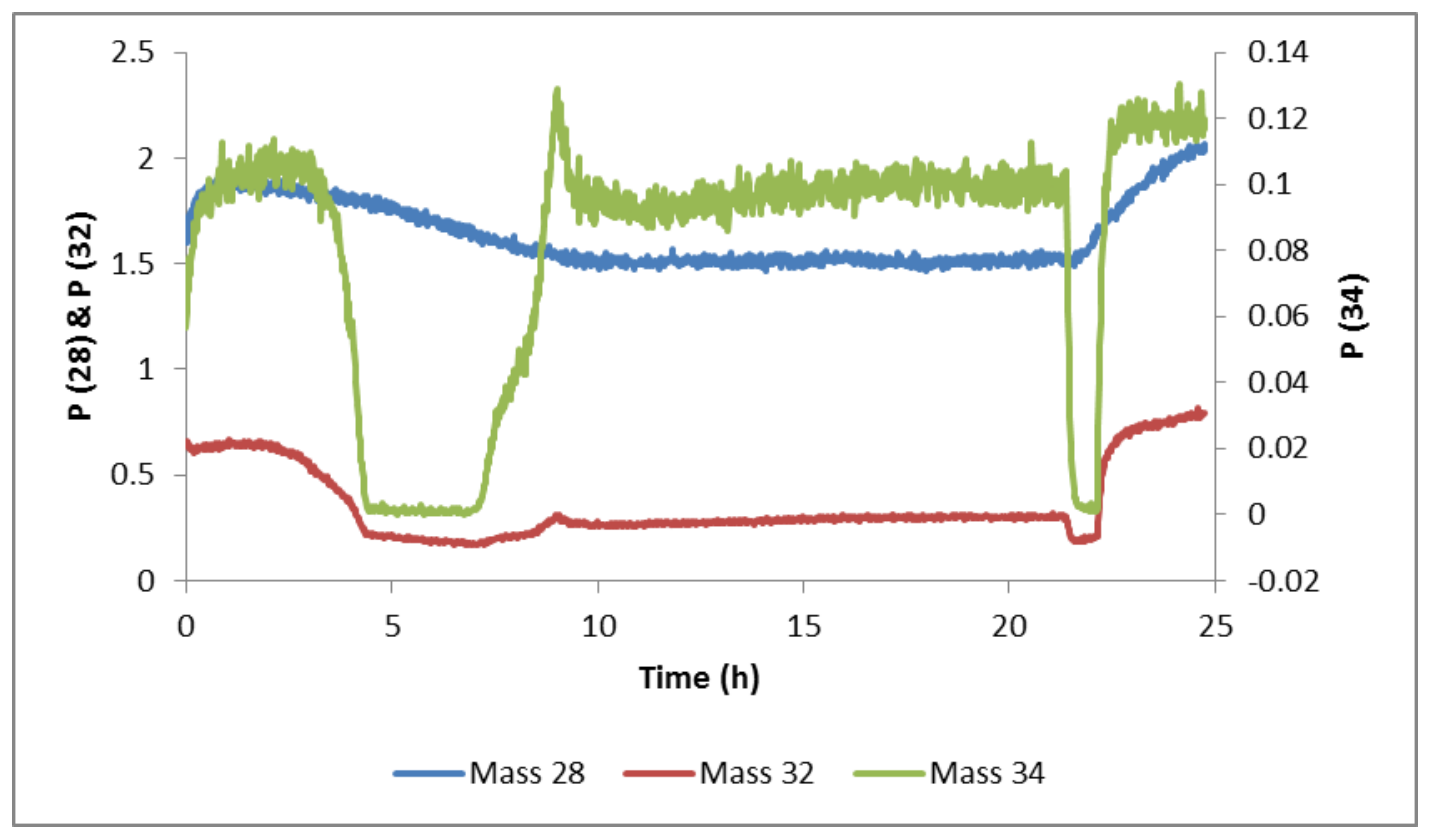

Figure 5.25 Gas pressures vs time in the "dry" $\mathrm{H}_{2}+20$ ppm $\mathrm{PH}_{3}$ test with the Probostat.

Figure 5.26 is a plot of mass 28,32 and 34 vs temperature during the heating up process. $\mathrm{N}_{2}$ and $\mathrm{O}_{2}$ pressures are similar to the previous blank tests. The $\mathrm{PH}_{3}$ signal was about 0.1 torr initially. After the temperature reaches $300{ }^{\circ} \mathrm{C}$, the $\mathrm{PH}_{3}$ signal quickly drops to nearly zero, below $10^{-3}$ torr range. With the temperature rising, after $600{ }^{\circ} \mathrm{C}$, the $\mathrm{PH}_{3}$ climbs up and reaches a peak about 0.12 torr, and then it stabilizes around 0.09 torr at $800{ }^{\circ} \mathrm{C}$. The "dipping" occurs during the cooling down within roughly the same temperature range. These results are consistent with the tube furnace results described previously. The $\mathrm{PH}_{3}$ may react with $\mathrm{O}_{2}$ at $300-600^{\circ} \mathrm{C}$ to form either a non-volatile product or a product with mass greater than 100 that is out of the detectable mass range. The products then becomes thermally unstable after $600^{\circ} \mathrm{C}$ and the $\mathrm{PH}_{3}$ re-appears. 


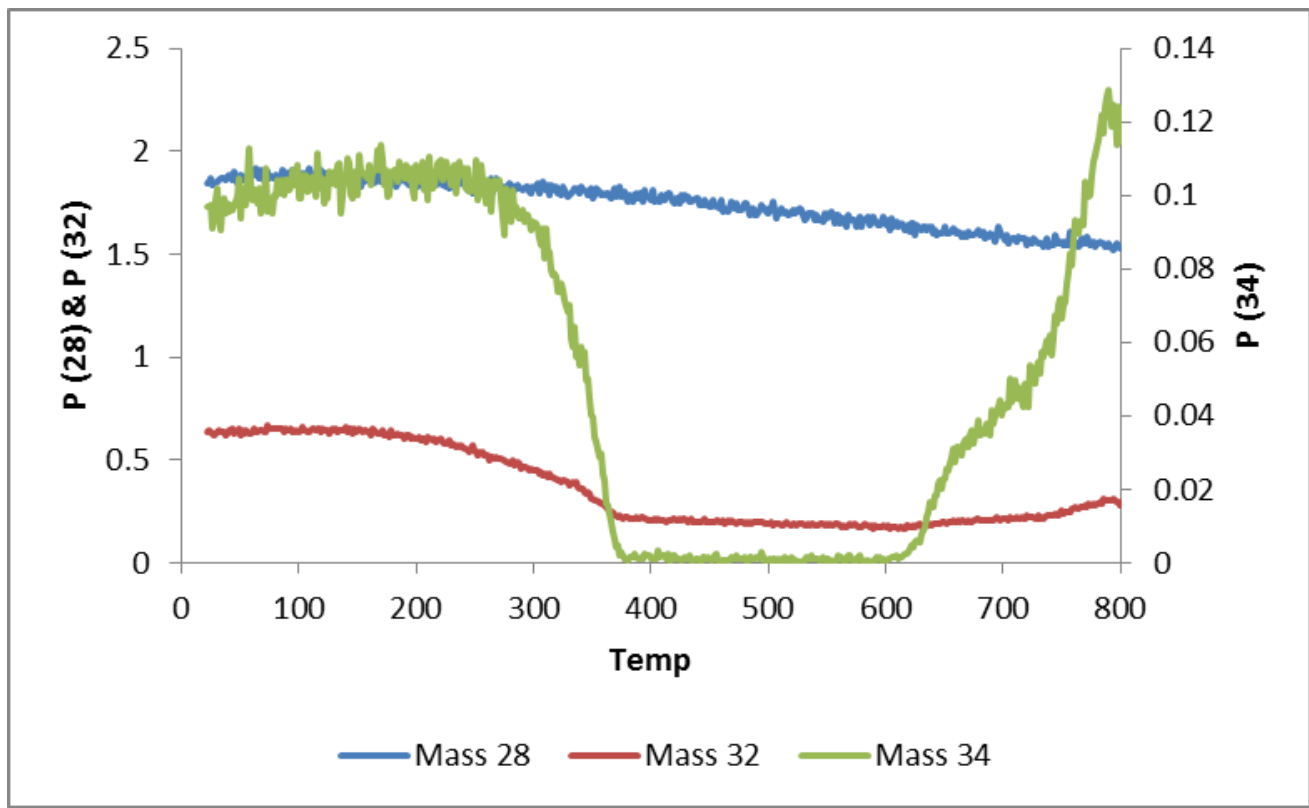

Figure 5.26 Pressures vs temperature during the heating phase of "dry" $\mathrm{H}_{2}+20$ ppm $\mathrm{PH}_{3}$ test with the Probostat.

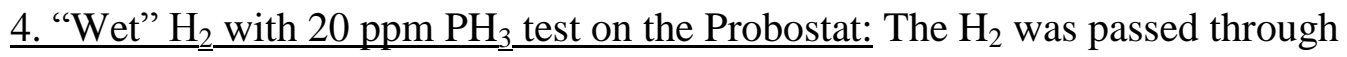
the humidifier before being mixed 1:1 with the $40 \mathrm{ppm} \mathrm{PH}_{3}$ in $\mathrm{H}_{2}$. The temperature was ramped up to $800^{\circ} \mathrm{C}$ over 8 hours with a rate of $1.5^{\circ} \mathrm{C} / \mathrm{min}$. Then the furnace was kept at $800{ }^{\circ} \mathrm{C}$ for 12 hours, and then cooled down (not controlled) afterwards. An overview of gas pressures can be seen in Figure 5.27. 


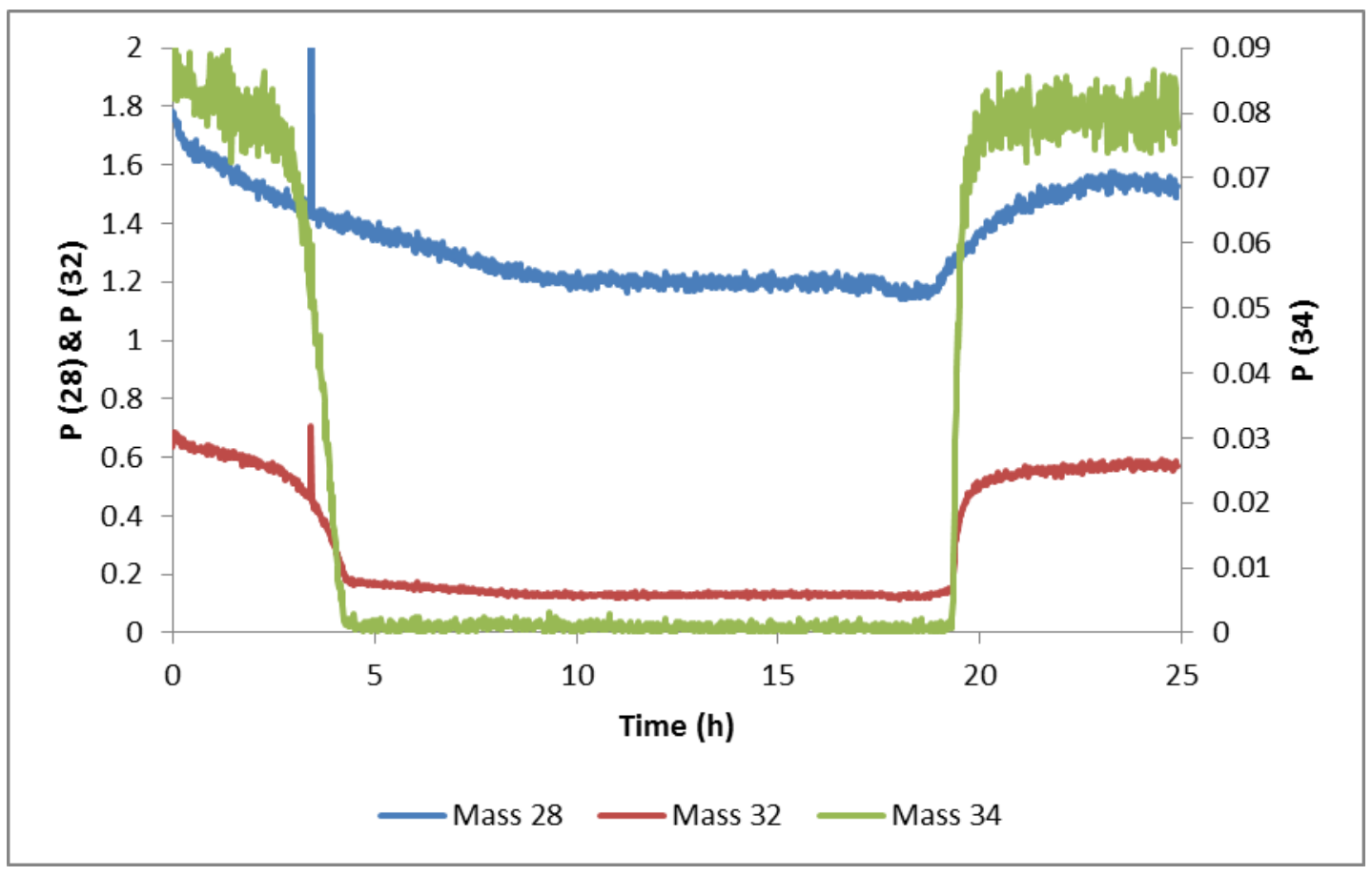

Figure 5.27 Gas pressures vs time during the "wet" $\mathrm{H}_{2}+20 \mathrm{ppm} \mathrm{PH}_{3}$ test with the Probostat.

Water is not included in Figure 5.27 because the water level is high around 100-120 torr. $\mathrm{N}_{2}$ and $\mathrm{O}_{2}$ signals behave just as in previous tests. A detailed plot of gas pressures vs temperature during heat up is shown in Figure 5.28. The $\mathrm{PH}_{3}$ (mass 34) starts dropping a little earlier at $220{ }^{\circ} \mathrm{C}$. This drop is quick and at about $400{ }^{\circ} \mathrm{C}$, the signal of $\mathrm{PH}_{3}$ is at the noise level. Unlike the "dry" test, the $\mathrm{PH}_{3}$ does not rise up when the temperature approaches $800{ }^{\circ} \mathrm{C}$. The $\mathrm{PH}_{3}$ signal stays in the noise range until the temperature reaches a low enough point during the cool down process. The $\mathrm{PH}_{3}$ signal finally recovers to the initial value about 0.08 torr after the furnace is cooled down. 


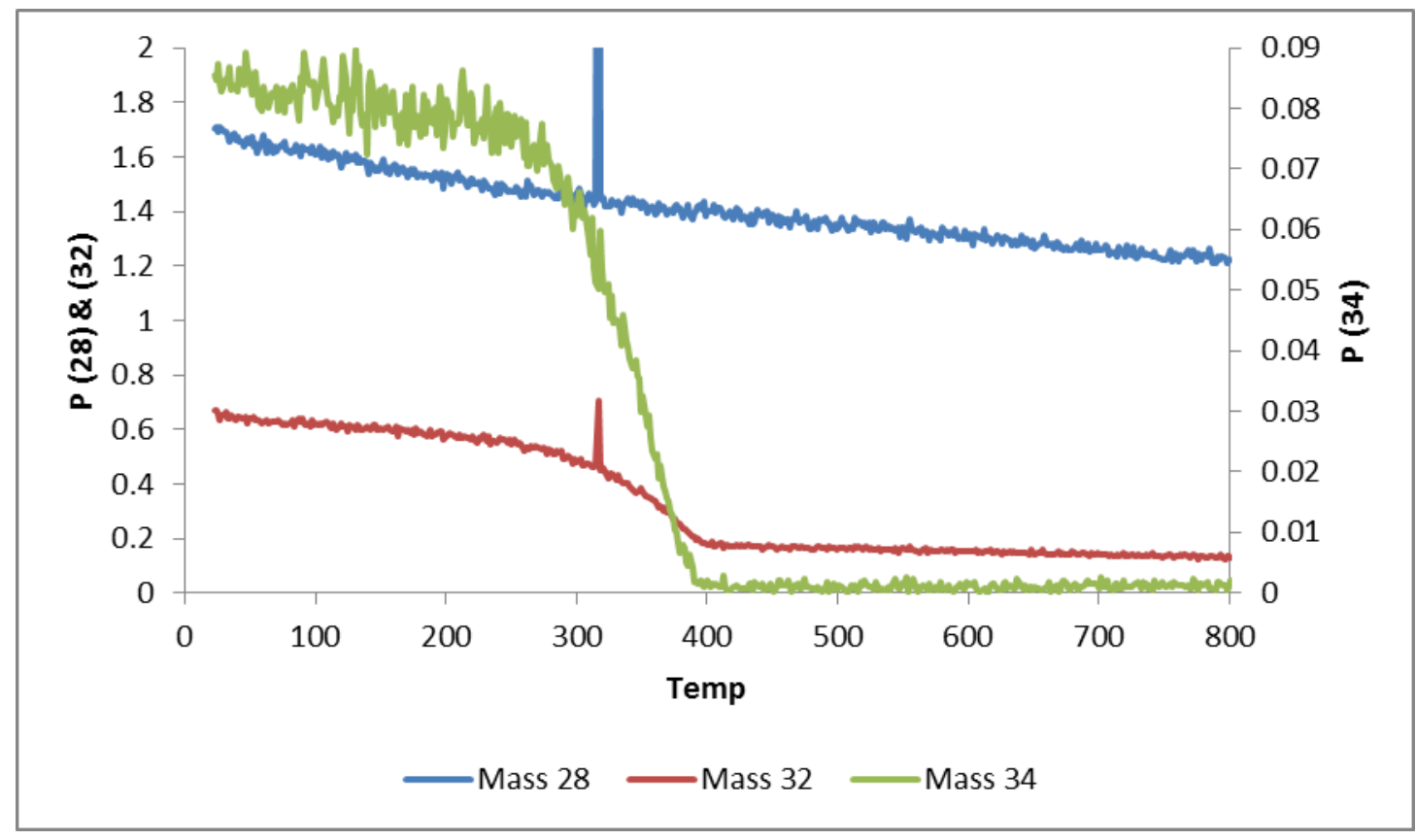

Figure 5.28 Gas pressures vs temperature during the heating phase of "wet" $\mathrm{H}_{2}+20 \mathrm{ppm}$

$\mathrm{PH}_{3}$ test with the Probostat.

Summary of the gas tests with the Probostat:

The leaks between the inner chambers of the Probostat and the outside air are acceptably low. The existence of water vapor does not affect the $\mathrm{N}_{2}$ and $\mathrm{O}_{2}$ behavior. In dry hydrogen, the $\mathrm{PH}_{3}$ reacts with other gases, or is adsorbed into the walls of the Probostat at temperature range of roughly $300-600{ }^{\circ} \mathrm{C}$. The product of $\mathrm{PH}_{3}$ reaction is either a non-volatile compound or a product with a molecular mass greater than $100 \mathrm{amu}$. In "wet" hydrogen, $\mathrm{PH}_{3}$ reacts quantitatively above $300^{\circ} \mathrm{C}$. Again, no products containing phosphorus are detected by the mass spectrometer. 


\subsubsection{Gas tests with a loose NiO/YSZ sample piece inside the Probostat.}

The NiO/YSZ sample is similar to the ones used in tube furnace tests. The sample piece is placed into the supporting alumina tube of the Probostat, not blocking the inner tube. The cathode side and anode side are still connected as before.

"Dry" $\mathrm{H}_{2}$ and the $\mathrm{NiO} / \mathrm{YSZ}$ sample in $20 \mathrm{ppm} \mathrm{PH}{ }_{3}$ with the Probostat test: The sample was a piece of anode supported half cell $(\mathrm{NiO} / \mathrm{YSZ})$ with an area of about $1 \mathrm{~cm}^{2}$. The temperature was controlled to ramp up to $800^{\circ} \mathrm{C}$ with a $1.5^{\circ} \mathrm{C} / \mathrm{min}$ rate, and was held at $800^{\circ} \mathrm{C}$ for 40 hours and then cooled to room temperature. The profile of gases overview during the entire experiment is shown in Figure 5.29.

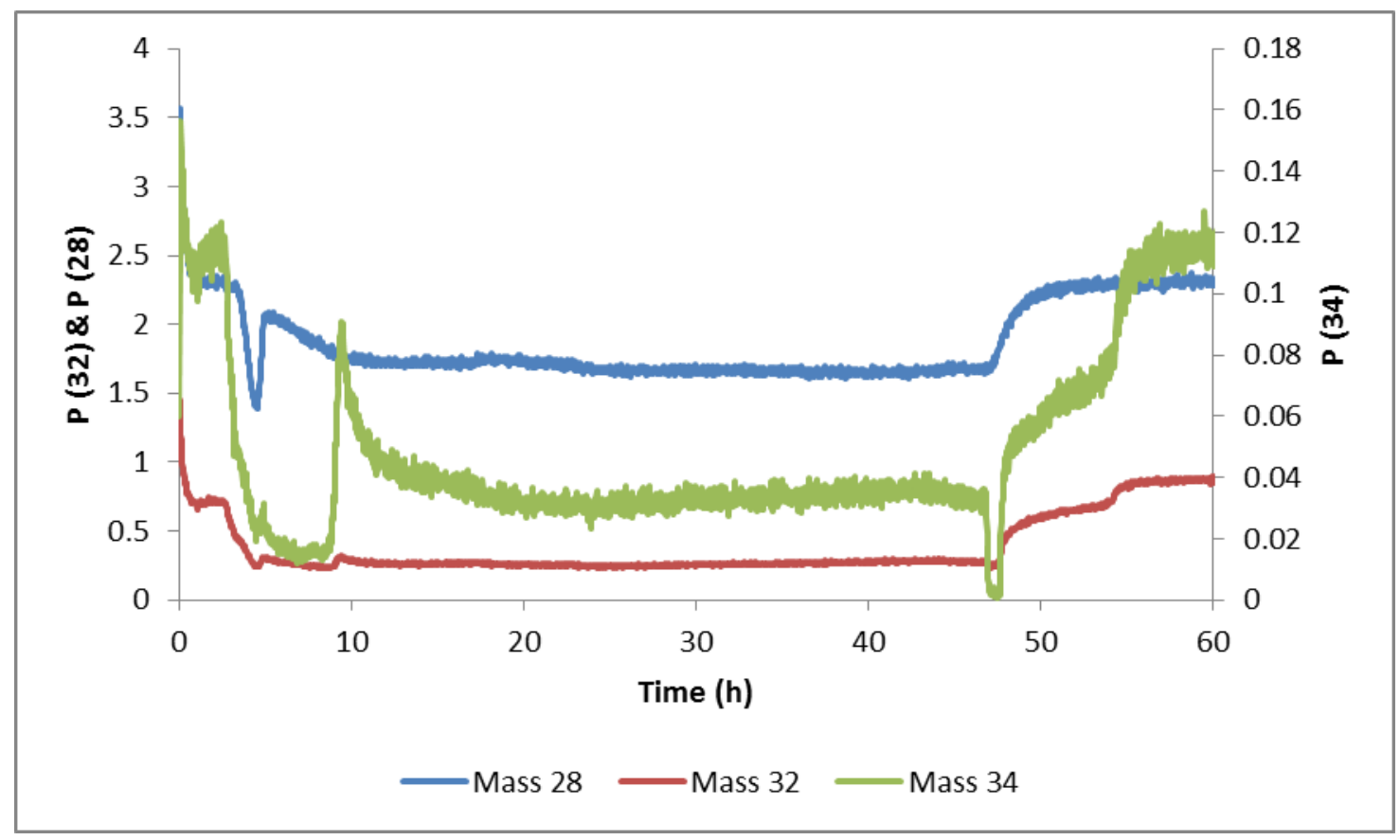

Figure 5.29 Gas pressures vs time during the "dry" $\mathrm{H}_{2}+\mathrm{NiO} / \mathrm{YSZ}$ sample in $20 \mathrm{ppm}$ $\mathrm{PH}_{3}$ with the Probostat test 
As described in other experiments, the $\mathrm{N}_{2}$ signal decreases linearly with increasing temperature. Due to reduction reaction of the $\mathrm{NiO}$ with $\mathrm{H}_{2}$ to form metallic $\mathrm{Ni}$, a large amount of water is released, replacing part of the $\mathrm{N}_{2}$ signal at mass 28 . The dip in the $\mathrm{N}_{2}$ signal is clearly seen in detail in Figure 5.31, with a water peak at $300-400^{\circ} \mathrm{C}$.

Figure 5.30 is a plot of gases during the heating phase. The $\mathrm{PH}_{3}$ signal drops with temperature rise to about 0.02 torr, starting at $200^{\circ} \mathrm{C}$. When the furnace temperature approaches $800^{\circ} \mathrm{C}$, the $\mathrm{PH}_{3}$ signal rises back to a spike peak of 0.09 torr, and then slowly coasts to a stable 0.03 torr level (Figure 5.29). There is also a dip of $\mathrm{PH}_{3}$ during the cooling down process. Then the $\mathrm{PH}_{3}$ signal climbs back to its initial value above 0.1 torr after complete cool down. The presence of $\mathrm{PH}_{3}$ in the exhaust at $800^{\circ} \mathrm{C}$ with a piece of $\mathrm{Ni} / \mathrm{YSZ}$ in the Probostat suggests that some of the $\mathrm{PH}_{3}$ passes by the $\mathrm{Ni}$ without reaction.

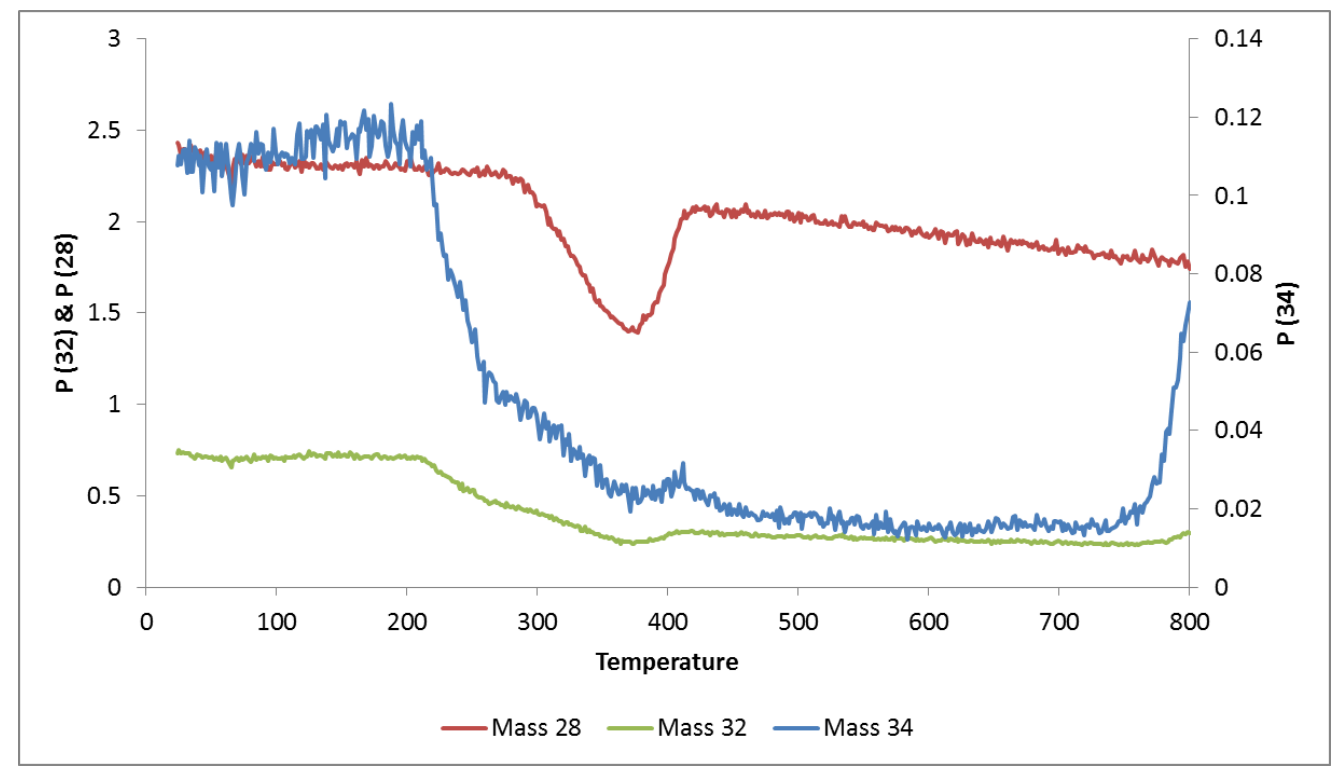

Figure 5.30 Pressures of $\mathrm{O}_{2}, \mathrm{~N}_{2}$ and Mass34 vs temperature during the heating phase of “dry" $\mathrm{H}_{2}+\mathrm{NiO} / \mathrm{YSZ}$ sample in 20 ppm $\mathrm{PH}_{3}$ with the Probostat. 


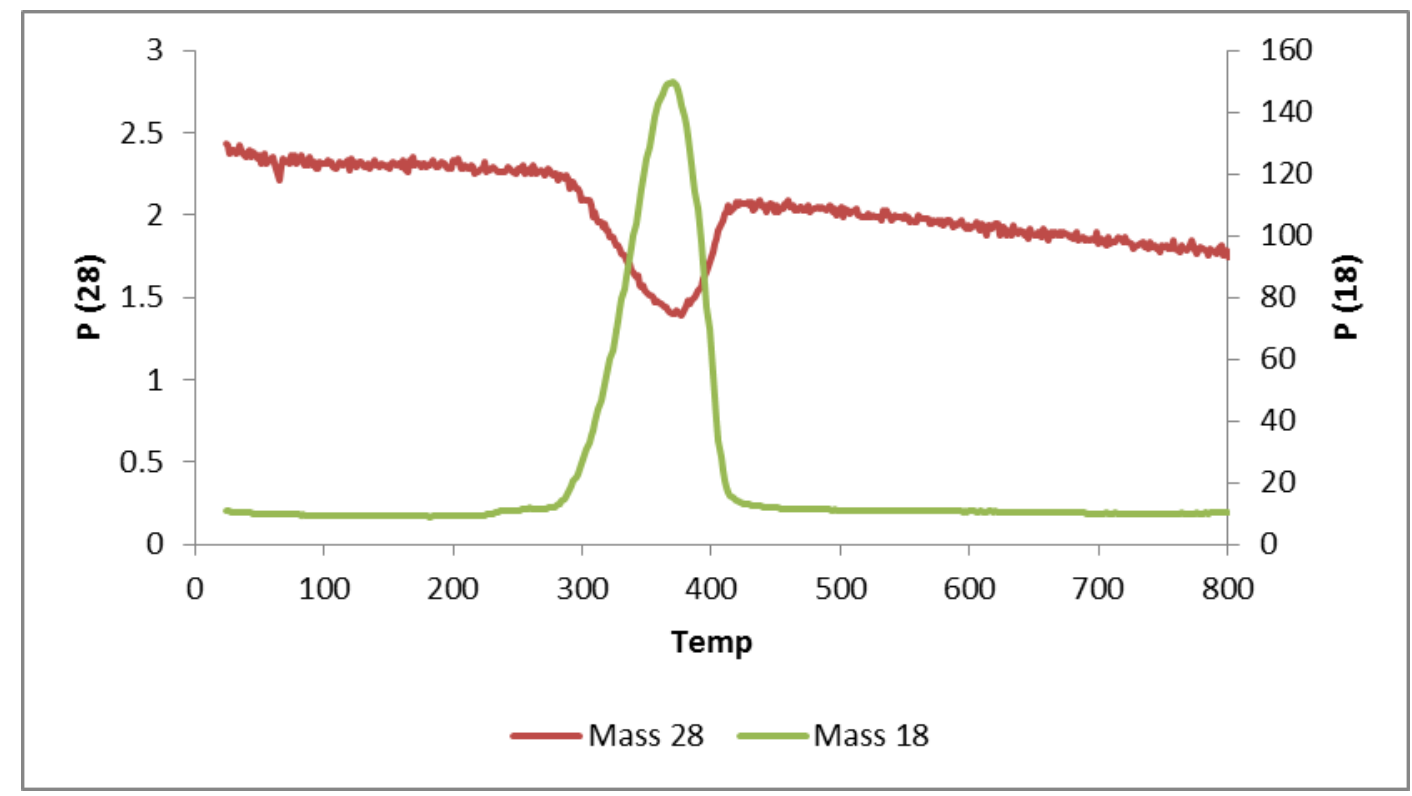

Figure 5.31 Pressures of water and $\mathrm{N}_{2}$ vs temperature during the heating phase of "dry"

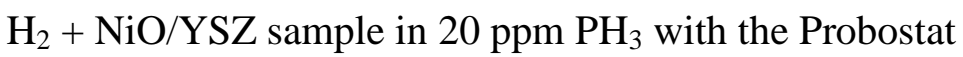

\section{"Wet" $\mathrm{H}_{2}$ and $\mathrm{NiO} / \mathrm{YSZ}$ exposed to $20 \mathrm{ppm} \mathrm{PH}{ }_{3}$ test with the Probostat: A NiO/YSZ}

piece was placed inside the inner alumina tube of the Probostat. The gases were prepared as described in other "wet" $\mathrm{PH}_{3}$ tests. The temperature was ramped up with a $1.5^{\circ} \mathrm{C} / \mathrm{min}$ rate to $800^{\circ} \mathrm{C}$ and stayed at $800^{\circ} \mathrm{C}$ for about 40 hours. Then the furnace was cooled down.

Figure 5.32 is the gas overview of the whole process. The water signal (not shown) is very high (100-120 torr) and stable. The other major differences between "dry" and "wet" conditions are the $\mathrm{PH}_{3}$ levels at $800^{\circ} \mathrm{C}$. In "wet" conditions, the $\mathrm{PH}_{3}$ signal drops to the noise level and does not recover when the temperature is close to $800^{\circ} \mathrm{C}$. Figure 5.33 is a detailed plot of gases vs the temperature during the heating step. However, the $\mathrm{PH}_{3}$ still climbs up to the initial value near the end of the experiment, when the temperature is cool enough. 


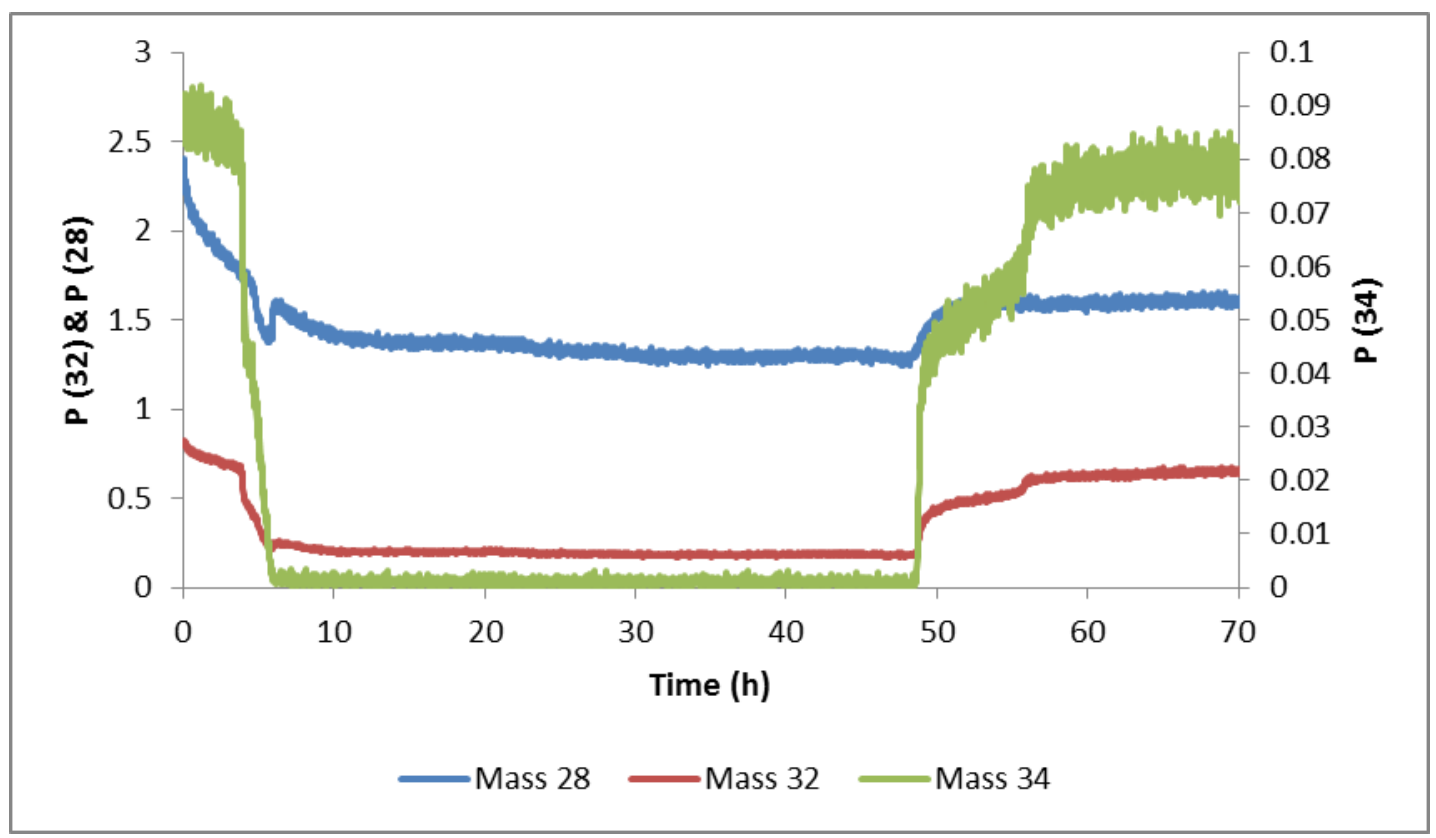

Figure 5.32 Gas pressures vs time during the "wet" hydrogen $+20 \mathrm{ppm} \mathrm{PH}_{3}$ with $\mathrm{NiO} / \mathrm{YSZ}$ in the Probostat.

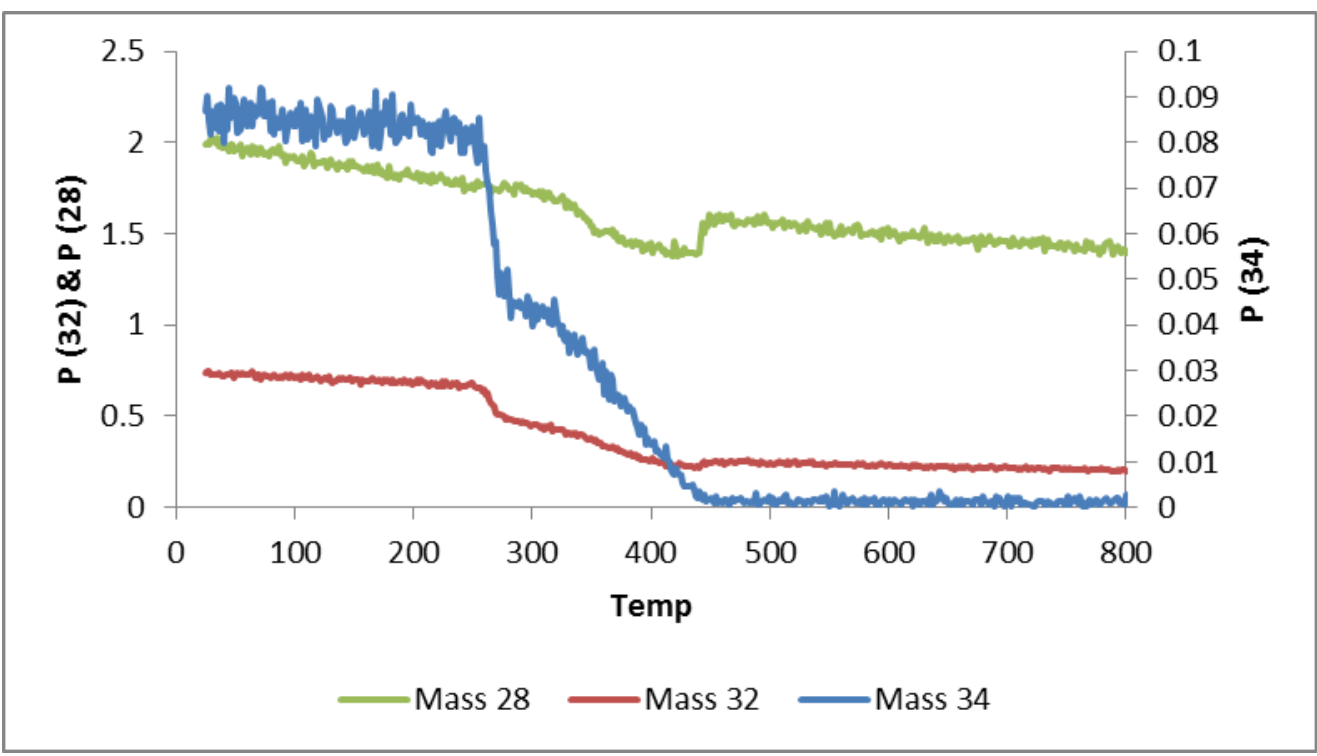

Figure 5.33 Gas pressures vs temperature for water, $\mathrm{N}_{2}$ and $\mathrm{PH}_{3}$ signal during heating phase of "wet" hydrogen +20 ppm $\mathrm{PH}_{3}$ test with NiO/YSZ present in the Probostat.

The $\mathrm{PH}_{3}$ signal at mass 34 in the Probostat tests shows a similar behavior with the tests using tube furnace configuration. $\mathrm{PH}_{3}$ drops when the temperature is ramping up, and then recovers when the temperature reaches $800^{\circ} \mathrm{C}$ in some of the tests. The signal of $\mathrm{N}_{2}$ 
is much different. In the ceramic tube tests, the $\mathrm{N}_{2}$ increases with temperature while in the Probostat tests it decreases. The reason is unknown. One hypothesis is that small leaks develop around the fittings of the ceramic tube during heating.

\subsection{Gas test with quartz tube.}

A quartz tube with outer diameter of 1 inch was used to replace the alumina tube. The purpose is to investigate any possible reactions between the alumina or quartz tube with the $\mathrm{PH}_{3}$. As before, $20 \mathrm{ppm}$ of $\mathrm{PH}_{3}$ in "dry" $\mathrm{H}_{2}$ was fed through the tube. The furnace was kept at room temperature for 3 hours to allow air impurities to be purged out. Then the temperature was ramped up to $800^{\circ} \mathrm{C}$ over 6 hours, kept at $800^{\circ} \mathrm{C}$ for 10 hours, and then cooled down over 6 hours. The overall view of masses 28,32 and 34 is shown in

Figure 5.34. A detailed gas pressure vs temperature is in Figure 5.35. The $\mathrm{PH}_{3}$ at mass 34 is at 0.03 torr initially. When the temperature reaches $348^{\circ} \mathrm{C}$, the $\mathrm{PH}_{3}$ signal decreases very sharply. Within 3 minutes, the signal at mass 34 drops to nearly zero (noise level). With the temperature still rising, the mass 34 signal gradually recovers at about $600^{\circ} \mathrm{C}$. After $800^{\circ} \mathrm{C}$, the $\mathrm{PH}_{3}$ signal stabilizes at 0.02 torr, about $60 \%$ of the initial amount. This same "dip" behavior occurs also during the cool down phase. The final sharp rise of $\mathrm{PH}_{3}$ signal occurred at $277^{\circ} \mathrm{C}$. 


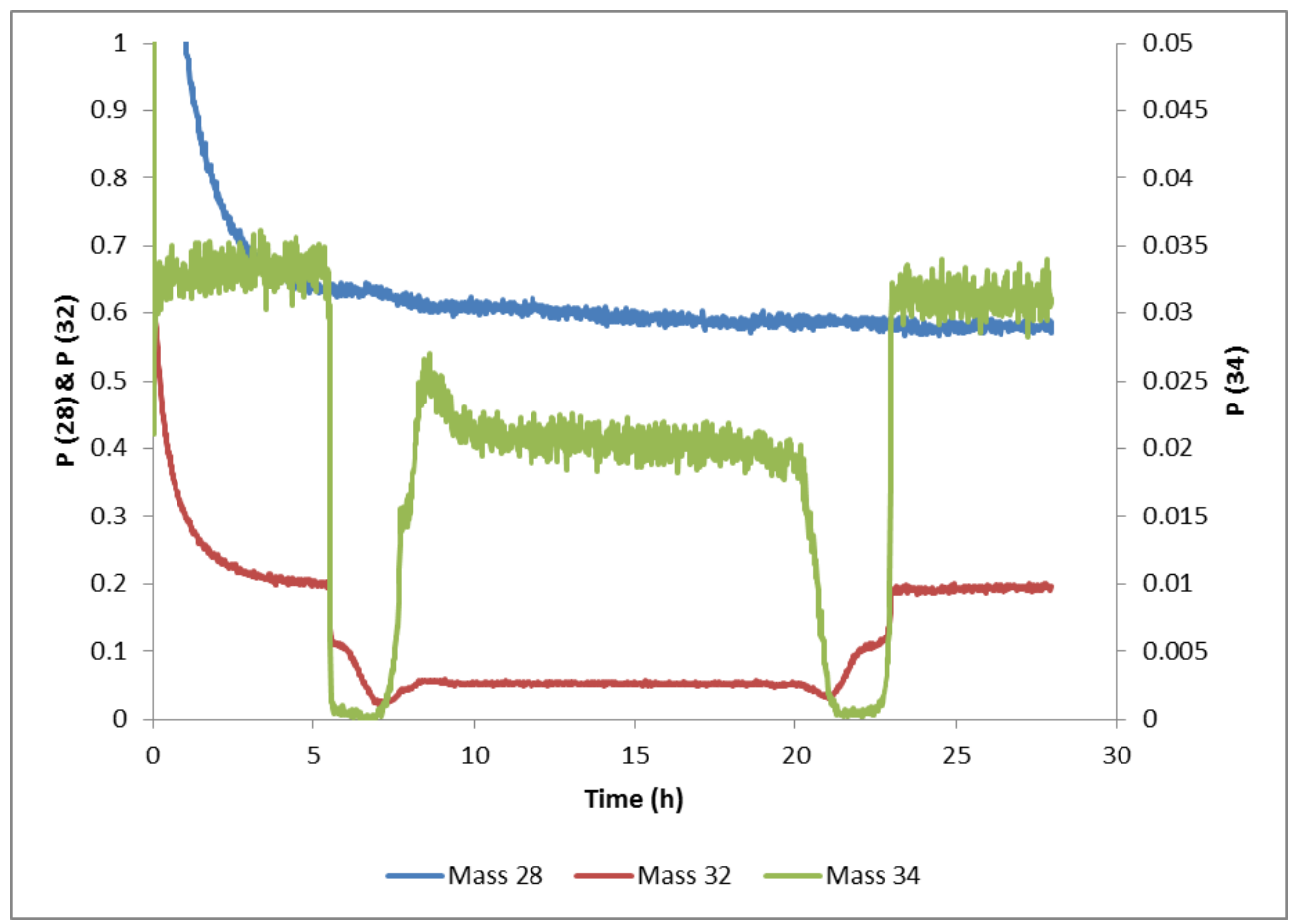

Figure 5.34 Gas pressures vs time in "dry" $\mathrm{H}_{2}+20$ ppm $\mathrm{PH}_{3}$ with the quartz tube..

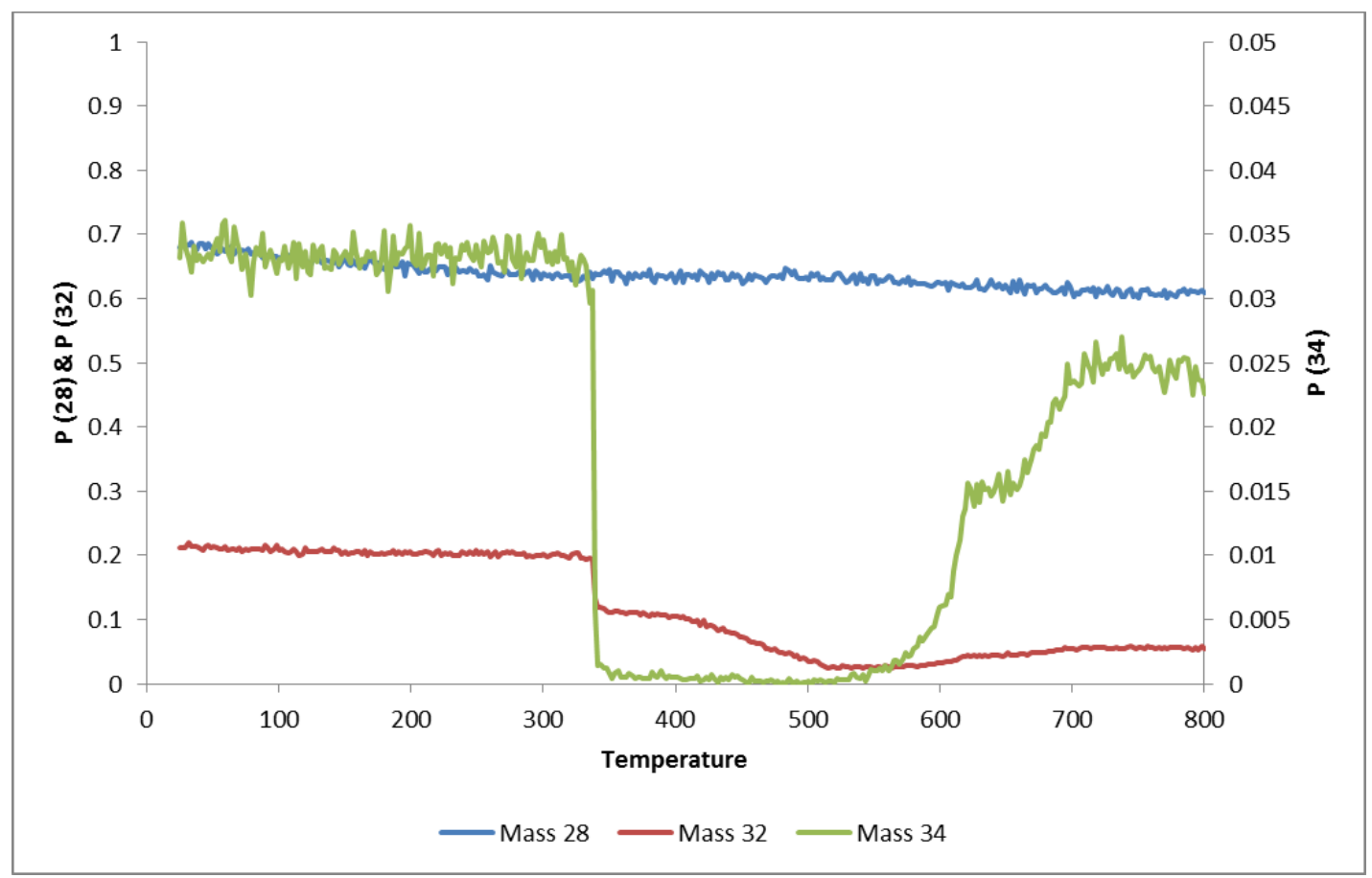

Figure 5.35 Gas pressures vs temperature for water, $\mathrm{N}_{2}$ and $\mathrm{PH}_{3}$ signal during the heating phase of the test with the quartz tube. 
A comparison of mass spectra taken at $300^{\circ} \mathrm{C}$ and $500^{\circ} \mathrm{C}$ is shown in Figure 5.36. Masses 31, 32, 33 and 34 signals all show a decrease with the increased temperature. No new species appear above mass 44 . The pattern with a quartz tube is very similar to the pattern with an alumina tube, suggesting that reactions of $\mathrm{PH}_{3}$ are not associated with the surface or the material of the tube. After the experiment, the quartz tube was checked visually and no deposits were found in the inner surface.

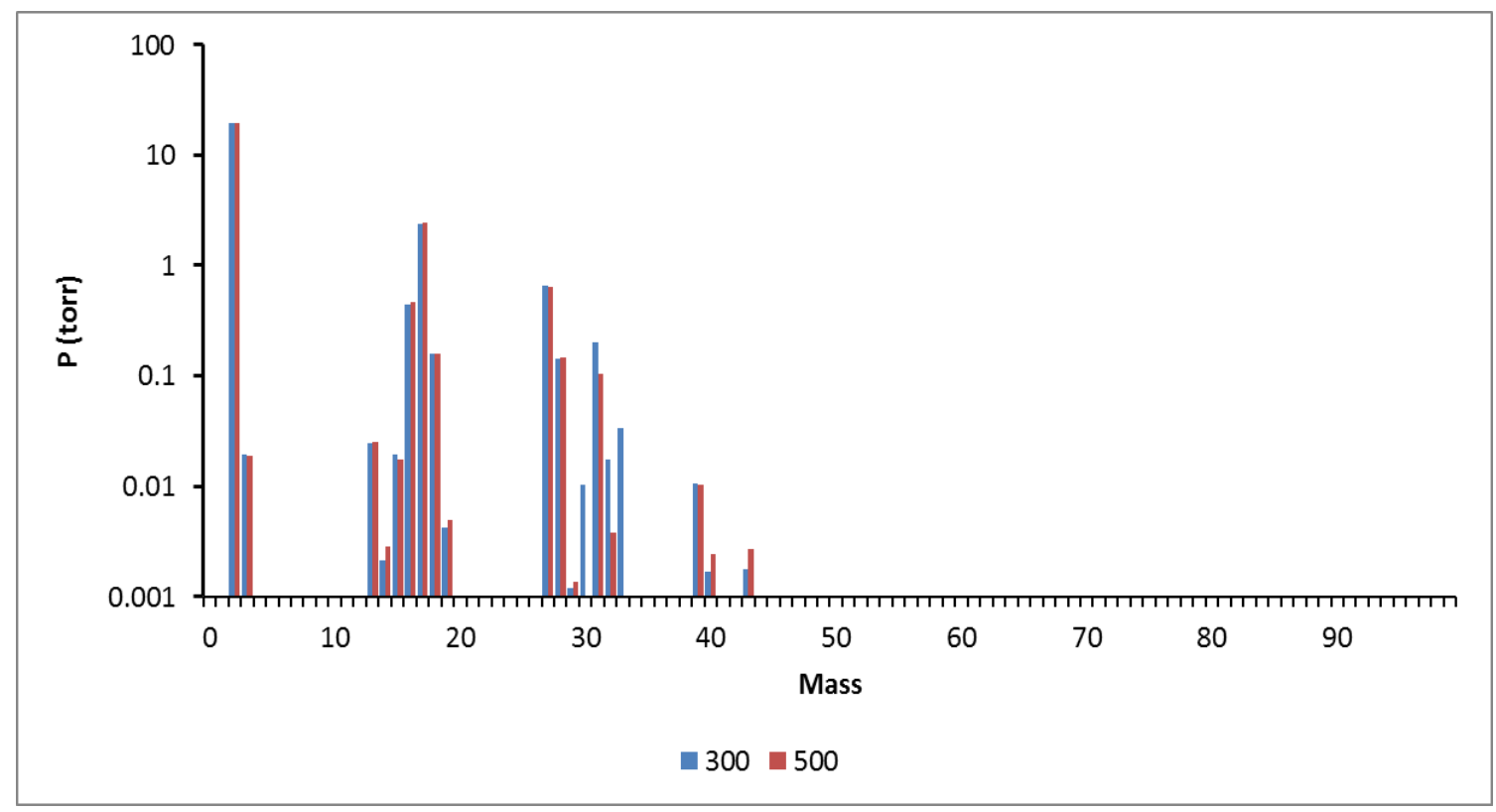

Figure 5.36 Comparison of mass spectra at $300^{\circ} \mathrm{C}$ and $500^{\circ} \mathrm{C}$.

\subsection{Conclusion and discussions}

Loss of $\mathrm{PH}_{3}$ is observed in most of the tests at various temperatures. However, at no point in any of the tests and at any of the conditions are any significant mass signals observed at masses above 44. One hypothesis is that the loss of the $\mathrm{PH}_{3}$ is due to reactions, and that the products of these reactions are not detected because either they are 
not volatile or they have molecular mass greater than $100 \mathrm{amu}$. The "nonvolatile" hypothesis is inconsistent with the known effect of phosphine on the anode of a SOFC.

In the "dry" $\mathrm{H}_{2}$ without water added, $\mathrm{PH}_{3}$ reacts at intermediate temperatures in the range of about $300-600^{\circ} \mathrm{C}$. But the $\mathrm{PH}_{3}$ does not react at high temperatures (close to $\left.800^{\circ} \mathrm{C}\right)$. With the presence of $\mathrm{NiO} / \mathrm{YSZ}$ sample, $\mathrm{PH}_{3}$ reacts with the $\mathrm{Ni} / \mathrm{YSZ}$ once the $\mathrm{NiO}$ is reduced in $\mathrm{H}_{2}$. The trends in loss/recover of $\mathrm{PH}_{3}$ signals are tracked by $\mathrm{O}_{2}$ signals (mass 32), but not by water signals (mass 18).

The result in the test with quartz tube in Section 5.4 is similar to the results on the alumina tube in Section 5.1.3. This result suggests that there is no reaction between the $\mathrm{PH}_{3}$ and the tube wall. The "dip" of $\mathrm{PH}_{3}$ signal during heating is reproducible with both tubes even though they are made from different material.

From the observations discussed above, a conclusion is drawn that in "dry" $\mathrm{H}_{2}$ conditions at $800^{\circ} \mathrm{C}, \mathrm{PH}_{3}$ will retain its form and reaches the anode of the SOFC. And, in "wet" conditions, $\mathrm{PH}_{3}$ reacts to form other species that not detected by the RGA. Thus, the species reaching the anode in "wet" conditions are currently not known. However, in the previous cell tests, the anode reacts with $\mathrm{PH}_{3}$ in both dry and wet conditions. Nickel phosphides $\left(\mathrm{Ni}_{\mathrm{x}} \mathrm{P}_{\mathrm{y}}\right)$ are observed on the anode surface as a product. [3-5] The phosphorous species is reaching the anode in either dry or wet case and reacting with the nickel to form nickel phophides. 


\section{References in Chapter 5}

[1] J.P. Trembly, R.S. Gemmen, D.J. Bayless Journal of Power Sources 2007, 163, 986996

[2] United States Environmental Protection Agency Material Safety Data Sheet for Phosphine $\left(\mathrm{PH}_{3}\right)$.

[3] Chunchuan Xu, J. Zondlo, H. O. Finklea, O. Demircan, M. Gong, X. Liu Journal of Power Sources 2009, 193, 739-746

[4] Mingjia Zhi, Xinqi Chen, Harry Finklea, Ismail Celik, Nianqiang Q.Wu Journal of Power Sources 2008, 183, 485-490

[5] O. Demircan, W. Zhang, C. Xu, J. Zondlo, H. Finklea, Journal of Power Sources

2010, 195, 3091-3096

[6] K. Haga, Y. Shiratori, Y. Nojiri, K. Ito, and K. Sasaki, Journal of The

Electrochemical Society 2010, 157, B1693-B1700 


\section{Chapter 6 In-situ cell tests with Mass Spectrometry in WVU}

\section{Chemistry Research Lab}

\subsection{Experimental set up}

The gas manifold described in Chapter 5 is modified to deliver gas to the Probostat for the cell test. The modified diagram is in Figure 6.1. In this set up, $\mathrm{H}_{2}$ goes to the anode side, air goes to the cathode side and He can be fed to both sides if needed. The air source is a compressed air cylinder.

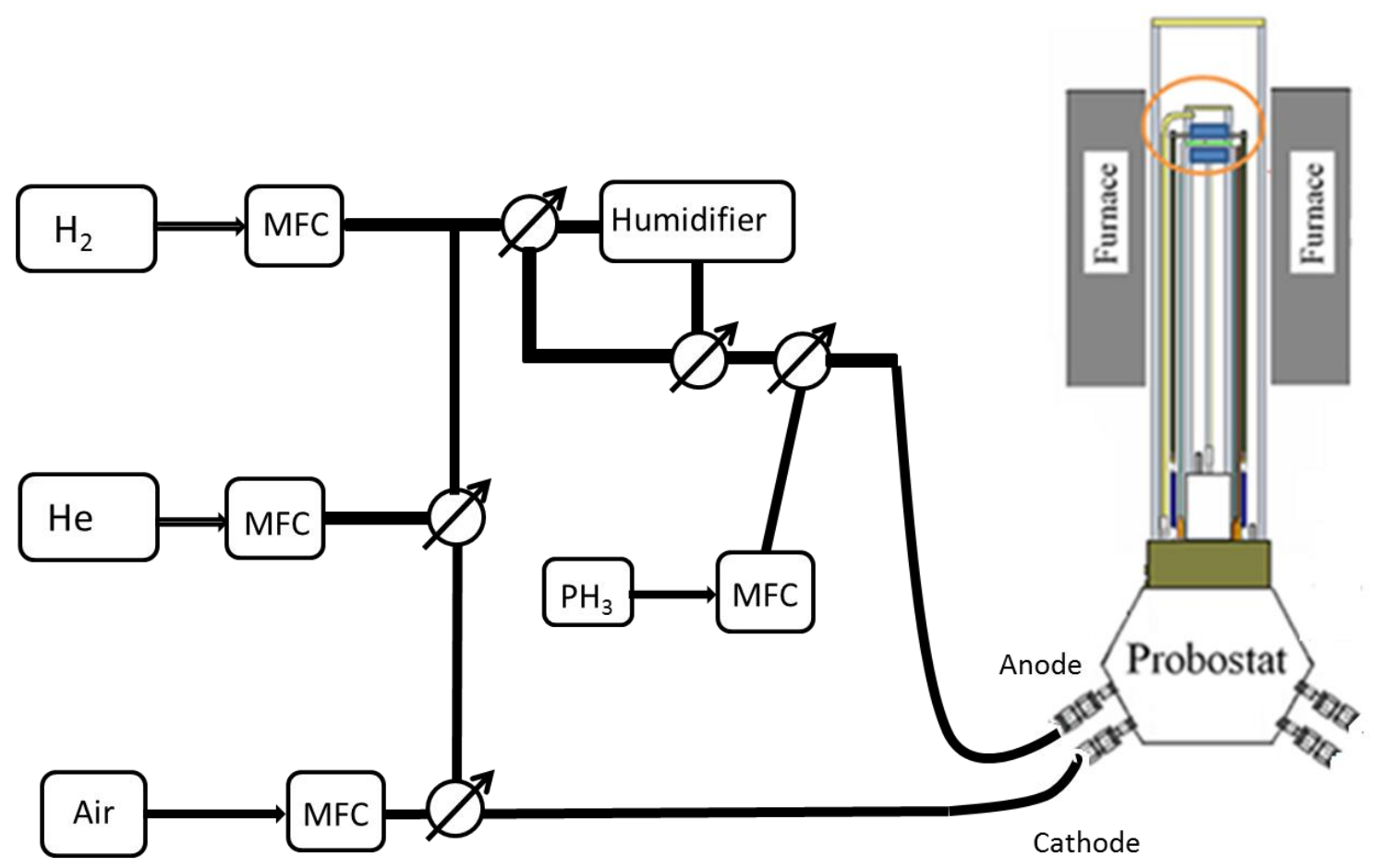

Figure 6.1 gas manifold used in the cell test

The Probostat was used as the testing platform and a MSRI anode-supported cell was mounted in the Probostat. The original cell had a diameter of $27 \mathrm{~mm}$. It was polished down to $25 \mathrm{~mm}$ to fit in the Probostat. The cathode area of the cell was $1.54 \mathrm{~cm}^{2}$, smaller 
than the anode. In the experiments that follow, the normalization of the electrochemical data is based on the area of the cathode. The connection to the cell cathode was made through the inner tube as described earlier in Chapter 4. A new method using a glass tape sealing material to prevent leaks was employed in this test. Two layers of O-ring shaped glass tape were nested together to make a gasket between the cell and the supporting tube. A photo showing the assembling of the cell is in Figure 6.2. The cell was pressed down with a spring-loaded alumina assembly. High tension springs were chosen in this test.

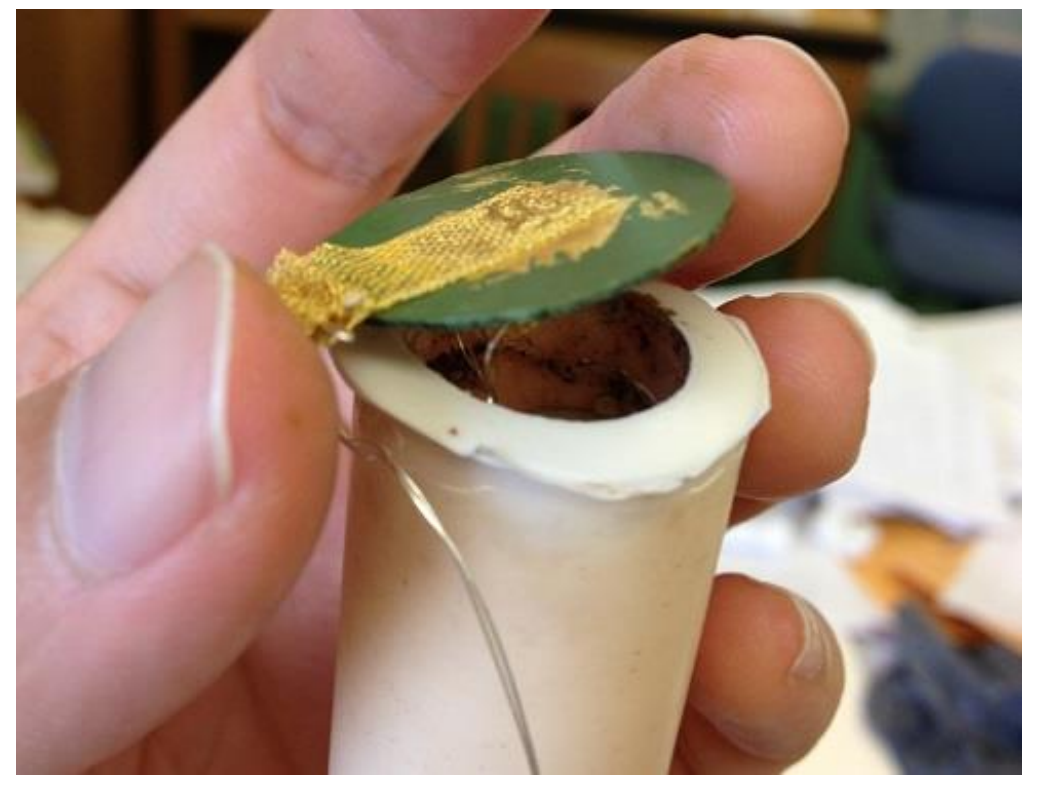

Figure 6.2 Assembling a cell with glass tape seals.

The electrochemical tests were performed using a Gamry potentiostat, which was connected to the cell using four leads: working electrode (for current), working sense (voltage sense), counter electrode (current) and reference electrode (voltage sense). The anode was connected as the working electrode. The polarization curves were obtained from the cyclic voltammetry tests. The impedance was tested from $100 \mathrm{kHz}$ to either 0.1 or $0.01 \mathrm{~Hz}$. 


\subsection{Cell test I - pre-conditioning.}

After the mounting the cell, the cathode side was fed with air and the anode side with He. The mass spectrometer was connected to the exhaust of the anode. The furnace was heated to $800^{\circ} \mathrm{C}$ at a rate of $0.8^{\circ} \mathrm{C} / \mathrm{min}$. The heating phase took 16.4 hours. $\mathrm{N}_{2}$ and $\mathrm{O}_{2}$ pressures during heating are plotted vs time in Figure 6.3. Water and mass 34 signals are in Figure 6.4. During this heating step, the $\mathrm{N}_{2}$ and $\mathrm{O}_{2}$ and mass 34 (mainly from ${ }^{34} \mathrm{O}_{2}$ as a leak indicator) pressures increased and then abruptly decreased, suggesting that the glass tape had sealed the cell. The abrupt drop in pressures appears to occur before the furnace reached the set point temperature $\left(800^{\circ} \mathrm{C}\right)$ at 16.4 hours, suggesting that the glass seal had formed at a lower than expected temperature $\left(850^{\circ} \mathrm{C}\right)$. The water signal at mass 18 dropped to about 0.25 torr.

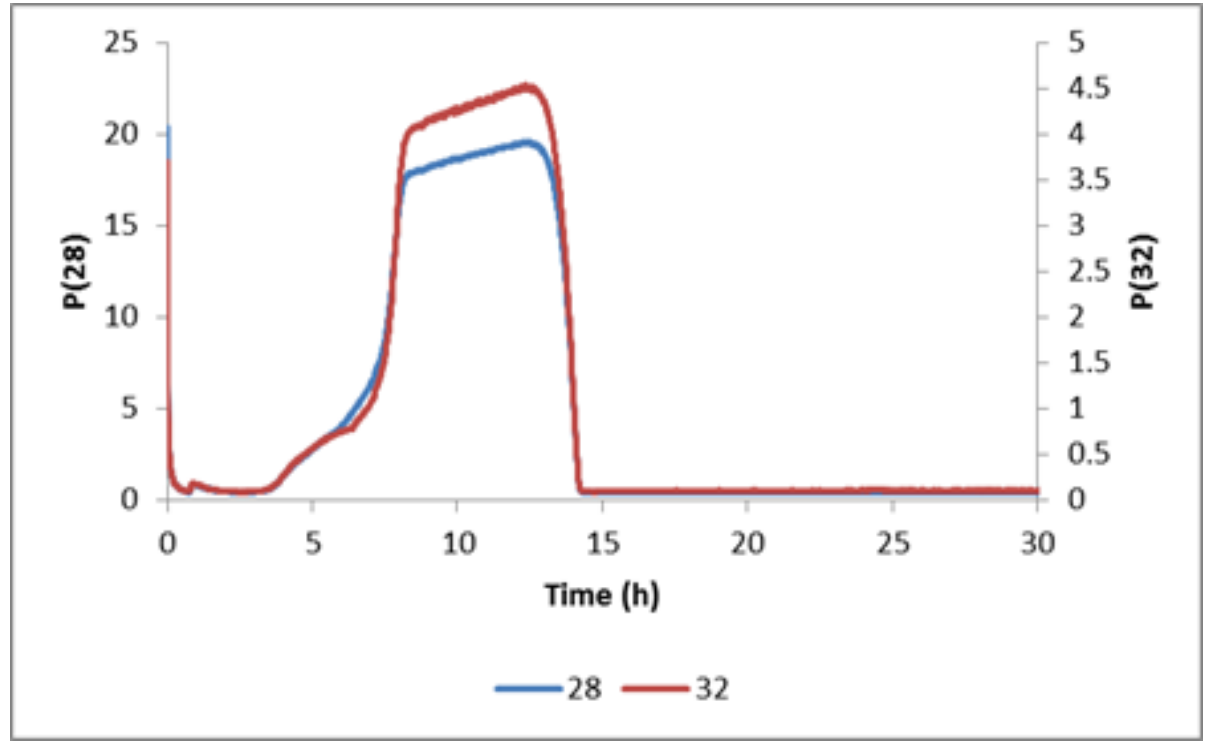

Figure 6.3 Gas pressures vs time for $\mathrm{N}_{2}$ and $\mathrm{O}_{2}$ during the initial heating phase, the cell reached $800^{\circ} \mathrm{C}$ at 16.4 hours. 


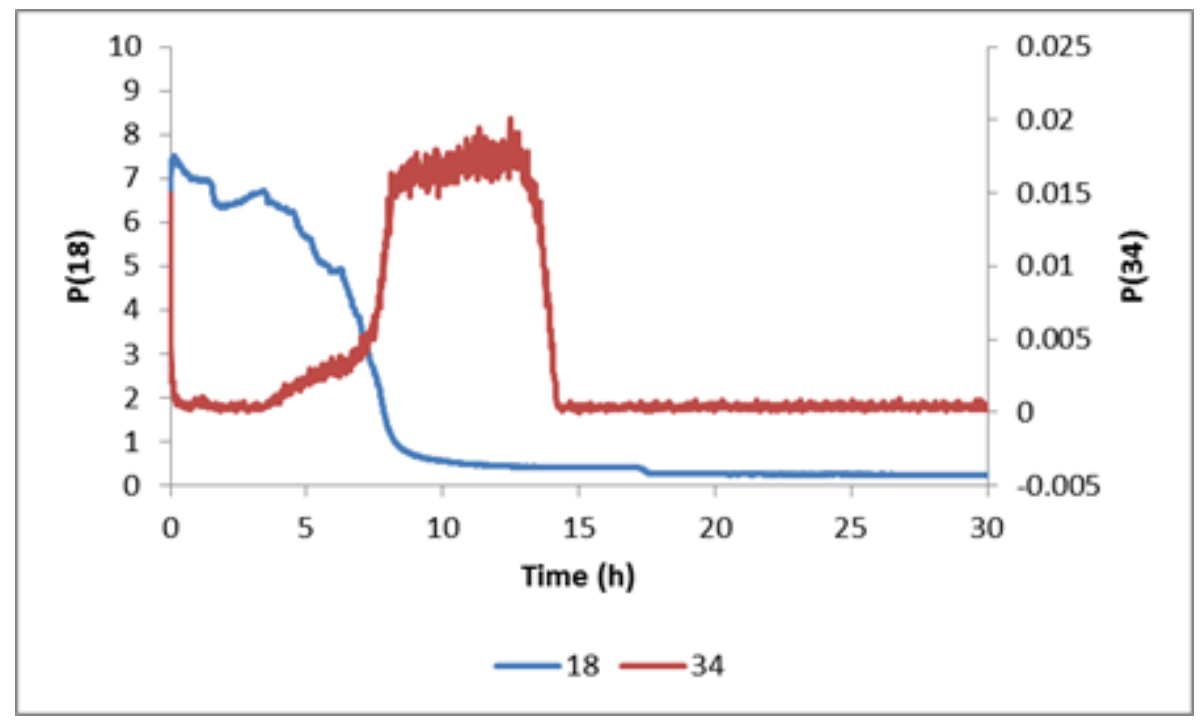

Figure 6.4 Gas pressures vs time for water and mass 34 during the initial heating phase, the cell reached $800^{\circ} \mathrm{C}$ at 16.4 hours.

The cell was then reduced in $10 \% \mathrm{H}_{2}$ in helium (at 32.1 hours in Figure 6.5), $50 \% \mathrm{H}_{2}$ in helium (at 43.9 hours) and $100 \% \mathrm{H}_{2}$ (at 48.5 hours). The open circuit voltage of the cell was $1.174 \mathrm{~V}$ at this point. The $\mathrm{N}_{2}$ and $\mathrm{O}_{2}$ pressures are in Figure 6.5, and the water and mass 34 signals are in Figure 6.6. The spike in mass 28 at 32 hours corresponds to the addition of $10 \% \mathrm{H}_{2}$ to the He. There are usually some residual air impurities in a gas line that appear when that line is switched on. The water pressure rises to $\sim 10$ torr for 3.5 hours and then suddenly drops. This step corresponds to the water generated by the reduction of $\mathrm{NiO}$ to $\mathrm{Ni}$. During this time, $\mathrm{N}_{2}$ and $\mathrm{O}_{2}$ signals show a slight rise. At $44 \mathrm{~h}$, the change to $50 \% \mathrm{H}_{2}$ causes step rises in $\mathrm{N}_{2}, \mathrm{O}_{2}$, and $\mathrm{H}_{2} \mathrm{O}$. Steps also appear at the change to $100 \%$ of $100 \mathrm{sccm} \mathrm{H}_{2}$ at 48 hours. These changes are attributed to the impurities in the hydrogen supply. The open circuit voltage was $1.189 \mathrm{~V}$ after the cell was reduced. This high OCV is consistent with a leak-free seal and with "dry" $\mathrm{H}_{2}$ as the fuel. $200 \mathrm{sccm}$ of air was fed to the cathode during the entire experiment. 


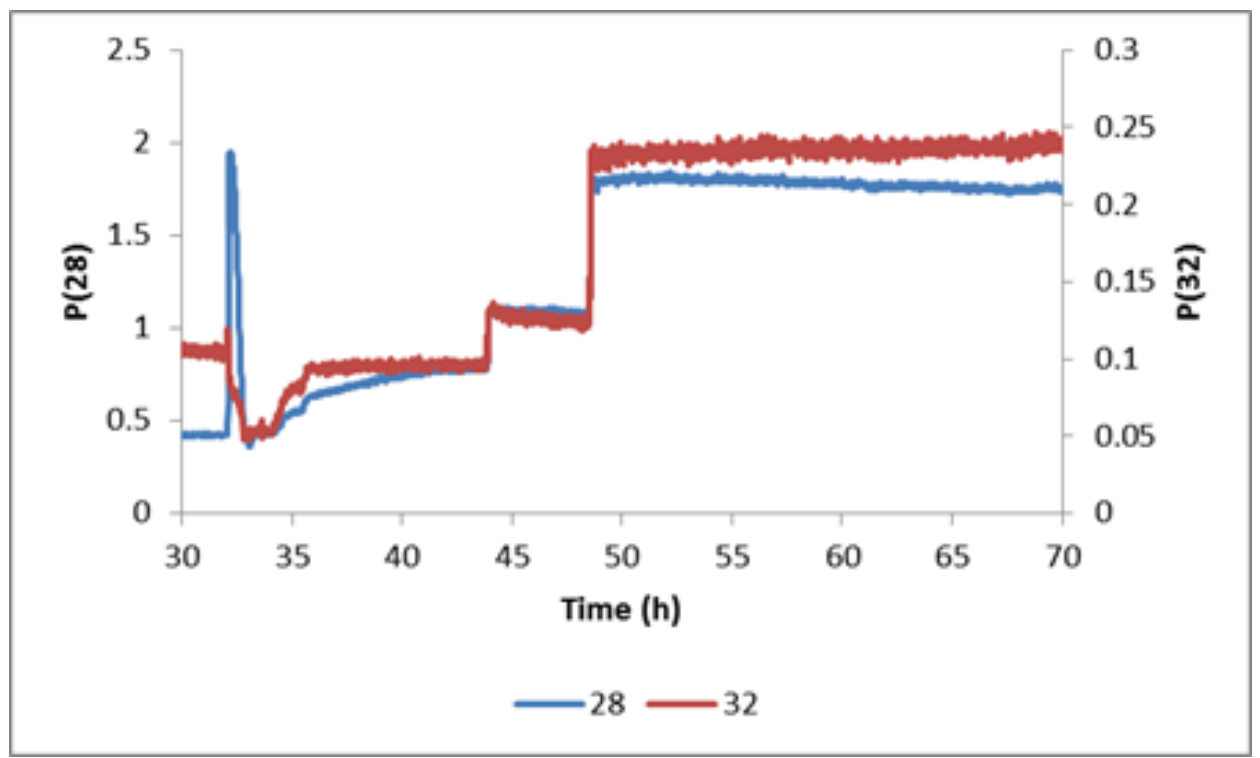

Figure 6.5 $\mathrm{N}_{2}$ and $\mathrm{O}_{2}$ pressures vs time during cell reduction. $\mathrm{H}_{2}$ was introduced to $10 \%$ at 32 hours, increased to $50 \%$ at 44 hours and $100 \%$ at 48 hours.

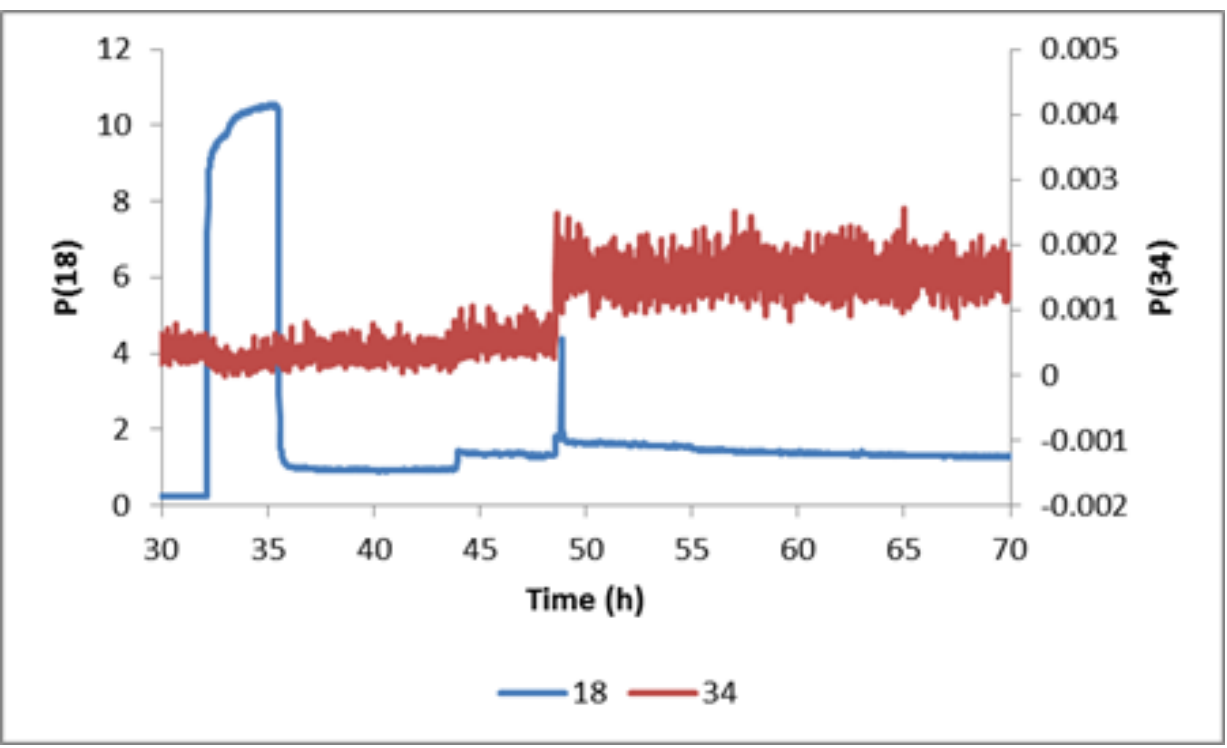

Figure 6.6 Water and mass 34 pressures vs time during cell reduction. The time of gas changes are the same as in Figure 6.5

A polarization curve from cyclic voltammetry was acquired after the cell was reduced (Figure 6.7). There is a slight hysteresis on the forward and reverse scan, possibly caused by generated water vapor near the anode during the reverse scan. The cell current density reaches nearly $0.64 \mathrm{~A} \mathrm{~cm}^{-2}$ at $0.1 \mathrm{~V}$. The peak power is $0.18 \mathrm{~W} \mathrm{~cm}^{-2}$ at $0.35 \mathrm{~A} \mathrm{~cm}^{-2}$. 
Impedance data in Figure 6.8 show that the normalized $R_{s}$ is $1.18 \Omega \mathrm{cm}^{2}$ and that $R_{p}$ is above $3.0 \Omega \mathrm{cm}^{2}$. The impedance scan extends from $100 \mathrm{kHz}$ to $0.1 \mathrm{~Hz}$ in this data set. The arc does not come down to the real axis at low frequencies, so the later impedance data sets were collected down to $0.01 \mathrm{~Hz}$. The high series resistance found in the impedance data accounts for the poor power performance of this cell. If the cell voltage

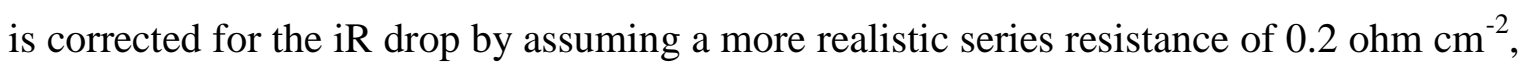
then the corrected cell voltage at $0.64 \mathrm{~A} / \mathrm{cm}^{2}$ is $0.74 \mathrm{~V}$, and the corresponding cell power is $0.48 \mathrm{~W} \mathrm{~cm}^{-2}$.

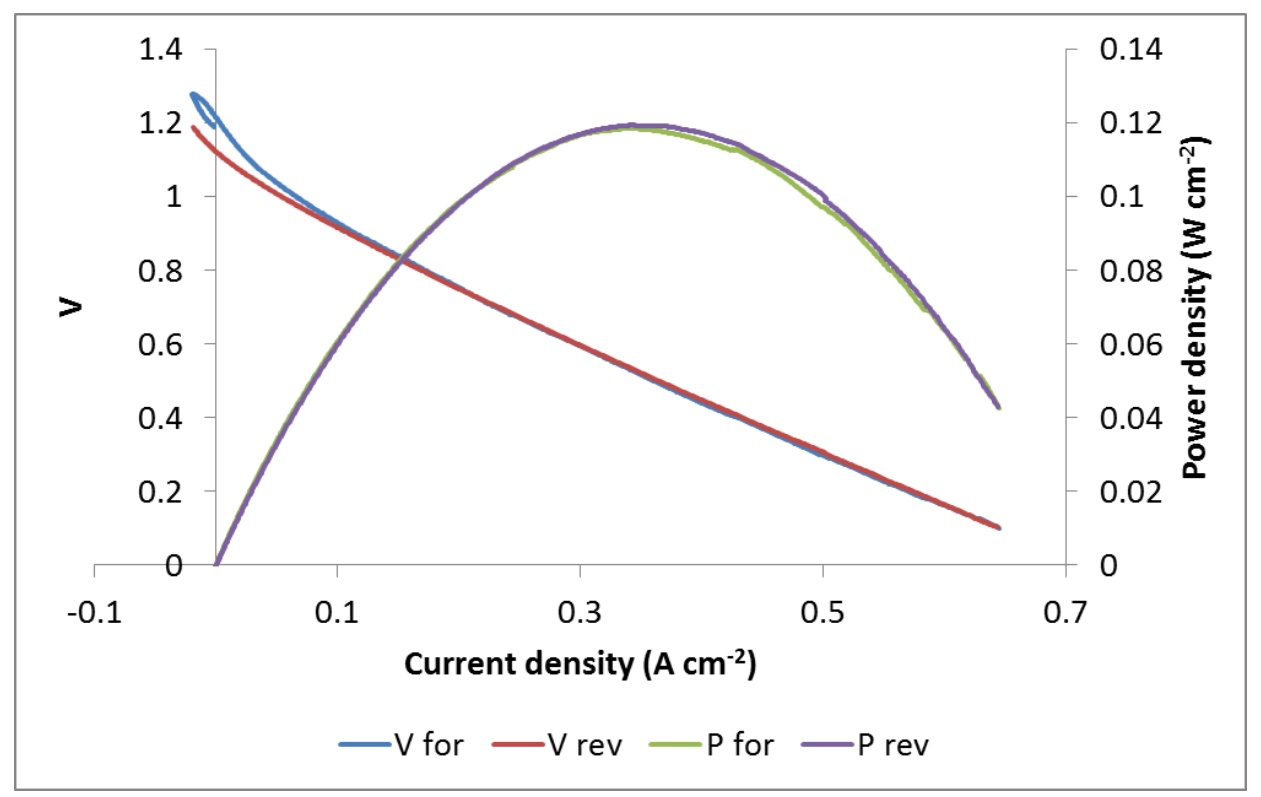

Figure 6.7 Cyclic voltammetry and power curve after cell reduction. Cell was in pure $\mathrm{H}_{2}$ at $800^{\circ} \mathrm{C}$. 


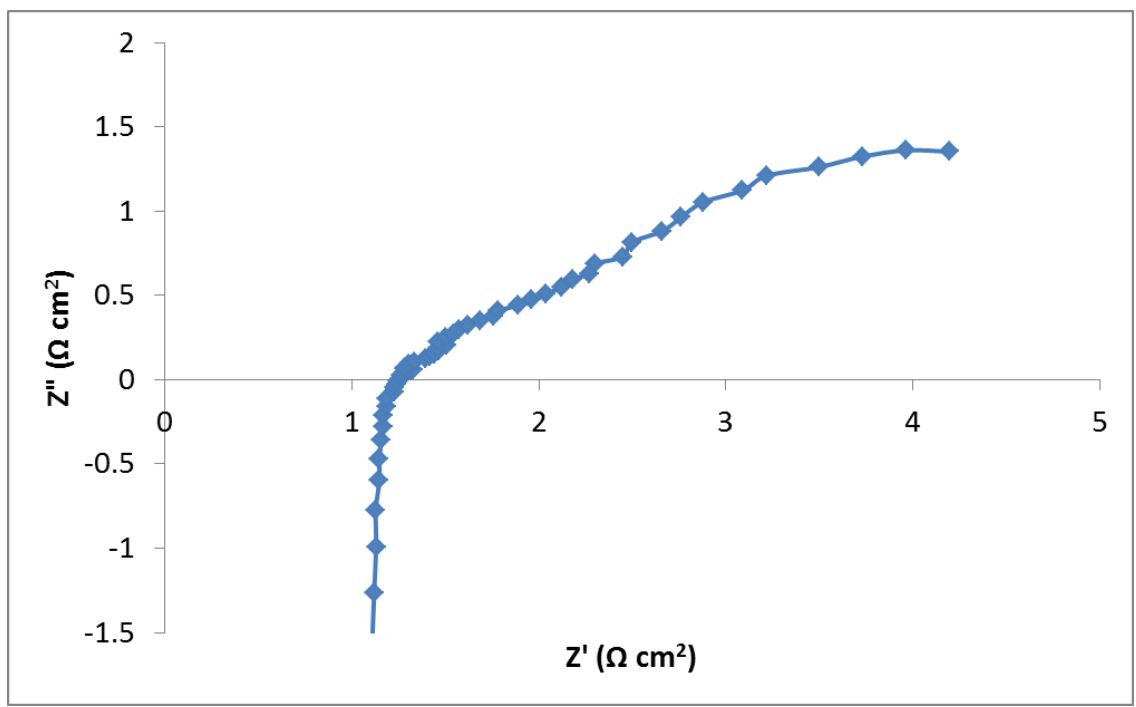

Figure 6.8 Nyquist plot in dry $\mathrm{H}_{2}$ after cell reduction. The cell was at $800^{\circ} \mathrm{C}$.

The $\mathrm{N}_{2}, \mathrm{O}_{2}$, water and mass 34 signals during the $\mathrm{CV}$ test are in Figures 6.9 and 6.10. The $\mathrm{CV}$ test was at 76 hours. Beginning from 76.4 hours, the cell was loaded at $1.0 \mathrm{~V}$ cell voltage to burn in the cell (a standard technique in SOFC research). The air peaks (mass 28 and 32) increase during current flow after 76.4 hours. This may due to a slight leak developed around the cell when the current is applied. The water generated during current flow is detected.

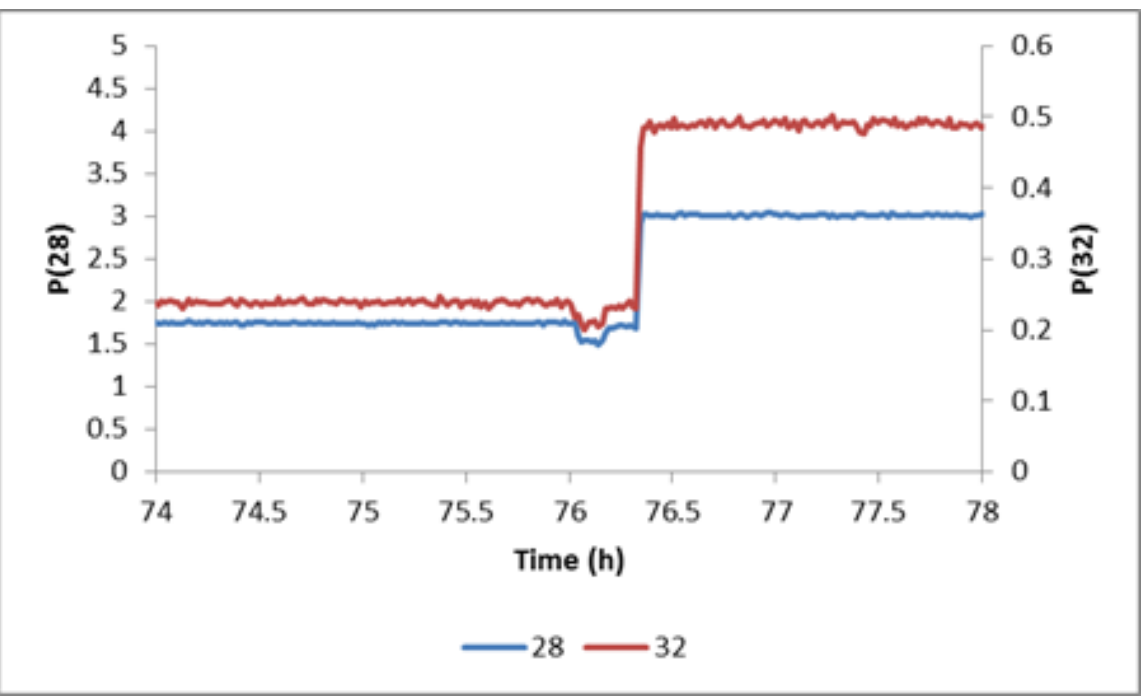

Figure 6.9 $\mathrm{N}_{2}$ and $\mathrm{O}_{2}$ pressures during the $\mathrm{CV}$ test. The cell was at $800^{\circ} \mathrm{C}$. 


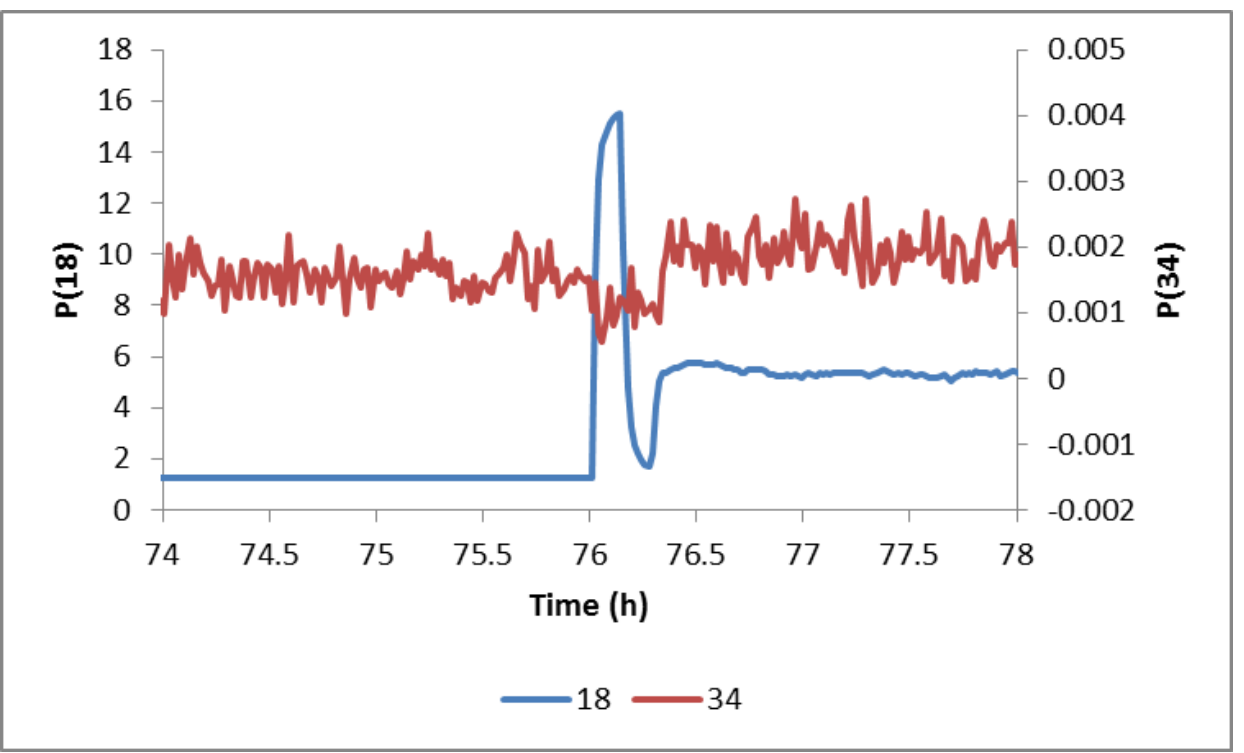

Figure 6.10 Water and mass 34 signals during the $\mathrm{CV}$ test. The cell was at $800^{\circ} \mathrm{C}$.

The current flow is stopped at 100 hours. In Figure 6.11, the $\mathrm{H}_{2} \mathrm{O}$ signal drops, but the $\mathrm{O}_{2}$ and $\mathrm{N}_{2}$ signals do not. This observation suggests that the formation of a leak occurs at the onset of current flow. The mass 34 signal tracks the mass 32 signal, suggesting that this small signal is caused by ${ }^{34} \mathrm{O}_{2}$.

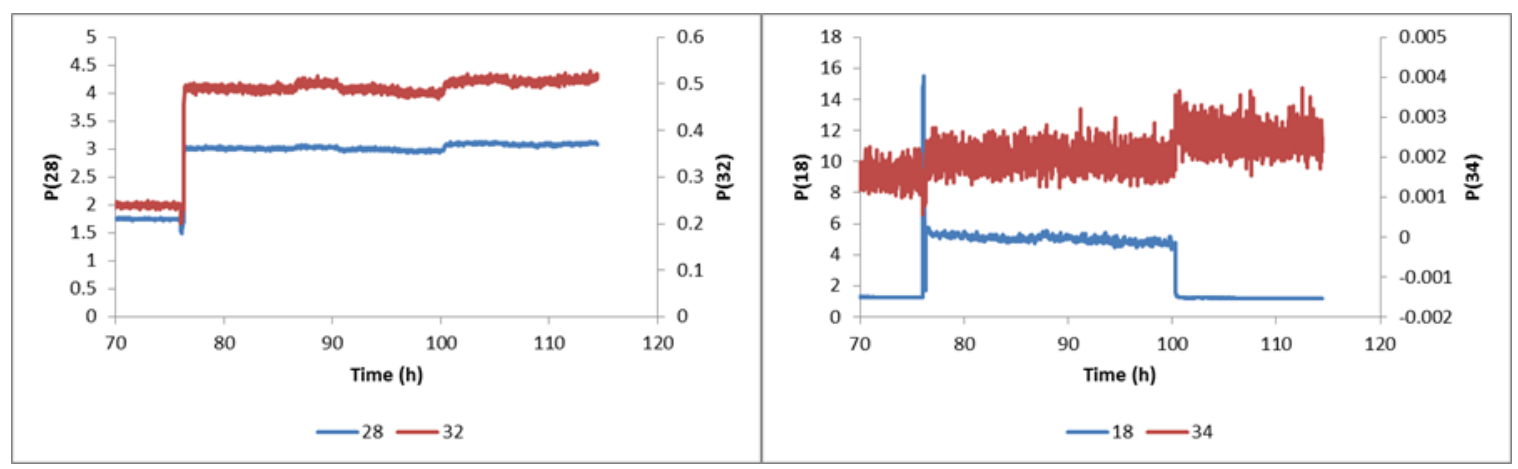

Figure 6.11 $\mathrm{N}_{2}, \mathrm{O}_{2}$, water and mass 34 pressures when a small current is applied. The cell was in "dry" $\mathrm{H}_{2}$ at $800^{\circ} \mathrm{C}$.

\subsection{Cell test II - different gas composition and cell voltages.}

In this section, the cell was the same single cell described in Section 6.2 with the same glass seal. The cell was first operated in "dry" $\mathrm{H}_{2}$, then the fuel flow was changed 
to "wet" $\mathrm{H}_{2}$, "dry" $\mathrm{H}_{2}+20$ ppm $\mathrm{PH}_{3}$ and "wet" $\mathrm{H}_{2}+20 \mathrm{ppm} \mathrm{PH}_{3}$, respectively. Mass spectrometry, cyclic voltammetry (CV) and electrochemical impedance (EIS) data were obtained for each gas composition.

\subsection{1 "Dry" hydrogen test.}

The fuel flow for this test is pure $\mathrm{H}_{2}$ at $100 \mathrm{sccm}$ from the cylinder. The cell is kept at open circuit except during electrochemical tests. The open circuit voltage is $1.189 \mathrm{~V}$. A polarization curve with the dry hydrogen as fuel is shown in Figure 6.12. The peak power density of $0.18 \mathrm{~W} \mathrm{~cm}^{-2}$ is seen at $0.49 \mathrm{~V}$. The current is $0.49 \mathrm{~A} \mathrm{~cm}^{-2}$ at $0.3 \mathrm{~V}$. While this cell performance improved after current burn-in, the figures of merit here are considered to be lower than cell performances in the previously published studies by Xu et al. [2-3] The current density of the cells tested by Xu can be up to $1 \mathrm{~A} \mathrm{~cm}^{-2}$ at $0.3 \mathrm{~V}$. As noted previously, the low performance is caused by the high series resistance. There are some hysteresis and noise in the polarization and power curves. This may due to the water generated during the scan to higher currents accumulating near the anode surface. 


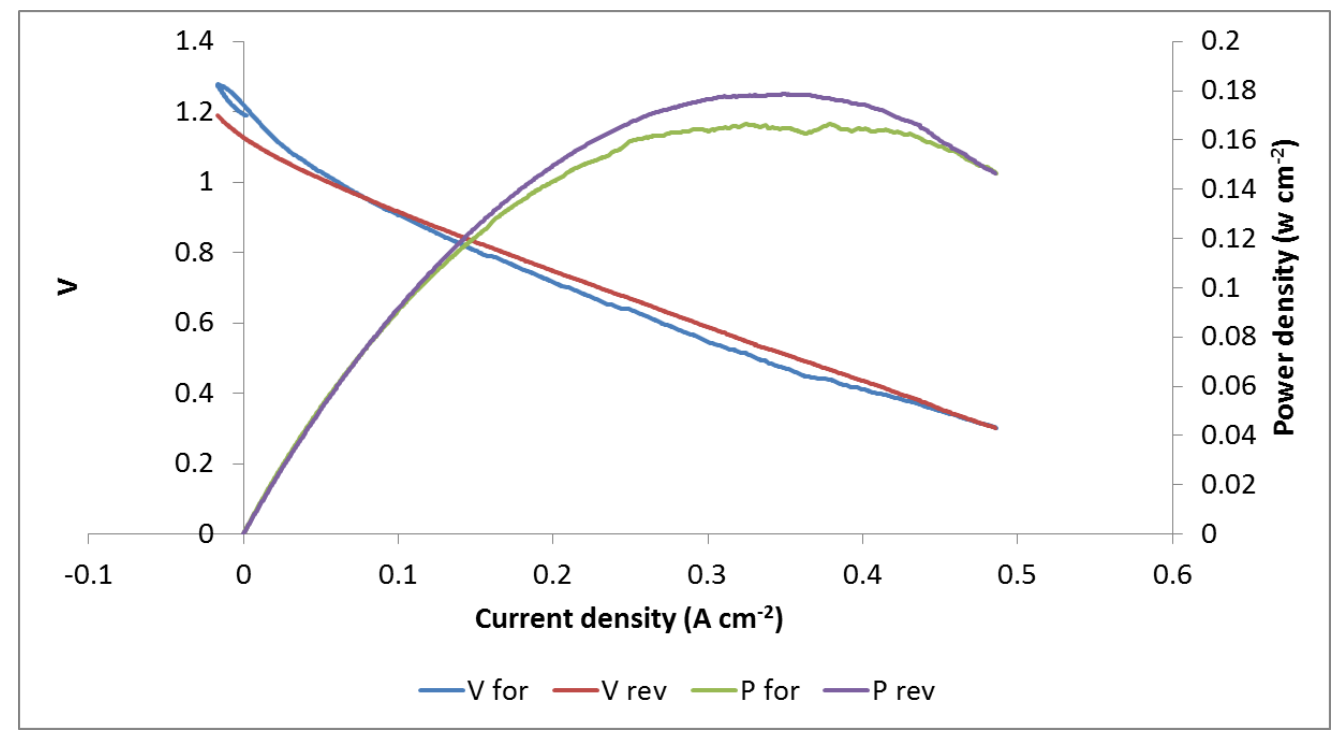

Figure 6.12 Polarization and power curves in "dry" $\mathrm{H}_{2}$ after burn-in. The cell was at $800^{\circ} \mathrm{C}$.

The EIS data (Nyquist plot) is in Figure 6.13 for a scan from $100 \mathrm{kHz}$ to $0.01 \mathrm{~Hz}$. The peak frequency is at $0.10 \mathrm{~Hz}$. The normalized $R_{s}$ is $1.2 \Omega \mathrm{cm}^{2}$ and the $R_{p}$ is larger than 5 $\Omega \mathrm{cm}^{2}$. Both of the resistances are very high compare to the cell tested by Xu et al., which is $0.2-0.3 \Omega \mathrm{cm}^{2}$ for the $\mathrm{R}_{\mathrm{s}}$ and less than $1 \Omega \mathrm{cm}^{2}$ for the $\mathrm{R}_{\mathrm{p}}[2]$. Correcting the cell voltage for iR drop and assuming a true series resistance of $0.2 \Omega \mathrm{cm}^{2}$ for $\mathrm{R}_{\mathrm{s}}$ leads to a minimum cell voltage of $0.78 \mathrm{~V}$ and a power of $0.38 \mathrm{~W} \mathrm{~cm}^{-2}$ at the maximum current of $0.48 \mathrm{~A} \mathrm{~cm}^{-2}$. With this correction, this cell's performance is closer to that of $\mathrm{Xu}$ et al. As will be shown later, the high polarization resistance arises from the low water pressure in the "dry" hydrogen. The test stand used by Xu et al. likely had higher water pressure due to leaks across the anode seal. 


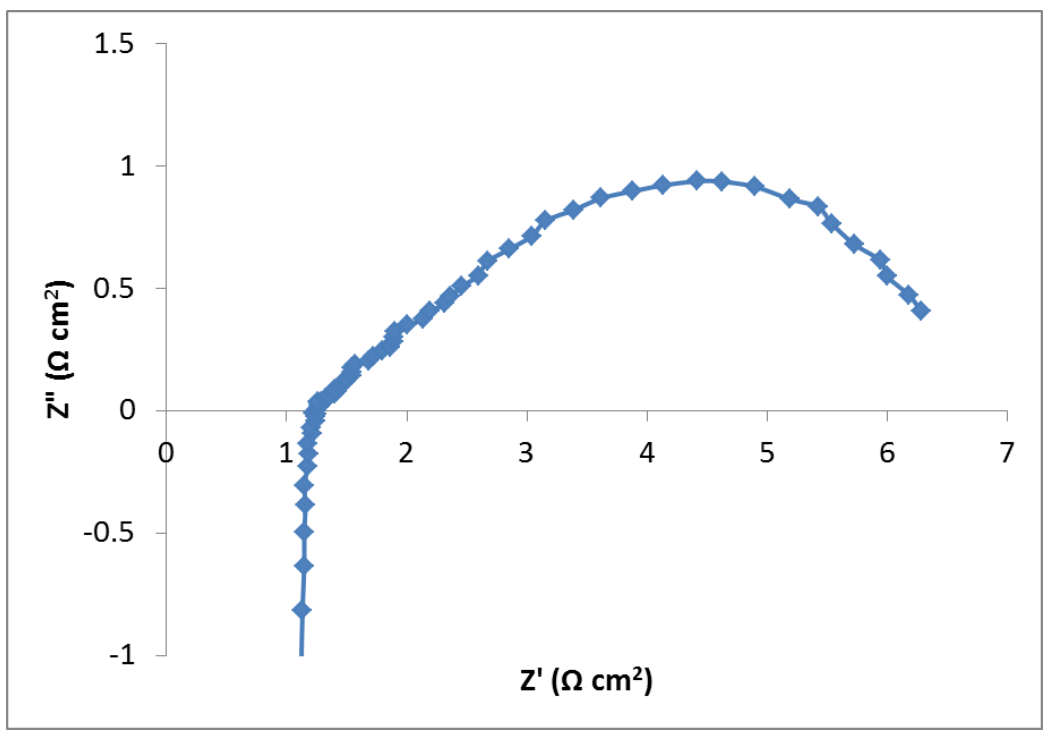

Figure 6.13 Nyquist plot for the cell in "dry" $\mathrm{H}_{2}$. The cell was at $800^{\circ} \mathrm{C}$.

The cell is then subjected to $0.9 \mathrm{~V}, 0.7 \mathrm{~V}$ and $0.5 \mathrm{~V}$ for one hour at each voltage. The $\mathrm{N}_{2}$ and $\mathrm{O}_{2}$ pressures are in Figure 6.14. Water and mass 34 data are shown in Figure 6.15. The effects of electrochemical tests are clearly seen at 3.4, 3.8, 6.3 and 10.0 hours. The water shows large rises when the current is turned on due to the water generated by hydrogen oxidation. Other gas signals have slight dips because of partial displacement of each gas by the large amount of water generated. The relation of cell current and the partial pressure of water are shown in Table 6.1. The water concentration is not linear with the cell current. At high water content, the detector may have been nearly saturated. 


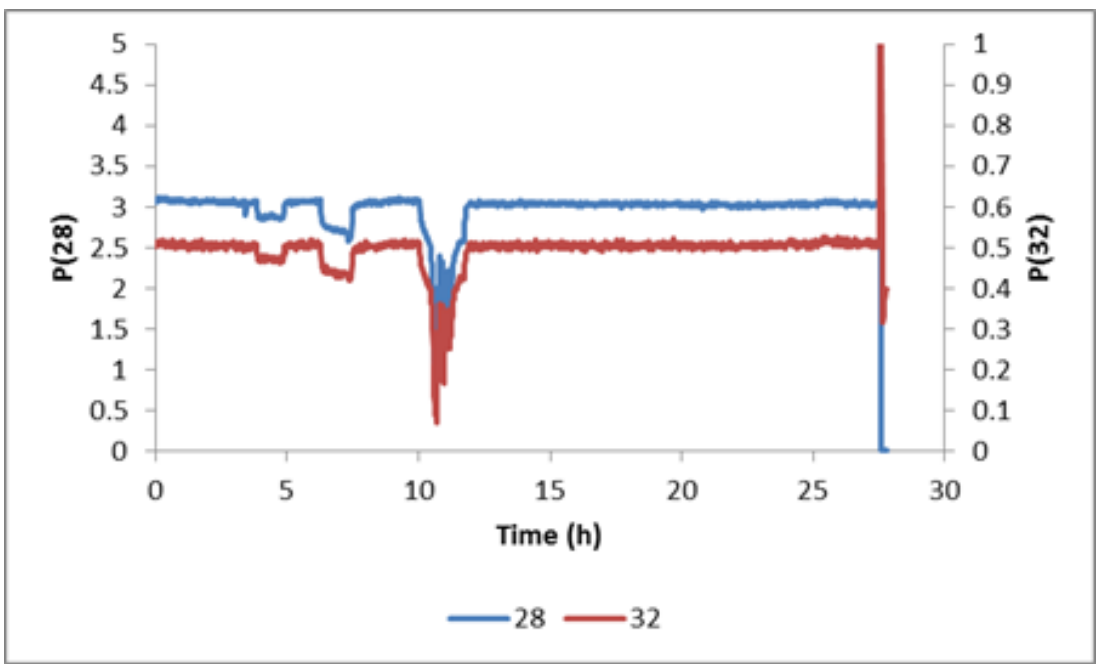

Figure 6.14 $\mathrm{N}_{2}$ and $\mathrm{O}_{2}$ pressures in "dry" $\mathrm{H}_{2}$ during applied cell voltages. The cell was at $800^{\circ} \mathrm{C}$.

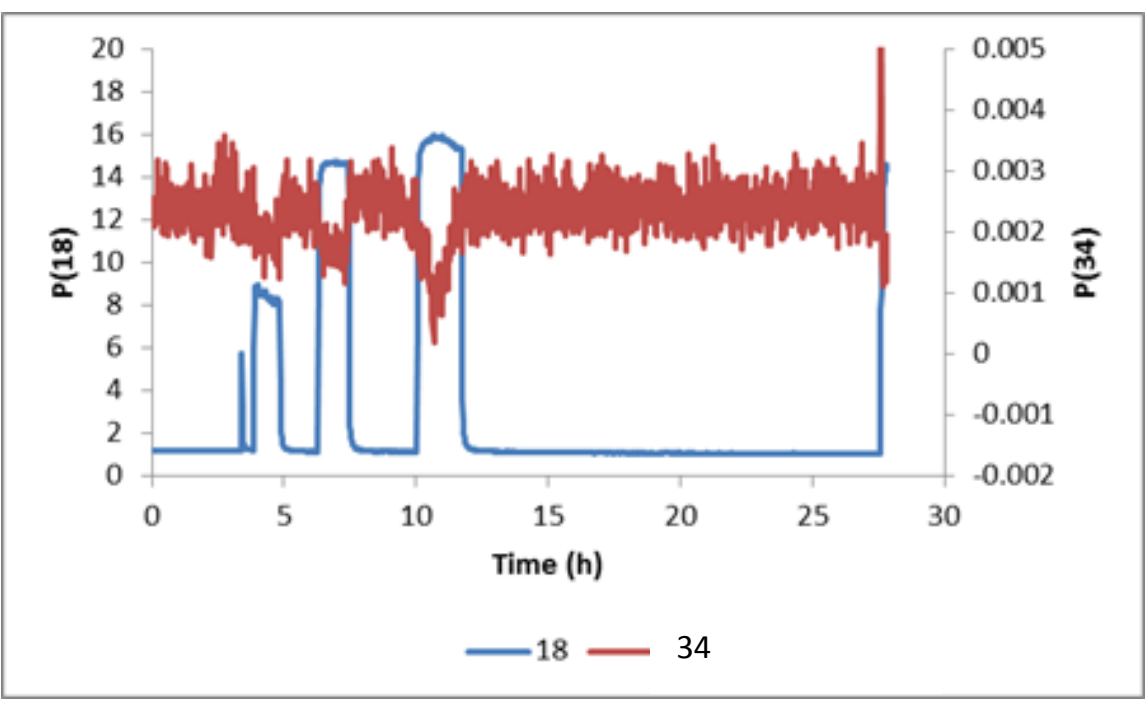

Figure 6.15 Water and mass 34 pressures in "dry" $\mathrm{H}_{2}$ during applied cell voltages. The cell was at $800^{\circ} \mathrm{C}$. 
Table 6.1 Cell current and the water concentrations

\begin{tabular}{ccc}
\hline Cell Voltage (V) & Current (A) & Partial pressure of water (torr) \\
\hline 1.2 & 0 & 1 \\
0.9 & 0.15 & 8 \\
0.7 & 0.34 & 15 \\
0.5 & 0.52 & 16 \\
\hline
\end{tabular}

By comparing the mass spectrometry data taken at open circuit and $0.5 \mathrm{~A}$ current, it is evident that no new products above mass 44 are found.

\subsection{2 "Wet" hydrogen test.}

The $\mathrm{H}_{2}$ from the cylinder is passed through the humidifier at room temperature. The air trapped inside the dead volume of the humidifier is purged over one hour. The polarization and power curves are in Figure 6.16. The peak power is $0.17 \mathrm{~W} / \mathrm{cm}^{2}$ at 0.46 $\mathrm{V}$, slightly lower than the peak power in dry $\mathrm{H}_{2}$. There is less hysteresis at low currents because of the presence of water at open circuit. The Nyquist plot from the EIS data is in Figure 6.17. The normalized $\mathrm{R}_{\mathrm{s}}$ is $1.2 \Omega \mathrm{cm}^{2}$ and the $\mathrm{R}_{\mathrm{p}}$ is $1.1 \Omega \mathrm{cm}^{2}$. Correcting the series resistance from 1.2 to $0.2 \Omega \mathrm{cm}^{2}$ yields a cell voltage of $0.77 \mathrm{~V}$ and a cell power density of $0.36 \mathrm{~W} \mathrm{~cm}^{-2}$ at the maximum current density of $0.47 \mathrm{~A} \mathrm{~cm}^{-2}$. The polarization resistance drops dramatically from over $5 \Omega \mathrm{cm}^{2}$ in the dry $\mathrm{H}_{2}$ to $1.1 \Omega \mathrm{cm}^{2}$ in the wet $\mathrm{H}_{2}$. This behavior is caused by the well-known decrease in activation resistance in the presence of higher water content. [7] 


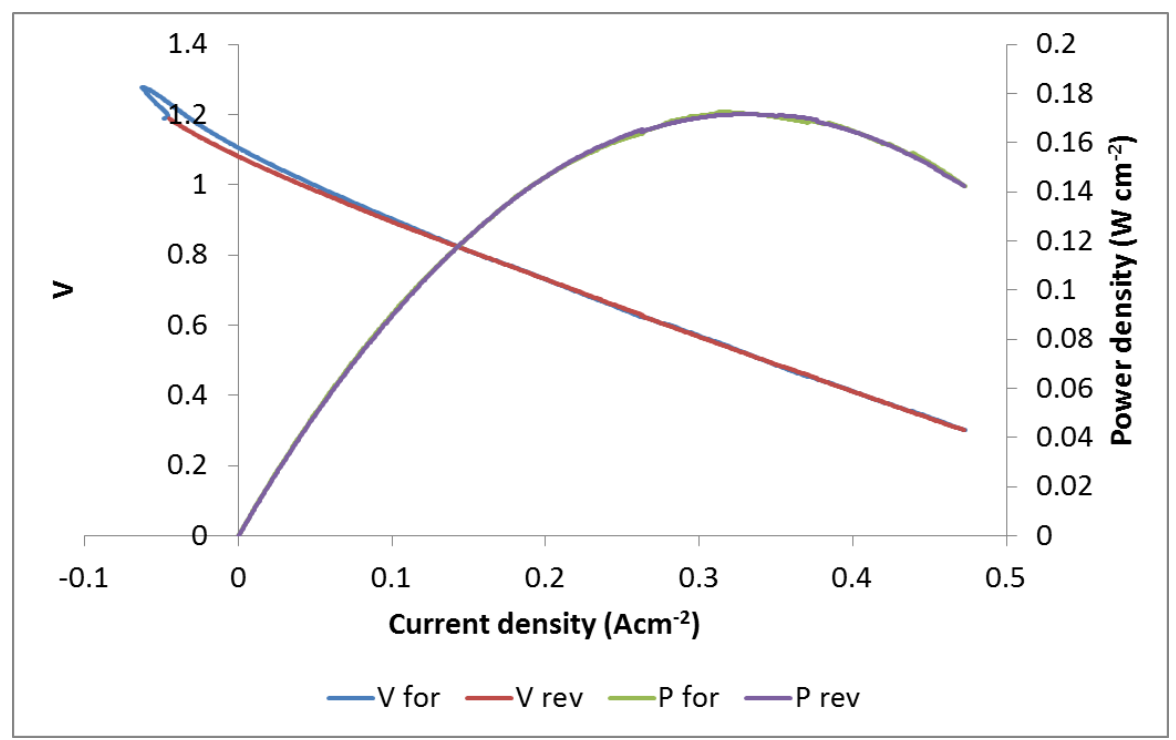

Figure 6.16 Polarization and power curves in "wet" $\mathrm{H}_{2}$. The cell was at $800^{\circ} \mathrm{C}$.

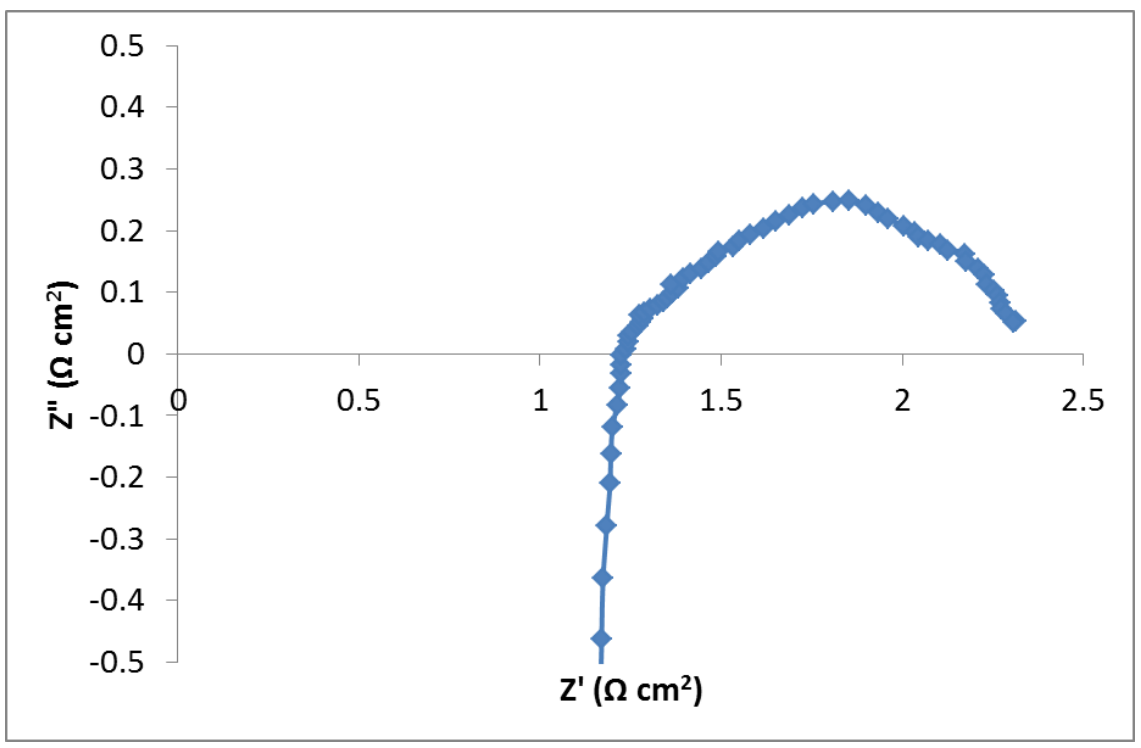

Figure 6.17 Nyquist plot at $\mathrm{OCV}$ in "wet" $\mathrm{H}_{2}$. The cell was at $800^{\circ} \mathrm{C}$.

The cell is then subjected to applied voltages of $0.9 \mathrm{~V}, 0.7 \mathrm{~V}$ and $0.5 \mathrm{~V}$ for one hour starting at times of 1.3, 3.0 and 5.4 hours, respectively. Signals of $\mathrm{N}_{2}$ and $\mathrm{O}_{2}$ are in Figure 6.18. Water and mass 34 signals are in Figure 6.19. Changes in $\mathrm{N}_{2}$ and $\mathrm{O}_{2}$ are apparent during the electrochemical tests. The water signal at mass 18 stays high at about 15 torr until the fuel stream is turned back to "dry" $\mathrm{H}_{2}$ at 7.4 hours. This high water level is close 
to the saturation of the electron multiplier detector in this data set. The water generated by the electrochemical reactions is not seen due to the high water background. However, the mass 18 pressure does not start dropping until 9.6 hours. This lingering water signal may be because liquid water trapped in the system (possibly in the base of the Probostat) needs time to be swept out.

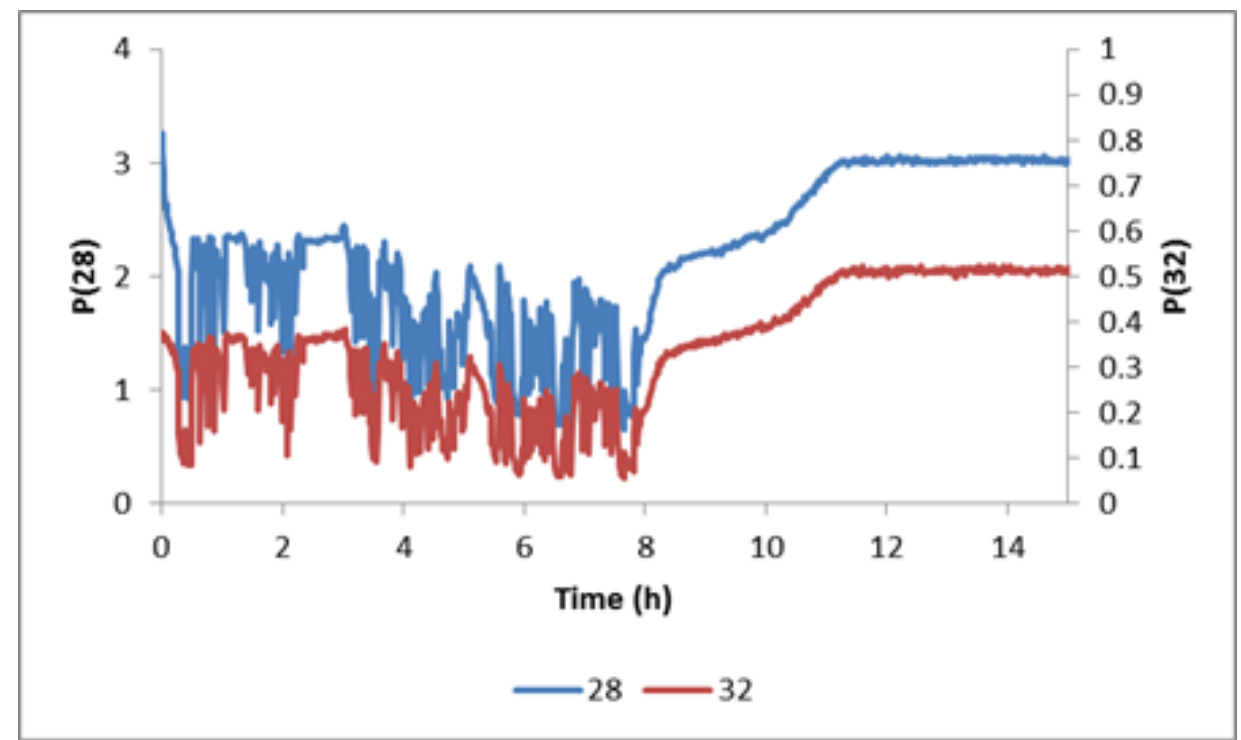

Figure 6.18 $\mathrm{N}_{2}$ and $\mathrm{O}_{2}$ pressures during current flow in the "wet" $\mathrm{H}_{2}$ test. The cell was at $800^{\circ} \mathrm{C}$. 


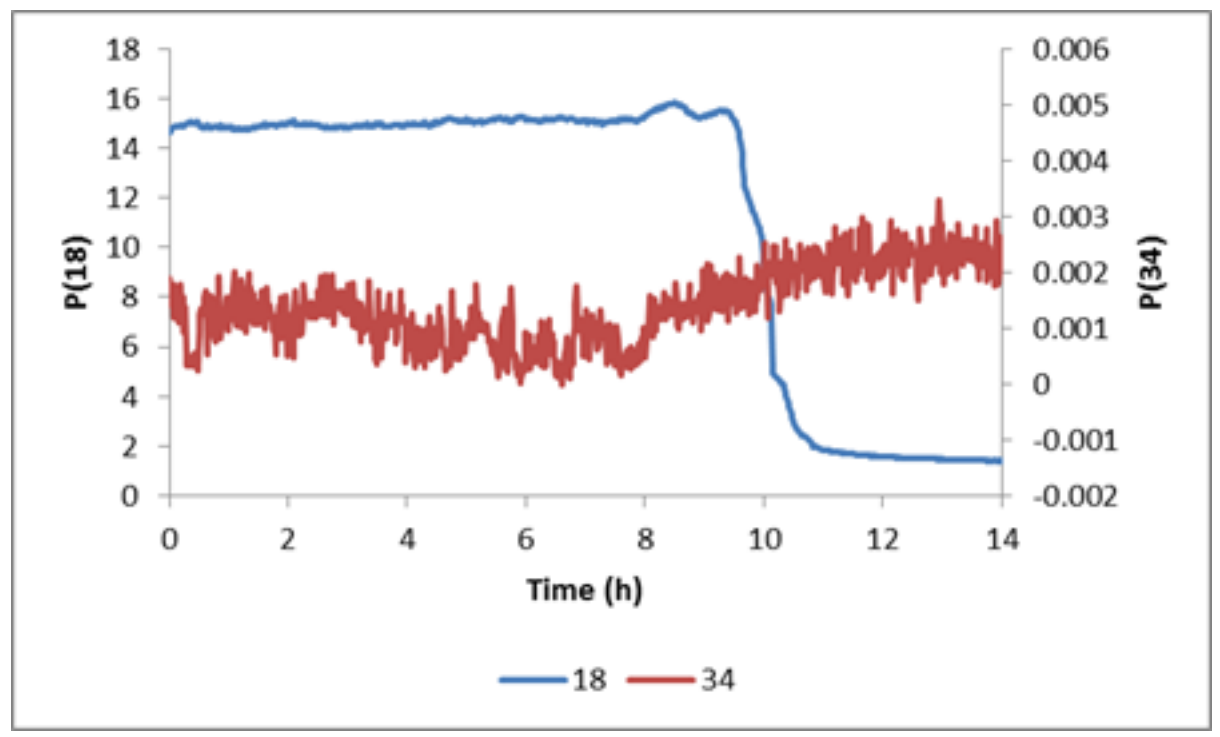

Figure 6.19 Water and mass 34 pressures during current flow in the "wet" $\mathrm{H}_{2}$ test. The cell was at $800^{\circ} \mathrm{C}$.

\subsection{3 "Dry" hydrogen with $20 \mathrm{ppm} \mathrm{PH}_{3}$.}

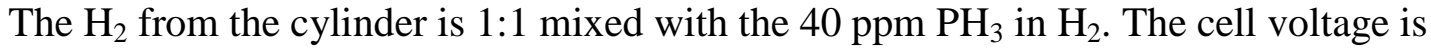
applied $0.9 \mathrm{~V}, 0.7 \mathrm{~V}$ and $0.5 \mathrm{~V}$ at 23.5, 29.7 and 31.7 hours. Each voltage is applied for one hour. Signals of $\mathrm{N}_{2}$ and $\mathrm{O}_{2}$ are in Figure 6.20. Water and mass 34 signals are in Figure 6.21. Addition of $\mathrm{PH}_{3}$ at 19.2 hours causes spikes in the air signals $\left(\mathrm{N}_{2}\right.$ and $\left.\mathrm{O}_{2}\right)$, but there is no increase in the mass 34 signal. The current flow yields increases in the water signal at mass 18 during the electrochemical tests. The air signals also show dips according to the current flow. The signal at mass 34 stays almost unchanged during the entire experiment. In comparison to the "dry" clean $\mathrm{H}_{2}$ without $\mathrm{PH}_{3}$, the mass 34 level is not changed. The $\mathrm{PH}_{3}$ is not getting out of the furnace at any time during the test. 


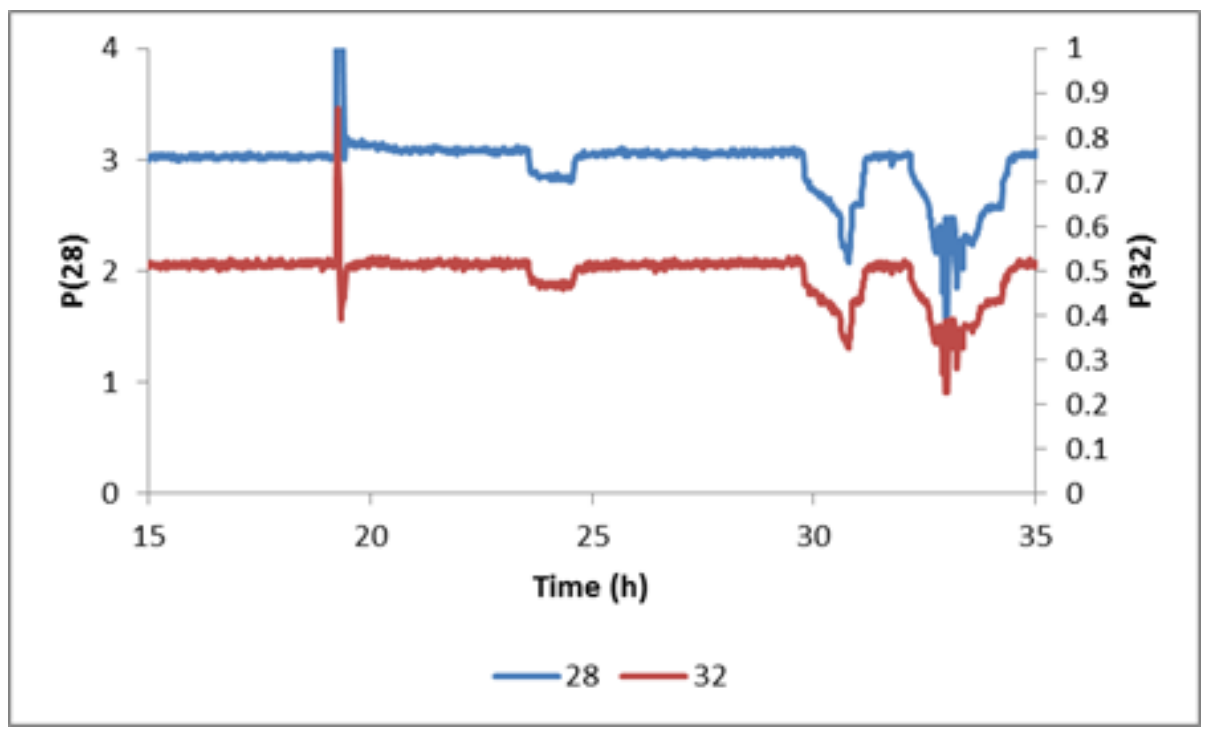

Figure 6.20 $\mathrm{N}_{2}$ and $\mathrm{O}_{2}$ signals during addition of phosphine and application of voltages in "dry" $\mathrm{H}_{2}+20 \mathrm{ppm} \mathrm{PH}_{3}$. The cell was at $800^{\circ} \mathrm{C}$.

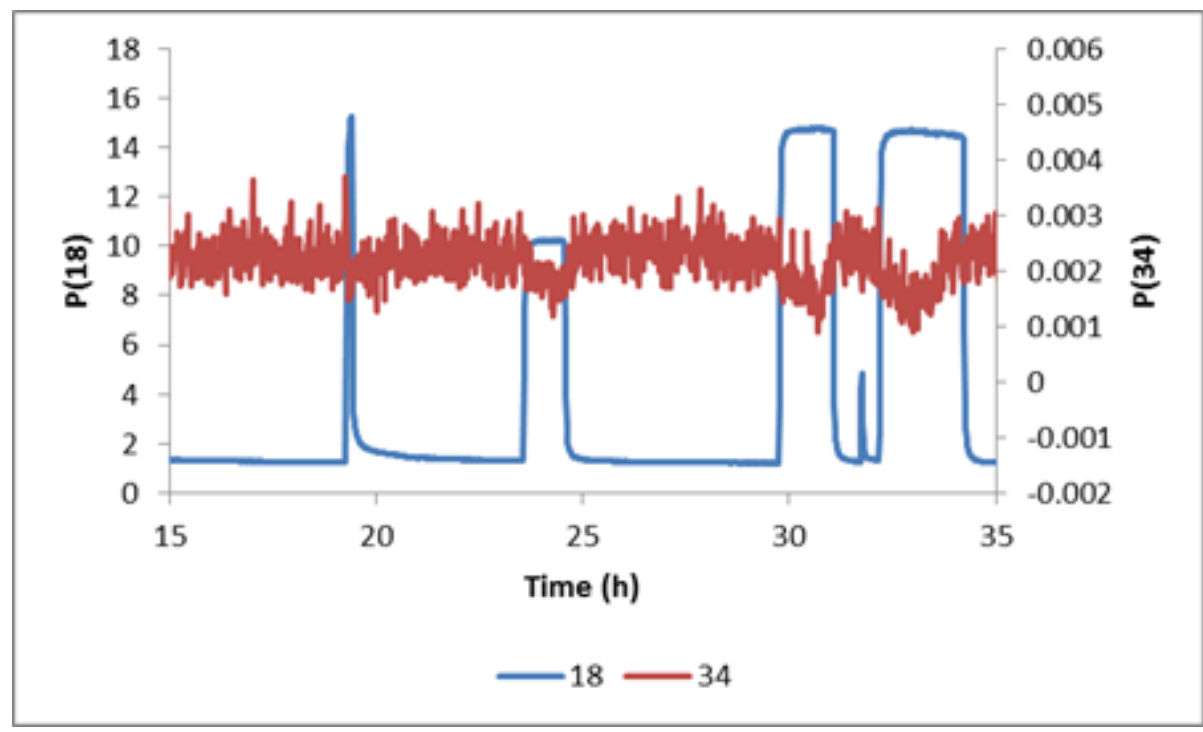

Figure 6.21 Water and mass 34 signals during addition of phosphine and application of

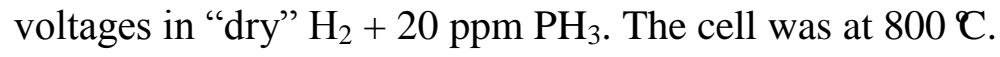

Polarization and power curves with 20 ppm phosphine present are shown in Figure 6.22. The peak power density is $0.19 \mathrm{~W} / \mathrm{cm}^{2}$ at $0.47 \mathrm{~V}$, which is better than in clean "dry" $\mathrm{H}_{2}$, despite the presence of $\mathrm{PH}_{3}$ in the fuel stream. EIS data in Figure 6.23 shows that the normalized $R_{s}$ is $1.0 \Omega \mathrm{cm}^{2}$ and the $R_{p}$ is about $5 \Omega \mathrm{cm}^{2}$. The series and polarization 
resistances are slightly smaller than in the clean $\mathrm{H}_{2}$. This improvement of performance may be because the cell is better conditioned in the "wet" hydrogen for a while. The high series resistance, whatever its cause, appears to be decreasing. Correcting the cell voltage and power for iR drop from 1.0 to $0.2 \mathrm{ohm} \mathrm{cm}^{2}$ yields a voltage of $0.72 \mathrm{~V}$ and a power of $0.37 \mathrm{~W} \mathrm{~cm}^{-2}$ at the maximum current density of $0.52 \mathrm{~A} \mathrm{~cm}^{-2}$.

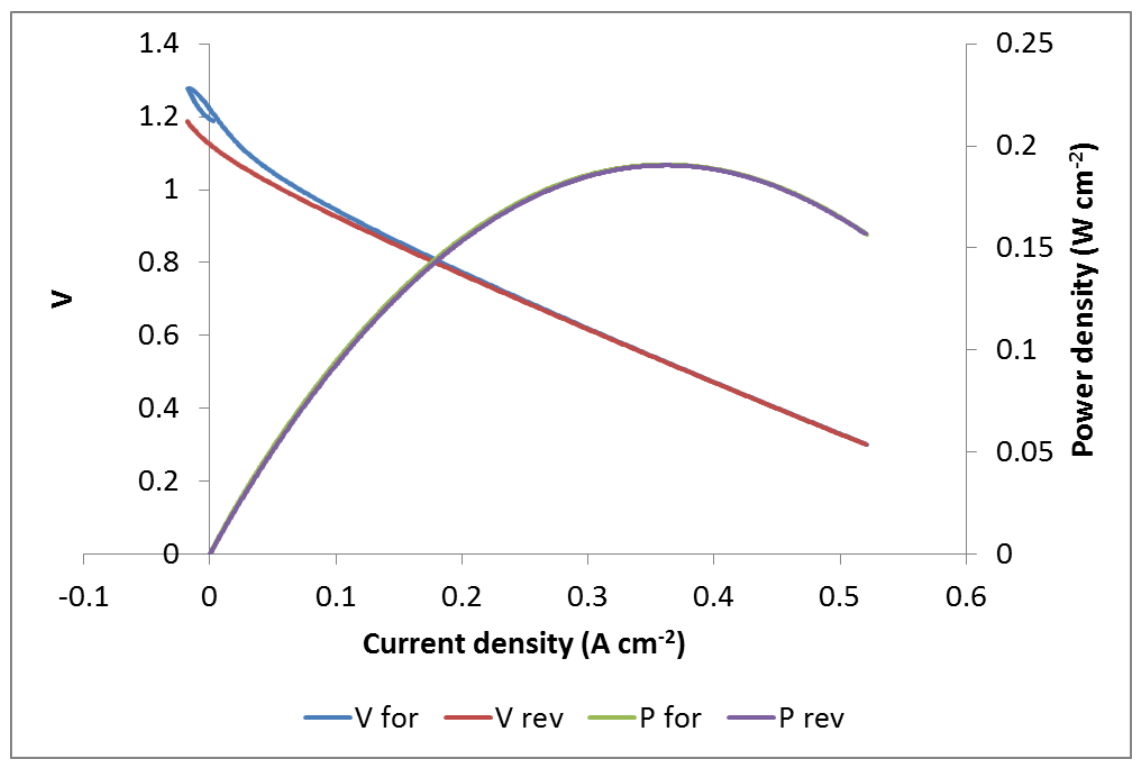

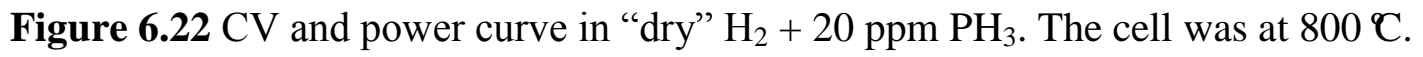




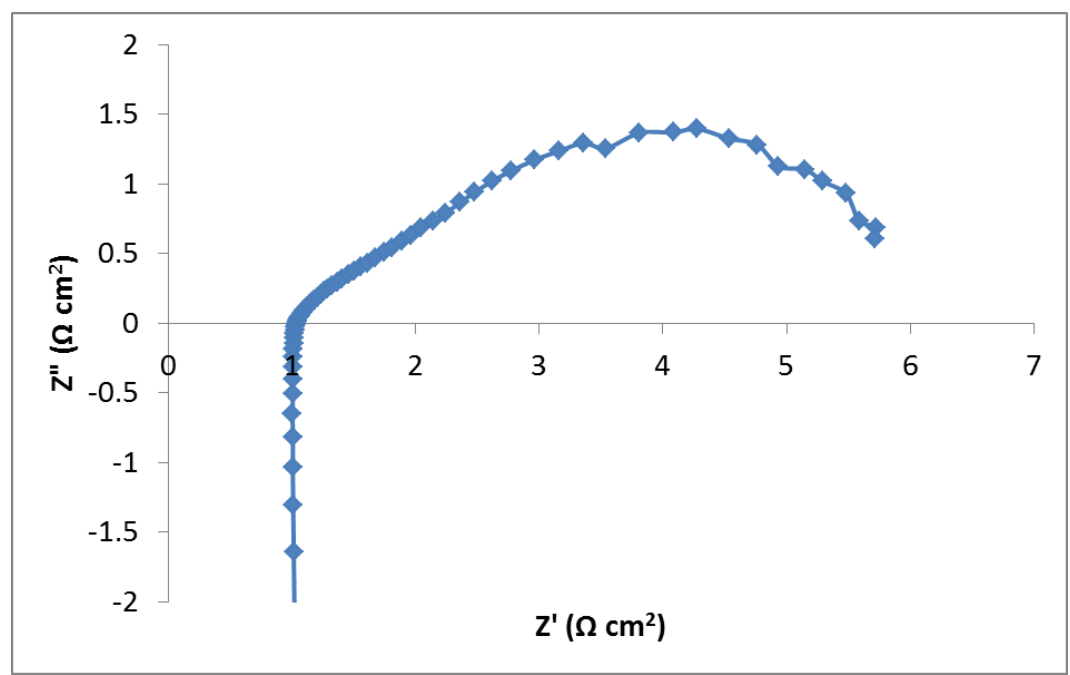

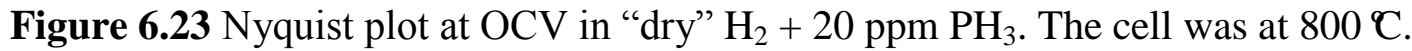

\subsection{4 "Wet" hydrogen with 20 ppm $\mathrm{PH}_{3}$.}

For this test, only the pure hydrogen is passed through the humidifier at room temperature. Then the "wet" $\mathrm{H}_{2}$ is $1: 1$ mixed with the $40 \mathrm{ppm} \mathrm{PH}_{3}$ in $\mathrm{H}_{2}$ (dry). So the actual humidity of this gas mixture is expected to be half of the "wet" $\mathrm{H}_{2}$ test in Section 6.3.2. The cell voltage is set at $0.9 \mathrm{~V}, 0.7 \mathrm{~V}$ and $0.5 \mathrm{~V}$ at $3.8,5.3$ and 10.4 hours, respectively. Each voltage is applied for one hour. Signals of $\mathrm{N}_{2}$ and $\mathrm{O}_{2}$ are in Figure 6.24. Water and mass 34 signals are in Figure 6.25 .

The dips in air signals and rises in water due to the electrochemical tests are similar to the signal changes in previous tests. The water background signal is about 8 torr in this test because of the half humidity set up. However, the water signal does not go down until 1.5 to $2.8 \mathrm{~h}$ after the current is turned off. Also, the water signal is nearly the same (15 torr, believed to be saturation) for all 3 currents. There is no detectable $\mathrm{PH}_{3}$ in the exhaust gas. 


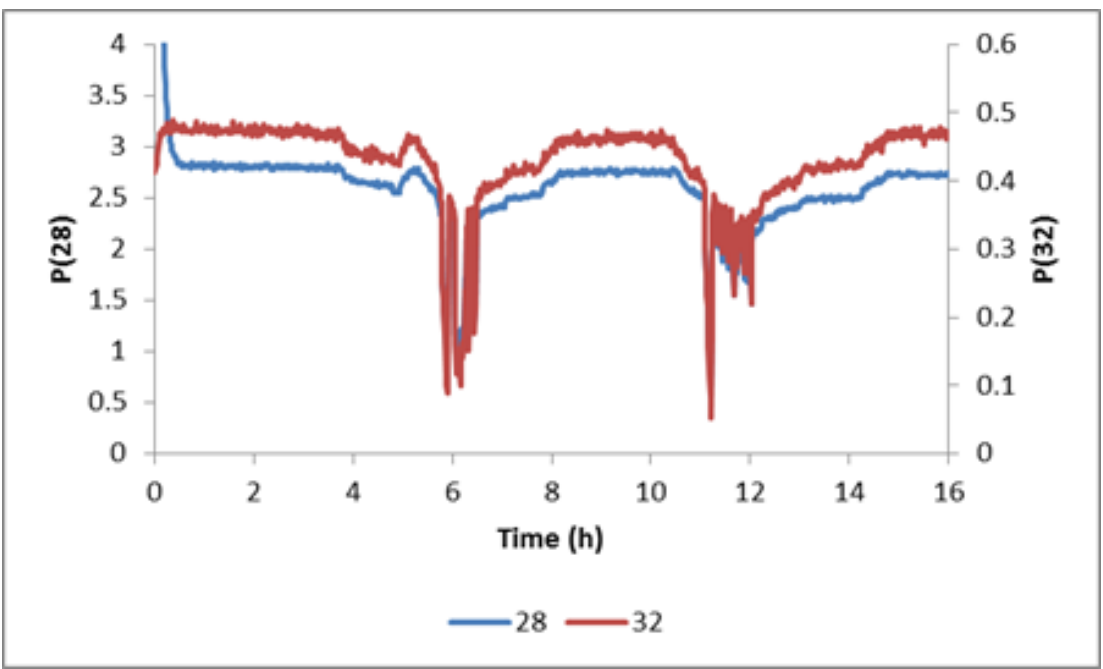

Figure 6.24 $\mathrm{N}_{2}$ and $\mathrm{O}_{2}$ signals during application of voltages in "wet" $\mathrm{H}_{2}+20 \mathrm{ppm} \mathrm{PH}_{3}$. The cell was at $800^{\circ} \mathrm{C}$.

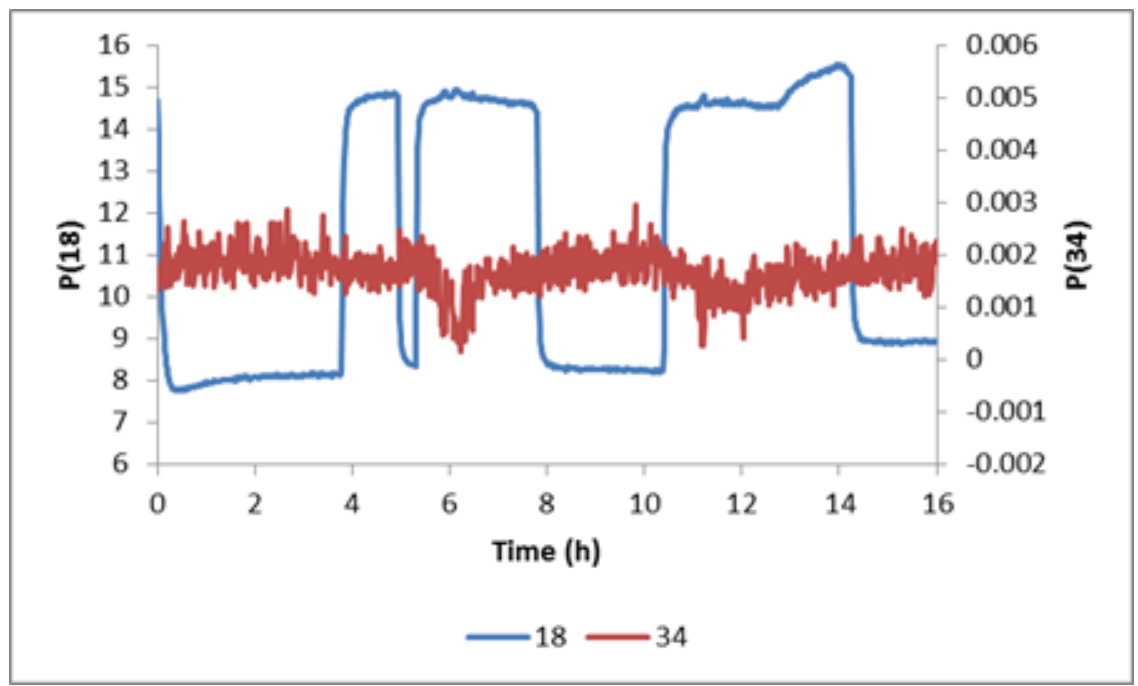

Figure 6.25 Water and mass 34 signals during application of voltages in "dry" $\mathrm{H}_{2}+20$ ppm $\mathrm{PH}_{3}$. The cell was at $800^{\circ} \mathrm{C}$.

A polarization and power curves are shown in Figure 6.26. The peak power is 0.18 $\mathrm{W} / \mathrm{cm}^{2}$ at $0.49 \mathrm{~V}$, which is comparable to the results in wet $\mathrm{H}_{2}$ without $\mathrm{PH}_{3}$. The Nyquist plot is shown in Figure 6.27. The normalized $R_{s}$ is $1.0 \Omega \mathrm{cm}^{2}$ and $R_{p}$ is $1.7 \Omega \mathrm{cm}^{2}$. The $R_{p}$ increased from the wet clean $\mathrm{H}_{2}$ test $\left(1.3 \Omega \mathrm{cm}^{2}\right)$. This increase may due to the change in the water concentration near the cell anode. Correcting the series resistance from 1.0 to 
$0.2 \Omega \mathrm{cm}^{2}$ yields a cell voltage of $0.70 \mathrm{~V}$ and a power density of $0.345 \mathrm{~W} \mathrm{~cm}^{-2}$ at a maximum current density of $0.495 \mathrm{~A} \mathrm{~cm}^{-2}$.

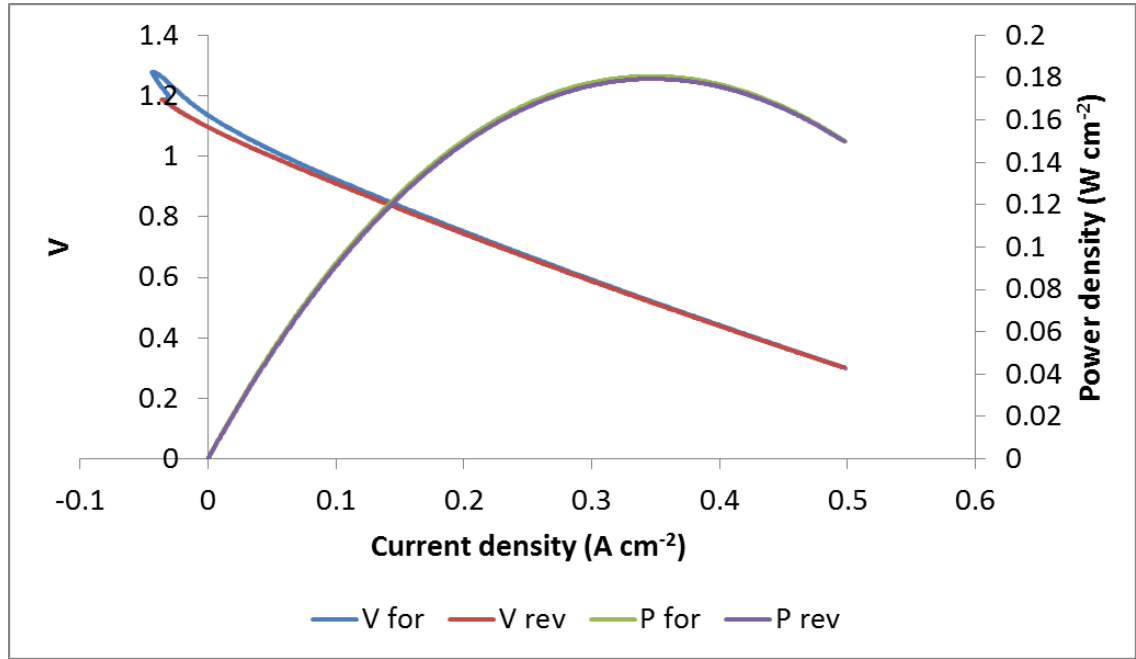

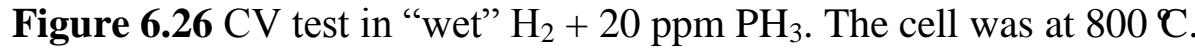

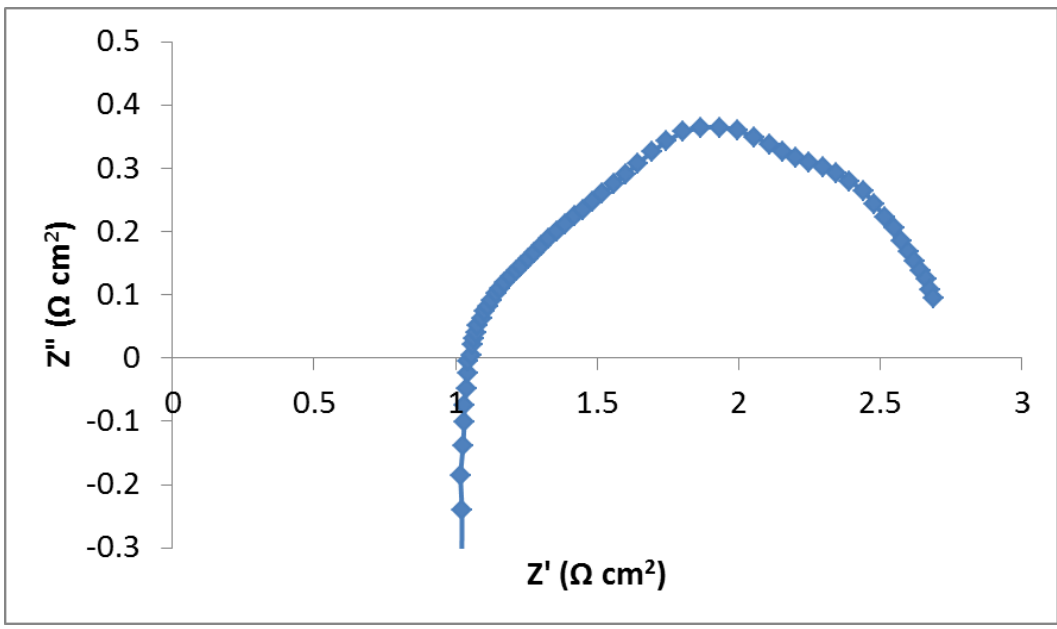

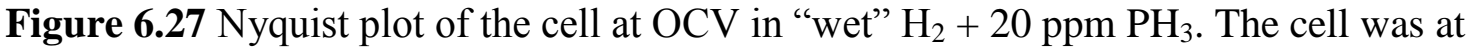
$800^{\circ} \mathrm{C}$.

\subsection{Cell test III - long term constant cell voltage tests.}

The tests in this section are still on the same cell described earlier with the glass seal. 


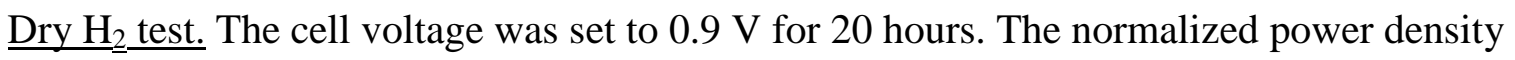
is plotted vs time in Figure 6.28. The power density starts at $0.107 \mathrm{~W} \mathrm{~cm}^{-2}$ and shows a slight decay although no $\mathrm{PH}_{3}$ is added. This decay may due to the residual $\mathrm{PH}_{3}$ left over. The power loss rate is $0.345 \mathrm{~mW} \mathrm{~cm}^{-2} \mathrm{~h}^{-1}$, which is comparable to the results with the

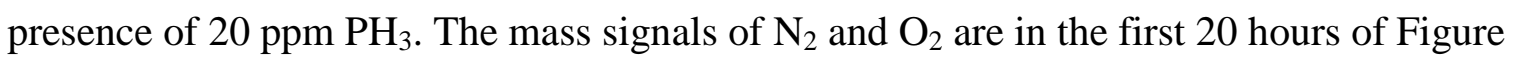
6.29. Similarly, water and mass 34 signals are in the first 20 hours of Figure 6.30.

At 20 hours, the cell voltage was returned to OCV, and at 24.8 hours, $3 \%$ water vapor was added into the fuel stream. Changes in the common gas signals are shown in Figures 6.29 and 6.30. During current flow in dry $\mathrm{H}_{2}$ (0-20 hours), the water signal at mass 18 was about 10 torr. When the current was turned off, water signal dropped to 1 torr. When water vapor was added to the fuel, the water signal rose to 14 torr. All other masses reflected the changes in the water signal.

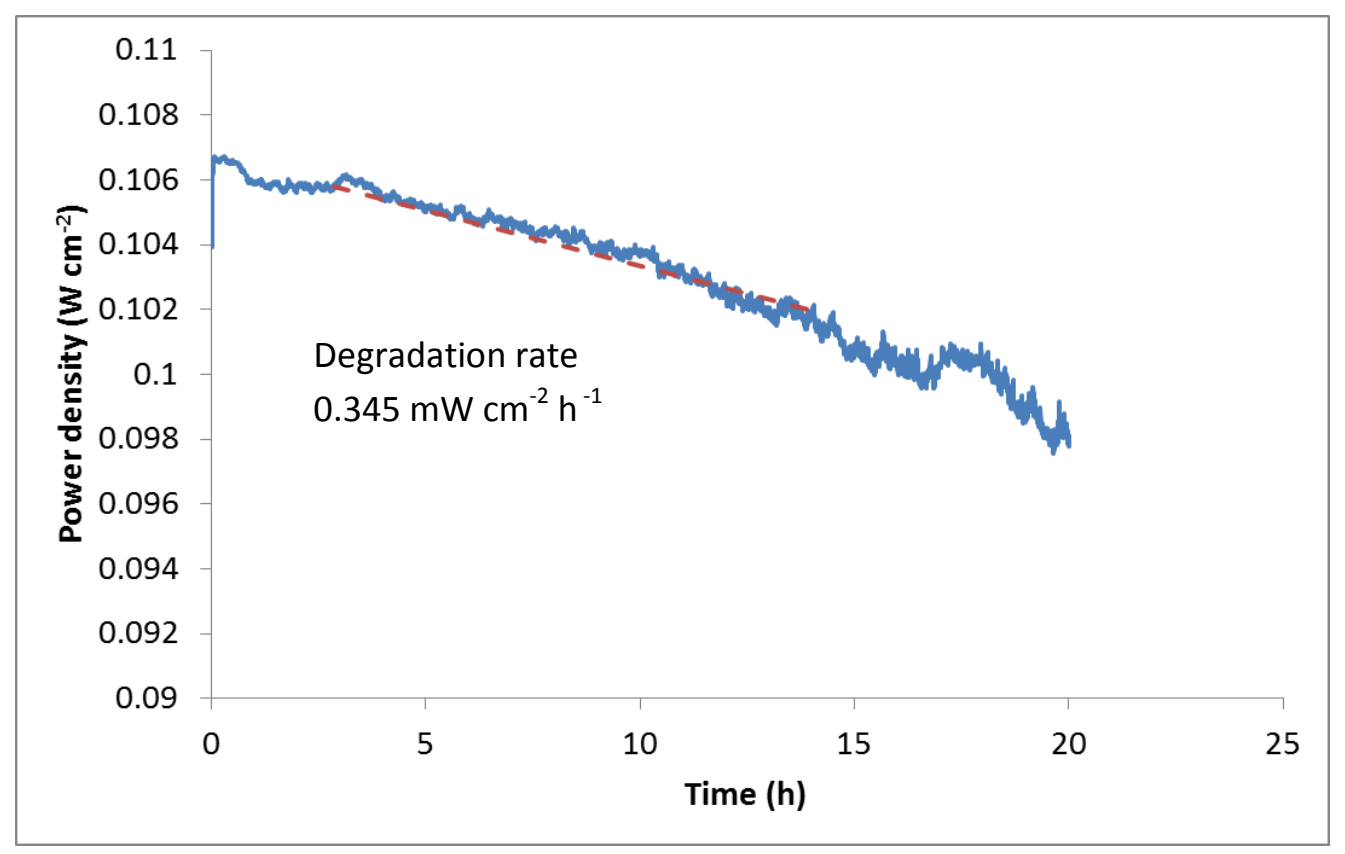

Figure 6.28 Power density vs time in "dry" $\mathrm{H}_{2}$ with $0.9 \mathrm{~V}$ cell voltage. The cell was at $800^{\circ} \mathrm{C}$. 


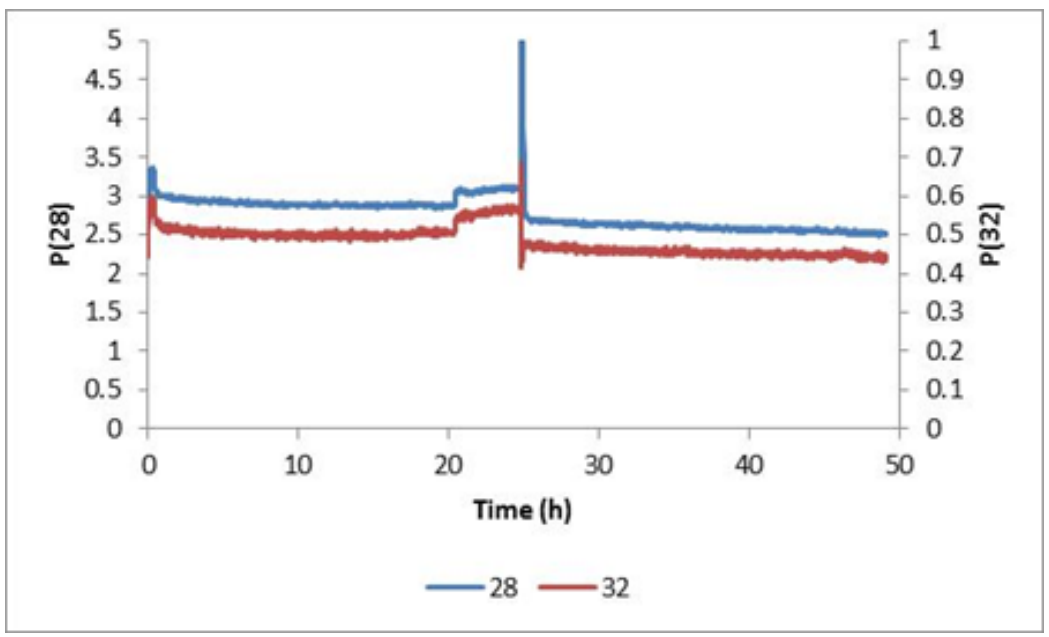

Figure 6.29 $\mathrm{N}_{2}$ and $\mathrm{O}_{2}$ signals vs time in "dry" $\mathrm{H}_{2}$ at $0.9 \mathrm{~V}$ (first 20 hours), open circuit (20-22 hours) and in "wet" $\mathrm{H}_{2}$ (24-50 hours). The cell was at $800^{\circ} \mathrm{C}$.

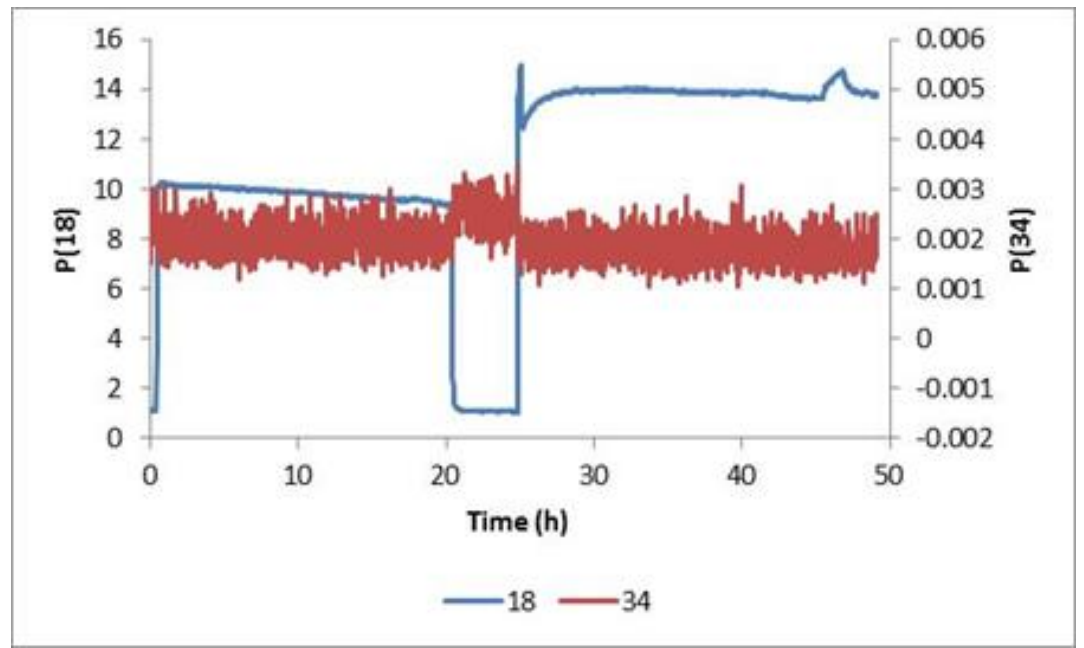

Figure 6.30 Water and mass 34 signals vs time in "dry" $\mathrm{H}_{2}$ at $0.9 \mathrm{~V}$ (first 20 hours), open circuit (20-22 hours) and in "wet" $\mathrm{H}_{2}$ (24-50 hours). The cell was at $800^{\circ} \mathrm{C}$.

"Wet" $\mathrm{H}_{2}$ test. The fuel was $\mathrm{H}_{2}$ with $\sim 20$ torr of water vapor. The cell voltage was set at $0.9 \mathrm{~V}$ for 20 hours. The power density is plotted vs time in Figure 6.31. The power density was approximately $0.09 \mathrm{~W} \mathrm{~cm}^{-2}$ with some fluctuations. 


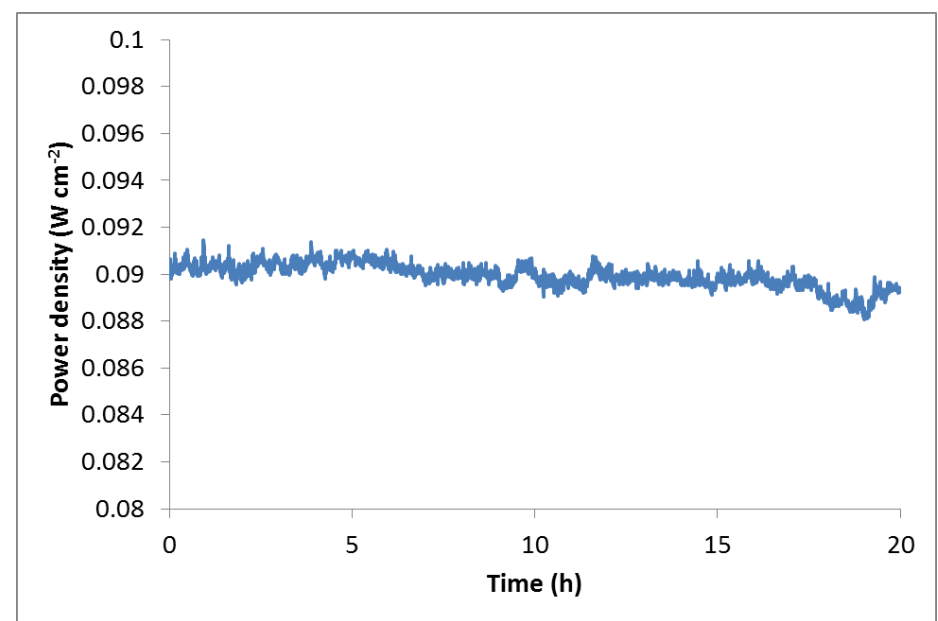

Figure 6.31 Power density vs time in "wet" $\mathrm{H}_{2}$ with $0.9 \mathrm{~V}$ cell voltage. The cell was at $800^{\circ} \mathrm{C}$.

The mass signals of $\mathrm{N}_{2}, \mathrm{O}_{2}$, water and mass 34 signals are in Figure 6.32. The air peaks $\left(\mathrm{N}_{2}\right.$ at mass 28 and $\mathrm{O}_{2}$ at mass 32 ) were fluctuating by a large amount during the current flow. When the current was turned off, the fluctuation disappeared. This fluctuation may because of the changes in water content in the exhaust stream. The water signal showed a "blip" at 18-20 hours. The reason for the "blip" is unknown.
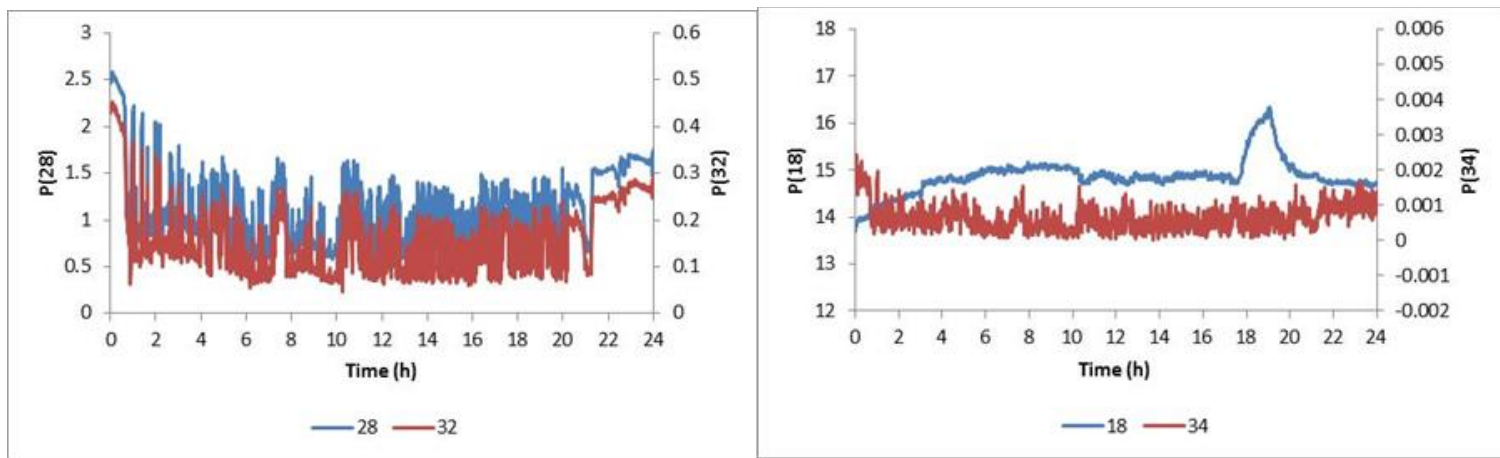

Figure 6.32 Gas pressures vs time in "wet" $\mathrm{H}_{2}$ at $0.9 \mathrm{~V}$. The cell was at $800^{\circ} \mathrm{C}$.

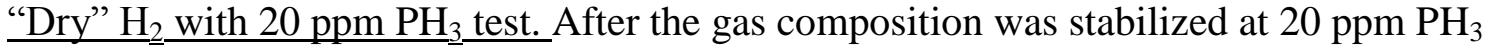
in "dry" $\mathrm{H}_{2}$, the cell was set for an applied cell voltage of $0.9 \mathrm{~V}$. The power density at this setting is plotted vs time in Figure 6.33. The power decayed continuously over time with 
the presence of $20{\mathrm{ppm} \mathrm{PH}_{3} \text {. The degradation rate is } 0.346 \mathrm{~mW} \mathrm{~cm}}^{-2} \mathrm{~h}^{-1}$, determined by linear fit of part of the curve shown in Figure 6.33. This rate is comparable to the values in the literature around $0.3-0.6 \mathrm{~mW} \mathrm{~cm}^{-2} \mathrm{~h}^{-1}$ [2-3]. The mass signals of $\mathrm{N}_{2}, \mathrm{O}_{2}$, water and mass 34 signals are shown in Figure 6.34. The spikes at 24 hours correspond to the change from dry $\mathrm{H}_{2}$ to wet $\mathrm{H}_{2}$ with $\mathrm{PH}_{3}$. During the next $23 \mathrm{~h}$, the water (mass 18) signal dropped rapidly to 2 torr and then slowly to 1 torr. The air impurities signals (mass 28 and 32) show corresponding increases. Mass 34 signal shows a slight increase which is likely due to the drop in water and not due to $\mathrm{PH}_{3}$ getting to the exhaust port. $\mathrm{The} \mathrm{PH}_{3}$ concentration at the exhaust point remains low. The low $\mathrm{PH}_{3}$ concentration is similar to the results of the tests in Chapter 5. The $\mathrm{PH}_{3}$ level was low with a Ni/YSZ piece in the gas stream, under both dry and wet conditions. However, the $\mathrm{PH}_{3}$ in dry conditions is slightly higher than in wet gas stream, which is also consistent with the results in Chapter 5. At $47 \mathrm{~h}$, when the current is turned on, water signal shoots up to 10 torr, and all other signals show a slight decrease. 


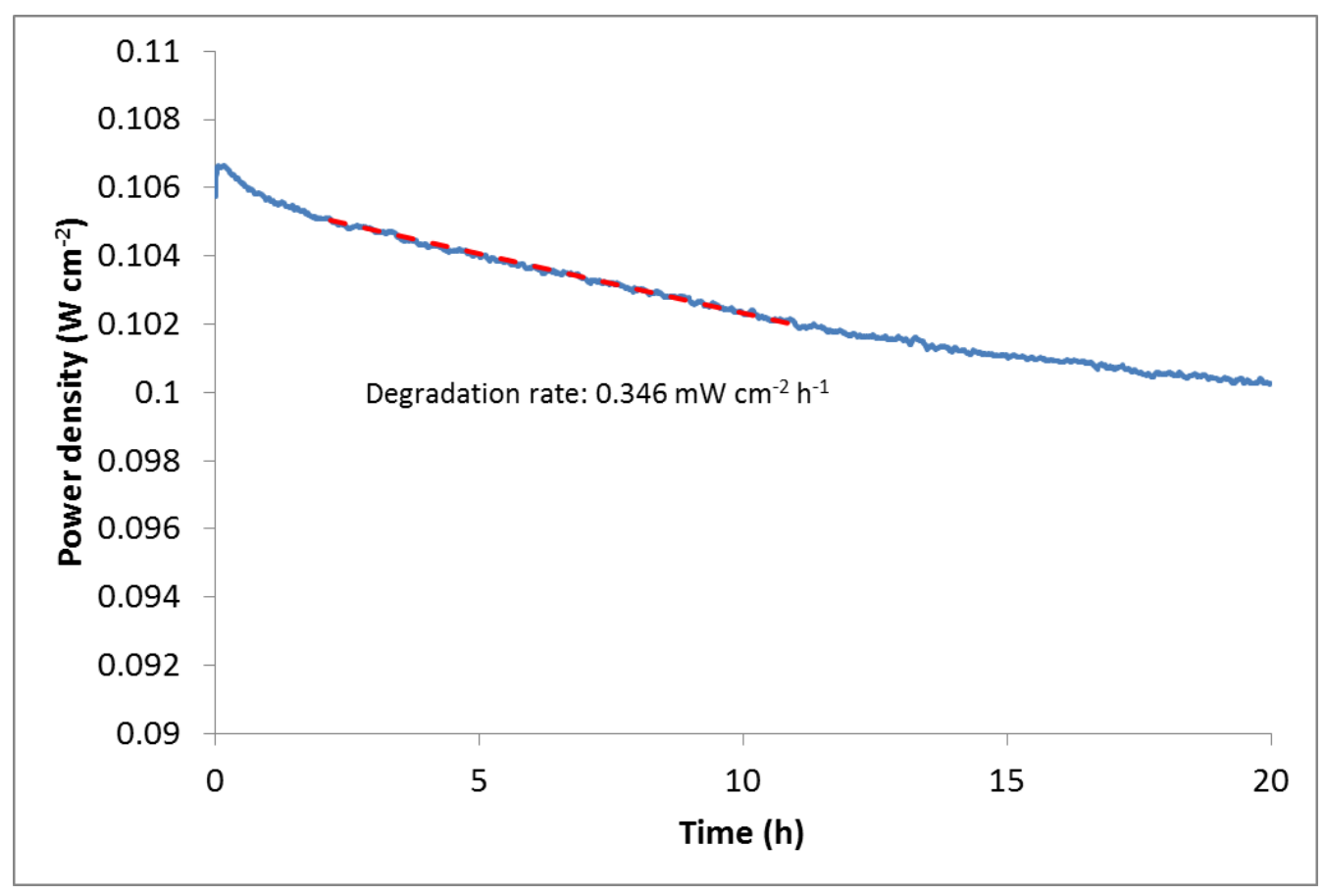

Figure 6.33 Power density vs time in "dry" $\mathrm{H}_{2}+20$ ppm $\mathrm{PH}_{3}$ with $0.9 \mathrm{~V}$ cell voltage.

The cell was at $800^{\circ} \mathrm{C}$.
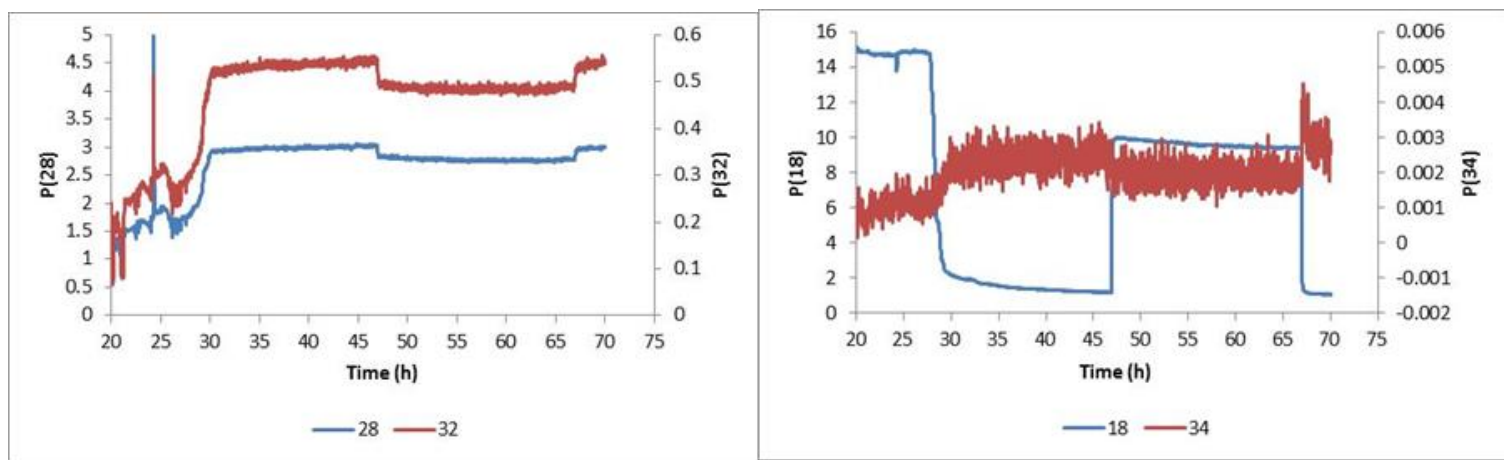

Figure 6.34 Gas pressures vs time in "dry" $\mathrm{H}_{2}+20 \mathrm{ppm} \mathrm{PH}_{3}$. See the text for details about cell voltage and gas composition. The cell was at $800^{\circ} \mathrm{C}$.

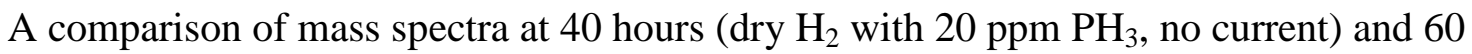
hours (dry $\mathrm{H}_{2}$ with $20 \mathrm{ppm} \mathrm{PH}_{3}, \sim 120 \mathrm{~mA} / \mathrm{cm}^{2}$ current flow) is shown in Figure 6.35. The only changes are due to the higher pressure of water at 60 hours. There are no new signals appearing at masses higher than 44. 


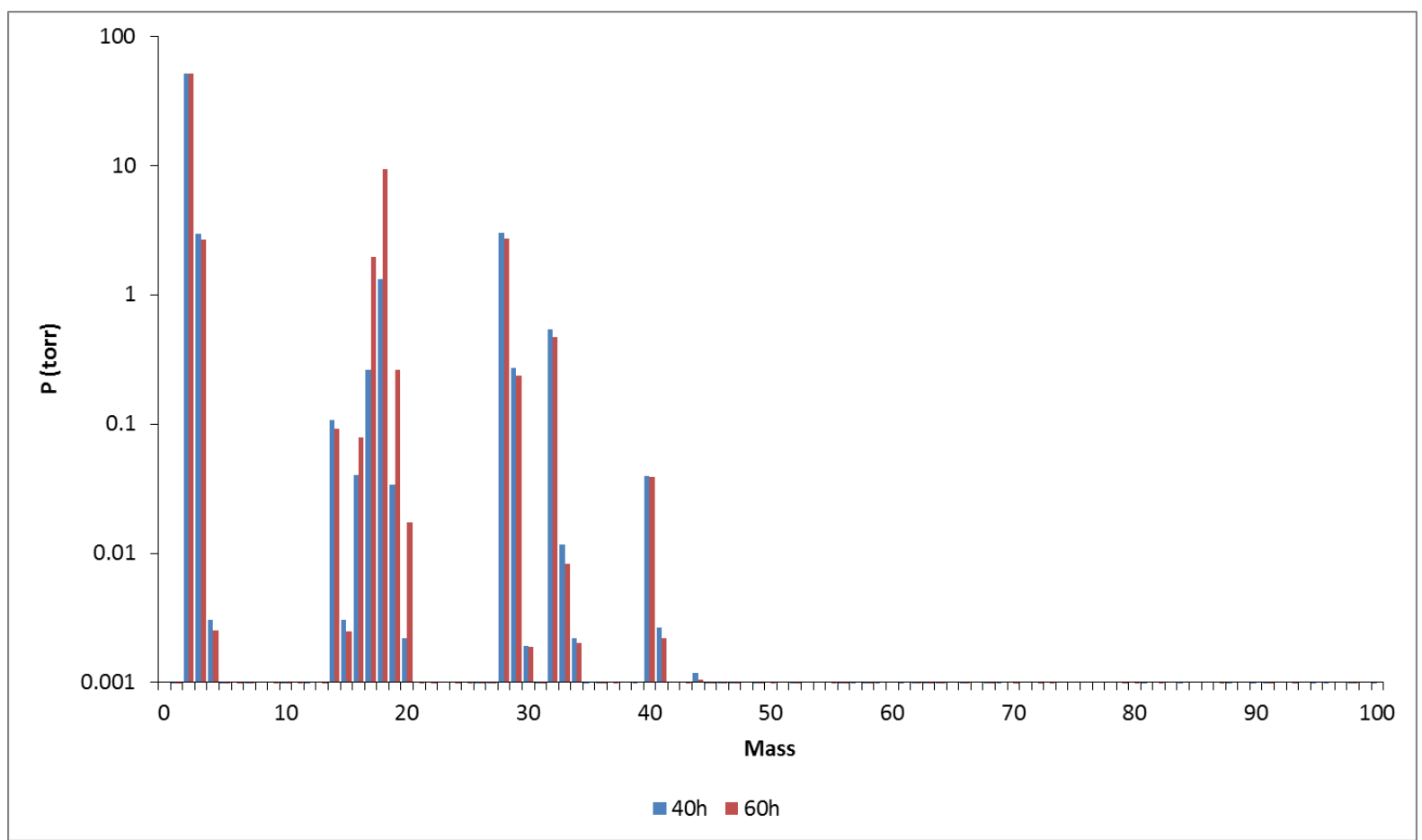

Figure 6.35 Mass spectra in dry $\mathrm{H}_{2}$ with 20 ppm $\mathrm{PH}_{3}$ without (40 hours) and with (60 hours) current flow.

"Wet" $\mathrm{H}_{2}$ with $20 \mathrm{ppm} \mathrm{PH}_{3}$ test. The $\mathrm{H}_{2}$ from the gas cylinder is passed through the

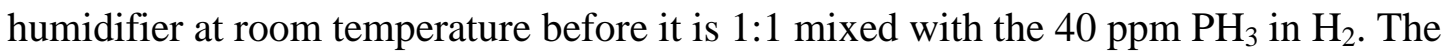
cell voltage is set at $0.9 \mathrm{~V}$ for 20 hours. The power density vs time is plotted in Figure 6.36. The degradation of cell performance is very fast initially with a rate of $0.498 \mathrm{~mW}$ $\mathrm{cm}^{-2} \mathrm{~h}^{-1}$, and then dropping to a moderate rate. After 7 hours, the degradation rate becomes very slow at $0.077 \mathrm{~mW} \mathrm{~cm}^{-2} \mathrm{~h}^{-1}$. The low degradation rate is unusual. $\mathrm{Xu}$ and Zhi et al. reported that the degradation occurs at a constant rate in the range of 0.4-0.6 $\mathrm{mW} \mathrm{cm} \mathrm{ch}^{-1} \cdot[3-4]$ 


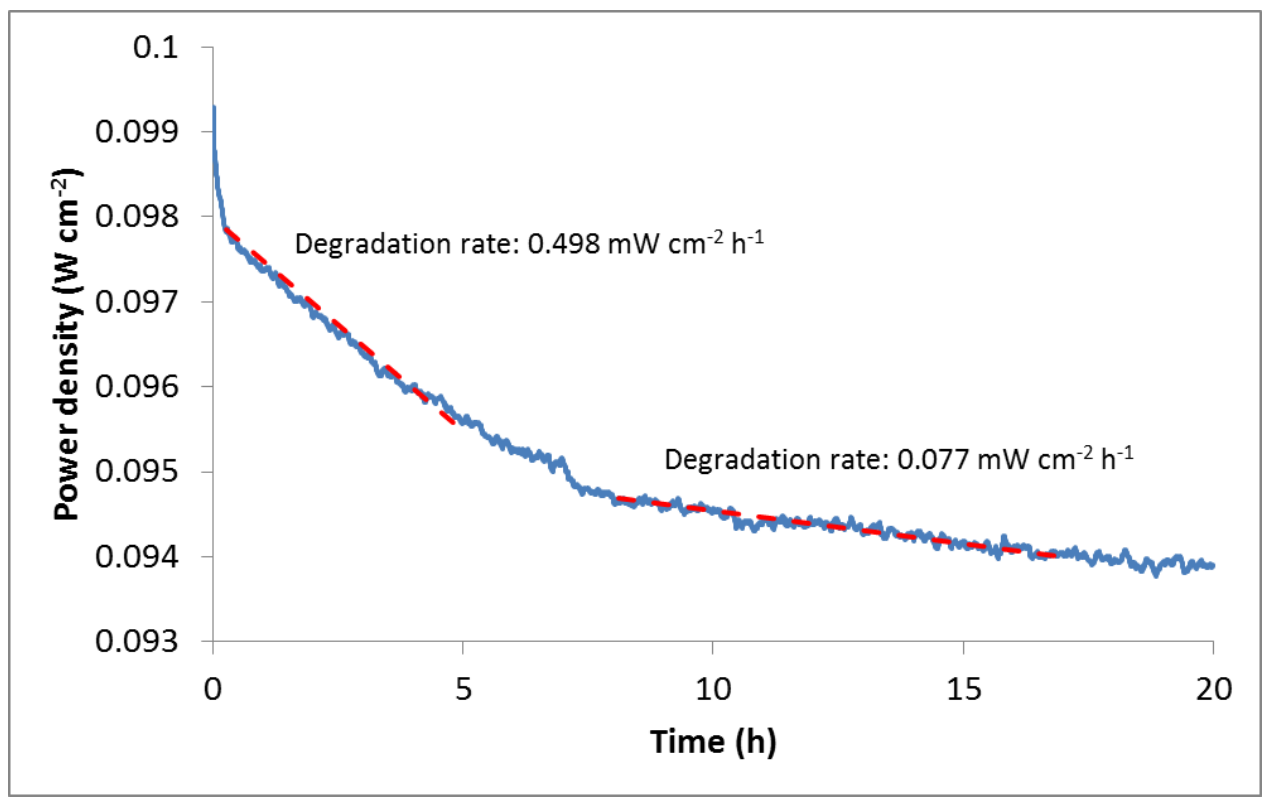

Figure 6.36 Power density vs time in "wet" $\mathrm{H}_{2}+20$ ppm $\mathrm{PH}_{3}$ with $0.9 \mathrm{~V}$ cell voltage. The cell was at $800^{\circ} \mathrm{C}$.

The mass signals of $\mathrm{N}_{2}, \mathrm{O}_{2}$, water and mass 34 signals are in Figure 6.37. The water signal at mass 18 was at 8 torr before the current was turned on at 2.4 hours. Then the water increased to 14 torr with $\sim 160 \mathrm{~mA}$ of current. The water signal dropped to 8 torr after the current was turned off at 22.4 hours. The water signal then dropped to less than 2 torr corresponding to the time that the humidifier was bypassed at 25 hours. Other gases showed decreases with current flow due to partial replacement by the water vapor.

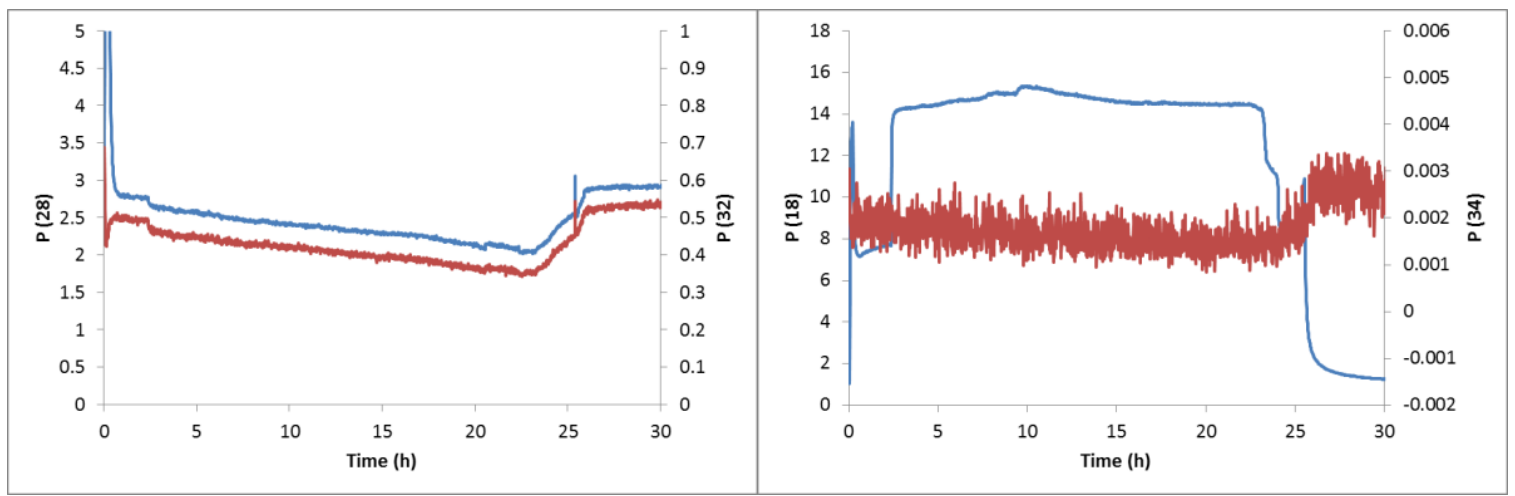

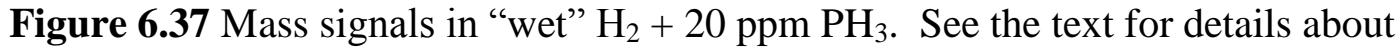
applied voltage and changes in fuel composition. The cell was at $800^{\circ} \mathrm{C}$. 


\subsection{Post-mortem analysis of the cell}

After the cell is taken out of the furnace, a shiny layer of new crystalized material is visible on the anode surface. This new phase is also seen in previous studies [2-3, 5].

SEM images of the top surface of the anode are shown in Figure 6.38. The clean reduced anode surface (left) is very porous and consists of fine grains of Ni and YSZ. The grain size is very small, in the order of $0.5-1 \mu \mathrm{m}$. The porous structure is favorable for the fuel gas to penetrate through the thick anode and reach the active layer. This structure is consistent with the structures of previous cells from MSRI. [5, 7] After exposure to 20 ppm of $\mathrm{PH}_{3}$, there is a new phase formed on top of the anode surface. The new phase exhibits well-defined facets and is believed to be crystalline. The grain size is about 100 $\mu \mathrm{m}$, much larger than the YSZ particles on the clean reduced anode. The formation of the additional phase is also described in the previous studies. [5, 7]
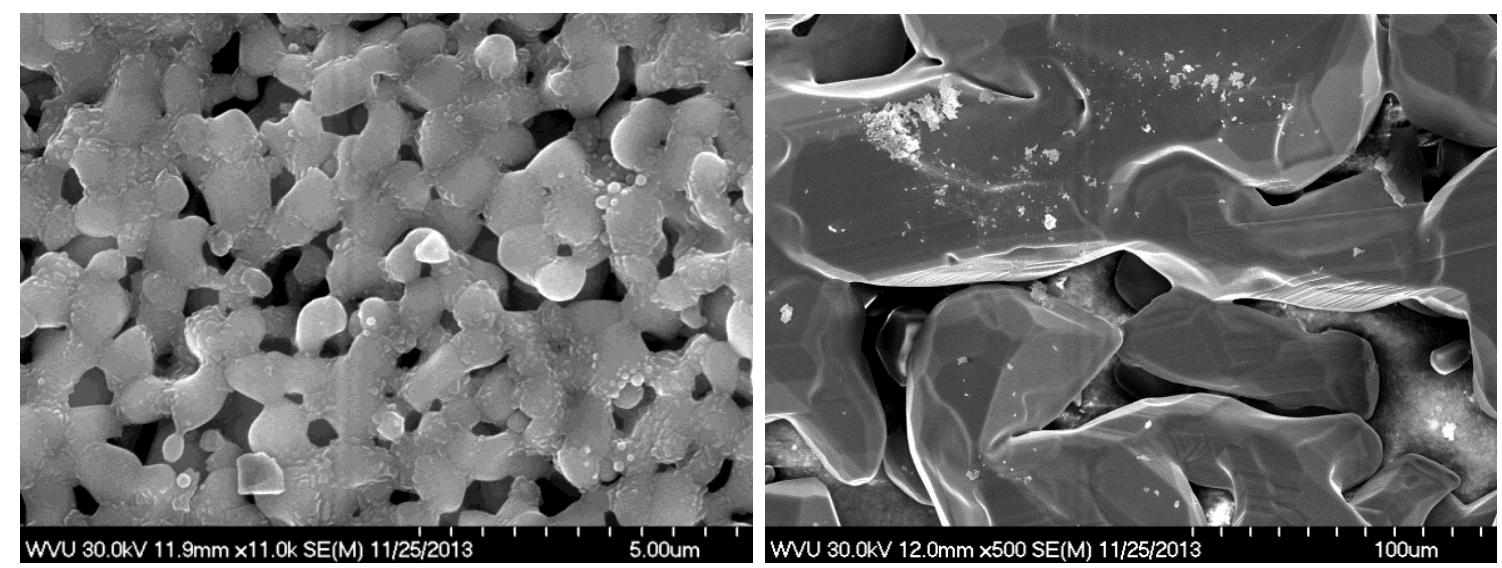

Figure 6.38 SEM image of the clean reduced anode (left) and the area exposed to $20 \mathrm{ppm}$ $\mathrm{PH}_{3}$ (right).

EDX analyses were performed within the same area of clean and $\mathrm{PH}_{3}$-exposed anode mentioned above. Figure 6.39 is the EDX spectra of the clean reduced anode. The graph 
is shown with a smaller scale on the right to emphasize the smaller peaks. The major elements are $\mathrm{Ni}, \mathrm{Zr}$, $\mathrm{Y}$ and $\mathrm{O}$. The small $\mathrm{C}$ peak is from impurities on the anode.

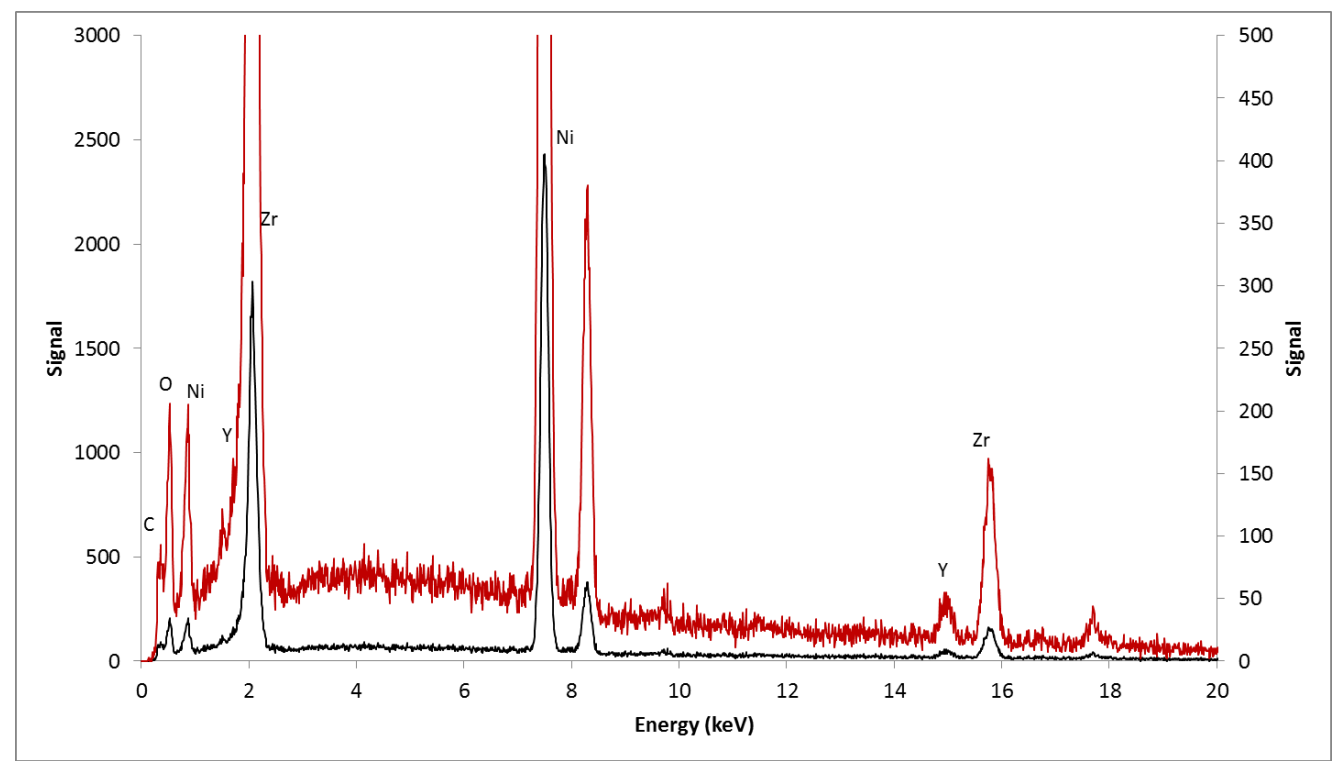

Figure 6.39 EDX analysis of the clean reduced anode surface.

The EDX spectra of the anode area that was exposed to $20 \mathrm{ppm} \mathrm{PH}_{3}$ is shown in Figure 6.40. In comparison to the clean anode, the $\mathrm{PH}_{3}$-exposed anode exhibits peaks for nickel and phosphorus. $\mathrm{Zr}$ and $\mathrm{Y}$ peaks are strongly suppressed indicating that the new nickel phosphide layer is completely covering the entire area on the anode that exposed to $\mathrm{PH}_{3}$. The new phase formed is identified in previous studies by $\mathrm{Xu}$ and Demircan et al. as nickel phosphide. [2, 5, 7] 


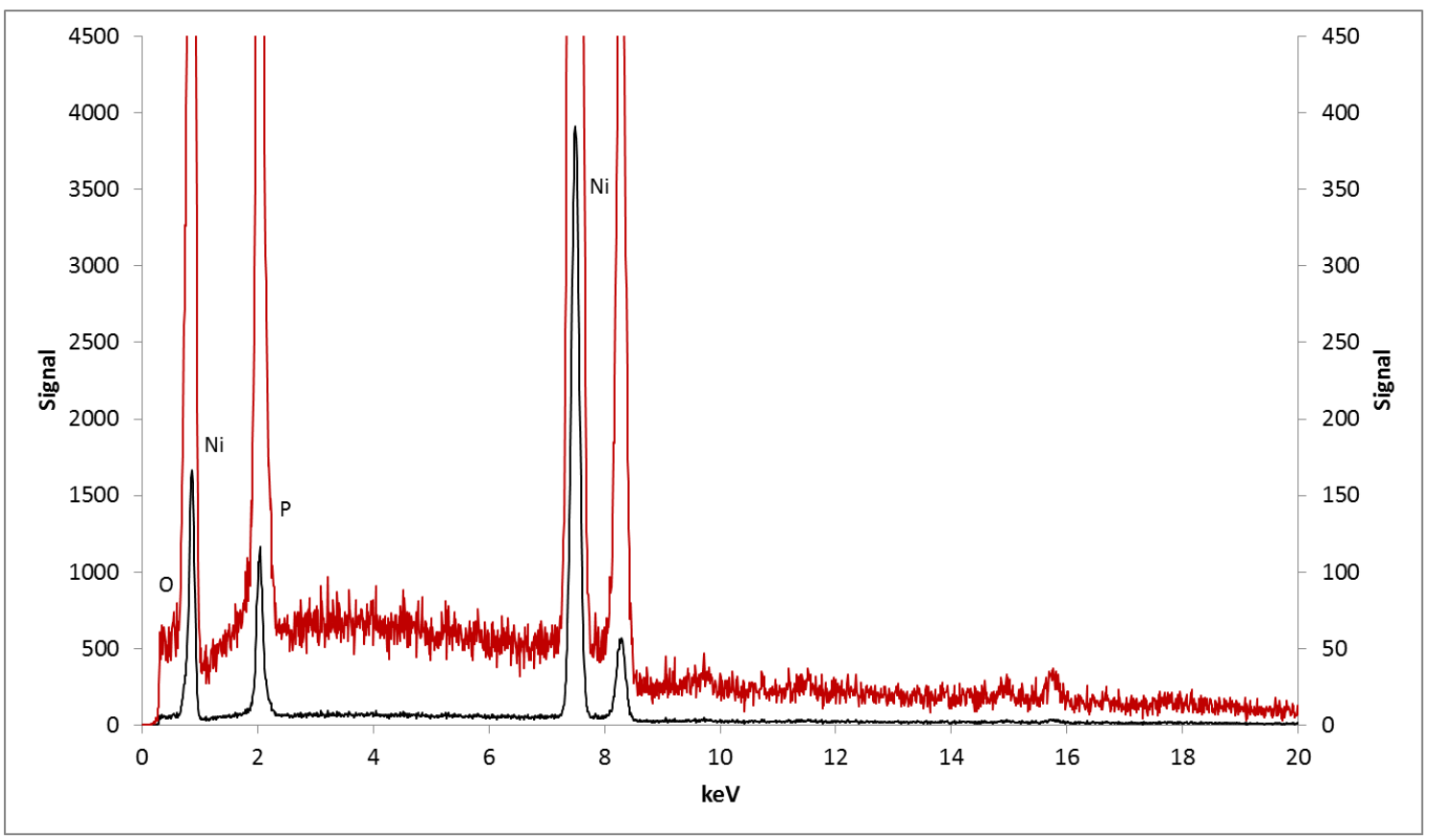

Figure 6.40 EDX analysis of the $\mathrm{PH}_{3}$ exposed anode surface.

The XRD pattern of the $\mathrm{PH}_{3}$ exposed anode in Figure 6.41 provides the evidence of the presence of nickel phosphide. The signature peaks for YSZ are at $2 \theta$ of $30.10^{\circ}, 34.98^{\circ}$, $50.21^{\circ}, 59.79^{\circ}$ and $62.86^{\circ}(\mathrm{PDF} \# 01-082-1241)$. The two peaks at $44.65^{\circ}$ and $51.99^{\circ}$ are assigned to metallic nickel (PDF\# 4-850). Nickel phosphide (mainly $\mathrm{Ni}_{5} \mathrm{P}_{2}$ ) peaks are at $38.31^{\circ}, 41.77^{\circ}$ and $46.32^{\circ}$. However, some of other nickel phosphide peaks $\left(\mathrm{Ni}_{3} \mathrm{P}, \mathrm{Ni}_{8} \mathrm{P}_{3}\right.$, etc.) may overlap with the stronger $\mathrm{Ni}_{5} \mathrm{P}_{2}$ signals. [8-9] The dominant form of nickel phosphide in the anode after $\mathrm{PH}_{3}$ exposure is $\mathrm{Ni}_{5} \mathrm{P}_{2}$. Xu and Trembly et al. also reported that the dominant phase is $\mathrm{Ni}_{5} \mathrm{P}_{2}$ under similar conditions. [2] Thermodynamic calculations by $\mathrm{Xu}$ et al. suggest that the most stable form of nickel phosphide under SOFC anode conditions is $\mathrm{Ni}_{5} \mathrm{P}_{2}$ as well. [2] The presence of $\mathrm{Ni}_{3} \mathrm{P}$ has been reported by Marina et al. [11] 


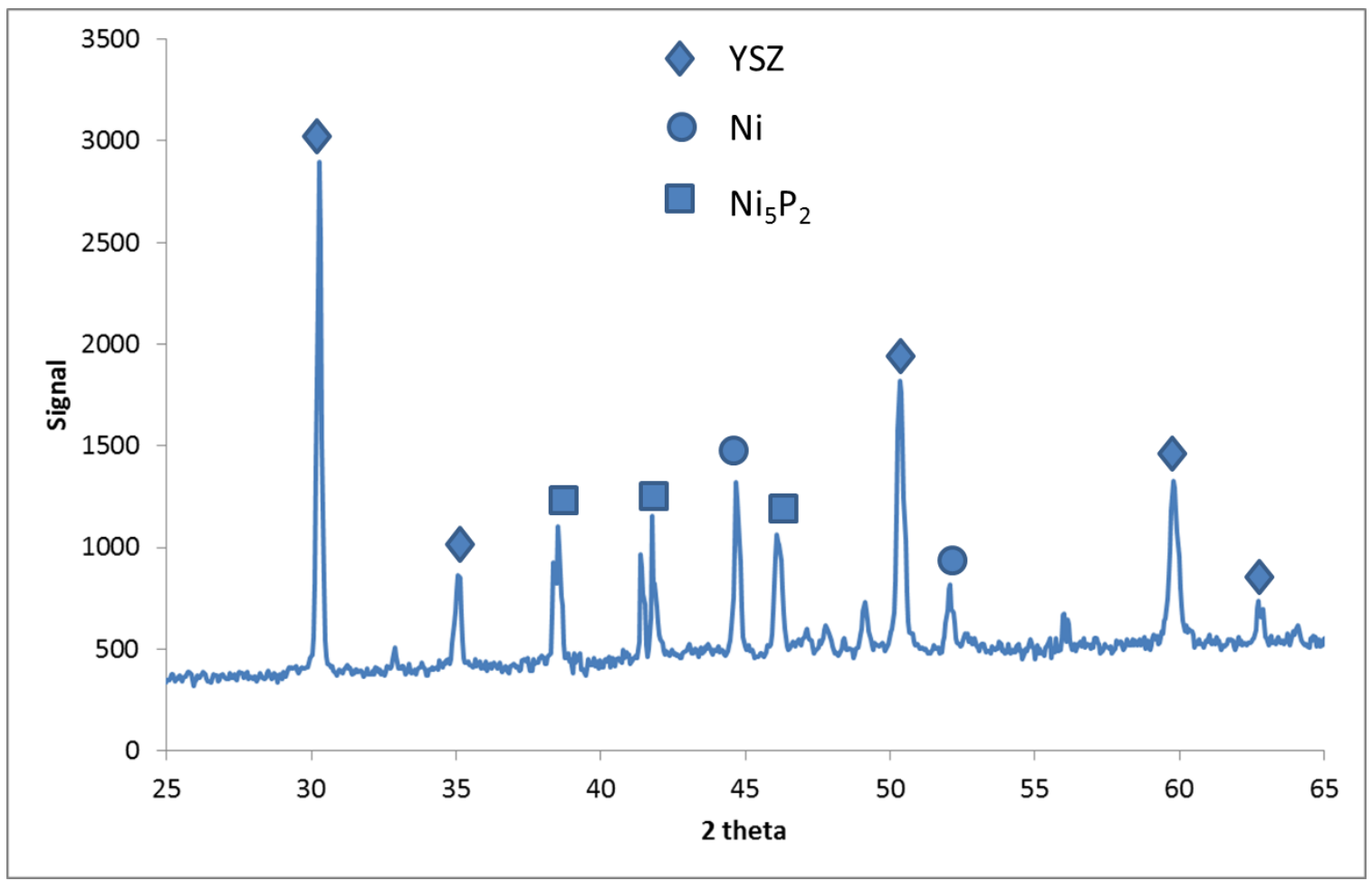

Figure 6.41 XRD analysis of the $\mathrm{PH}_{3}$ exposed anode surface. $(\bullet \mathrm{YSZ}$ - nickel phosphide - metallic Ni)

\subsection{Conclusions.}

The electrochemical performance of the SOFC tested in this chapter fueled by $\mathrm{H}_{2}$ is significantly lower than similar cells reported in previously published work. The peak power is lower and both series and polarization resistances are much higher. The SOFC degrades with a power loss after a long time operation in wet and dry $\mathrm{H}_{2}$, with and

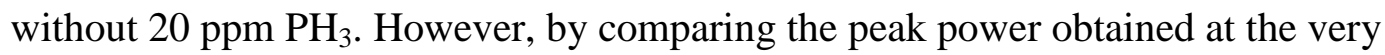
beginning and very end of the entire test, the overall performance did not show a significant loss. The water generated from the electrochemical reactions (oxidation of hydrogen) and chemical reactions (reduction of $\mathrm{NiO}$ ) is readily detected. The product water volume is large and is displacing the other gases in the exhaust. No new masses 
above mass 44 were detected at any time. In particular, $\mathrm{HPO}$ (mass 48), $\mathrm{HPO}_{2}$ (mass 64), and $\mathrm{HPO}_{3}$ (mass 80) are not detected as products of $\mathrm{PH}_{3}$ reactions. Due to the change of the calibration of the RGA during the experiment, the gas partial pressures are considered reliable only for their relative values. The accuracy of the measured pressures may be compromised. The post-mortem SEM, EDX and XRD analyses showed the evidence of a new layer of nickel phosphide on the top surface of the $\mathrm{PH}_{3}$ exposed anode similar to the results in previous studies. 


\section{References in Chapter 6}

[1] Huang Guo, PhD Dissertation, College of Engineering and Mineral Resources, West Virginia University

[2] Chunchuan Xu, J. Zondlo, H. O. Finklea, O. Demircan, M. Gong, X. Liu Journal of Power Sources 2009, 193, 739-746

[3] Chunchuan Xu, J. Zondlo, M. Gong, X. Liu Journal of Power Sources 2011, 196, $116-125$

[4] Mingjia Zhi, Xinqi Chen, Harry Finklea, Ismail Celik, Nianqiang Q.Wu Journal of Power Sources 2008, 183, 485-490

[5] O. Demircan, W. Zhang, C. Xu, J. Zondlo, H. Finklea, Journal of Power Sources

2010, 195, 3091-3096

[6] Anil V. Virkar, Jong Chen, Cameron W. Tanner, Jai-Woh Kim Solid State Ionics 2000, 131, 189-198

[7] Oktay Demircan, Chunchuan Xu, John Zondlo, Harry O. Finklea Journal of Power Sources 2009, 194, 214-219

[8] M. Yashima, S. Sasaki, M. Kakihana, Acta Crystallogr. Sect. B 1994, 50, 663-672.

[9] M. Yousuf, P. CH. Sahu, H.K. Jajoo, S. Rajagopalan, K. Govinda Rajan, J. Phys. 1986, $16 F, 373-378$. 
[10] J.P. Trembly, R.S. Gemmena, D.J. Bayless Journal of Power Sources 2007, 163, 986-996

[11] ] O.A.Marina, L.R. Pederson, D.J. Edwards, C.W. Coyle, J. Templeton, M.

Engelhard, Z. Zhu, Proceedings of the 8th Annual SECA Workshop, 2007, San Antonio, TX 


\section{Chapter 7 Discussion, Conclusions and Future Work}

\subsection{Discussion}

The major observations in Chapter 3 are the transient behavior of $\mathrm{H}_{2} \mathrm{~S}$ when introduced into the gas stream and the change of $\mathrm{H}_{2} \mathrm{~S}$ signal at mass 34 when the current is turned on and off. The slow rise of impurities signal is very reproducible and was seen numerous times in the data. In the mass detection range, only $\mathrm{H}_{2} \mathrm{~S}$ and $\mathrm{PH}_{3}$ at mass 34 show a slow rise with time. No other gases exhibit this behavior. However, there is no direct evidence showing that either $\mathrm{PH}_{3}$ or $\mathrm{H}_{2} \mathrm{~S}$ reacts with alumina. In the current test with $\mathrm{H}_{2} \mathrm{~S}$ in Chapter 3, the signal at mass 34 jumped up when the current is turned on, and then slowly decayed to the background value. The signal also decreased sharply when the current is turned off, and then returned slowly back to the normal value. These changes are only seen once in the experiments. After the apparatus has been moved, there was not a chance to repeat the $\mathrm{H}_{2} \mathrm{~S}$ and current test to confirm the reproducibility. A hypothesis for this phenomenon is due to the local heating of the cell. Both thermodynamic calculations and experimental studies confirmed that when current is loaded to the cell, the temperature rises up to $10^{\circ} \mathrm{C}$ higher than at open circuit (also depends on the current flow) [1-3]. The $\mathrm{H}_{2} \mathrm{~S}$ adsorbed onto the cell may be released when the temperature becomes higher. However, the amount of the released $\mathrm{H}_{2} \mathrm{~S}$ is limited, so the mass 34 signal slowly went back to track the normal level. Another possible oxidation product is $\mathrm{SO}_{2}$ at mass 64. Mass 64 signals were in the noise level at all times during the experiment. The $\mathrm{H}_{2} \mathrm{~S}$ may have also adsorbed on to the sampling capillary to the RGA or reacted with the Ni. 
In Chapter 4, the $\mathrm{H}_{2} \mathrm{O}$ generated by the oxidation of $\mathrm{H}_{2}$ via the fuel cell reaction is detected by the mass spectrometer as anticipated. Although the results are compromised by the leaks to the air, the amount of $\mathrm{H}_{2} \mathrm{O}$ generated is so large that it can be easily detected. Part of the $\mathrm{H}_{2}$ in the fuel stream was oxidized by the leaked air to form $\mathrm{H}_{2} \mathrm{O}$, causing a high background level of $\mathrm{H}_{2} \mathrm{O}$ signal. The $\mathrm{H}_{2} \mathrm{O}$ formed by the electrochemical reaction is seen as an increase on top of the background when current is turned on.

From the gas tests in Chapter 5, $\mathrm{PH}_{3}$ is found to be stable from room temperature up to at least $300^{\circ} \mathrm{C}$ and $1 \mathrm{~atm}$ in $\mathrm{H}_{2}$, regardless of the humidity (up to 10 torr of $\mathrm{H}_{2} \mathrm{O}$ ) or the presence of $\mathrm{Ni} / \mathrm{YSZ}$ sample. The $\mathrm{PH}_{3}$ fed into the system is detected unchanged at mass 34 at the exhaust sampling point. Although Trembly and Bao et al. predict that the $\mathrm{PH}_{3}$ will decompose and react with $\mathrm{H}_{2} \mathrm{O}$ or the residual $\mathrm{O}_{2}$ due to impurity gas or leaks, these predictions are based on thermodynamic calculations. [4-5] No kinetic data are provided such as a reaction rate or an equilibration time. One hypothesis is that the reaction may be slow at lower temperatures, so the phosphorus remains as $\mathrm{PH}_{3}$. As the temperature rises, the $\mathrm{PH}_{3}$ starts to react. The initial temperature of the reaction in dry hydrogen is $400^{\circ} \mathrm{C}$ and in wet hydrogen is about $300^{\circ} \mathrm{C}$. The onset of reaction of $\mathrm{PH}_{3}$ is rapid after reaching this critical temperature. The product is so thermodynamically favorable and the reaction rate is so fast that little or no phosphorus as $\mathrm{PH}_{3}$ at mass 34 is detected in the exhaust gas. No products of the phosphine reaction are detected.

As the temperatures continue to rise, the discussion separates into three cases.

1. Under the dry condition, the $\mathrm{PH}_{3}$ reappears at $600-800^{\circ} \mathrm{C}$ at a pressure almost the same as the initial pressure. The products of the reaction at intermediate temperatures are 
presumably unstable at high temperatures. Thus the reaction direction is reversed and $\mathrm{PH}_{3}$ is regenerated or the reaction simply stops. Again, the return of the $\mathrm{PH}_{3}$ signal during temperature increases occurs over a narrow range of temperatures. This process is observed during both the heating and cooling phases of the experiment. It is also observed in alumina and quartz tubes, suggesting that the reaction occurs in the gas phase and not on surfaces or between the surface and gas. The $\mathrm{O}_{2}$ pressure at mass 32 tracks the $\mathrm{PH}_{3}$ signal at mass 34, suggesting that oxygen is a possible reactant, although some of the changes are due to changes in concentration of $\mathrm{PH}$, a fragment of $\mathrm{PH}_{3}$. The $\mathrm{H}_{2} \mathrm{O}$ signal at mass 18 shows no correlated changes. However, this result may be due to the large pressure of water relative to the pressure of $\mathrm{PH}_{3}$. In any event, it is evident that $\mathrm{PH}_{3}$ will reach the anode of the SOFC with dry hydrogen as the fuel.

2. Under wet conditions, the $\mathrm{PH}_{3}$ stays at noise level and is not regenerated at 600$800^{\circ} \mathrm{C}$. The water vapor plays a critical role in the $\mathrm{PH}_{3}$ reaction. The products are more thermodynamically stable with water vapor present, although the products are not detected with the current instrument. The species reaching the anode is not known.

3. With a Ni/YSZ sample present in the gas stream, the $\mathrm{PH}_{3}$ reacts with the sample. The Ni/YSZ is very attractive to $\mathrm{PH}_{3}$ at high temperatures [6]. So even in dry conditions, only a small signal at mass 34 is seen (less than $10 \%$ of the initial amount). This result is consistent with rapid gettering of $\mathrm{PH}_{3}$ by nickel mesh (a proposed filter for $\mathrm{PH}_{3}$ ). [9-10] After the furnace is cooled, the sample is taken out and a shiny layer of new material has formed on the surface, which is similar to the results for cells exposed to $\mathrm{PH}_{3}$ in the previous studies described in Section 2.5. At low temperatures, $\mathrm{PH}_{3}$ does not react with nickel at a rapid rate, and the mass 34 signal returns to its initial levels. 
In the gas tests in Chapter 5, there are no signals detected above mass $44\left(\mathrm{CO}_{2}\right)$. This implies that no product of $\mathrm{PH}_{3}$ reaction is detected by the mass spectrometer. HPO (mass 48), $\mathrm{HPO}_{2}$ (mass 64) and $\mathrm{HPO}_{3}$ (mass 80) are excluded as possible products. The other types of compounds that may be products are phosphorus oxides. In the $\mathrm{P}_{2} \mathrm{O}_{5}$ sample test, there is no new signal detected in the exhaust gas from room temperature to $350^{\circ} \mathrm{C}$. The products of decomposition and hydrolysis of $\mathrm{P}_{2} \mathrm{O}_{5}$ may have masses beyond the mass range of $100 \mathrm{amu}$. This result contradicts the finding in the paper by Sasaki et al. [11] $\mathrm{PH}_{3}$ was generated by heating $\mathrm{P}_{2} \mathrm{O}_{5}$ to $300^{\circ} \mathrm{C}$ by Sasaki. Also, no fragments of $\mathrm{P}_{2} \mathrm{O}_{5}$ or $\mathrm{P}_{4} \mathrm{O}_{10}$ under $100 \mathrm{amu}$ are detected. The mass spectrometer readily detects organic vapors with masses in the 40-100 range, so the fault does not lie with the spectrometer. The quartz tube test shows similar results with the alumina tube. The "dip" of $\mathrm{PH}_{3}$ is not related to the alumina material but due to the gas reactions.

In Chapter 6, all the three stages of testing were on the same single cell. The cells tested by Xu et al. exhibited a voltage of $0.72 \mathrm{~V}$ at $0.5 \mathrm{~A} \mathrm{~cm}^{-2}$ in clean $\mathrm{H}_{2}$. [2] This cell in the present study, after correcting the series resistance to the same value, exhibits a voltage of $0.73 \mathrm{~V}$ at the same current density. The performance of this cell is comparable to the performance of previous cells from the same vendor. The main problem is the high series resistance. Since four leads (two current, two voltage sense) extend from the potentiostat to a point near the SOFC, lead wire resistance is not the source of the series resistance. Usually, such a high series resistance arises from one of two sources, a faulty contact with the current collectors or delamination flaws within the SOFC. However, the current collectors and the cell was well intact under visual examine. Whatever the cause of the high series resistance, that resistance decreased slightly during the experiment. The 
polarization resistance of the current cell with 20 torr of water in clean hydrogen is 1.1 $\mathrm{ohm} \mathrm{cm}^{2}$. A similar cell in hydrogen $+3 \%$ water (23 torr) exhibited a polarization resistance of $1.4 \mathrm{ohm}^{2}$. [7] The polarization resistances at OCV in dry hydrogen are much larger because of the effect of low water concentration on the kinetics of hydrogen oxidation at $\mathrm{OCV}$.

Deconvolution analysis provides greater detail of the number and types of processes appearing in the impedance spectra. [8] Deconvolution analysis of this cell's impedance data shows that the polarization resistance can be assigned to three parts, the anode at low frequency, the electrolyte at intermediate frequency and the cathode at high frequency. In the deconvolution plot of dry and wet $\mathrm{H}_{2}$ conditions shown in Figure 7.1, the presence of water vapor makes a significant difference in the $R_{p}$ values. The large peak at $0.1 \mathrm{~Hz}$ in dry $\mathrm{H}_{2}$ largely disappears due to the lower activation energy of $\mathrm{H}_{2}$ oxidation with the presence of water, leaving behind a small peak at $0.16 \mathrm{~Hz}$.

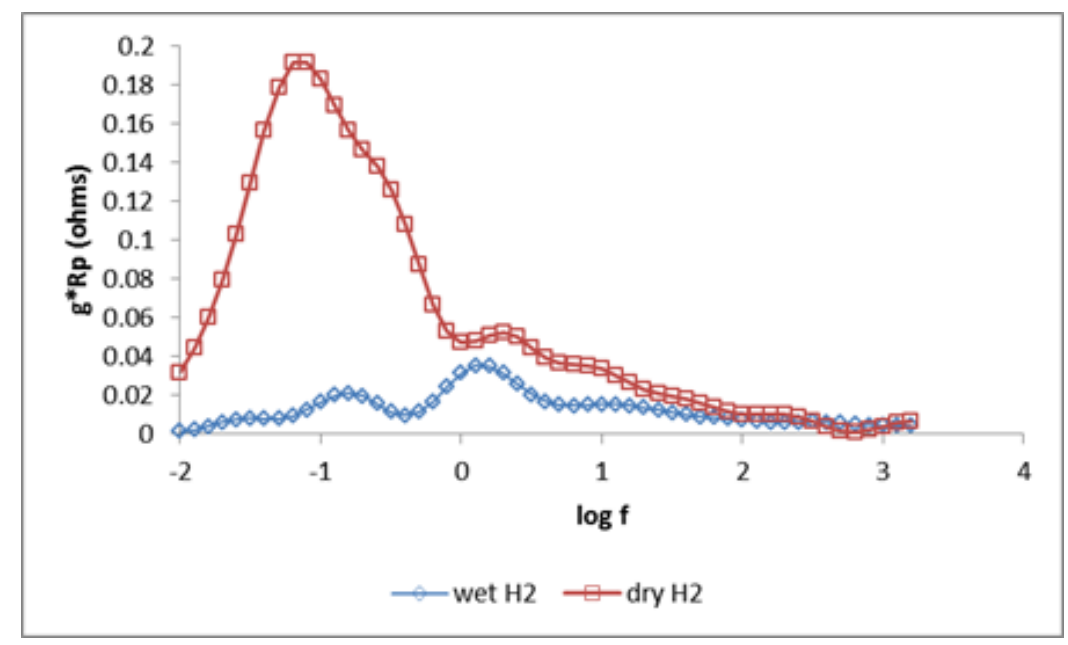

Figure 7.1 Deconvolution overlay comparison for dry and wet $\mathrm{H}_{2}$ conditions with no $\mathrm{PH}_{3}$. 
Another comparison of deconvolution spectra in dry hydrogen with and without $\mathrm{PH}_{3}$ is shown in Figure 7.2. The two plots overlap well above $1 \mathrm{~Hz}$. At lower frequencies, the slight discrepancies are attributed to noise in the impedance data.

Comparison of deconvolution spectra of wet condition with and without added $\mathrm{PH}_{3}$ is shown in Figure 7.3. The multiple peak patterns of the two plots are very similar. The only difference is the absolute value of the impedance. One possible cause of the difference is a change in the water concentration. The "wet" $\mathrm{H}_{2}$ with $20 \mathrm{ppm} \mathrm{PH}_{3}$ has only half the humidity of the pure "wet" $\mathrm{H}_{2}$ (10 torr vs 20 torr), as described in section 5.1.3.

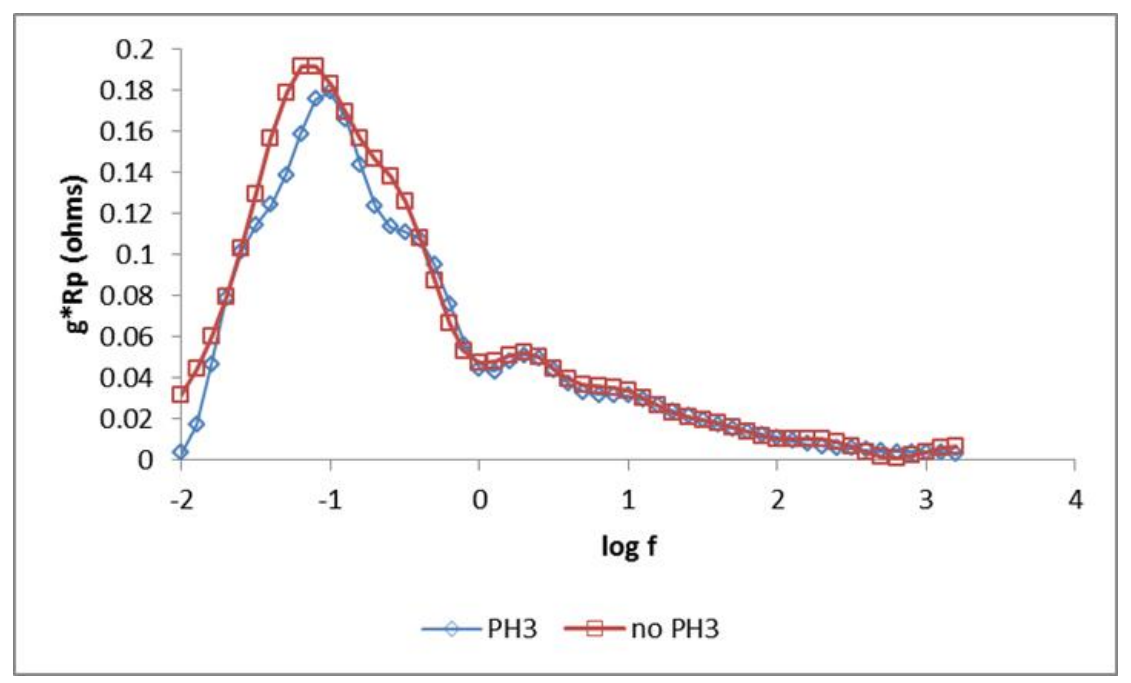

Figure 7.2 Comparison of deconvolution of impedance in dry $\mathrm{H}_{2}$, with and without $\mathrm{PH}_{3}$ 


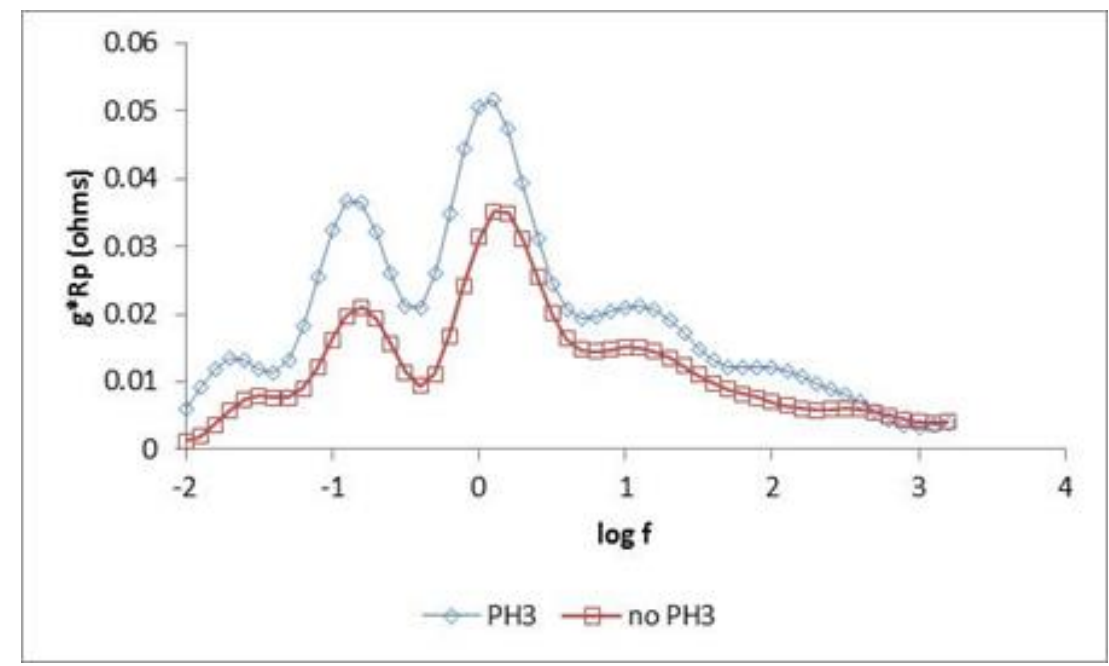

Figure 7.3 Comparison of deconvolution of impedance in wet $\mathrm{H}_{2}$, with and without $\mathrm{PH}_{3}$

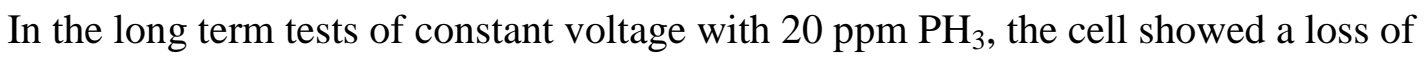
power. The degradation rate in dry condition is $0.35 \mathrm{~mW} \mathrm{~cm}^{-2} \mathrm{~h}^{-1}$, which is comparable to previous results by $\mathrm{Xu}$. However, in the wet condition, the degradation rate did not stay constant. The starting rate was $0.50 \mathrm{~mW} \mathrm{~cm}^{-2} \mathrm{~h}^{-1}$ and after 8 hours it gradually decreased to $0.077 \mathrm{~mW} \mathrm{~cm}^{-2} \mathrm{~h}^{-1}$. Xu et al. observed a constant degradation rate of $0.4-0.6 \mathrm{~mW} \mathrm{~cm} \mathrm{~cm}^{-2}$ $\mathrm{h}^{-1}$ through the entire testing period. By comparing the power density data collected near the end of the test to the data in the very beginning, the cell tested in Chapter 6 does not show a significant change of performance over 16 days of operation. At a current density of $0.3 \mathrm{~A} \mathrm{~cm}^{-2}$, the iR-corrected power densities are $\left(\right.$ dry $\left.\mathrm{H}_{2}\right) 0.25 \mathrm{~W} \mathrm{~cm}^{-2}$, (wet $\left.\mathrm{H}_{2}\right) 0.26$ $\mathrm{W} \mathrm{cm}{ }^{-2}$, (dry $\left.\mathrm{H}_{2}+\mathrm{PH}_{3}\right) 0.26 \mathrm{~W} \mathrm{~cm}^{-2}$ and (wet $\left.\mathrm{H}_{2}+\mathrm{PH}_{3}\right) 0.25 \mathrm{~W} \mathrm{~cm}^{-2}$. Although a continuous run in the presence of $\mathrm{PH}_{3}$ caused some degradation, this cell surprisingly recovers between runs. The 20 hours of run time may not be long enough to see significant degradation. However, most literature data show that the $\mathrm{PH}_{3}$ will cause immediate and irreversible loss of performance to the SOFC anode. The post-mortem analyses (see below) prove that phosphine is reacting with the anode during this extended 
test. It is possible that the $\mathrm{PH}_{3}$ or its reaction products are not reaching the active layer of the anode.

During the cell test, the $\mathrm{H}_{2} \mathrm{O}$ generated by the electrochemical reaction of the cell is detected by the mass spectrometer. The detection of $\mathrm{H}_{2} \mathrm{O}$ is highly reproducible and reliable. When the current is turned on, a significant increase in signal appears at mass 18 . All other gases show a decrease in their mass signal because the amount of generated water is so large that all other gases are displaced. A larger current load applied to the cell yields a higher signal at mass 18 . However, the linearity of $\mathrm{H}_{2} \mathrm{O}$ concentration with the mass 18 signal is valid only for water levels lower than 16 torr. At higher current densities, the electron multiplier detector is saturated with water so it cannot further increases in signal. In some cases, the water vapor may have condensed in the exhaust lines so it took some time to evaporate and purged out the water after turning off the current. Again, no mass above 44 amu is detected under any experimental configuration or any gas composition.

After the cell test was finished, the cell was taken out for further analysis. The cell and the current collectors were intact under visual check. The inner surface of the cellsupporting tube was examined visually, but there were no significant amount of deposits found. A shiny, highly crystalline new phase formed on top of the anode surface. SEM, EDX and XRD tests were performed on the post mortem cell. The SEM images show there is an additional dense phase formed on top of the anode with a much larger grain size than the clean reduced anode. This new phase is similar to the one observed by $\mathrm{Xu}$ and Demircan et al. in similar experiments. [2, 7, 9-10] The EDX analyses confirmed the 
existence of nickel and phosphorus in the new phase. XRD indicated that the new phase was nickel phosphide.

\subsection{Conclusions}

The Residual Gas Analyzer is applied to the study of fuel and exhaust gases of the Solid Oxide Fuel Cell. It is capable of detecting major gases $\left(\mathrm{H}_{2}, \mathrm{~N}_{2}, \mathrm{O}_{2}, \mathrm{H}_{2} \mathrm{O}\right.$, etc. $)$ and trace amount of gases $\left(\mathrm{H}_{2} \mathrm{~S}, \mathrm{PH}_{3}, \mathrm{CO}_{2}\right.$, etc. $)$.

The results obtained in the experiments in WVU MAE laboratory are consistent with the data collected later in WVU Chemistry laboratory, despite the significant leak in the system. The electrochemical reactions of the operating SOFC can be seen as a distinct rise of water content in the exhaust gas.

The $\mathrm{PH}_{3}$ is readily detectable at $10 \mathrm{ppm}$ level with the Cirrus unit. Mass spectrometry observations confirm that the $\mathrm{PH}_{3}$ reaches the cell anode. The degradation of the cell performance is due to the presence of $\mathrm{PH}_{3}$, even at $10 \mathrm{ppm}$ level.

The gas phase reactions of $\mathrm{PH}_{3}$ at high temperatures were investigated. The $\mathrm{PH}_{3}$ reacts at temperatures above $\sim 400^{\circ} \mathrm{C}$. However, no expected products $\left(\mathrm{HPO}, \mathrm{HPO}_{2}, \mathrm{HPO}_{3}\right.$, fragments of $\mathrm{P}_{4} \mathrm{O}_{10}$, etc) were detected under any gas compositions with the current instrument. The possible products may be non-volatile or have mass numbers larger than $100 \mathrm{amu}$.

The use of Residual Gas Analyzer in the study of SOFC is a novel application. This analytical method has its great advantages and some drawbacks. The most remarkable feature of this instrument is the large dynamic range from sub ppm level to atm level. The 
large dynamic range provides the ability to detect trace gases and major gases at the same time. The continuous gas phase sampling is another advantage. The RGA can be connected on to the gas system and perform on-line analyses of the gases. The response time is very fast. However, there are some limitations. The RGA is usually calibrated with only one point and this calibration is used over its entire dynamic range. And, the RGA can be calibrated based on one single mass. While different molecules have different calibration coefficients, the readings of some gases may be inaccurate. During operation, the RGA gave different readings for the same gas compositions. The results are not precisely quantitative, but only provides relative readings or semi-quantitative data. For qualitative purposes, the RGA will provide reliable results.

\subsection{Future work}

For the Cirrus RGA unit, it is better to develop a new version of software that will have the capability to calibrate with multiple points. The ratios of calibration coefficient of different masses are to be set and stored in the software. For the study of trace amount of $\mathrm{PH}_{3}$ in the ppm level, it is necessary to have the instrument calibrated with a standard $\mathrm{PH}_{3}$ gas within the working range. For example, an accurate $40 \mathrm{ppm}$ standard $\mathrm{PH}_{3}$ balanced in $\mathrm{N}_{2}$ or $\mathrm{H}_{2}$ will be sufficient.

The tests and analyses in Chapter 6 were on the same single cell. More repeated cell tests are necessary to further understand the gas-phase composition both at the inlet and exhaust of the fuel cell. The problem of high series resistance needs to be solved. 
The state of $\mathrm{PH}_{3}$ and the products of the $\mathrm{PH}_{3}$ reactions under SOFC operating conditions are still unclear. One approach is to purchase a mass spectrometer with an increased mass detection range. The new instrument will have the possibility to reveal any products over the mass number of 100. Another approach is to investigate the inner surfaces of the furnace for any deposited products of the $\mathrm{PH}_{3}$ reaction. The residual deposits can be collected and studied using microscopic methods. The elemental information can be obtained by XPS. The crystal structure can be determined by diffraction patterns to identify the compound.

The mechanism of the degradation of cell performance caused by $\mathrm{PH}_{3}$ is yet to be discovered. More in-situ methodsneed to be developed to reveal the gas reactions close to the anode surface. 


\section{References in Chapter 7}

[1] Sudip K. Mazumder, Kaustuva Acharya, Comas Lamar Haynes, Robert Williams, Jr., Michael R. von Spakovsky, Douglas J. Nelson, Diego F. Rancruel, Joseph Hartvigsen, and Randy S. Gemmen IEEE Transactions on Power Electronics, Vol. 19, No. 5, September 2004

[2] Chunchuan Xu, J. Zondlo, H. O. Finklea, O. Demircan, M. Gong, X. Liu Journal of Power Sources 2009, 193, 739-746

[3] S.C. Singhal, K.Kendall, High Temperature Solid Oxide Fuel Cells Fundamentals, Design and Application 2003, 1st edition, Elsevier Ltd., p280.

[4] J.P. Trembly, R.S. Gemmena, D.J. Bayless Journal of Power Sources 2007, 163, 986996

[5] J. Bao, G.N. Krishnan, P. Jayaweera, J. Perez-Mariano, A. Sanjurjo. Journal of Power Sources 2009, 193, 607-616

[6] O.A.Marina, L.R. Pederson, D.J. Edwards, C.W. Coyle, J. Templeton, M. Engelhard, Z. Zhu, Proceedings of the 8th Annual SECA Workshop, 2007, San Antonio, TX

[7] Oktay Demircan, Chunchuan Xu, John Zondlo, Harry O. Finklea Journal of Power Sources 2009, 194, 214-219

[8] Harry Finklea, Xiaoke Chen, Kirk Gerdes, Suryanarayana Pakalapati and Ismail Celik J. Electrochem. Soc. 2013 160 F1055-F1066 
[9] Chunchuan Xu, John W. Zondlo, Edward M. Sabolsky, Journal of Power Sources 2011, $196,7665-7672$

[10] Chunchuan Xu, John W Zondlo. Edward M Sabolsky, Proceedings of the ASME International Conference on Fuel Cell Science, Engineering, and Technology, 9th, Washington, DC, United States, Aug. 7-10, 2012, 2011, 63-71

[11] K. Haga, Y. Shiratori, Y. Nojiri, K. Ito, and K. Sasaki, Journal of The Electrochemical Society 2010, 157, B1693-B1700 